ENGINEERING CHANGE NOTICE

Page 1 of 2

\begin{tabular}{|c|c|c|c|c|c|c|}
\hline \multirow{3}{*}{$\begin{array}{l}\text { 2. ECN Category } \\
\text { (mark one) } \\
\text { Supplemental } \\
\text { Direct Revision } \\
\text { Change ECN } \\
\text { Tefporary } \\
\text { Standby } \\
\text { Supersedure } \\
\text { Cancel/Void }\end{array}$} & \multirow{3}{*}{$\begin{array}{r}{[]} \\
{[X]} \\
{[]} \\
{[]} \\
{[]} \\
{[1} \\
{[]}\end{array}$} & \multicolumn{2}{|c|}{$\begin{array}{l}\text { 3. Originator's Name, Organization, MSIN, } \\
\text { and Telephone No. } \\
\text { JR Weidert/87810/T4-02/376-8132 }\end{array}$} & \multicolumn{2}{|c|}{ 3a. USQ Required? } & $\begin{array}{l}\text { 4. Date } \\
04 / 09 / 96\end{array}$ \\
\hline & & \multicolumn{2}{|c|}{$\begin{array}{l}\text { 5. Project Title/No./Work Order No. } \\
\text { WRAP/W026 }\end{array}$} & \multicolumn{2}{|c|}{$\begin{array}{c}\text { 6. Bldg./Sys./Fac. No. } \\
\text { M0720/200W }\end{array}$} & $\begin{array}{c}\text { 7. Approval Designator } \\
Q\end{array}$ \\
\hline & & \multicolumn{2}{|c|}{$\begin{array}{l}\text { 8. Document Numbers Changed by this ECN } \\
\text { (includes sheet no; and rev.) }\end{array}$} & \multicolumn{2}{|c|}{$\begin{array}{l}\text { 9. Related ECN No(s). } \\
D /\end{array}$} & 10. Related PO No. \\
\hline \multicolumn{2}{|c|}{$\begin{array}{l}\text { 11a. Modification Work } \\
\text { [] Yes (fill out Blk. } \\
{[X] \text { No (NA Blks. } 11 b \text {, }} \\
11 c, 11 d \text { ) }\end{array}$} & $\begin{array}{l}\text { 116. Work Package } \\
\text { No. } \\
\text { N/A }\end{array}$ & \multicolumn{2}{|c|}{ 11c. Modification Hork Lomplete } & \multicolumn{2}{|c|}{$\begin{array}{l}\text { 11d. Restored to Original Condi- } \\
\text { tion (Temp. or Standby ECN only) } \\
\text { N/A }\end{array}$} \\
\hline
\end{tabular}

12. Description of Change

Complete revision to document WHC-SD-W026-SDD-001, REV. 1

13a. Justification (mark one)

Criteria Change [] Design Improvement [] Environmental [] Facility Deactivation [] As-Found [X] Facilitate const []

13b. Justification Details

Specify the detail design selected to implement the system requirements.

14. Distribution (include name, MSIN, and no. of copies)

See Distribution List

A-7900-013-2 (11/94) GEF095 


\section{WRAP Module 1 Data Management System (DMS) Software Design Description (SDD)}

\section{J. R. Weidert}

Westinghouse Hanford Company, Richland, WA 99352

U.S. Department of Energy Contract DE-AC06-87RL10930

$\begin{array}{llll}\text { EDT/ECN: } & 193579 & \text { UC: } 605 & \\ \text { Org Code: } & 62100 & \text { Charge Code: } & \text { A451E } \\ \text { B\&R Code: } & \text { EW3130020 } & \text { Total Pages: } & 640-639 \\ & & \text { de } & \end{array}$

Key Words: WRAP, DMS, SDD, Software

Abstract: The WRAP I DMS SDD describes the logical and physical architecture of the system specified in WHC-SD-W026-CSRS-001, WRAP 1 DMS Software Requirements Specification (SRS), Rev. 0 (WHC 1994). The WRAP 1 DMS SDD formally partitions the elements of the system described in the WRAP 1 DMS SRS into design objects and describes the key properties and relationships among the design objects and interfaces with external systems such as the WRAP Plant control system (PCS). The WRAP 1 DMS system is being developed to assist the Project $W-026$, Waste Receiving and Processing Module 1, in their management functions. The WRAP 1 DMS is required to collect, store, and report data related to certification, tracking, packaging, repackaging, processing, and shipment of waste processed or stored at the WRAP 1 facility. The WRAP I DMS SDD is used as the primary medium for communicating software design information.

TRADEMARK DISCLAIMER. Reference herein to any specific commercial product, process, or service by trade name, trademark, manufacturer, or otherwise, does not necessarily constitute or imply its endorsement, recommendation, or favoring by the United States Government or any agency thereof or its contractors or subcontractors.

Printed in the United States of America. To obtain copies of this document, contact: WHC/BCS Document Control Services, P.O. Box 1970, Mailstop H6-08, Richland WA 99352, Phone (509) 372-2420; Fax (509) 376-4989.

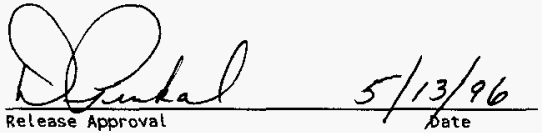

Approved for Public Release

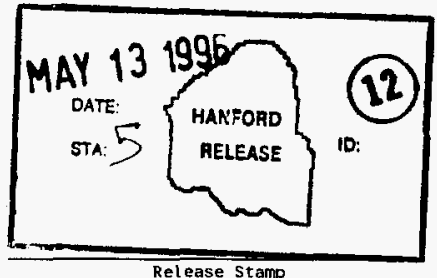

Rel ease Stamp

(1) 
RECORD OF REVISION

RECORD OF REVISION

(2) Title

WRAP Module 1 Data Management System PRELIMINARY SOFTWARE DESIGN DESCRIPTION (PSDD)

\begin{tabular}{|c|c|c|c|}
\hline \multirow{2}{*}{ Revision } & \multirow{2}{*}{ (4) Description of Change - Replace, Add, and Delete Pages } & \multicolumn{2}{|c|}{ Authorized for Release } \\
\hline & & (5) Cog. Engr. & (6) Cog. Mgr. Date \\
\hline 0 & $\begin{array}{l}\text { Initial Release dated } 3 / 17 / 95 \text { on EDT- } \\
142393\end{array}$ & $N / A$ & N/A \\
\hline 1 & Genera1 Revision per ECN 188089 & PAT Tamagel & RE flark \\
\hline $\mathrm{RS} 2$ & General Revision per ECN 193579 & JR weidert & 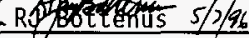 \\
\hline & & & \\
\hline & & & \\
\hline & & & \\
\hline & & & \\
\hline & & & \\
\hline & & & \\
\hline & & & \\
\hline & & & \\
\hline & & & \\
\hline & & & \\
\hline & & & \\
\hline & & & \\
\hline & & & \\
\hline & & & \\
\hline & & & \\
\hline & & & \\
\hline & & & \\
\hline & & & \\
\hline & & & \\
\hline & & & \\
\hline & & & \\
\hline & & & \\
\hline & & & \\
\hline & & & \\
\hline & & & \\
\hline & & & \\
\hline & & & \\
\hline & . & & \\
\hline
\end{tabular}


WHC-SD-W026-SDD-001, Rev. 2

\author{
WRAP Module 1 Data Management System \\ PRELIMINARY SOFTWARE DESIGN DESCRIPTION (PSDD) \\ WHC-SD-W026-SDD-001, Rev. 2
}

March 18, 1996

Issued By:

Westinghouse Hanford Company

for the

United States Department of Energy, Richland Operations Office

Richland, Washington

Prepared by:

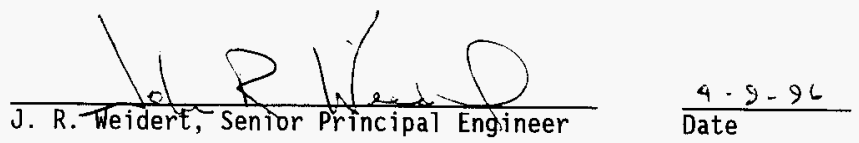

Contractor Approval:
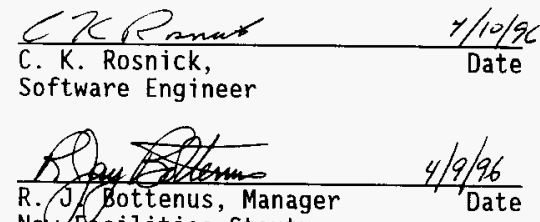
New Facilities Startup

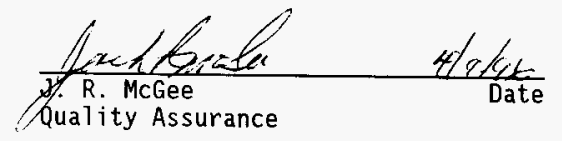

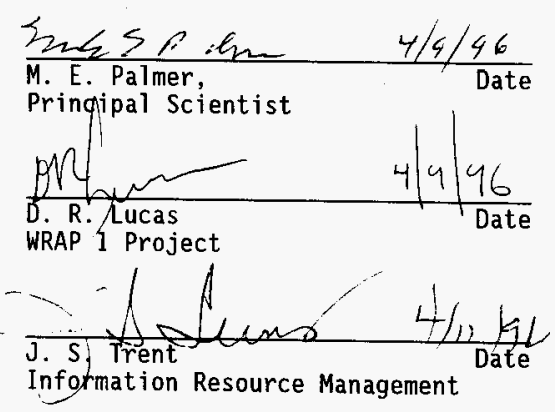


WHC-SD-W026-SDD-001, Rev. 2

This page intentionally left blank. 


\section{OVERVIEW}

Revision 2 of the Waste Receiving and Processing (WRAP) Module 1 Data Management System (DMS) Preliminary Software Design Description (PSDD) provides a high-level design description of the system. The title of this document has been amended to reflect the pre-release design and development phase status of the WRAP I DMS system. This release provides design descriptions for the following process modules produced under Phase 1 of the development effort:

- Receiving Drum or Box Containers

- Process Routing and Picklists

- Waste Inventory by Location and/or Container Relationships

- LLW Process GTovebox

- Facility Radiologic Material Inventory Check (partial)

- Shipping (partial production)

- Drum or Box NDE Operations

- Drum or Box NDA Operations

- Data Review (partial production).

In addition, design descriptions are included for the following process modules scheduled for development under Phases 2 and 3:

- Activity Comment

- LLW RWM Glovebox

- Sample Management

- TRU Process Glovebox

- TRU RWM Glovebox

- TRUPACT Processing.

Detailed design descriptions for Reports and Facility Metrics have also been provided for in Revision 2 of this document. The shipping documentation/ reports defined for screens DMSS0601 and DMSSO604 in the Shipping module have been $\mathrm{placed}$ on hold pending the resoution of data requirements for shipping documentation. This function will be performed manually upon startup of the WRAP facility.

Responsibility for issuance of the completed as-built detailed Software Design Description (SDD) shall lie with the BCSR software development project team. 
WHC-SD-W026-SDD-001, Rev. 2

This page intentionally left blank. 
3.4 .2 Indexes ....................... 3-19

3.4.2.1 Unique Indexes ............. 3-20

3.4.2.2 Foreign Indexes .......... 3-20

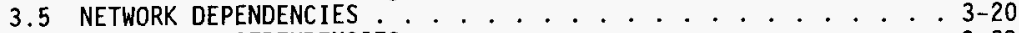

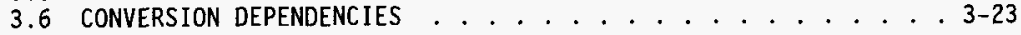

4.0 INTERFACE DESCRIPTION . . . . . . . . . . . . . . . . . . 4-1

4.1 INTERNAL INTERFACES ................. . . . . .

4.2 EXTERNAL INTERFACES .................. . . . . . .

4.2.1 Software Interfaces ............. 4-1

4.2.2 Communications Interfaces ........... . 4-1

4.2.3 Hardware Interfaces ............ . 4-2

$4.3 \mathrm{MAN} /$ MACHINE INTERFACES ............... . . 4-2

4.3.1 WRAP I DMS Security ............. 4-2

4.3.2 User Interfaces .............. 4-4

4.3.3 Developer Interface .......... . 4-5

4.3.3.1 Data/Database Administration ....... 4-5

4.3.3.2 Developers ............ 4-5

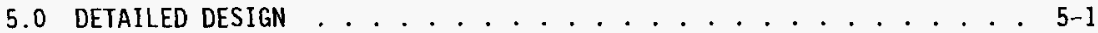

5.1 GENERAL DESIGN SPECIFICATIONS . . . . . . . . . . . 5-1

5.1 .1 Screens ................. 5-2

5.1 .2 Error and Message Handling ........... 5-2

5.1.3 System Security ............... 5-2

5.1.4 System Administration . . . . . . . . . . . . 5-2

5.2 SYSTEM NAVIGATION ................. . . . . 5-2

5.2.1 WRAP I DMS System Screen - WRAP I DMS User Menu . . . 5-5

5.2.2 Receiving Screens ............. 5-5

5.2.2.1 Container Receiving (DMSSO101) . . . . . 5-5

5.2.2.2 Bar Code Generator (DMSSO102) . . . . . . . 5-6

5.2.3 NDE/NDA Operations Screens . . . . . . . . . . 5-6

5.2 .3 .1 NDE (DMSS0201) . . . . . . . . . 5-6

5.2.3.2 NDA (DMSS0202) . . . . . . . . . . . 5-6

5.2 .4 Process Operations Screens . . . . . . . . . . 5-6

5.2.4.1 G1ovebox Operations Menu . . . . . . . 5-6

5.2.4.2 LLW Process Glovebox Menu . . . . . . . . . 5-6

5.2.4.3 LLW Drum Status at Entry (DMSS0311) . . . . . 5-7

5.2.4.4 LLW Sorting Table (DMSS0312) . . . . . . . 5-7

5.2.4.5 LLW Non-Compliant Packet (Pop-up) . . . . . . 5-7

5.2.4.6 Sample Data (DMSS0501) . . . . . . . . . 5-7

5.2.4.7 LLW Physical Component (Pop-Up) . . . . . . 5-7

5.2.4.8 LLW Chemical Component (Pop-Up) . . . . . . . 5-7

5.2.4.9 LLW NDE Results (Pop-up) …..... 5-7

5.2.4.10 LLW Exit Glovebox (DMSSO315) . . . . . . . . 5-7

5.2.4.11 LLW RWM Process Glovebox Menu . . . . . . . 5-7

5.2.4.12 LLW RWM Waste Sorting (DMSS0321) . . . . . 5-8

5.2.4.13 LLW RWM Repackaging (DMSSO322) . . . . . . . 5-8

5.2.4.14 Sample Data (DMSS0501) . . . . . . . 5-8

5.2.4.15 LLW RWM Compliant Waste Loadout (DMSS0323) : 5-8

5.2.4.16 LIW RWM Treatment Item Assembly (DMSS0324) . 5-8

5.2.4.17 LLW RWM Processing Instructions (DMSS0325) . 5-9

5.2.4.18 LLW RWM Treatment (DMSS0326) . . . . . . 5-9

5.2.4.19 LLW RWM Treated Waste Loadout (DMSS0328) . . 5-9

5.2.4.20 TRU Process Glovebox Menu . . . . . . . 5-9

5.2.4.21 TRU Drum Status at Entry (DMSSO331) . . . . 5-9 
5.2.4.22 TRU Sorting Glovebox (DMSS0332) . . . . . 5-9

5.2.4.23 TRU Non-compliant Packet . . . . . . . . 5-9

5.2.4.24 Sample Data (DMSS0501) . . . . . . . . 5-10

5.2.4.25 TRU Chemical Component (DMSS0333) . . . . 5-10

5.2.4.26 TRU Physical Component (DMSS0334) . . . . 5-10

5.2.4.27 TRU Exit Glovebox (DMSS0335) ...... . 5-10

5.2.4.28 TRU RWM Process G1ovebox Menu . . . . . . . 5-10

5.2.4.29 TRU RWM Waste Sorting (DMSS0341) ..... . 5-10

5.2.4.30 TRU RWM Waste Repackaging (DMSS0342) . . . . 5-10

5.2 .4 .31 Sample Data (DMSS0501) .......... 5-11

5.2.4.32 TRU RWM Comp 1 iant Waste Loadout (DMSS0343) . 5-11

5.2.4.33 TRU RWM Treatment Item Assembly (DMSS0344) . 5-11

5.2.4.34 TRU RWM Processing Instructions (DMSS0345) . 5-11

5.2.4.35 TRU RWM Treatment (DMSSO346) . . . . . . 5-11

5.2.4.36 TRU RWM Treated Waste Loadout (DMSS0348) . . 5-11

5.2.5 Data Validation Table Maintenance Screens . . . . . 5-12

5.2.5.1 Profile/Profile Isotope Tables (DMSS0454) , 5-12

5.2.5.2 Route Description Table (DMSS0455) . . . . 5-12

5.2.5.3 Shipment Picklist Description Table

(DMSS0456) . . . . . . . . . . 5-12

5.2.5.4 SIE Isotopic Name Table (DMSS0457) . . . . 5-12

5.2.5.5 TRU Container Code Table (DMSS0458) . . . . 5-12

5.2.5.6 Field Analys is Type Table (DMSSO459) . . . . 5-12

5.2.5.7 Material Table (DMSS0460) ....... . 5-12

5.2.5.8 WRAP Miscellaneous Table (DMSS0461) . . . . 5-12

5.2.5.9 Laboratory Analys is Table (DMSS0462) . . . . 5-12

5.2.5.10 Sample Container Table (DMSS0463) . . . . 5-12

5.2.5.11 Sample Matrix Table (DMSSO464) . . . . . 5-12

5.2.5.12 Sampling Method Table (DMSS0465) ..... . 5-12

5.2.5.13 Treatment Procedure Table (DMSS0466) . . . . 5-12

5.2.6 Sample Management Screens .. . . . . . . . . . 5-12

5.2.6.1 Sample Management Menu . . . . . . . . . 5-12

5.2.6.2 Sample Data (DMSS0501) . . . . . . . . . 5-13

5.2.6.3 Electronic Chain of Custody (DMSSO502) . . . 5-13

5.2.6.4 Field Screening (DMSS0503) ....... . 5-13

5.2.6.5 Sample Analys is Request (DMSS0504) . . . . . 5-13

5.2.6.6 Waste Designation (DMSS0505) . . . . . . . 5-13

5.2.6.7 Worksheet Data Entry (DMSS0506) . . . . . . . 5-13

5.2.6.8 Sample Management and Chain of Custody

(DMSS0507). . . . . . . . . 5-14

5.2.6.9 Sample Labels (DMSS0508) . . . . . . . . . 5-14

5.2.6.10 Sample/Bottle Tracking (DMSS0509) . . . . . 5-14

5.2.6.11 Purge Port/Transfer Pig Location (DMSS0510) 5-14

5.2.7 Shipping Screens ................ . 5-14

5.2.7.1 Shipping Menu .. . . . . . . . . . . 5-14

5.2.7.2 Loading Dock Shipping Data (DMSS0601) . . . . 5-14

5.2.7.3 Loading Dock Container Shipping (DMSS0602) . 5-15

5.2.7.4 TRUPACT Cask Loading/Certification

(DMSS0603) . . . . . . . . . . . 5-15

5.2.7.5 TRUPACT Shipping Documentation (DMSS0604) . . 5-15

5.2.8 System Administration Tables........... . 5-15

5.2.8.1 Error Message Table (DMSS0701) . . . . . . 5-15

5.2.8.2 User Table (DMSS0702) . . . . . . . . . . 5-15

5.2.8.3 Role Table (DMSS0703) . . . . . . . . . 5-16

5.2.8.4 Screen Table (DMSS0704) . . . . . . . . . 5-16 
5.2.8.5 Report Table (DMSS0705) . . . . . . . . 5-16

5.2.8.6 User Role Table (DMSSO708) . . . . . . . . 5-16

5.2.8.7 Role Screen Table (DMSS0709) . . . . . . . . 5-16

5.2.8.8 Field Help Table (DMSSO710) . . . . . . . 5-16

5.2.8.9 Form Help Table (DMSSO711) . . . . . . . . 5-16

5.2.9 Report Screens .. . . . . . . . . . . . . . . 5-16

5.2.9.1 Reports Menu .. . . . . . . . . . . . . . 5-16

5.2.10 Process Routing and Pick Lists Screens . . . . . . . 5-16

5.2.10.1 Pick List Menu .. . . . . . . . . . . . 5-16

5.2.10.2 Processing List Additions (DMS50901) . . . . 5-17

5.2.10.3 Process List (DMSSO902) . . . . . . . . . . 5-17

5.2.10.4 AS/RS Storage Pick List (DMSSO903) . . . . . 5-17

5.2.10.5 AS/RS Shipping Pick List Screen (DMSS0904) . 5-17

5.2.10.6 TRUPACT Assembly Pick List (DMSS0905) . . . 5-17

5.2.11 Facility Inventories Screen . . . . . . . . . . 5-18

5.2.11.1 Radiologic Inventory Summary (DMSS1101) . . 5-18

5.2.11.2 Container Location and Relationships

(DMSS1 102) . . . . . . . . . . . 5-18

5.2.12 Process Data Review Screens . . . . . . . . . 5-18

5.2.12.1 Processed Waste NDA Data Review (DMSS1201) . 5-18

5.2.12.2 Waste Puck NDA Data Review (DMSS1202) . . . 5-18

5.2.12.3 Verification NDA Data Review (DMSS1211) . . 5-18

5.2.12.4 Certification \& Verification NDA Data Review (DMSS1212) .......... 5-18

5.2.12.5 Processed Waste Data Review \& Modification (DMSS1221) . . . . . . . . . 5-18

5.2.12.6 Verification Data Review (DMSS1231) . . . 5-19

5.2.13 Activity Comment Screen (DMSS1301) ....... . 5-19

5.3 REPORTS ................... . . . . . . . . . . . . . . . .

5.4 DATA DETAIL DESIGN . . . . . . . . . . . . . . . . . . . . . . . . . 5

6.0 REFERENCES . . . . . . . . . . . . . . . . . . . . 6-1

6.1 Trademarks...................... . . 6-1

TABLES

3-1. WRAP 1 DMS Process Model Data . . . . . . . . . . . . . . . 3-6

4-1. DMS Screen/Data Access Table. . . . . . . . . . . . . . . . . . . . . . $4-4$

FIGURES

2-1. WRAP 1 DMS Module Decomposition. . . . . . . . . . . . . . . 2-2

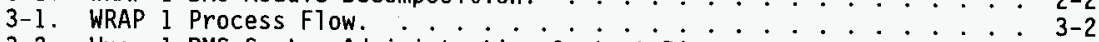

3-2. Wrap l DMS System Administration Context Diagram. . . . . . . . . . . . . $3-4$

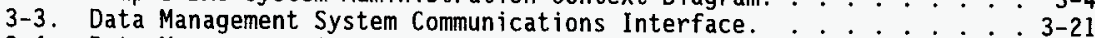

3-4. Data Management System Context Diagram. . . . . . . . . . . . . . . . . . . $3-22$

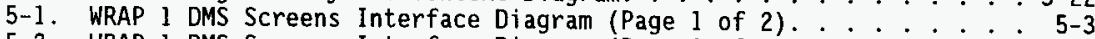

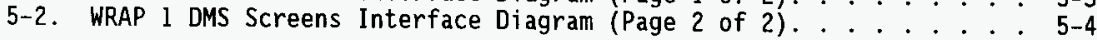


WHC-SD-W026-SDD-001, Rev. 2

\section{APPENOICES}
A. Screen Design Details
B. Report Design Details
C. Data Dictionary
D. Relationship Model
E. DMS Communications Design Details
F. Process Model
G. (Deleted)
H. SWITS/DMS Data Interfaces 


\section{GLOSSARY}

The definitions and terminology used in this document are documented in ANSI/IEEE 729-1983, Standard Glossary of Sof tware Engineering Technology (ANSI/IEEE 1989). Definitions which may be of special interest to the reader, deviations, and additions are defined in this section. Acronyms and initialisms are also defined.

\section{ACRONYMS AND INITIALISMS}

$\begin{array}{ll}\text { ANSI } & \text { American National Standards Institute } \\ \text { AS/RS } & \text { Automatic Stacker/Retriever System } \\ \text { BWAS } & \text { Boxed Waste Assay System } \\ \text { Ci } & \text { Curies } \\ \text { DBA } & \text { Database Administrator } \\ \text { DBMS } & \text { database management system } \\ \text { DMS } & \text { Data Management System } \\ \text { FIPS } & \text { Federal Information Processing Standard } \\ \text { GEA } & \text { gamma energy assay } \\ \text { GUI } & \text { graphical user interface } \\ \text { HLAN } & \text { Hanford Local Area Network } \\ \text { IEEE } & \text { Institute of Electrical and Electronics Engineers } \\ \text { LAN } & \text { local area network } \\ \text { LLW } & \text { low-level waste } \\ \text { MSDS } & \text { Material Safety Data Sheet } \\ \text { NDA } & \text { non-destructive assay } \\ \text { NDE } & \text { non-destructive examination } \\ \text { OOM } & \text { object-Oriented Methodology } \\ \text { PAM } & \text { Packet Assay Monitor } \\ \text { PAN } & \text { Passive Active Neutron } \\ \text { PC } & \text { personal computer } \\ \text { PCS } & \text { Plant Control System } \\ \text { PIN } & \text { Package Identification Number } \\ \text { QA } & \text { Quality Assurance } \\ \text { RDBMS } & \text { relational database management system } \\ \text { RSR } & \text { radioactive shipment record } \\ \text { RWM } & \text { restricted waste management } \\ \text { SA } & \text { System Administrator } \\ \text { SDD } & \text { Software Design Description } \\ \text { SIE } & \text { System Integration Equipment } \\ \text { SII } & \text { Systems Interface, Inc. } \\ \text { SPMP } & \text { Software Project Management Plan } \\ \text { SQL } & \text { Structured Query Language } \\ \text { SRS } & \text { Software Requirements Specification } \\ \text { SWB } & \text { Solid Waste Box } \\ \text { SWITS } & \text { Solid Waste Information and Tracking System } \\ \text { SWSDR } & \text { Solid Storage Disposal Record } \\ \text { TRU } & \text { Transuranic } \\ \text { TSD } & \text { treatment storage, and disposal (facility) } \\ & \end{array}$


UHWM Uniform Hazardous Waste Manifest

WHC Westinghouse Hanford Company

WIPP Waste Isolation Pilot Plant (Carlsbad, NM)

WLAN WRAP Local Area Network

WRAP Waste Receiving and Processing

\section{DEFINITIONS}

Application. The data manipulation and processing operations that are related to specific requirements of an information system.

Software or program that is specific to the solution of a specific business problem or process.

Application System. A collection of applications that uses the services provided by the human-computer interface, communications facility, and data management system to perform the processing necessary to meet the requirements of the information system.

Architecture. The manner in which hardware, software, or data are structured. Architecture typically describes how the system or program is constructed, how its components fit together, and the protocols and interfaces used for communication and cooperation among modules or components of the system.

Archive. To save data for possible later use.

Attribute. Any detail that serves to qualify, identify, classify, quantify, or express the state of an entity. Or, any description of a 'thing of significance'. Attributes are extracted into database elements.

Audit Trail. The capability to report manual data entry and database changes at the data field level. The audit trail provides a record of the date, time, previous value (for data changes), current value, and the identity of the person entering the data (identified through the signature password).

Background Drums (also referred to as "white" drums). Drums containing an uncontaminated waste matrix. Drums are assayed at the start of each operating shift.

Cardinality. Describes the number of instances between two objects.

Certification. The process of certifying that waste is compliant with the regulatory requirements for shipment and/or disposal of the waste.

Certification data. Waste data used to certify that the waste is compliant with the regulatory requirements for shipment and/or disposal of the waste.

Certification drums. (1) Drums generated in the WRAP 1 Process Area. The assay data generated in WRAP for these drums will be the certification data that is used to support disposal of the waste 
in a final repository. Radionuclide abundance data will not be available for verification by the SIE (except for LLW pucks). (2) Drums comprised of newly-generated wastes which have been shipped to WRAP for verification of the waste certification data provided by the waste generator. These drums do not go into the Process Area. Radionuclide abundance data will be available and will be verified by the SIE.

Characterization/Default data. Data is expressed as a decimal fraction representing the $\mathrm{Ci}$ of activity attributed to a given isotope divided by the $\mathrm{C} i$ of activity attributed to the entire waste package. Also referred to as Relative abundance data.

$$
\text { Example: Pu-239 } 0.22
$$

Collection Container. A container used in the restricted waste management (RWM) gloveboxes to collect liquids from aerosol cans for sampling and storage prior to treatment. Collection containers are stored in transfer drums.

Commit. The process of storing new, changed, or deleted records from the work space to a table in the database.

Computer system. A collection of hardware that is managed as a single unit by software such as an operating system, which may also provide common services such as access control, interprocess communications, and a graphical user interface.

Context Diagram. A drawing that shows the boundaries of a system and the interfaces associated with the system.

Data Dictionary. (1) A description of the characteristics of data. The system tables that contain descriptions of the database objects and how they are structured. (2) An inventory that describes, defines, and lists all the data elements that are stored in a database.

Data Element. The logical definition of a unit of information, apart from its actual use (that is, physical rendering) within any given program, file, database report, screen, and so on; the smallest unit of physical data about which attributes are defined; the lowest level of addressable data in which data value(s) are physically stored.

Data Flow. A representation of the passage of data or relationships among business processes, data stores, data flows, and external entities.

Data Flow Diagram. A graphical representation, following a certain style, of business processes, data stores, data flows, and external entities.

Data Integrity. The ability to preserve the completeness, currency, and accuracy of the data without unintentional changes; the ability to produce results that are correct to a predefined level and to 
maintain data availability; conformance of data values to a specified set of rules.

Data Standards. The definition of how facts are to be referred to, how they are to be represented, what they will mean, and the rules governing their informational use throughout the enterprise.

Database. (1) A collection of data logically organized to meet the information and time requirements of a universe of users. (2) A collection of interrelated, largely unique data items or records, in one or more computer files, that may be processed by many different application programs.

Database Management System (DBMS). A computerized system consisting of numerous components which have as their collective purpose the implementation, processing, management, and protection of databases.

Design. The process of defining the software architecture, components, modules, interfaces, test approach, and data from a software system to satisfy requirements.

Domain. The range of values, format constraints, and other properties that apply to an attribute.

Drums for processing. Drums containing a contaminated waste matrix. Drums are destined for processing in the WRAP 1 facility and require an assay to support the processing of the waste. Waste drums are generally "retrieved" from the burial grounds, however, approximately $10 \%$ of these drums will be newly-generated waste which is processed to remove non-compliant items or verify generator's waste.

Entity. Any external system which may communicate with the WRAP 1 DMS system.

Field. In a table, the information stored at the intersection of a row and a column. In a block, a highlighted or underlined area on the screen that can display an output value or accept an input value.

File. (1) A collection of related data that is stored and retrieved by an assigned name. Synonymous with data set. (2) A collection of rows (or records) that have associated columns (or files). The logical equivalent of a table. (3) A named set of records stored or processed as a unit.

Foreign key. One or more columns in a table that implement a many to one relationship that the table in question has with another table. This concept allows the two tables to be joined together.

Hardware. All or part of the physical components of an information system or computer environment. 
Isotopic Quantity Data. A data value that defines the actual mass of an isotope present in an item. Units are grams for TRU isotopes and Curies for all other isotopes.

Local Area Network (LAN). A local area network connects information processing equipment, such as PCs and printers, in a limited geographical area to allow high-speed communications for information resource sharing.

Module. (1) A program unit that is discrete and identifiable with respect to compiling, combining with other units and loading. (ANSI); (2) A logically separable part of a program.

Network. A computer communications system linking a series of computer elements. A system of interconnected computing devices that can communicate and share resources. Networks may be private (for one user) or shared (for many users).

object. A physical thing or component that best represents process boundaries. Design objects are abstractions which, in the final stage of design, evolve into database structures.

Object-Oriented Methodology. A disciplined approach to the development of software which involves the conscious and deliberate use of the notion of an object as an organizing criteria for the data abstractions and the procedures which act on those abstractions.

One Trip Drum. A 55-gallon drum used for TRU loadout.

Oracle. A commercial relational database management software package. It includes software for data entry, database queries, and reports from the database.

Overpack Drum. An 85-gallon drum containing a 55-gallon waste drum. An 85-gallon drum used to contain waste or pucks is not an overpack drum, but an 85-gallon waste drum.

Packet. A package containing non-compliant or suspected non-compliant waste which has been removed from a waste drum in a process glovebox. Each packet is labeled and placed in a transfer drum for transfer to an RWM glovebox.

Pallet. A platform used to hold up to four drums during transport and storage in the Automatic Stacker/Retriever System (AS/RS). Pallets are not uniquely identified.

Pig. A labeled shielded container used to transport purge ports and samples.

Pop-Up. Screen area that overlays all or a portion of the display screen. Pop-ups have unique functionality, but all pop-ups display information to the user while maintaining context in the session. 
Primary Key. The set of mandatory columns within a table that is used to enforce uniqueness of rows, and that is normally the most frequent means by which rows are accessed.

Process. (1) A predetermined course of events defined by its purpose or by its effect, achieved under given conditions. (2) An active component of an information system.

Puck. A supercompacted drum containing low level waste. A1l pucks are low level waste and are placed in 85 gallon drums for storage and/or disposal.

Purge Port. A container used to remove and transport samples from gloveboxes. The purge port acts as an air-lock and provides contamination controT.

Relational database. (1) A database that is organized and accessed according to relationships between data items. (2) A data structure perceived by its users as a collection of tables. A relational database consists of tables, rows, and columns. Most mini-computers and mainframes today have relational database systems available for business use. Relational databases differ from non-relational databases in that there are no system dependencies stored within the data; for example, hierarchical databases are not relational because they contain pointers to other data. Oracle is a relational database management system (RDBMS).

Revisit Drum. Drum that has been assayed in WRAP prior to recejpt of characterization data. The drum may be shipped from the WRAP facility, but the assay data is retained in the SIE until such time as the characterization data becomes available. The original assay is then revisited and the final assay results generated.

Sample. A labeled package of material to be transported to the laboratory for analysis. Samples may be random confirmatory samples from the process gloveboxes or restricted waste samples from the RWM gloveboxes. Samples may be returned from the laboratory when analys is is complete. Returned restricted waste samples are treated with the corresponding parent item.

Set. A group of 1ike objects.

Software. (1) A compitable piece of code. (2) All or part of the programs, procedures, rules, and associated documentation of an information system.

Software Design Description (SDD). A representation of a software system created to facilitate analysis, planning, implementation, and decision making. A blueprint or model of the software system. The SDD is used as the primary medium for communication of software design information. SQL is defined in Federal Information Processing Standard (FIPS) publication 127-1, Database Language SQL. 
Structured Query Language (SQL). A standardized language for requesting data from a database.

Table. A tabular view of data, which may be used on a relational database management system to hold one or more columns to data. It is often an implementation of an object.

Transaction Log. In conjunction with the system backup capability, can be used to facilitate reconstruction of the database if the disk is damaged. The system records the transaction log of a disk other than the one this database is on.

Transfer Drum. A 55 gallon Drath \& Schrader drum used to move and store packets, parent items, and collection containers.

Treatment Container. A container used in the RWM gloveboxes to collect parent items and samples for treatment.

TRUPACT Assembly. A seven drum or single box assembly forming the upper or lower portion of a TRUPACT cask load.

TRUPACT Cask. The shipping container used to transport TRU waste to the Waste Isolation Pilot Plant (WIPP). A TRUPACT cask can be used to transport 14 drums or two boxes.

Unique Key. Any combination of attributes and/or relationships that serves, in all cases, to uniquely identify an occurrence of an object.

Verification. Comparing newly generated waste characterization data with existing certification data to insure the values are within a specified tolerance.

Verification data. Data collected to verify existing certification data.

Verification drums (also referred to as "pink" drums or " $Q C$ " drums). Drums containing a waste matrix with known levels of radionuclide quantities. Drums are assayed at the start and the end of each operating shift. There are two different Verification drums: a high standard and a low standard.

Waste Drum. A labeled 55-gallon or 85-gallon drum containing waste.

$X$ Windows. $X$ Windows is a bit mapped user display. It uses the clientserver model, where the client is the windowed application and the server is the window system. The client-server model allows the user almost complete machine independence. Although $x$ Windows is currently a de facto standard, the National Institute of Standards and Technology plans to adopt the $X$ Windows System as a Federal Information Processing Standard (FIPS). 
WHC-SD-W026-SDD-001, Rev. 2

WRAP MODULE 1 DATA MANAGEMENT SYSTEM

SOFTWARE DESIGN DESCRIPTION

\subsection{INTRODUCTION}

The Waste Receiving and Processing (WRAP) Module 1 Data Management System (DMS) Preliminary System Design Description (PSDD) describes the logical and physical architecture of the system specified in WHC-SD-W026-CSRS-001, WRAP I DMS Sof tware Requirements Specification (SRS), Rev. 1 (WHC 1995).

The WRAP 1 DMS PSDD formally partitions the elements of the system described in the WRAP 1 DMS SRS into design modules and describes the key properties and relationships among the data elements within these modules as well as the modules interfaces with external systems such as the WRAP Plant Control System (PCS). The WRAP 1 DMS PSDD can be thought of as a detailed blueprint for implementation activities.

The WRAP I DMS PSDD is formally reviewed in compliance with the Quality Assurance (QA) program WHC-CM-4-2, Quality Assurance, (WHC 1989) QI 3.2. This document will be reviewed against the WRAP 1 DMS SRS and revised as necessary to reflect changes in the WRAP 1 DMS requirements.

The organization and contents of this document are in compliance with WHC-CM-3-10, Software Practices (WHC 1993) and follow the guidance in American National Standards Institute (ANSI)/Institute of Electrical and Electronics Engineers (IEEE) Standards 1016-1987, Software Design Descriptions (ANSI/IEEE 1989).

\subsection{PURPOSE}

Each function in the WRAP 1 DMS SRS has been partitioned into database tables and elements which can be traced to design modules in the WRAP 1 DMS PSDD. The design modules identified are judged best able to meet WRAP 1 DMS SRS objectives within the constraints identified in Section 1.2 below. The purpose of this document is to describe the content and relationships of the design modules to which WRAP 1 DMS SRS system functions have been allocated. The WRAP 1 DMS PSDD is used as the primary medium for communicating software design information.

This document is a sustainable deliverable and shall be maintained by revision throughout the design and development phase of the Waste Receiving and Processing Module I (WRAP 1) Data Management System (DMS). Applicability of the WRAP 1 DMS PSDD shall begin immediately when released for issue. At project completion, this document will be revised to reflect the structure of the as-built system and will be released as the WRAP 1 DMS Software Design Description (SDD). It will be a sustainable deliverable and shall be maintained by revision for the life of the WRAP 1 DMS, including the phase of system operation and maintenance following project completion. 


\subsection{SCOPE}

The design descriptions contained within this document will describe, in detail, the software products that will be developed to assist the Project W-026, Waste Receiving and Processing Module 1 , in their management functions. The WRAP I DMS is required to collect, store, and report data related to certification, tracking, packaging, repackaging, processing, and shipment of waste processed or stored at the WRAP 1 facility. The software products to be produced are: 1) the WRAP 1 DMS applications software; 2) communications software between the DMS and other WRAP 1 facility systems; and 3) Solid Waste Information and Tracking System (SWITS) interface software. Appendix $H$ provides a description of the necessary changes to the SWITS system to support the WRAP 1 DMS.

The scope of this document is limited to a description of the software design for the WRAP 1 DMS, and this document is used as the primary medium for communicating software design information. Host hardware and operating software, terminal devices, communications hardware and software, and host software products will be provided for systems developers.

The WRAP 1 DMS project development efforts progress in accordance with the latest approved version of WHC-SD-W026-SDP-001, Waste Receiving and Processing Facility Module 1 Data Management System Software Project Management Plan (SPMP) (WHC 1994).

\subsection{OVERVIEW}

The general structure of this document supports the concept of design modules with multiple design views by organizing data tables and their associated attributes and behaviors into separate design views. Each design view represents a separate concern about the software system. Both logical and physical representations of the design are presented in the WRAP 1 DMS SDD. The WRAP I DMS SDD is organized into six chapters.

Chapter 1.0 provides an introduction to the document.

Chapter 2.0 describes the division of the software system into design modules. This chapter describes how the system has been structured and the purpose and function of each module.

Chapter 3.0 describes the relationships and behavior among the design modules and their associated database tables and data elements. This chapter defines the interaction among design objects and provides the information needed to easily perceive why, how, where and at what level system actions occur.

Chapter 4.0 describes internal and external system interfaces. The human-machine interface is addressed in this chapter.

Chapter 5.0 describes the internal details and attributes of the design modules. This chapter provides the developers with specific programming instructions.

Chapter 6.0 provides references to related project documentation. 
The appendices contain additional supporting information including Screen Details (Appendix A), Report Details (Appendix B), Data Dictionary (Appendix C), Relationship Models (Appendix D), DMS Communications (DMSCOM) Details (Appendix E), Process Models (Appendix F), and SWITS/DMS Data Interfaces (Appendix $H$ ). The information in the appendices will be revised as appropriate as the software design phase is completed and development progresses.

An Object-Oriented Methodology (OOM) was initially used in the WRAP 1 DMS design. During each revision of the PSDD, the prior models have been revised to reflect impacts generated as a result of subsquent module definition and interfaces. The subsequent design efforts have addressed the design from a functional perspective as defined by the software modules and database structure. This functional perspective also facilitates the phased approach utilized in the detailed design and development process, with development following design definition for related modules; therefore, there is no clear break between preliminary and detailed design phases. However, this iterative method has provided the developers with a comprehensive understanding of the system requirements, the discovery of new or mis-stated requirements, and issue resolution prior to implementation.

The WRAP 1 DMS design and development documentation was not broken down into Preliminary and Detail SDDs as advocated by WHC-CM-3-10, Sof tware Practices. Because of this inequity, several versions of the PSDD have been issued throughout the development cycle. This release, Rev. 2, provides the final preliminary detailed design description for the original scope of the WRAP 1 DMS. Any future DMS enhancements or software changes shal t be documented on Software Change Requests. Once the WRAP 1 DMS system has been documented in the completed detailed SDD and released for implementation, it will be left up to the document custodian to determine when these changes are to be formally incorporated into the SDD and whether or not an ECN or a document revision will be used to incorporate the changes. 
WHC-SD-W026-SDD-001, Rev. 2

This page intentionally left blank. 


\subsection{DECOMPOSITION DESCRIPTION}

The WRAP 1 DMS is composed of severat system and process modules. This chapter describes the purpose and function of each module. The purpose of this chapter is to provide a high level understanding of the system, which will provide the primary data collection, tracking, presentation, and storage capability for waste stored at the WRAP 1 facility.

\subsection{MODULE DECOMPOSITION}

Design modules result from decomposition of system requirements. The objective of functional decomposition is to divide the system into separate modules that can be implemented, changed, maintained, and tested with minimal effect on the other design modules. The WRAP 1 DMS functional areas have been separated into individual design modules which are structurally and functionally distinct.

The WRAP I DMS functional areas include both process modules and system modules. Each module contains one or more of the following data processing elements: Updates, Displays, and/or Reports. These elements will be described in greater detail in Chapter 5.0.

\subsubsection{Process Modules}

The WRAP 1 DMS process moduTes encompass the tracking and maintaining of regulated solid waste information as specified in the WRAP 1 DMS SRS and associated deliverables. Process modules encompass the following functions: Receiving; Non-destructive Examination/Non-destructive Assay (NDE/NDA) Operations; Process Operations; Sample Management; Shipping; and Process Routing and Pick Lists. Each function is comprised of one or more independent modules (see Figure 2-1).

2.1.1.1 Receiving. Receiving consists of the processing of waste drums, waste boxes, and empty drums into the WRAP 1 facility at the receiving dock. This process ensures that the container labels are all intact, the location/relocation history on SWITS is confirmed and associated data is downloaded, the waste container is on a process pick list, the waste container has been assigned a routing code, and the curie inventory for the facility is updated with each waste container's curie loading. The module that encompasses Receiving is Receiving Drum or Box Containers.

2.1.1.2 NDE/NDA Operations. NDE/NDA 0perations provides operational data and data collection functions for the non-destructive examination/non-destructive assay (NDE/NDA) operations. NDE/NDA operations are conducted in two different areas. Boxes are evaluated in the Box NDE system and the Boxed Waste Assay System (BWAS). Drums are routed through the drum NDE/NDA area, which is further segmented into Drum NDE, Passive Active Neutron (PAN) and Gamma Energy Assay (GEA) operations. The modules that encompass NDE/NDA Operations are: 


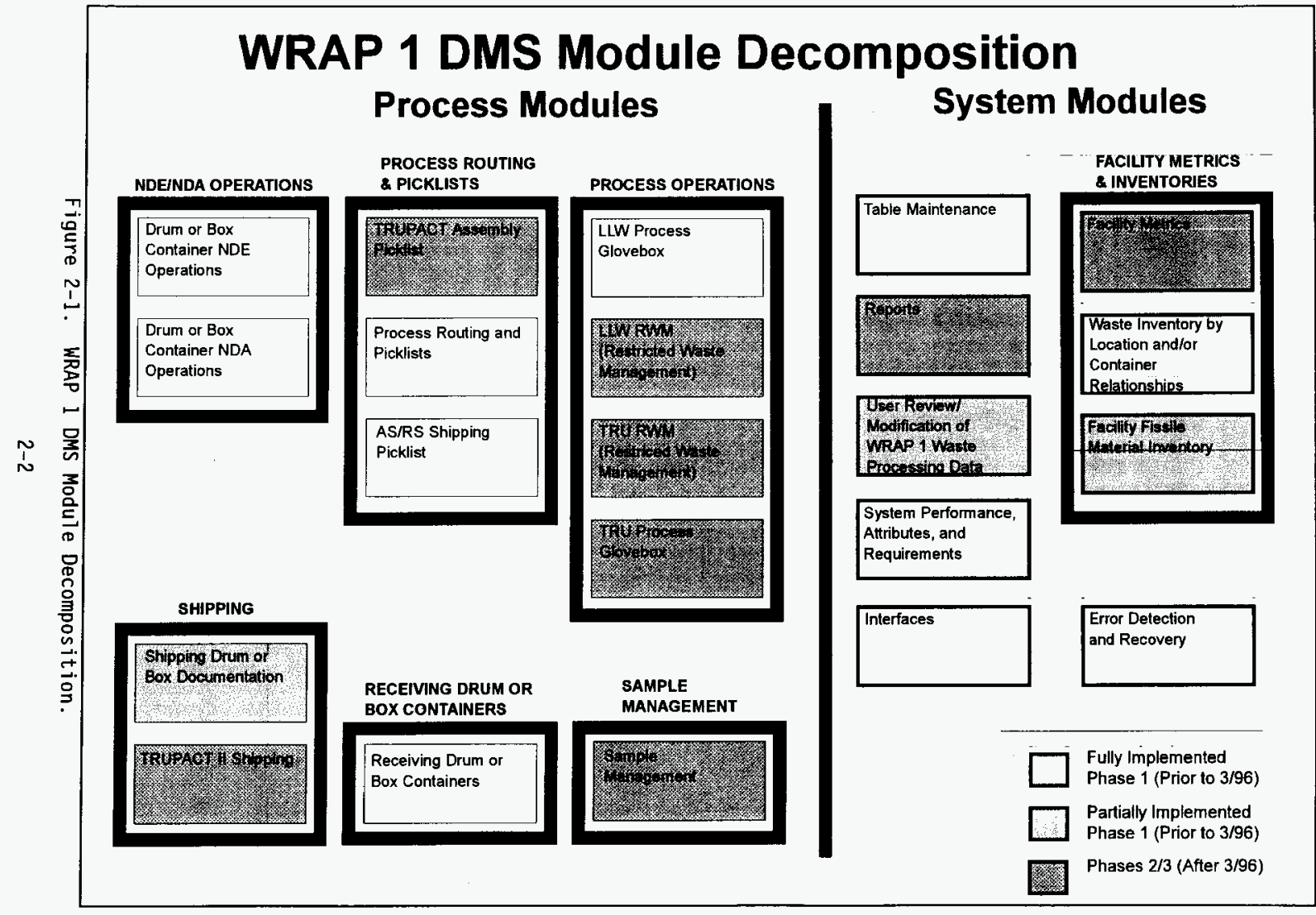


WHC-SD-W026-SDD-001, Rev. 2

Drum or Box Container NDE Operations; Drum or Box Container NDA Operations; and NDA Verification and Background Containers.

2.1.1.3 Process Operations. Process Operations provides operational data and data collection functions for the process area gloveboxes. Waste drums are removed from overpack containers when applicable, and are opened and emptied. Waste drum contents are sorted, sampled, repackaged, and compacted when possible. Limited waste treatment capabilities will be provided in the RWM gloveboxes. The modules that encompass Process Operations are: Low-Level Waste (LLW) Process Glovebox; LLW Restricted Waste Management; TRU Process Glovebox; and TRU Restricted Waste Management.

2.1.1.4 Sample Management. Sample Management manages the analytical sample data from the point of generation to the final disposal. Activities will include sample tracking and manually updating the WRAP I DMS with waste type designators and treatment procedures to be used in the restricted waste management (RWM) gloveboxes: Laboratory analytical results will not be loaded into the WRAP 1 DMS. Updating of sample container locations as they leave the Process Area and as they are received back from the laboratories wi11 also be addressed in this module. The module that encompasses the Sample Management function is Sample Management.

2.1.1.5 Shipping. Shipping supports the shipment of empty drums, waste drums and waste boxes from the WRAP 1 facility by providing the proper shipping documentation, verification that the correct drums are in the shipment, and updates to SWITS with certification data, shipping data, and location data. The modules that encompass Shipping are: Shipping Drum or Box Documentation and TRUPACT II Shipping.

2.1.1.6 Process Routing and Pick Lists. This function assists the operations personne] with the creation and maintenance of the various container process routing designations and pick lists for the Automatic Stacker/Retriever System (AS/RS). As the pick lists are selected, they will be uploaded to the PCS. If a pick list or routing code is modified, the modified pick list is uploaded to the PCS. It is assumed that the PCS will overwrite an existing pick list with the new one for that activity. The modules that encompass Process Routing and Picklists are: Process Routing and Picklists; AS/RS Shipping; and TRUPACT Assembly Picklist.

\subsubsection{System Modules}

The WRAP 1 DMS system modules encompass those functions which are integral to the system operation and maintenance and which are incorporated into each of the process modules. The system modules are: Waste Inventory by Location and/or Container Relationships; User Review/Modification of WRAP 1 Processing Data; Reports; Table Maintenance; Error Detection and Recovery; Interfaces and Communications, System Attributes, Requirements, and Performance; and Activity Comment.

2.1.2.1 Waste Inventory by Location and/or Container Relationships. The PCS will send a number of data messages to the WRAP 1 DMS over the WRAP Local Area Network (WLAN) that will be sorted into message types and then operated on according to the type and the data. A major function of the PCS messages is to maintain a dynamic inventory of all waste items and empty drums by interior 
location at the WRAP 1 facility. The next major function is to maintain relationship records between associated waste items at the WRAP 1 facility. Each location record update or relationship record generated will also include the current date and time elements.

This function also provides radiological loading audits and checks for the WRAP 1 facility. Radiological limits tracking in WRAP 1 includes tracking total facility inventory and inventory inside the TRU and TRU RWM gloveboxes.

2.1.2.2 User Review/Modification of WRAP 1 Processing Data. The WRAP 1 users will review the WRAP 1 DMS data as applicable to verify that all data required to be generated in WRAP 1 was in fact obtained. Data to be reviewed include all associated waste container tables. Other tables may be added to the user review process as needed. Missing or incorrect data elements will be manually entered or corrected. Once the waste containers have been processed through the WRAP I facility and returned to the Shipping Area, satisfactory completion of this activity will allow the waste container to be flagged as "data review complete".

\subsubsection{Reports. Reports to be generated by the WRAP 1 DMS encompass}

facility performance data reporting, waste data reporting, reference table reporting, and ad hoc reports. The descriptions for the various reports are in Chapter 5.0. In general, reports generated can be viewed on the screen, printed, or sent to a file.

2.1.2.4 Table Maintenance. Maintenance functions that need to be performed to ensure the efficient and correct operation of the WRAP 1 DMS include SWITS compatible table maintenance and WRAP 1 DMS table maintenance. These

functions will be performed by the WRAP 1 System Administrator (SA) and/or the Database Administrator (DBA).

2.1.2.5 Error Detection and Recovery. Error detection and recovery shall be a integral part of the design. Diagnostic software to test the health of the WRAP 1 DMS and the status of the communication interfaces will be provided. Software will also be provided to facilitate restoration to normal operation following a failure. Specific error detection and recovery functions to be provided witl be determined during software construction.

2.1.2.6 Interfaces. The DMS will be include three general interface types: message communications within the DMS and with other WRAP 1 facility systems (e.g., PCS, SIE, and BWAS); interfaces with SWITS; and user interface.

\subsubsection{Performance, Attributes, and Requirements. This module encompasses} systemic WRAP 1 DMS characteristics including programmed function keys, error and update messages, data acceptance checks, security features, system and data maintenance and administration, transaction $\log$, system backup, and the audit trail. It also addresses the ability of the system to meet the static and dynamic numerical requirements placed on the software or on human interaction with the software as a whole.

2.1.2.8 Activity Comment. The ability for an operator to assign a comment to any DMS activity that he is performing will be accommodated by this module. A11 activity comments will be associated with specific waste containers being processed within the WRAP facility; i.e. this module is not to be used for a general operator diary of the day's events. Data associated with packaged 
waste that is not appropriate for other data tables and modules may be entered using the activity comment module.

\subsection{CONCURRENT PROCESS DECOMPOSITION}

A11 modules and processes within each module will be able to operate concurrently; however, operations on any given waste item are performed sequentially. A multiple screen capability shall be available to allow the user to skip to other screens to perform separate functions while suspending the operations on the current screens. It will also allow the system to popup another screen to alert the user or request data on an immediate basis. The concurrent process decomposition for each module is described in Appendix $F$.

\subsection{DATA OBJECT DECONPOSITION}

The records and tables comprising the WRAP 1 DMS will be implemented using Oracle products. The individual data design objects and object attributes are defined in detail in the appendices. Both logical and physical data definitions are described in models and accompanying descriptions. The logical definition is comprised of the Relationship Models, while the physical definition is comprised of the Process Models, Screen Details, Report Details, and Data Dictionary. 
WHC-SD-W026-SDD-001, Rev. 2

This page intentionally left page. 


\subsection{OBJECT-ORIENTED DESIGN DESCRIPTION}

This chapter defines the interaction among design objects (database tables and elements) and provides the information needed to easily perceive why, how, where, and at what level system actions occur. The object-oriented design description will be expressed through a series of object models. These models define the relationships between objects (Relationship Model) and physical data structure (Process Models).

\subsection{INTERMODULE AND INTERPROCESS DEPENDENCIES}

This design is structured around modules utilizing shared objects that will function individually and independently. Each module and database process is dependent on objects, and may depend upon the results from other modules or processes. These dependencies are related to the container (drum or box) moving from one process area to the next by the routing applied to that container.

For example, the NDE/NDA process is dependent upon the SWITS data downloaded during the previous Receiving process. This is then carried forward to the gloveboxes in the Process area where the NDE/NDA data determines which glovebox to go to and what non-compliant items to look for on the sorting table. The treatments to apply to the non-compliant items are dependent upon the Sample Management process laboratory results. The final process, Shipping, is dependent upon the data collected in the Process Operations area and the NDA process.

Data dependencies within a process are tightly coupled. These dependencies are discussed in Section 3.3 of this document. This section will discuss the high-level relationships among the WRAP 1 DMS modules and processes as well as the key data elements.

\subsubsection{Work Flow Description}

A top-level WRAP 1 process flow diagram is shown in Figure $3-1$. The planned mode of operation for the WRAP 1 facility is described in WHC-SD-W026-SD-001, Waste Receiving and Processing Module 1 Operating Plan (WHC 1994).

\subsubsection{Data Sources}

Data sources utilized by the WRAP 1 DMS system include SWITS, the WRAP PCS, the SIE, the BWAS, the HLAN time clock, and user input. 


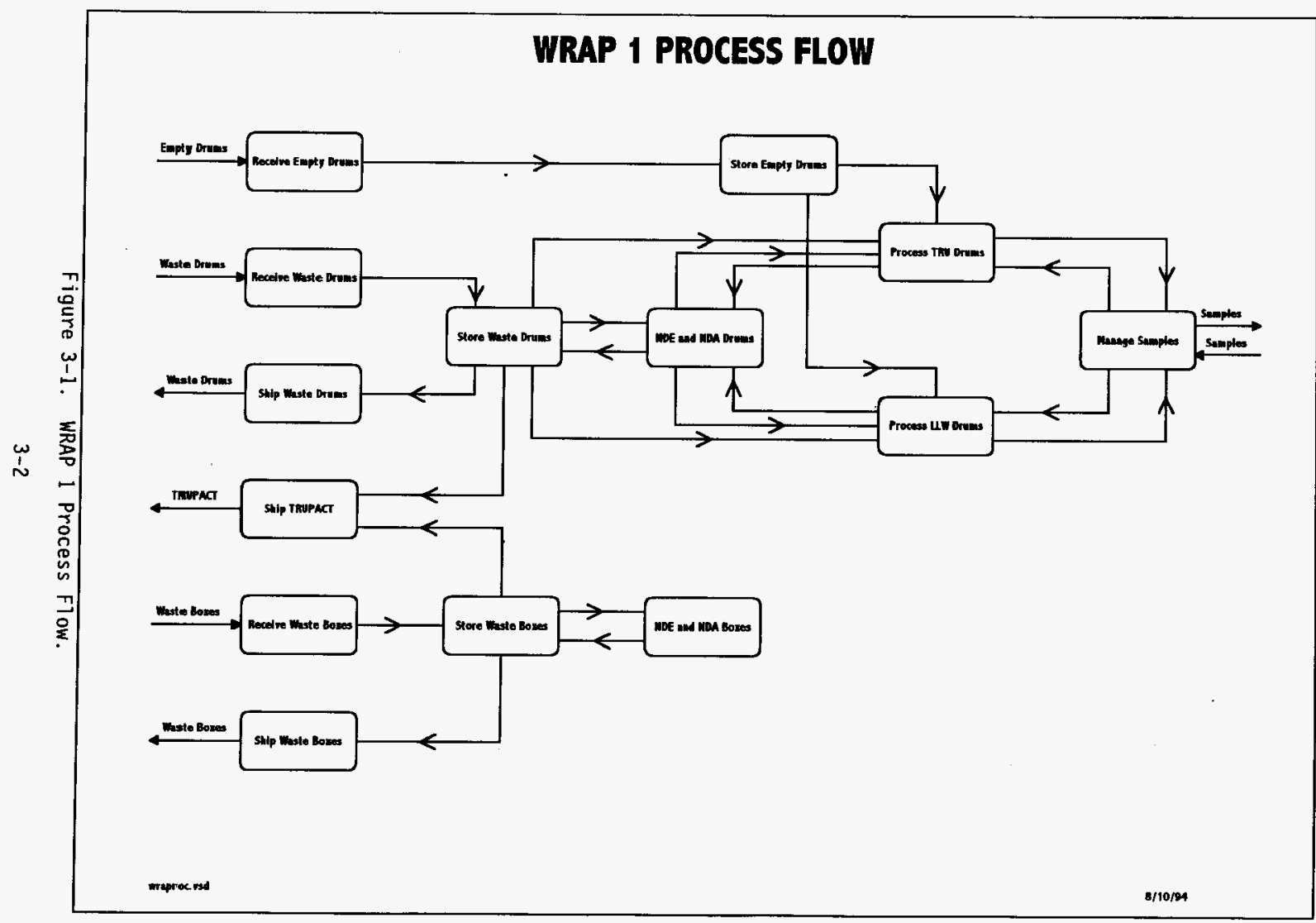


WHC-SD-W026-SDD-001, Rev. 2

\subsubsection{WRAP 1 DMS System Administration Context Diagram}

The WRAP 1 DMS SRS is used as the basis for development of the system administration data flow. The system administration context diagram (Figure 3-2) presents a high level view of the interfaces of users and systems manager(s) with the administrative functions of the WRAP 1 DMS. The interfaces to the system's administration activities of the WRAP 1 DMS are:

WRAP 1 Operations Personnel (Operational Users). Operational users are those persons, authorized access to the WRAP 1 DMS, who use the data presentation and data entry screens to perform the functional activities supported by the system.

WRAP 1 Operations Management and Support Personnel. Management and support personnel utilize the WRAP 1 DMS data presentation and data entry screens to review and update data and to generate reports.

System Administrator(s). The system administrator is a high level user who has been granted additional authority to maintain portions of the database that affect overall operation of the system. These include determining the processing authority of other system users, maintaining data validation tables, and tracking system activity.

Operating System Access Controls. The operating system of the computer platform on which the WRAP 1 DMS operates implements security constraints that restrict who may utilize the computer. These constraints must be managed for WRAP 1 DMS users.

WRAP 1 DMS Access Controls. The WRAP 1 DMS system has a more restrictive set of security controls. Access to the WRAP 1 DMS may be by user job function and/or personal authorization.

Developers. The WRAP 1 DMS developers have the responsibility of creating, implementing, and maintaining the oracle application modules supporting the users' requirements.

The system administration context diagram identifies the processes supporting both administrative and functional users of the WRAP 1 DMS system. These include the following processes performed as part of the system administration activities:

Log on to a DMS-enabled workstation. Before accessing any WRAP 1 DMS functions, the potential user must successfully either log on to a $P C$ which is connected to the HLAN and is set up as a DMS client, or log on to the computer on which the WRAP 1 DMS system resides through an X-terminal.

Log onto the WRAP 1 DMS. Based on the security criteria established in the system portion of the WRAP 1 DMS database, each user must log onto the WRAP 1 DMS prior to performing any activity.

Execute WRAP 1 DMS user database transactions. Authorized users execute database transactions to perform those functions required to support their assigned duties in the operation of the WRAP 1 facility. 
WHC-SD-W026-SDD-001, Rev. 2

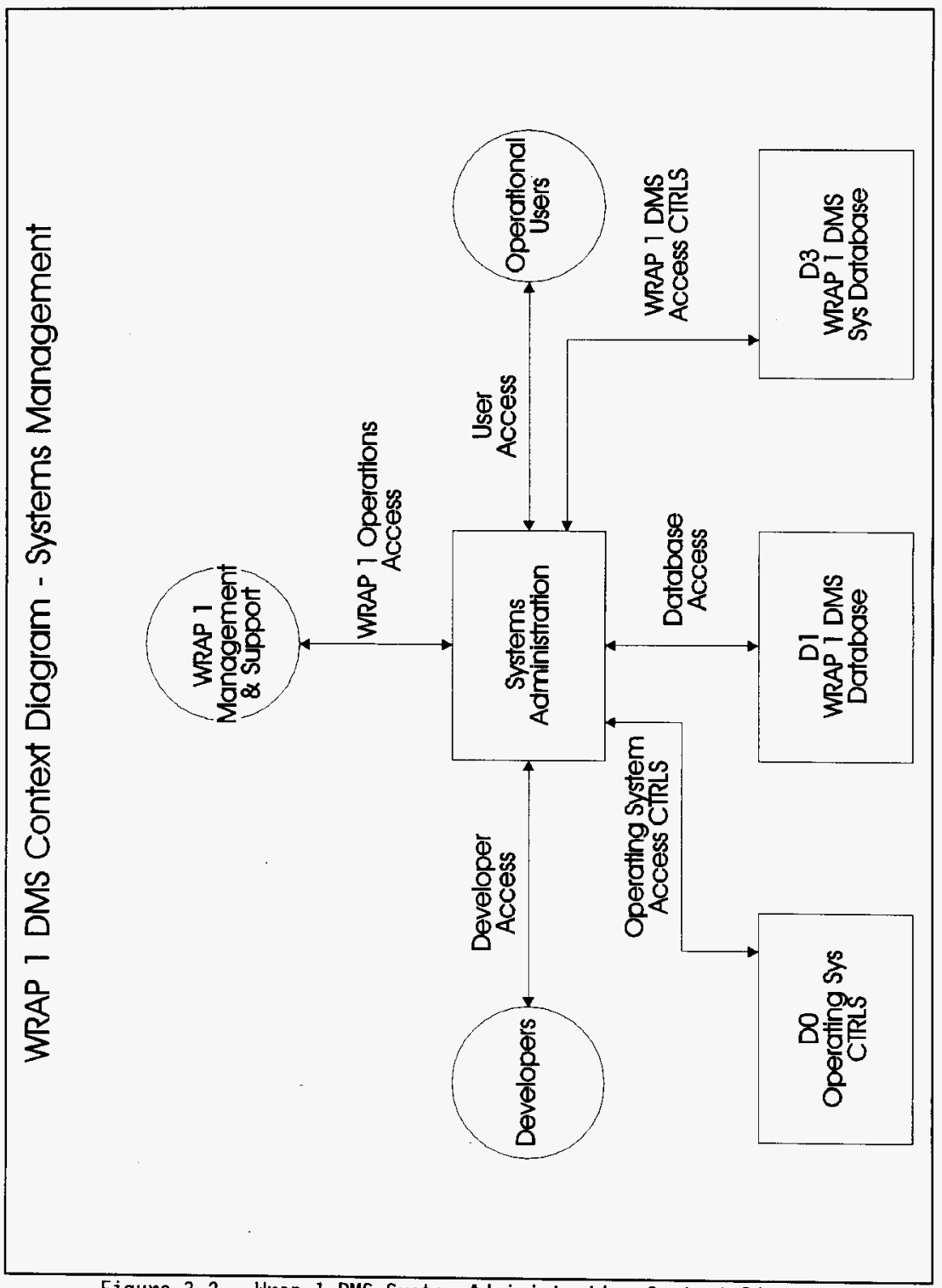

Figure 3-2. Wrap I DMS System Administration Context Diagram. 
Execute WRAP 1 DMS system manager transactions. Authorized system managers execute database transactions to maintain control, data integrity, and effective use of the overall system.

\subsection{OBJECT MODEL DIAGRAMS}

Object model diagrams present a view of the processes, data flows, and interfaces supported by the WRAP 1 DMS. The overa11 business supported by the WRAP 1 DMS can be viewed through Relationship and Process data models. These data models describe the cardinalities, relationships, and data flows between abjects. This section describes the object model diagram approach. Detailed object model diagrams are found in Appendices $D$ and $F$ of this document.

\subsubsection{Data Dictionary}

The Data Dictionary was developed by abstracting all the needed data elements from the Objects and the forms required to process waste at Hanford. The Data Dictionary contains a summary list of all the data tables and data elements in the WRAP 1 DMS system, as well as an expanded 1ist providing each data element's description and domain (character, number). A large portion of the WRAP 1 DMS data elements were abstracted from the SWITS database and incorporated into the WRAP I DMS. The Data Dictionary is provided in Appendix $\mathrm{C}$.

\subsubsection{Relationship Model}

The purpose of the Relationship Model is to create one model that represents an entire system or an entire sub-system or an entire module of a system. The Relationship Model documents the significant connections, associations, or relationships between and among objects. The relationships represent data abstractions between objects that have similar sets of constraints and characteristics. A relationship exists when some number of instances are connected in a significant manner. Relationships can be thought of as a mapping between members of a set (Set Theory); given a member of set $A$, is a member of set $B$ associated to it?

Relationships use a layered square box to notate objects and a rectangle box to show software systems. Relationships are bi-directional, and utilize cardinality (multiplicity) to show dependencies or conditionality. Appendix D includes all WRAP I DMS module Relationship Models.

\subsubsection{Process Model}

The Process Model is comprised of a diagram displaying the Physical Unit Processes occurring in a module and a columnar table describing the Unit Processes in the order that they occur. Revision 2 of this document reformatted the Unit Processes to provide a separate line item for each module trigger and associated processing.

Each major process is represented in the diagram with a circle that describes the process. A line with an arrowhead pointing to or from a 
Process or Data Store represents the data flow direction. Information provided in the columnar table is summarized in Table 3-1. Process Models are presented in Appendix F.

Table 3-1. WRAP 1 DMS Process Model Data.

\begin{tabular}{ll}
\hline Column & \multicolumn{1}{c}{ Description } \\
\hline 1. & Process sequence number \\
2. & Unit Process name \\
3. & Screens and Reports utilized by the Process \\
4. & User or system triggers for updates \\
5. & $\begin{array}{l}\text { Conditions and events (or Sub-Unit Processes), } \\
\text { including special instructions for the developers } \\
\text { (pseudo-code) }\end{array}$ \\
6. & $\begin{array}{l}\text { Data Stores (actual database table names) } \\
\text { 7. }\end{array}$ \\
\end{tabular}

\subsection{DATA DEPENDENCIES}

Computer databases are made up of associated groups of data. The association of data is made at two basic levels, "object" and "database".

Individual data items (or data elements) that support a common function or activity are brought together. This grouping is commonly known as a record or table. In its early design stage, this group is known as an "object."

Groups of related objects are brought together to form a "database." A database may be made up of a single object or many objects linked together.

The linking of multiple objects is accomplished by defining the relationship between objects. The Relationship Model (see Appendix D) is the resulting graphical representation of the database's objects and relationships.

\subsubsection{Object Dependency Descriptions}

This section describes object dependencies. Dependencies described in this section are preliminary, and will be updated as the system is developed. Appendix C, the Data Dictionary, provides definitions of all WRAP 1 DMS objects.

3.3.1.1 Functional Database objects. Functional database objects can be grouped according to their support of the primary function object, the CONTAINER object. 
WHC-SD-W026-SDD-001, Rev. 2

3.3.1.1.1 The CONTAINER Object. The CONTAINER object is the central object of the WRAP 1 DMS database. It provides unique information about each waste container and its contents. This is the core object of the database. The main purpose of the WRAP I DMS system is to maintain and track occurrences of this object, representing physical waste containers and their contents.

The CONTAINER object encompasses the following container types: box, overpack drum, product drum, empty container, waste container, transfer drum, aerosol can, collection container, calibration drum, packet, purge port, treatment container, and transfer pig.

The CONTAINER object is comprised of the Container and Content Record (WASTE) and Container and Content Extension Record (WASTEXT) tables in the database.

3.3.1.1.2 objects Dependent on CONTAINER. The following objects are dependent on the CONTAINER object for their existence. Occurrences of these objects will not exist unless there is a corresponding occurrence of the CONTAINER object. The objects dependent on CONTAINER are:

- Activity Comment

- Applicable Material Safety Data Sheet (MSDS)

- Bin List

- Chain of Custody Transfer

- Hazardous Chemical Component Record

- Container and Content Extension Record

- Container Location

- Container Relationship Record

- Container Treatment

- Discharge Conveyor List

- Field Screening Record

- Hazardous Waste Container Detail Record

- Radioactive Isotope Quantity Record

- Metrics Record

- NDA Assay Results

- NDA Assay Isotopic Records

- NDE Results

- Not Process List

- Not Ship Pick List

- Isotopic Distribution

- Payload Container Certification Record

- Payload Assembly Certification Record

- Physical Component Record

- Package Dangerous Waste Numbers Record

- Radioactive Waste Container Detail Record

- Sample Data Relationship Record

- Shipment History Record

- Shipping Pick List

- TRUPACT Waste Container Record

- Verification Record

- Worksheet Item.

3.3.1.1.3 objects Independent of CONTAINER CONTENT. The following objects can occur independent of the CONTAINER object. These objects support data that has value in its own right, regardless of the status of the 
CONTAINER object. The objects that may exist independent of CONTAINER CONTENT are:

- Bottle Analysis Record

- Bottle Data Record

- Chain of Custody

- Field Analysis

- Message Log Record

- Process Pick List

- Processing Add List

- Radiological Material Inventory

- Receiving Display Record

- Sample Analysis Request

- Sample Data Record

- Sample Bottle Location Record

- Shipment Item Record

- Shipment Record

- Treatment Worksheet

- TRUPACT Shipping Record

- TRUPACT Shipping Pick List

- WRAP Shipment Record.

3.3.1.2 Systems Management objects. The systems management objects are those whose primary purpose is to enable the system to attain its functional requirements. These objects are seldom visible to the functional user of the WRAP 1 DMS. Instead, the systems management objects support the functionality of the system software. The systems management objects are divided into the following groups.

3.3.1.2.1 Security and Access Control objects. The security and access control objects identify authorized users and those system activities and data that each may utilize. It is important to recognize that WRAP 1 DMS data must withstand public comment. The security and access control objects are:

- Role Table

- Role Screen Table

- Screen Table

- User Table

- User Role Table

- User Signature Password Table.

3.3.1.2.2 Functional Support objects. Functional support objects provide background data to support the application software. The functional support objects are:

- Communication Table

- Error Message Table

- Field Help Table

- Form Help Table

- Report Table.

3.3.1.2.3 Data Integrity and Validation Objects (Look-Up Tables). Data integrity and validation objects are used by the software to dynamically validate the content of data entered by the functional user. By using data objects instead of hard coding the validation values into the software, 
changes in valid value ranges over time can be quickly and economically handled by simple validation table changes. Appendix $G$ contains a listing of the contents of the look-up tables. The look-up table objects are:

- Miscellaneous Code Table

- Company Table

- Container Size Table

- Container Type Table

- DOT Container Specification Table

- Dangerous Waste Number Table

- Facility Table

- Field Analysis Type

- Hazardous Chemical Component Table

- Isotope Table

- Laboratory Table

- Laboratory Analysis

- Location Table

- Material Group Code Table

- Material Safety Data Sheets

- Person Table

- Physical Component Description Table

- Package Status Table

- Primary Waste Type Code Table

- Generator Assay Profile Table

- Profile Isotopic Table

- Route Description Table

- Sample Container Type

- Sample Matrix

- Sampling Method

- Secondary Waste Type Code Table

- Shipment Picklist Type Table

- SIE Isotopic Name Table

- State Table

- Storage Category Table

- Treatment Procedure

- TRU Container Code Table

- TRU Shipping Category Table

- TSD Facility Table

- WRAP Miscellaneous Code Table.

\subsection{The Miscellaneous Code (CODECHECK) and WRAP Miscellaneous}

(WRAPMISC) Tables. A number of data elements need validity checks for which there are so few valid values that it is not advantageous to establish a separate table for them. In general, if a table would have only two elements (the code value and its description) and there would be only a few entries, the values are put into either the CODECHECK table or the WRAPMISC table with a code field name to identify the group of valid values. The CODECHECK table is used for SWITS controlled table miscellaneous codes, and the WRAPMISC table is used for DMS-only table miscellaneous codes. These value sets and the fields to which they apply are listed in Appendix C. 


\subsubsection{Object Relationship Descriptions}

This section describes the relationships between objects. These descriptions include specifying the number of instances of a particular object that may relate to a specified number of instances of another object (cardinality).

A number of objects have description names which have been assigned a short form for ease of use in the data models. The following objects and their corresponding short names have been utilized in this section:

- Container Relationship

- Hazardous Chemical Component

- Hazardous Waste Container Detail

- Radioactive Isotope Quantity Record

- Radioactive Waste Container Detail

- Radiologic Material Inventory

- Sample Analysis Request

- WRAP Shipment Record

- Treatment, Storage, or Disposal

ConRel
ChemComp
HazDetail
IsoQty
RadDetail
RadMat
SAR
SHIPWRAP
TSD.

3.3.2.1 Functional Database Relationships. Functional database relationships are associated with functional database objects. These relationships support the associations of data that comprise the operational system functions within the database. This section also identifies the process functions (see Section 2.1.1) in which each type of relationship is valid. The relationships in this group are:

Chain of Custody-Sample. A chain of custody transmits one or many samples. A sample is transmitted by zero or one chain of custody.

Company-Container. A company may generate zero, one, or many containers. A container is generated by one and only one company.

Company-Person. A company may employ zero, one, or many persons. A person may be employed by one and only one company.

Company-Shipment (1). An offsite company may receive zero, one, or many shipments. A shipment may be received by zero or one offsite company. (Shipping)

Company-Shipment (2). A transportation company may transport zero, one, or many shipments. A shipment may be transported by one and only one transportation company.

Container-Activity Comment. A container may relate zero, one, or many activity comments. An activity comment relates to one and only one container. (Receiving; NDE/NDA; Process Operations; Sample Management; Shipping)

Container-Applicable MSDS. A container may apply zero, one, or many applicable MSDSs. An applicable MSDS applies to one and on $y$ one container.

Container-Bin List. A container is located by zero or one bin list. A bin list locates one to four containers. (Process Routing and Picklists) 


$$
\text { WHC-SD-W026-SDD-001, Rev. } 2
$$

Container-Chain of Custody Transfer. A container may be related to zero, one, or many chain of custody transfer records. A chain of custody transfer record relates one and only one container. (Sample Management)

Container-ChemComp. A container may be related to zero, one, or many hazardous chemical component records. A hazardous chemical component record relates one and only one container. (Shipping)

Container-Container Extionsion (1). A (overpack) container is related to one container extension record. A container extension record relates zero or one (overpack) container.

Container-Container Extension (2). A (waste) container is related to one container extension record. A container extension record relates one and only one (waste) container.

Container-Container Location. Each container location may relate to zero, one, or many containers. A container is related to one and only one container location. (Receiving; NDE/NDA; Process Operations; Sample Management;

Shipping; Process Routing and Pick Lists)

Container-Container Relationship. A container may be related to zero, one, or many container relationships. A container relationship relates two containers ("from" container and "to" container). (Receiving; NDE/NDA; Process Operations; Sample Management; Shipping; Process Routing and Pick Lists)

Container-Container Treatment. A container may be related to zero, one, or many container treatments. A container treatment relates to one and only one container. (Process Operations)

Container-Discharge Conveyor List. A container may be located on zero or one discharge conveyor lists. A discharge conveyor list locates one and only one container.

Container-Field Screening. A container relates zero, one, or many field screening records. A field screening record is related to one and only one container. (Sample Management)

Container-HazDetail. A container may relate zero or one hazardous waste container detail records. A hazardous waste container detail record relates to one and only one container. (Sample Management; Process Routing and Pick Lists; Shipping)

Container-IsoQty. A container may relate zero, one, or many radioactive isotope quantity records. A radioactive isotope quantity record relates to one and only container. (NDE/NDA; Shipping)

Container-Isotopic Distribution Record. A container may relate zero or one isotopic distribution (PAM) record. An isotopic distribution record relates to one and only one container. (NDE/NDA)

Container-Metrics Record. A container may relate zero, one, or many metrics records. A metrics record relates to one and only one container. 
Container-NDA Assay Results. A container relates to zero, one, or many NDA assay results records. NDA assay results records are related to one and only one container. (NDE/NDA)

Container-NDE Results. A container may be related to zero, one, or many NDE results records. An NDE results record relates to one and only one container record. (NDE/NDA)

Container-Not Process List. A container may be 1 isted on zero or one Not Process List. A Not Process List lists one and only one container. (Process Routing and Pick Lists)

Container-Not Ship Pick List. A container may be listed on zero or one Not Ship Pick List. A Not Ship Pick List lists one and only one container. (Process Routing and Pick Lists)

Container-Package Dangerous Waste Numbers Record. A container may relate zero, one, or many package dangerous waste numbers records. A package dangerous waste numbers record relates to one and only one package.

Container-Payload Container Certification Record. A container may be supported by zero or one payload container certification record. A payload certification record supports one and only one container. (Shipping)

Container-PhysComp. A container relates to zero, one, or many physical component records. A physical component record is related to one container. (Process Operations; Shipping)

Container-RadDetail. A container relates to zero or one radioactive waste container detail records. A radioactive waste container detail record is related to one container. (NDE/NDA; Process Operations; Process Routing and

Pick Lists; Shipping)

Container-RadMat. A container may relate zero, one, or many radiologic material inventories. A radiological material inventory is related to one and only one container. (Process Operations)

Container-Sample. A container relates zero, one, or many sample records. A sample record is related to one and only one container. (Sample Management)

Container-Sample Relationship. A container may relate zero, one, or many sample relationships. A sample relationship relates one or many samples to a container. (Sample Management)

Container-Shipment History. A container may relate to zero or one shipment history records. A shipment history record is related to one or many containers. (Shipping)

Container-Shipping Pick List. A container may be selected by zero or one shipping pick list. A shipping pick list selects one and only one container. (Process Routing and Pick Lists; Shipping)

Container-Verification Record. A container may be reviewed by zero, one, or many verification records. A verification record reviews one and only one container. 
Container-Worksheet Item. A container may be specified by zero or one worksheet items. A worksheet item specifies one and only one container. (Process Operations)

Container Size-Container. A container size may apply to zero, one, or many containers. A container applies one and only one container size.

Container Type-Container. A container type may describe zero, one, or many containers. A container is described by one and only one container type.

Container Type-Container Size. A container type may apply one or many container sizes. A container size may apply to one and only one container type.

Container Type-Payload Container Certification Record. A container type may be recorded by zero, one, or many payload container certification records. A payload container certification record records one and only one container type. (Shipping)

Container Type-Sample Container Type. A container type may describe zero, one, or many sample container types. A sample container type is described by one and only one container type.

Dangerous Waste Number-Package Dangerous Waste Numbers Record. A dangerous waste number may relate zero, one, or many package dangerous waste numbers records. A package dangerous waste numbers record relates to one and only one dangerous waste number.

DOT Specification-Container. A DOT specification may apply to zero, one, or many containers. A container applies one and only one DOT specification.

Facility-Container (1). A facility may locate zero, one, or many containers. A container is located at one and only one facility.

Facility-Container (2). A facility may generate zero, one, or many containers. A container is generated by one and only one facility.

Facility-Shipment. An onsite facility may receive zero, one, or many shipments. A shipment may be received by zero or one onsite facility. (Shipping)

Facility-SHIPWRAP. A facility may receive zero, one, or many WRAP shipments. A WRAP shipment may be received by one and only one facility. (Shipping)

Facility-TSD Facility. A facility may be zero or one TSD facility. A TSD facility may be one and only one facility.

Field Analysis Type-Field Analysis. A field analysis type relates zero, one, or many field analyses records. A field analysis record is related to one and only one field analysis type. (Sample Management)

Field Screening-Field Analysis. A field screening sample may apply zero, one, or many field analyses. A field analysis is applied to one and only one field screening sample. (Sample Management) 
HazComp-ChemComp. A hazardous chemical component (HazComp) may relate zero, one, or many hazardous chemical component records (ChemComps). A hazardous chemical component record relates to one and only one hazardous chemical component.

Isotope-IsoQty. An isotope may relate zero, one, or many radioactive isotope quantity records. A radioactive isotope quantity record relates to one and only one isotope.

Isotope-SIE Isotopic Name. An isotope is described by zero or one SIE isotopic names. An SIE isotopic name describes one and only one isotope. (NDE/NDA)

Laboratory Analysis-Bottle Analysis Record. A laboratory analys is may be relate to zero, one, or many bottle analysis records. A bottle analysis record relates one and only one laboratory analysis.

Laboratory Analysis-SAR. A laboratory analysis may define zero, one, or many sample analysis requests. A sample analysis request is defined by one and only one laboratory analysis. (Sample Management)

Laboratory-Chain of Custody. A laboratory is designated by zero, one, or many chain of custody records. A chain of custody record designates zero or one laboratory. (Sample Management)

Location-Container Location. A location is associated with zero, one, or many container locations. A container location associates with one and only one location. (Receiving; NDE/NDA; Process Operations; Sample Management;

Shipping; Process Routing and Pick Lists)

Location-Field Screening. A location may locate zero, one, or many field screening records. A field screening record is located by one and only one location. (Sample Management)

Location-Sample. A location may relate zero, one, or many samples records. A sample record relates to one and only one location. (Sample Management)

Location-Sample Bottle Location. A location is associated with zero, one, or many sample bottle locations. A sample bottle location associates with one and only one location. (Sample Management)

Material-Container Extension. A material group may apply to zero, one, or many container extension records. A container extension record applies one and only one material group.

MSDS-Applicable MSDS. An MSDS may apply to zero, one, or many applicable MSDSs. An applicable MSDS applies to one and only one MSDS.

NDA Assay Results-NDA Assay Isotopic Record. An NDA assay results record may relate zero, one, or many NDA assay isotopic records. An NDA assay isotopic record relates to one and only one NDA assay results record. (NDE/NDA)

Package Status-Container. A package status may apply to zero, one, or many containers. A container applies one and only one package status. 
Payload Assemb7y-Payload. A payload assembly may relate one or many payload records. A payload record is related to one and only one payload assembly.

Person-Chain of Custody. A person may be the company contact for zero, one, or many chains of custody. A chain of custody has one and only one company contact person. (Sample Management)

Person-Field Screening. A person may take zero, one, or many field screenings. A field screening is taken by one and only one person. (Sample Management)

Person-Sample. A person may take zero, one, or many samples. A sample is taken by one and only one person. (Sample Management)

Person-SHIPWRAP (1). A person may transport zero, one, or many WRAP shipments. A WRAP shipment is transported by one and only one person.

(Shipping)

Person-SHIPWRAP (2). A person may be responsible for sending zero, one, or many WRAP shipments. A WRAP shipment may be sent by one and only one person. (Shipping)

Person-SHIPWRAP (3). A person may receive zero, one, or many WRAP shipments. A WRAP shipment is received by one and only one person. (Shipping)

Person-TSD Facility (1). A person may be a scheduler for zero or one TSD facility. A TSD facility may have zero or one scheduler.

Person-TSD Facility (2). A person may be a supervisor for zero or one TSD facility. A TSD facility may have zero or one supervisor.

Person-User. A person may be zero, one, or many WRAP 1 DMS users. A WRAP 1 DMS user may be zero or one person.

Physical Component Description-PhysComp. A physical component description may apply to zero, one, or many physical component records. A physical component record applies one and only one physical component description.

Primary Waste Type-Container. A primary waste type may apply to zero, one, or many containers. A container applies one and only one primary waste type.

Profile-Container Extension. A generator assay profile may relate zero, one, or many container extension records. A container extension record relates to one and only one generator assay profile. (NDE/NDA)

Profile-NDA Assay Results.. A generator assay profile defines zero, one, or many NDA assay results records. An NDA assay results record is defined by one and only one generator assay profile. (NDE/NDA)

Profile-Process Pick List. A generator assay profile is selected by zero, one, or many process pick lists. A process pick list selects one and only one generator assay profile. (Process Routing and Pick Lists) 
Profile-Processing Add List. A generator assay profile is selected by zero, one, or many processing add lists. A process pick list selects one and only one generator assay profile. (Process Routing and Pick Lists)

Profile-Profile Isotope. A generator assay profile is supported by zero, one, or many profile isotopes. A profile isotope may support one and only one generator assay profile. (NDE/NDA)

Route-Container Extension. A route may apply to zero, one, or many container extension records. A container extension record applies one and only one route.

Route-Process Pick List. A route may direct zero, one, or many process pick lists. A process pick list is directed by one and only one route. (Process Routing and Pick Lists)

Route-Processing Add List. A route may direct zero, one, or many process pick lists. A processing add list is directed by one and only one route. (Process Routing and Pick Lists)

Sample-Sample Bottle. A sample may be contained in one or many sample bottles. A sample bottle may contain one and only one sample. (Sample Management)

Sample-SAR. A sample record may relate zero, one, or many sample analysis requests. A sample analys is request is related to one and only one sample record. (Sample Management)

Sample Bottle-Bottle Analysis Record. A sample bottle may be relate to zero, one, or many bottle analysis records. A bottle analysis record relates one and only one sample bottle.

Sample Bottle-Sample Relationship (1). A sample bottle is related to one parent waste container (packet or drum) sample relationship. A sample relationship relates a sample bottle to one and only one parent waste container. (Sample Management)

Sample Bottle-Sample Relationship (2). A sample bottle may be related to one purge port sample relationship. A sample relationship relates a sample bottle to one and only one purge port container. (Sample Management)

Sample Bottle Location-Sample Bottle. A sample bottle location may be related to one or many sample bottles. A sample bottle relates one and only one sample bottle location.

Sample Container Type-Labaratory Analysis. A sample container type may be specified by zero, one, or many laboratory analyses. A laboratory analysis specifies one and only one sample container type. (Sample Management)

Sample Matrix-Sample. A sample matrix may define zero, one, or many samples. A sample is defined by one and only one sample matrix. (Sample Management)

Sampling Method-Field Screening. A sampling method may relate zero, one, or many field screening records. A field screening record relates to one and only one sampling method. (Sample Management) 
Sampling Method-Sample. A sampling method may collect zero, one, or many samples. A sample is collected by one and only one sampling method. (Sample Management)

Secondary Waste Type-NDA Assay Results. A secondary waste type group describes zero, one, or many NDA assay results records. An NDA results record is described by zero or one secondary waste type group. (NDE/NDA)

Secondary Waste Type-RadDetail. A secondary waste type may relate zero, one, or many radioactive waste container detail records. A radioactive waste container detail record may relate to zero or one secondary waste type.

Shipment Item-Shipment History Record. A shipment item relates to one shipment history record. A shipment history record is related to one and only one shipment item. (Shipping)

Shipment Picklist Type-Container Extension Record. A shipment picklist type may apply to zero, one, or many container extension records. A container extension record applies one and only one shipment picklist type. (Process Routing and Pick Lists)

Shipment-Container. A shipment (manifest) may list one or many containers. A container may be 1 isted by zero or one shipment.

Shipment-Shipment History Record. A shipment relates to one or many shipment history records. A shipment history record is related to one and only one shipment. (Shipping)

Shipment-Shipment Item. A shipment may contain one or many shipment items. A shipment item is contained by one and only one shipment. (Shipping)

Shipment-SHIPWRAP. A shipment may manifest zero or one WRAP shipment. A WRAP shipment may be manifested by one and only one shipment. (Shipping)

SHIPWRAP-Shipping Pick List. A WRAP shipment record relates one or many shipping pick lists. A shipping pick list is related to one and only one WRAP shipment record.

SHIPWRAP-TRUPACT Shipping Record. A WRAP shipment record may relate zero or one TRUPACT shipping record. A TRUPACT shipping record is related to one and only one WRAP shipment record. (Shipping)

SIE Isotope Name-NDA Assay Isotopic Record. An SIE isotope name may relate zero, one, or many NDA assay isotopic records. An NDA assay isotopic record relates to one and only one SIE isotope name. (NDE/NDA)

SIE Isotope Name-Profile Isotope. An SIE isotope name describes zero or one profile isotope. A profile isotope is described by one and only one SIE i sotope name. (NDE/NDA)

State-Company. A state may address zero, one, or many companies. A company record may be addressed by one and only one state.

State-Person. A state may address zero, one, or many persons. A person is addressed by one and only one state. 
WHC-SD-W026-SDD-001, Rev. 2

Storage Category-Container. A storage category may apply to zero, one, or many containers. A container applies one and only one storage category.

Treatment Procedure-Treatment Worksheet. A treatment procedure may apply to zero, one, or many treatment worksheets. A treatment worksheet applies one and only one treatment procedure. (Process Operations)

Treatment Worksheet-Container Treatment Record. A treatment worksheet may be applied to zero, one, or many container treatment records. A container treatment record applies one and only one treatment worksheet.

Treatment Worksheet-Worksheet Item. A treatment worksheet records one or many worksheet items. A worksheet item is recorded by one and only one treatment worksheet. (Process Operations)

TRU Container Code-Container Extension Record. A TRU container code may apply to zero, one, or many container extension records. A container extension record may apply zero or one TRU container codes.

TRU Container Code-Payload. A TRU container code may apply to zero, one, or many payload records. A payload record applies one and only one TRU container codes.

TRU Shipping Category-Payload. A TRU shipping category may apply to zero, one, or many payload records. A payloard record applies one and only one TRU shipping category.

TRU Shipping Category-Payload Assembly. A TRU shipping category may apply to zero, one, or many payload assemblies. A payloard assembly applies one and only one TRU shipping category.

TRUPACT Shipping Record-Payload Assembly. A TRUPACT shipping record relates one, two, or three payload assemblies. A payload assembly is related to one and only one TRUPACT shipping record.

User-Activity Comment Record. A user may record zero, one, or many activity comment records. An activity comment record is recorded by one and only one user. (NDE/NDA; Process Operations; Sample Management)

User-Chain of Custody Transfer (1). A user may receive zero, one, or many chain of custody transfer records. A chain of custody transfer record is received by one and only one user. (Sample Management)

User-Chain of Custody Transfer (2). A user may relinquish zero, one, or many chain of custody transfer records. A chain of custody transfer record is relinquished by one and on]y one user. (Sample Management)

User-Container Treatment. A user may perform zero, one, or many container treatments. A container treatment is performed by one and only one user. (Process Operations)

User-NDE Results. A user may generate zero, one, or many NDE results records. An NDE results record is generated by one and only one user. (NDE/NDA) 
WHC-SD-W026-SDD-001, Rev, 2

3.3.2.2 Systems Management Relationships. Systems management relationships are associated with the corresponding objects. These relationships support the functional association of data that provides the background systems services for the WRAP 1 DMS system. The relationships in this group are:

Role-Role Screen. A role may relate zero, one, or many role screens. A role screen is related to one and only one role.

Role-User Role. A role may relate zero, one, or many user roles. A user role is related to one and only one role.

Screen-Role Screen. A screen may relate zero, one, or many role screens. A role screen is related to one and only one screen.

User-Person. A WRAP 1 DMS User may or may not be a Person. A Person may or may not be a WRAP 1 DMS User.

User-User Signature Password. A user relates zero or one user signature passwords. A user signature password is related to one and only one user.

User-User Role. A user may relate zero, one, or many user roles. A user role is related to one and only user.

\subsection{PHYSICAL DATA MODEL}

The physical data model translates the object/relationship definition into the form acceptable to the DBMS being used. The WRAP 1 DMS data model is translated into a series of Oracle tables and indexes. In general, objects become tables and relationships become indexes.

Complex applications often require unusual combinations of data in order to achieve the requirements of the user. Special definition subsets of the database may be identified to meet these requirements. Such subsets are known as "views." There is no limit to the number of views that may be defined in support of a relational database.

This section describes the physical database model, the database tables, the indexes that make accessing the database more efficient, and the specialized views of the database that have been defined to further simplify processing.

\subsubsection{Data Dictionary}

The data dictionary (see Appendix $C$ ). identifies the database tables and the indexes supporting each table. Each index is identified as either unique or foreign (non-unique).

\subsubsection{Indexes}

Indexes are pathways through the database that permit the user to quickly access specific data without having to physically look at every record (row) of a table in order to locate desired data. Indexes are normally sorted 
on a data item in the table. While ascending order is the most common, descending order may be selected. Indexes are of two basic types: unique and non-unique.

3.4.2.1 Unique Indexes. A unique index cannot contain any duplicate key values. This feature ensures that one and only one table occurrence exists for a particular key value. The unique index is always used to identify the primary key of a table. Primary keys are identified in the Data Dictionary, Appendix $\mathrm{C}$.

3.4.2.2 Foreign Indexes. This type of index is used to provide other pathways through the database to support specific requirements (i.e., searching, sorting, joining). Typically, foreign key fields have non-unique indexes defined.

\subsection{NETWORK DEPENDENCIES}

The WRAP 1 DMS system will primarily support users at the WRAP 1 facility, although some users will be located throughout the Hanford Site. Users wi1l access the system through the WRAP Local Area Network (WLAN) or the Hanford Local Area Network (HLAN). The WRAP 1 DMS will access the SWITS through the HLAN. This section describes those features of the WLAN and HLAN networks that will be utilized in support of WRAP I DMS processing.

WRAP 1 plant terminals accessing the WRAP 1 DMS database will utilize the WLAN network for access to the database computer. Some terminals external to the WRAP 1 facility will utilize the HLAN to access the WRAP 1 DMS database. The network diagram is provided in Figure 3-3.

The WRAP 1 DMS will interface to the SWITS database over HLAN to acquire the initial data on drums and boxes arriving at the WRAP 1 facility and will update the SWITS database with the necessary certification data on shipments of waste from the WRAP 1 facility. The WRAP 1 DMS will communicate with the WRAP 1 PCS, the SIE, and the BWAS over the WLAN to provide these other systems with required data and to receive location and characterization data. Terminals located throughout the plant will be used to review and enter data. Figure 3-3 presents a system architecture layout showing the WRAP 1 DMS communication interfaces, and Figure 3-4 presents a context diagram showing the WRAP 1 DMS data interfaces. The WRAP 1 DMS database will reside on a computer connected to the WLAN. The WRAP 1 DMS computer (server) must communicate with all of the computers and terminals represented in this figure.

An electronic interface may be implemented for waste data package transmission to the Waste Isolation Pilot Plant (WIPP). Details of this interface have not been defined at this time. 


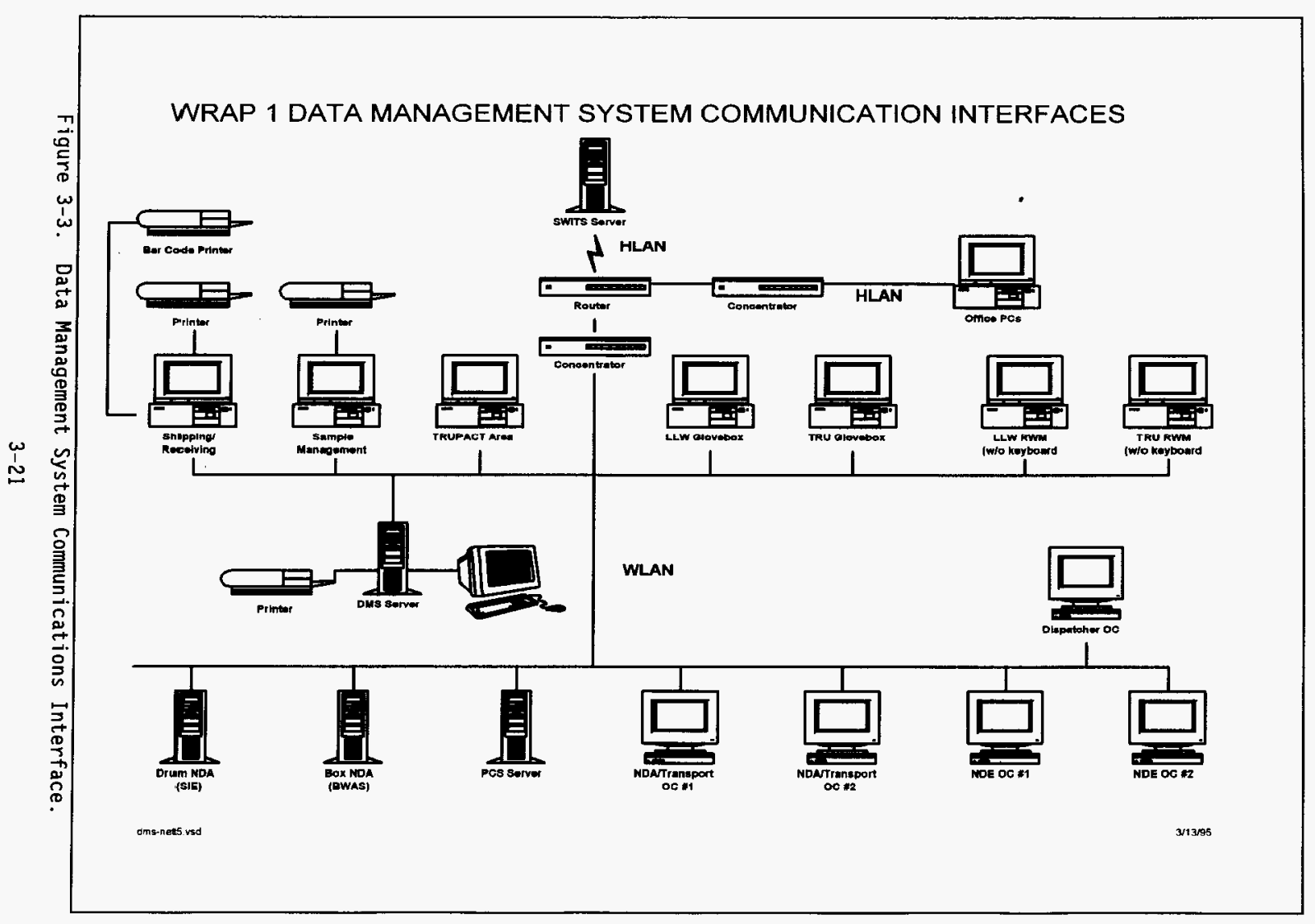




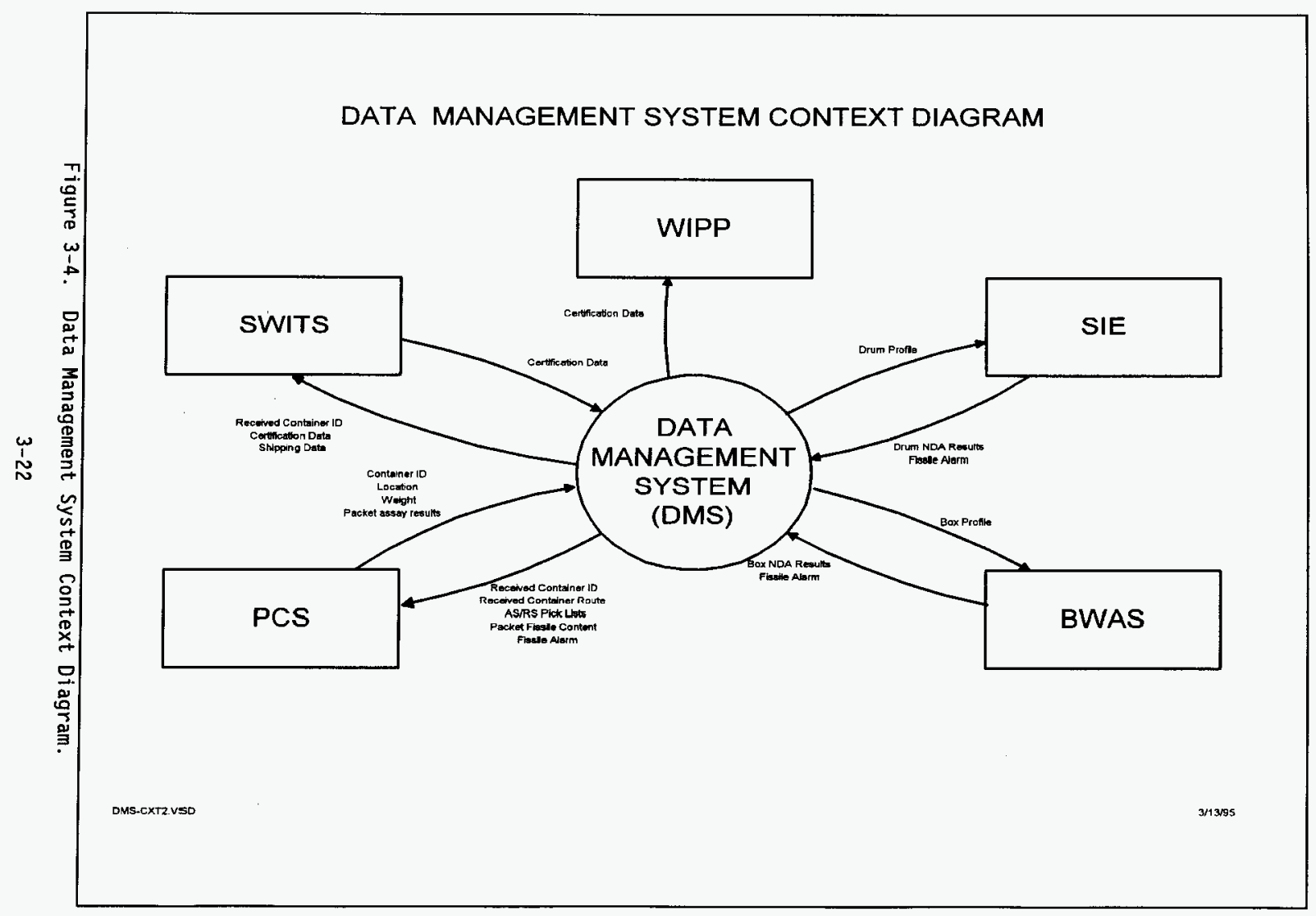


WHC-SD-W026-SDD-001, Rev. 2

\subsection{CONVERSION DEPENDENCIES}

Due to the similarity of the WRAP 1 DMS data and reporting requirements with those of SWITS, the WRAP 1 DMS will, where applicable, copy/duplicate the data structures of the SWITS Oracle database. The WRAP 1 DMS design will also incorporate appropriate SWITS applications and reports. Final screens and reports will be reviewed by the users onl ine during construction. The WRAP 1 DMS system will comply with current SWITS data standards and data element naming criteria. 
WHC-SD-W026-SDD-001, Rev. 2

This page intentionally left blank. 
WHC-SD-W026-SDD-001, Rev. 2

\subsection{INTERFACE DESCRIPTION}

Chapter 4.0 provides a high-level description of the interfaces inherent in the WRAP 1 DMS. Internal, external, and human/machine interfaces are utilized by the WRAP 1 DMS. These interfaces enable needed access to WRAP 1 DMS data by persons and other computer systems.

\subsection{INTERNAL INTERFACES}

The ORACLE relational database management system provides the management of the WRAP 1 DMS data. Oracle Forms Version 4.0 and Oracle Reports Version 1.1 are the principal programming tools.

\subsection{EXTERNAL INTERFACES}

External interfaces are those interfaces outside the WRAP 1 DMS software application product. These interfaces include other software products, systems enabling communication with external systems, and the associated hardware.

\subsubsection{Software Interfaces}

Software interfaces are interactions between the WRAP 1 DMS application software and other software products, such as data management systems, operating systems, process and equipment control systems, or other application systems. Interfaces also include those with the vendor supplied software products, i.e., Pro-C, $\mathrm{C}$, and Oracle and its interface products including Oracle Forms, Oracle Reports, and SQL*Net.

The WRAP 1 DMS software interfaces include SQL*NET calls to and from the SWITS database to allow remote access. The remote access to and from the PCS, SIE, and BWAS will be handled by the WRAP 1 DMS Interface module. Software interfaces describe the application software interfaces to the vendor supplied software products, such as the use of 0racle and its interface products such as $S Q L^{\star}$ Forms, SQL*Reports, and $S Q L^{\star}$ Net.

\subsubsection{Communications Interfaces}

The communication interfaces to the WRAP 1 DMS are the HLAN and WLAN. operations users and development staff access the WRAP 1 DMS server through the Ethernet connections to one of the available LANs. The WRAP 1 OMS will interface to the SWITS database over the HLAN to acquire the initial data on drums and boxes arriving at the WRAP 1 facility. The WRAP 1 DMS will also update the SWITS database with the necessary certification data on shipments of waste from the WRAP 1 facility. The WRAP 1 DMS will communicate with the WRAP 1 PCS, the drum NDA SIE and the box NDA BWAS over the WLAN to provide the 
other systems with required data and to receive location and characterization data. Terminals located throughout the plant will be used to review and enter data.

An electronic communications interface may be implemented for waste data package transmission to the Waste Isolation Pilot Plant (WIPP). Details of this interface have not been defined at this time.

\subsubsection{Hardware Interfaces}

Hardware interfaces describe the interface of the application software with the hardware, such as devices to be supported and protocols to be used. The WRAP 1 DMS host hardware has been selected to meet anticipated capacity and performance requirements (disk space, main memory, and peripheral devices) of the system. The DMS will run on a Hewlett Packard HP-9000 Model 800/E35 computer using the HP-UX (UNIX) operating system. User access will be from HP Vectra 486DX/66 personal computers (PCs) and HP ENVIZEX A Series $X$ stations. The interfaces with the hardware will be transparent to most users. The users access the host using IBM-PC compatible personal computers and/or X-terminals operating over the WLAN. Each user is required to have a username/password and a signature password in order to update or modify critical data. The specific steps required for computer access will be provided in the WRAP 1 DMS User Manual.

\subsection{MAN/MACHINE INTERFACES}

The interface between the user and the WRAP 1 DMS system is necessary to assure the effective utilization of the system. This section describes the characteristics of the human interfaces to the system.

\subsubsection{WRAP 1 DMS Security}

The primary purpose of the Data Management System (DMS) security system is to prevent unauthorized production, modification, validation, or use of data. This function is performed by granting permission via signature password to users who have the proper training and authority to perform critical data manipulation functions. A secondary purpose of security is to prevent nonessential functions from bogging down the system. This purpose is achieved by defining a set of user groups and granting access to various DMS functions based on the job descriptions of the system users included in the groups. A logon password would be assigned to each user which would identify the appropriate user group. Both the signature password and the logon password are described in the DMS.SRS. The following user groups have been defined:

System Administrator (SADMIN). DMS superuser and system administrator. This person is not technically a group since no functions are restricted. Read and write access is provided to all fields and data structures in the DMS as we 11 as access to DMS and " $C$ " development functions. This group would be responsible for setting up and maintaining the database structure including the tables and displays. This group is authorized to change anything within the system and consequently, any existing DMS security will be bypassed. 
Engineering Development (ENGDEV). This group should have read access to all screens and data fields as well as write access to the Lookup and data validation table entries but not table or database structures. No write access would be provided to actual waste data records. Access to DMS and the "C" development would be provided on a development system functions. This group would recommend and design changes to improve the system or meet new requirements. The design work would be performed on a development system prior to implementation by the system administrator. Security is by individual user ID logon.

operations Administrator (OPSADN). This group should have read access to all screens and data fields. Write access should be provided for planning and scheduling functions. These functions include shipping and receiving, pick list/processing 7 ist maintenance, sample data, and reports. This group would be responsible for scheduling waste to be received and shipped. This includes facilitating paperwork assembling and ensuring that SWITS data is sufficient to allow processing in WRAP 1 . Security is by individual ID logon.

SWOC Administrator (SWCOPSADM). This group should have read and write access only to the screens where waste being shipped to WRAP 1 is assembled. The screens filled in by this group are used by the receiving operators accept shipments into WRAP 1 . This is primarily a waste planning function for SWOC. Another function of this person could be to verify that SWITS has sufficient information for the waste to be processed at WRAP 1 prior to sending it there. Security is by individual ID logon.

NDA Analyst (NDAANL). This group should have read access to all screens and data fields. This group has write access to all NDA data and will be required to validate all NDA data. Security is by individual ID logon.

NDE Technician (NDEANL). This group should have read access to all screens and data fields. This group has write access to all NDE data and will be required to validate all NDE data. Security is by individual ID logon.

Operations Supervisor (OPSSUP). This group should have read and write access to all screens and data fields regarding waste data including ability to change alarm setpoints and clear alarms. Security is by individual user ID logon.

General 0perator (GENOPS). This group should have read access to all screens and data fields regarding waste data well as write access to non alarm setpoints and control functions as guided by procedure. Write access is also allowed for data entry and controlled by a signature password. Report printing required by procedure to is also allowed. Security is by group ID logon which will be the normal logon state of the terminal during operation.

Monitor (MONITR). This group should have read only access to all screens and data fields. Printing of limited reports should be allowed. Security is by group ID logon. 
Table 4-1. DMS Screen/Data Access Table.

\begin{tabular}{|c|c|c|c|}
\hline \multirow{2}{*}{$\begin{array}{l}\text { DMS } \\
\text { Category } \\
\text { No. }\end{array}$} & \multicolumn{3}{|c|}{ Access Privileges } \\
\hline & Description & Read & Write \\
\hline 1 & Shipping & All Groups & $\begin{array}{l}\text { SADMIN, and w/sig password } \\
\text { OPSADM, OPSSUP, GENOPS }\end{array}$ \\
\hline 2 & Receiving & A11 Groups & $\begin{array}{l}\text { SADMIN, and w/sig password } \\
\text { OPSADM, OPSSUP, GENOPS }\end{array}$ \\
\hline 3 & NDE/NDA & A11 Groups & $\begin{array}{l}\text { SADMIN, NDAANL and w/sig } \\
\text { password OPSADM, OPSSUP, GENOPS }\end{array}$ \\
\hline 4 & $\begin{array}{l}\text { Process } \\
\text { Operations }\end{array}$ & Al1 Groups & $\begin{array}{l}\text { SADMIN, and w/sig password } \\
\text { OPSADM, OPSSUP, GENOPS }\end{array}$ \\
\hline 5 & $\begin{array}{l}\text { Sample } \\
\text { Management }\end{array}$ & All Groups & $\begin{array}{l}\text { SADMIN, and w/sig password } \\
\text { OPSADM, OPSSUP, GENOPS }\end{array}$ \\
\hline 6 & $\begin{array}{l}\text { Fissile } \\
\text { Inventory }\end{array}$ & All Groups & SADMIN \\
\hline 7 & $\begin{array}{l}\text { Process Data } \\
\text { Review }\end{array}$ & A11 Groups & $\begin{array}{l}\text { SADMIN, and w/sig password } \\
\text { OPSADM, OPSSUP, GENOPS }\end{array}$ \\
\hline 8 & $\begin{array}{l}\text { Bar Code } \\
\text { Labels }\end{array}$ & All Groups & SADMIN, OPSADM, OPSSUP, GENOPS \\
\hline 9 & Reports & All Groups & $\begin{array}{l}\text { SADMIN, and w/sig password } \\
\text { ENGDEV, OPSADM, NDAANL, OPSSUP, } \\
\text { GENOPS, MONITR }\end{array}$ \\
\hline 10 & Pick Lists & All Groups & $\begin{array}{l}\text { SADMIN, and w/sig password } \\
\text { OPSADM, OPSSUP, GENOPS }\end{array}$ \\
\hline 11 & Process Routes & All Groups & $\begin{array}{l}\text { SADMIN, and } w / \text { sig password } \\
\text { OPSADM, OPSSUP, GENOPS }\end{array}$ \\
\hline 12 & $\begin{array}{l}\text { Data } \\
\text { Validation } \\
\text { Tables }\end{array}$ & A11 Groups & SADMIN, ENGDEV, OPSADM \\
\hline 13 & $\begin{array}{l}\text { System } \\
\text { Administration }\end{array}$ & All Groups & SADMIN \\
\hline
\end{tabular}

\subsubsection{User Interfaces}

User interfaces consist of the inputs, outputs, and displays on a display terminal used or seen by a WRAP I DMS user. All user interfaces will be tailored to the needs of the functional user. Selecting a particular option would allow access to data, provided the user has appropriate privileges.

All primary screens will have a "fast access" capability. Each screen displayed will be structured for ease of use. Navigational aids will be available to assist the user in maneuvering through the system. Error 
messages, along with possible resolution options, will be displayed on the screen when the system detects an error. User training will be addressed in the WRAP 1 DMS training and users manuals.

Printing of reports will not be suspended when user transfers to another screen. In some instances, the system will automatically display a message screen to alert the user or to request user input.

User reports fall into two categories: reports that generate certification and transportation papers for disposal and transport; and reports that support facility operations such as drum/box inventories, fissile material inventory for the facility, AS/RS pick lists, etc. Provisions will be made to assure that the printing of reports will not adversely impact facility operations.

\subsubsection{Developer Interface}

Responsibilities of the WRAP 1 DMS development staff include creating, implementing, and maintaining the Oracle application modules supporting the user's requirements. By the nature of these responsibilities, developers must have a high-level access authority to the WRAP 1 DMS system.

4.3.3.1 Data/Database Administration. The data/database administrator has authority to update the database structure, perform global data manipulation, and maintain the data dictionary.

4.3.3.2 Developers. Developers have authority to modify the application software, perform pre-authorized global data manipulation, maintain and access a development/test database, and access the production database. 
WHC-SD-W026-SDD-001, Rev. 2

This page intentionally left blank.

4-6 


\subsection{DETAILED DESIGN}

This chapter describes the internal details and specifications of the design modules and their associated objects. This chapter provides the developers with general programming guidelines and standards, including the mechanisms used in the navigation within the WRAP I DMS system. It also provides specifications for the processing modules, reports, and supporting utilities.

\subsection{GENERAL DESIGN SPECIFICATIONS}

This section describes the general design guidelines and standards that will be used in the development of the WRAP 1 DMS system. These design rules are to be applied to all development processes, including both the online screens and the generated reports. Any deviation to these guidelines is documented indicating where the guideline is not being followed. The general design rules are as follows:

- All data fields will translate to Uppercase, except where specified.

- A11 Date type fields will be displayed in MM/DD/YY format.

- All fields described as FLOAT will be displayed in scientific notation four significant digits ( $i . e .,-x . x x x E-x x$ ) unless specified otherwise.

Example: $\begin{array}{r}123.4 \text { is } 1.234 \mathrm{E}+02 \\ 1.234 \text { is } 1.234 \mathrm{E}+00 \\ .1234 \text { is } 1.234 \mathrm{E}-01\end{array}$

- All fields described as NUMBER with precision specified will be displayed appropriately.

- All enterable screen fields will make use of the Autohint feature, which displays a message upon entering the field. Applicable units of measure will be indicated in this message.

- All container-related fields will make use of the Journal feature, which records a history of all changes.

- On formatted screens (update and display), the Tab and Backtab functions cause the cursor to go from field to field for all enterable fields on the screen.

- All screens will have a similar appearance. They will contain the screen number, the WRAP 1 DMS title, date, time, and a message line.

- A11 reports will be in a similar format. The report number, WRAP I DMS title, date, time, page number, and report headings will appear in the same relative position. 
WHC-SD-W026-SDD-001, Rev. 2

- All quantities for volumes, weights, and areas will be stored in metric units (cubic meters, kilograms, square meters).

\subsubsection{Screens}

All screens will be constructed using Oracle Forms 4.0. Microsoft graphical user interface (GUI) User Standards wiTl be applied as development standards where possible.

\subsubsection{Error and Message Handling}

Individua 1 and detailed error and message handling is described in Appendix F. Additional data error reporting functions will be defined by the DMS developers during software implementation. Basic error checking to assure valid data entry will be performed. This feature is incorporated into the design of individual modules.

\subsubsection{System Security}

The first level of security will be provided by the necessity to have a valid user identifier and password to access the host computer. This feature is part of the host operating system.

The second level of security will require that the database administrator provide a user identifier to the WRAP 1 DMS system. An Oracle User Identifier and Password will be used to verify users in logging into the Oracle RDBMS.

The third level of security will be provided by the necessity to have internal user roles and privileges. Users will have limited authorized access to the functional modules in the WRAP 1 DMS based on their logon role.

\subsubsection{System Administration}

System administration will be managed by two different functions: database administrator (DBA) and system administrator (SA). The database administrator is responsible for maintaining the integrity of the data records contained within the WRAP 1 DMS. The system administrator is responsible for maintenance of the software system, communications, and hardware.

\subsection{SYSTEM NAVIGATION}

The WRAP 1 DMS online system navigation will be provided through the use of Oracle Forms 4.0 menus and the use of the fast access feature described in Section 4.3 .1 .

All screen functions assume that all the data placed into databases in any input function is available for the screens. The specific data elements and parameters are specified in Appendix $F$ for the individual screens. The screen interface diagram is provided in Figures 5-1 and 5-2. 


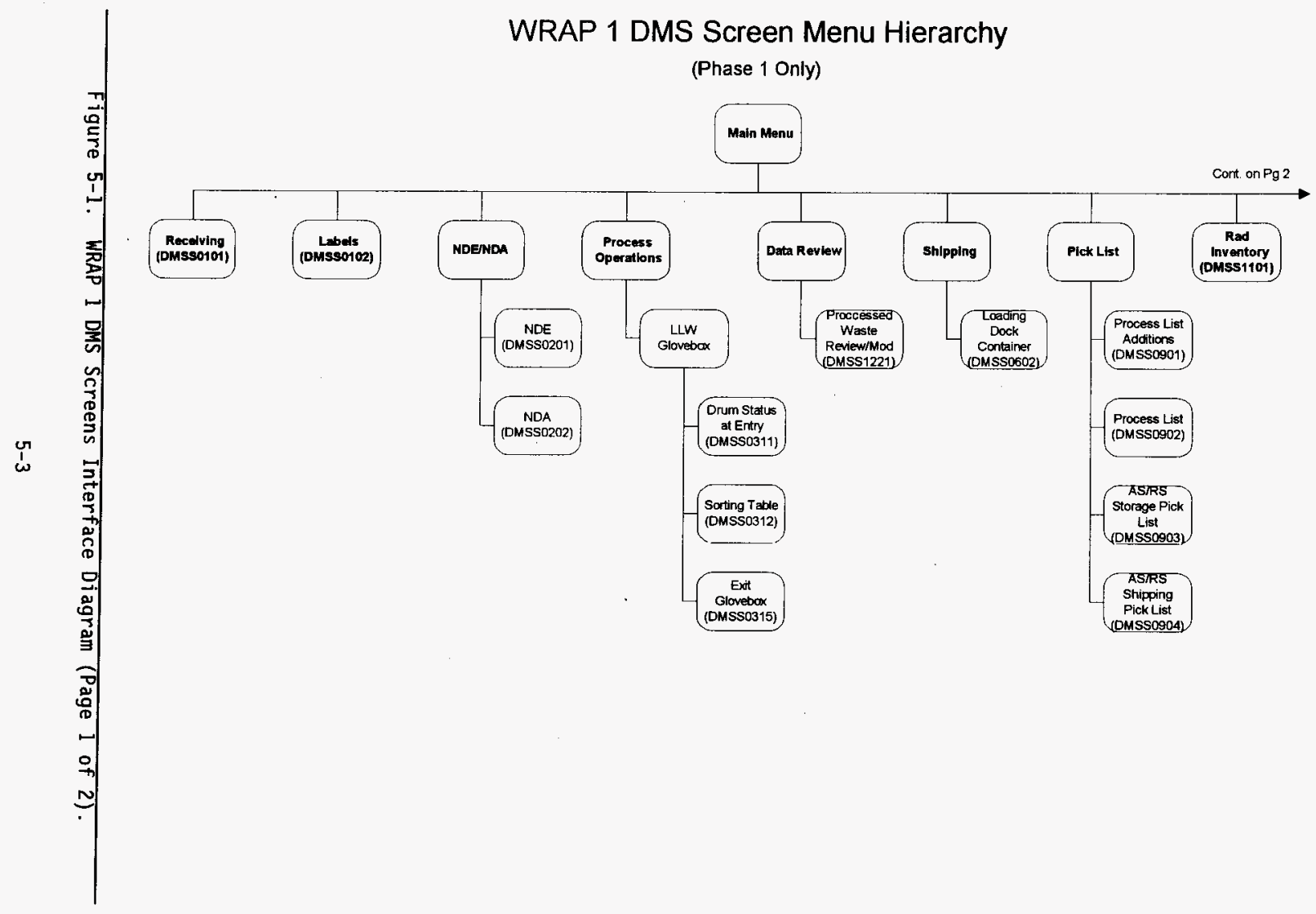

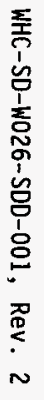


WHC-SD-W026-SDD-001, Rev. 2
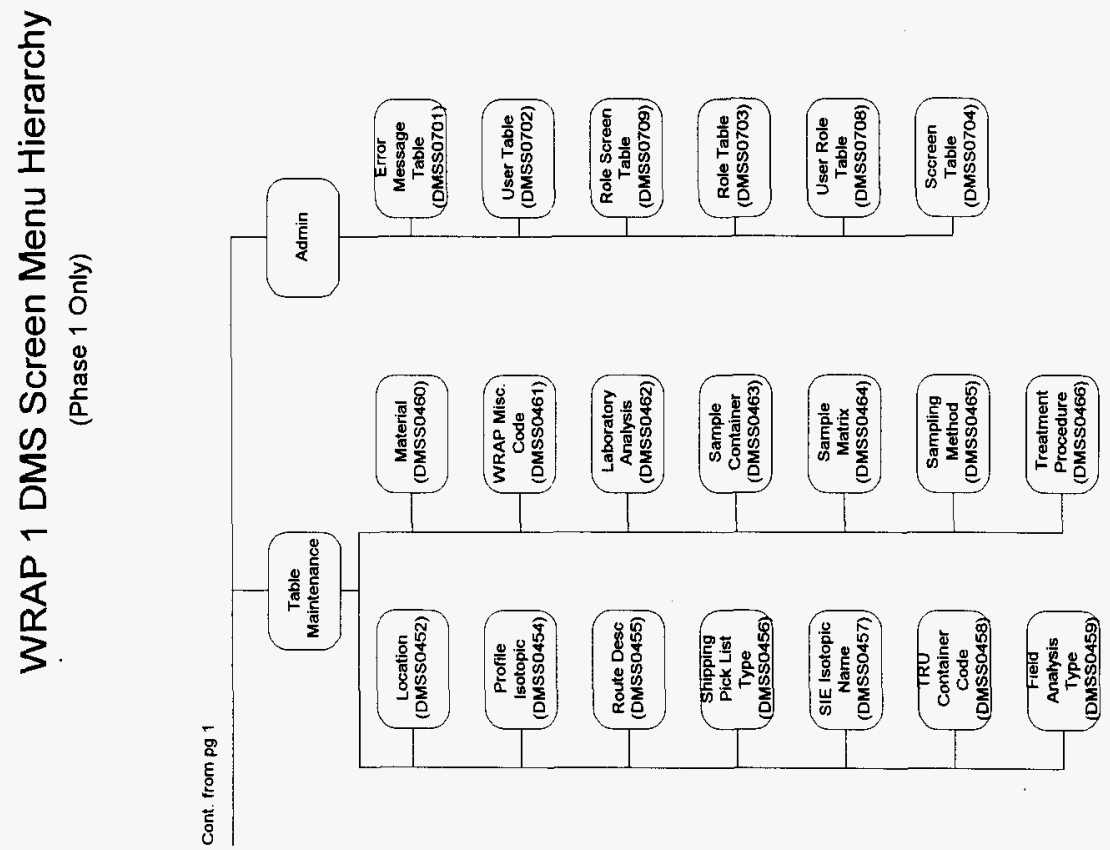

Figure 5-2. WRAP 1 DMS Screens Interface Diagram (Page 2 of 2). 


\subsubsection{WRAP 1 DMS System Screen - WRAP 1 DMS User Menu}

The function of this menu is to allow the user to identify the general task to be performed. Selection of a task will bring up subordinate menus or screens prompting the user for the data required to perform the task. The selections available from this menu include:

- Receiving

- Labels

- NDE/NDA Operations

- Process (Glovebox) Operations

- Tabie Maintenance

- Sample Management

- Shipping

- System Administration

- Reports

- Pick List

- Facility Inventories

- Process Data Review

- Activity Comment.

Layouts of the DMS screens can be seen in Appendix A. A hierarchy of the DMS menu and screen structure is also provided in this appendix.

\subsubsection{Recefving Screens}

The screens described in this section are utilized by the Receiving function.

5.2.2.1 Container Receiving (DMSSO101). The function of this screen is to allow the user to ident ify the empty drums, waste drums, or waste boxes (SWBs) in a shipment and accept them into the facility. Acceptance of the containers includes the following operations, the completion of which can be displayed on the same screen as a set of messages or check marks:

- Logging the containers into the facility for comparison to the hardcopy shipping papers.

- Updating the SWITS database as to the location of the containers. This includes SWITS confirmation that the update was successful.

- Creating records on the WRAP 1 DMS for the received containers.

- Downloading the existing certification data on the containers from SWITS into the newly created records.

- Flagging containers not on a processing pick list.

- Updating the curie inventory of the facility and display of any appropriate alarms on a pop-up screen.

This screen is generated upon selection of "Container Receiving" from the "WRAP 1 DMS User Menu" screen. 
5.2.2.2 Bar Code Generator (DMSSO102). This screen is generated upon selection of "Labels" from the DMS Main Menu or from the Receiving Menu. The function of this screen is to allow the user to produce a bar code label to replace a missing or damaged one. This function would normally be performed upon receipt of a container but should be available anytime in case a label is damaged within WRAP 1 .

\subsubsection{NDE/NDA Operations Screens}

The screens described in this section are utilized by the NDE/NDA Operations function.

5.2.3.1 NDE (DMSSO201). The function of this screen is to allow the user to retrieve existing NDE information about the drum or box for verification as well as to add data discovered during the WRAP 1 NDE to the database. This screen is generated upon selection of "NDE" from the "WRAP 1 DMS User Menu" screen.

5.2.3.2 NDA (DMSSO202). The function of this screen is to allow the user to retrieve existing NDA information about the drum or box for verification, as well as to specify certification data as required to properly characterize the containers. The operator may use this screen to request assay revisits for specific waste containers. This screen is generated upon selection of "NDA" from the "WRAP 1 DMS User Menu" screen.

\subsubsection{Process Operations Screens}

The screens described in this section are utilized by the Process Operations function.

5.2.4.1 Glovebox Operations Menu. The function of this menu is to allow the user to select the glovebox at which operations are to be performed. The selections available from this menu include:

- LLW Process Glovebox

- LLW RWM Process Glovebox

- TRU Process Glovebox

- TRU RWM Process Glovebox.

This screen is generated upon selection of "Glovebox Operations" from the "WRAP 1 DMS User Menu" screen.

5.2.4.2 LLW Process Glovebox Menu. The function of this menu is to allow the user to select the area of the LLW process glovebox at which operations are to be performed. This menu is generated upon selection of "LLW Process Glovebox" from the "Glovebox Operations Menu" screen. The selections available from this menu include:

- LLW Glovebox Status at Entry

- LLW Sorting Table

- LLW Exit Glovebox 
5.2.4.3 LLW Drum Status at Entry (DMSS0311). The function of this screen is to display the PIN of the inner drum, if any, for verification and to notify the operator whether sorting is required. The sorting display is based on whether or not the drum is compliant and whether sampling is required. This screen is generated upon selection of "LLW Drum Status at Entry" from the "LLW Process Glovebox" menu.

5.2.4.4 LLW Sorting Table (DMSS0312). The function of this screen is to provide the user with the information from the drum necessary for separating the compliant waste from the non-compliant waste, and to select other displays for sampling and for modification of the waste inventory. This screen will allow the user to select five subordinate screens: LLW Non-Compliant Packet screen; sample screen; chemical component screen; and physical component. screen. There is also a pop up display for viewing the NDE results. This screen is generated upon selection of "LLW Sorting Table" from the "LLW Process Glovebox" menu.

5.2.4.5 LLW Non-Compliant Packet (Pop-up). This screen shows the Packet PINs, the drum PIN from which the packets came, and the transfer drum PIN into which the packets went along with the user description of the contents of the packet and the material group code. This screen is generated upon selection of "LLW Non-compliant Packet" from the "LLW Sorting Glovebox" screen.

5.2.4.6 Sample Data (DMSSO501). See Section 5.2.6.2 for screen definition.

5.2.4.7 LLW Physical Component (Pop-Up). The function of this screen is to display and allow the user to modify the physical composition for the drum being sorted.

5.2.4.8 LLW Chemical Component (Pop-Up). The function of this screen is to display and allow the user to modify the chemical composition for the drum being sorted. Since the user cannot observe chemical concentrations, the user can change volume percents and delete chemical records only. If all chemical records are deleted, then the waste is no longer non-compliant.

5.2.4.9 LLW NDE Results (Pop-up). The function of this pop-up screen is to display the NDE results.

5.2.4.10 LLW Exit Glovebox (DMSS0315). The function of this screen is to fill in the data for product drums with pucks or uncompacted drums. The user is allowed to modify the outer drum waste description, and enter the dose rate, seal number, and void code. This screen also displays information for up to six pucks. The information displayed for each puck include puck PIN, PIN of drum before it was crushed, puck height, and puck weight. The puck height displayed is a default system setup parameter, and is the only field for the puck that is user modifiable. This screen is generated upon selection of "LLW Exit Glovebox" from the "LLW Process Glovebox" menu.

5.2.4.11 LLW RWM Process Glovebox Menu. The function of this menu is to allow the user to select the area of the LLW RWM Process Glovebox at which operations are to be performed. This screen is generated upon selection of "LLW RWM Process Glovebox" from the "Glovebox Operations Menu" screen. The selections available from this menu include: 
- LLW RWM Waste Sorting

- LLW RWM Compliant Waste Load Out

- LLW RWM Treatment Item Assembly.

5.2.4.12 LLW RWM Waste Sorting (DMSSO321). This screen shows the transfer drum PIN for the LLW RWM transfer drum currently connected to the transfer port. This screen lists the PINs of the packets contained in the transfer drum as well as their waste descriptions. The screen also lists those packets which have been removed from the transfer drum and placed at the RWM sampling location. Newly generated non-compliant waste packets will also be displayed as being located at the RWM sampling location. User modification of the transfer drum storage category (based on waste added to or subtracted from the drum) is also allowed from this screen. This screen is generated upon selection of "LLW RWM Waste Sorting" from the "LLW RWM Process Glovebox" menu.

5.2.4.13 LLW RWM Repackaging (DMSSO322). This screen provides the operator the ability to enter applicable waste packet data as non-compliant packets from the RWM transfer drum are repackaged. This screen lists the PIN of the packet being repackaged as well as the container type, material group, and waste description for the original packet. For waste packets which have compliant and non-compliant components, the PINs for the new containers along with the container type are displayed. The material group and waste description for the new containers may be modified by the user. This screen also displays the PIN of the compliant waste drum currently mated to the glovebox and the associated waste description which is available for operator entry of data. Container relationships between the packet being repackaged and the compliant loadout drum may be established from this screen via a check box. This screen is generated upon selection of "Repackage" from the "LLW RWM Waste Sorting" screen.

\subsubsection{Sample Data (DMSSO501). See Section 5.2.6 for screen definition.}

5.2.4.15 LLW RWM Compliant Waste Loadout (DMSS0323). This screen shows the PIN and contents inventory for the LLW RWM transfer drum currently connected to the transfer port. The screen allows the user to input new information and comments to describe the items placed in the compliant waste loadout drum.

The DMSS0323 screen is used when the packets are opened and the packet contents are sorted into compliant and non-compliant items. A general drum waste description may be entered via the DMSS0322 screen. The compliant items are described in greater detail on the DMSS0323 screen if necessary.

Appropriate DMS records (PHYSCOMP) are updated, and the items are placed in a product drum which is also identified. Summary level drum data such as dose rate is entered via this screen. This screen is accessed via the LLW RWM Repackaging screen or the "LLW RWM Process Glovebox" menu.

5.2.4.16 LLW RWM Treatment Item Assembly (DMSSO324). This screen is used once the laboratory analysis is complete, processing instructions are available, and the RWM waste is scheduled for treatment. This screen assists the user in identifying and removing the appropriate packets and samples from their associated overpack containers. The operator will remove the items from their drums/purge ports and stage the waste at the LLWRWM treatment station. The operator will select the "Treatment" and "Compliant Loadout" screens from this screen. This screen will alert operator if a waste container scanned for 
treatment is not listed on the current worksheet. This screen is accessed via the "LLW RWM Process Glovebox" menu.

5.2.4.17 LLW RWM Processing Instructions (DMSS0325). The function of this screen is to display a set of treatment instructions developed by the facility chemist specifically for a given set of non-compliant waste items on the LLW RWM Glovebox Monitor. This monitor is mounted on the back side of the RWM glovebox. This screen is generated upon selection of "Treatment " from the "LLW RWM Treatment Item Assembly" screen.

5.2.4.18 LLW RWM Treatment (DMSS0326). The function of this screen is to support waste treatment operations in the RWM glovebox. This screen will allow the user to input information concerning the progress of the treatment, addition of items to the treatment container, treatment container material group and treatment results. This screen also allows the user to place waste in the compliant loadout drum during treatment and update the loadout drum waste description accordingly. This screen is generated upon selection of "Treatment" from the "LLW RWM Treatment Item Assembly" screen.

\subsubsection{LLW RWM Treated Waste Loadout (DMSS0328). The purpose of this} screen is to allow the user to fill the treated waste product drum with waste as treatments are completed. Treatment container data may be reviewed and used to update the loadout drum waste description. This screen is also used ot enter general drum data such as the drum dose rate. This screen is accessed via the "LLW RWM Treatment Item Assembly" screen or the "LLW RWM Process Glovebox" menu.

5.2.4.20 TRU Process Glovebox Menu. The function of this menu is to allow the user to select the area of the TRU Process Glovebox at which operations are to be performed. This screen is generated upon selection of "TRU Process Glovebox" from the "Glovebox Operations Menu" screen. The selections available from this menu include:

- TRU Glovebox Status at Entry

- TRU Sorting Glovebox

- TRU Exit Gloveboxes.

5.2.4.21 TRU Drum Status at Entry (DMSSO331). This screen shows the PIN of the inner and outer drums located at the TRU Entry Port. The radiological inventory of the drum at the entry port, glovebox radiological inventory status, and glovebox radiological inventory limit is also provided. This screen is accessed via the "TRU Process Glovebox" menu.

5.2.4.22 TRU Sorting Glovebox (DMSS0332). The function of this screen is to provide the user with the information from the drum necessary for separating the compliant waste from the non-compliant waste, obtain waste samples if reqired, and to select other displays for sampling and for modification of the waste inventory. This screen will allow the user to select four subordinate screens: TRU Non-Compliant Packet screen; sample screen; chemical component screen; and physical component screen. There is also a pop up display for viewing the NDE results. This screen is accessed via the "TRU Process Glovebox" menu.

5.2.4.23 TRU Non-compliant Packet. The drum PIN from which the packets came, the transfer drum PIN into which the packets went, and the transfer drum 
material group code are displayed.. The PINs of all the packets placed in the transfer drum along with their waste description is also displayed on this screen for user modification. Results from the Packet Assay Monitor are also displayed on this screen.

\subsubsection{Sample Data (DMSS0501). See Section 5.2.6.2 for screen definition.}

5.2.4.25 TRU Chemical Component (DMSS0333). This screen shows the chemical composition for the drum currently on the sorting table and allows the user to select which loadout port (309 or 310) chemical component records should be displayed. User modification of data is allowed.

5.2.4.26 TRU Physical Component (DMSS0334). This screen shows the physical composition for the drum currently on the sorting table and allows the user to select which loadout port ( 309 or 310 ) physical component records should be displayed. User modification of data is allowed.

5.2.4.27 TRU Exit Glovebox (DMSS0335). This screen is used to define the product drum data such as Beta-Gamma dose rate and $Q C$ seal numbers. There are three TRU Exit ports; 308 (compacts), 309, and 310. Based on the port selected, the screen is refreshed using the drum PIN for the selected port. This screen is accessed via the "TRU Process Glovebox" menu.

5.2.4.28 TRU RWM Process Glovebox Menu. The function of this screen is to allow the user to select the area of the TRU RWM Process Glovebox at which operations are to be performed. This screen is generated upon selection of "TRU RWM Process Glovebox" from the "Glovebox Operations Menu" screen. The selections available from this menu include:

- TRU RWM Waste Sorting

- TRU RWM Compliant Waste Load 0ut

- $\quad$ TRU RWM Treatment Item Assembly.

5.2.4.29 TRU RWM Waste Sorting (OMSS0341). This screen shows the transfer drum PIN for the TRU RWM transfer drum currently connected to the transfer port. This screen lists the PINs of the packets contained in the transfer drum as well as their waste descriptions. The screen also lists those packets which have been removed from the transfer drum and placed at the RWM sampling location. Newly generated non-compliant waste packets will also be displayed as being located at the RWM sampling location. User modification of the transfer drum storage category (based on waste added to or subtracted from the drum) is also allowed from this screen. This screen is accessed via the "TRU RWM Process GTovebox" menu.

5.2.4.30 TRU RWM Waste Repackaging (DMSS0342). This screen provides the operator the ability to enter applicable waste packet data as non-compliant packets from the RWM transfer drum are repackaged. This screen lists the PIN of the packet being repackaged as well as the container type, material group, and waste description for the original packet. For waste packets which have compliant and non-compliant components, the PINs for the new containers along with the container type are displayed. The material group and waste description for the new containers may be modified by the user. This screen also displays the PIN of the compliant waste drum currently mated to the glovebox and the associated waste description which is available for operator entry of data. Container relationships between the packet being repackaged 
WHC-SD-W026-SDD-001, Rev. 2

and the compliant loadout drum may be established from this screen via a check box. This screen is accessed via the "TRU RWM Waste Sorting" screen.

\subsubsection{Sample Data (DMSS0501). See Section 5.2.6 for screen definition.}

5.2.4.32 TRU RWM Compliant Waste Loadout (DMSSO343). This screen shows the PIN and contents inventory for the TRU RWM transfer drum currently connected to the transfer port. The screen allows the user to input new information and comments to describe the items placed in the compliant waste loadout drum.

The DMSS0343 screen is used when the packets are opened and the packet contents are sorted into compliant and non-compliant items. A general drum waste description may be entered via the DMSS0342 screen. The comp1iant items are described in greater detail on the DMSSO343 screen if necessary.

Appropriate DMS records (PHYSCOMP) are updated, and the items are placed in a product drum which is also identified. Summary level drum data such as dose rate is entered via this screen. This screen is accessed via the "TRU RWM Waste Sorting" screen or the "TRU RWM Process Glovebox" menu.

5.2.4.33 TRU RWM Treatment Item Assembly (DMSS0344). This screen is used once the laboratory analys is is complete, processing instructions are available, and the RWM waste is scheduled for treatment. This screen assists the user in identifying and removing the appropriate packets and samples from their associated overpack containers. The operator will remove the items from their drums/purge ports and stage the waste at the TRURWM treatment station. The operator will select the "Treatment" and "Compliant Loadout" screens from this screen. This screen will alert operator if a waste container scanned for treatment is not listed on the current worksheet. This screen is accessed via the "TRU RWM Process Glovebox" menu.

5.2.4.34 TRU RWM Processing Instructions (DMSS0345). The function of this screen is to display a set of treatment instructions developed by the facility chemist specifically for a given set of non-compliant waste items on the TRU RWM Glovebox Monitor. This monitor is mounted on the back side of the RWM glovebox. This screen is generated upon selection of "Treatment" from the "TRU RWM Treatment Item Assembly" screen.

5.2.4.35 TRU RWM Treatment (DMSSO346). The function of this screen is to support waste treatment operations in the RWM glovebox. This screen will allow the user to input information concerning the progress of the treatment, addition of items to the treatment container, treatment container material group and treatment results. This screen also allows the user to place waste in the compliant loadout drum during treatment and update the loadout drum waste description accordingly. This screen is accessed via the "TRU RWM Treatment Item Assembly" screen.

5.2.4.36 TRU RWM Treated Waste Loadout (DHSS0348). The purpose of this screen is to allow the user to fill the treated waste product drum with waste as treatments are completed. Treatment container data may be reviewed and used to update the loadout drum waste description. This screen is also used ot enter general drum data such as the drum dose rate. This screen is accessed via the "TRU RWM Treatment Item Assembly" screen or the "RWM Process Glovebox" menu. 


\subsubsection{Data Validation Table Maintenance Screens}

The screens described in this section are utilized by the Data Validation Table Maintenance function. The DMS will not have table maintenance screens for the data validation tables received from SWITS. A new copy of the SWITS data validation table will be loaded on the DMS whenever the table is updated on SWITS.

5.2.5.1 Profile/Profile Isotope Tables (DMSS0454). Screen DMSS0454 is used to maintain the Profile and Profile Isotope tables.

5.2.5.2 Route Description Table (DMSSO455). Screen DMSS0455 is used to maintain the Route Description table.

5.2.5.3 Shipment Picklist Description Table (DMSS0456). Screen DMSS0456 is used to maintain the Shipping Pick List Type table.

5.2.5.4 SIE Isotopic Name Table (DMSSO457). Screen DMSS0457 is used to maintain the SIE Isotopic Name table.

5.2.5.5 TRU Container Code Table (DMSSO458). Screen DMSSO458 is used to maintain the TRU Container Code table.

5.2.5.6 Field Analys is Type Table (DMSS0459). Screen DMSSO459 is used to maintain the Field Analysis Type table.

5.2.5.7 Material Table (DMSSO460). Screen DMSSO460 is used to maintain the Material table.

5.2.5.8 WRAP Miscellaneous Table (DMSS0461). Screen DMSSO461 is used to maintain the WRAP Miscellaneous table.

5.2.5.9 Laboratory Analysis Table (DMSSO462). Screen DMSSO462 is used to maintain the Laboratory Analysis table.

5.2.5.10 Sample Container Table (DMSS0463). Screen DMSS0463 is used to maintain the Sample Container table.

5.2.5.11 Sample Matrix Table (DMSS0464). Screen DMSS0464 is used to maintain the Sample Matrix table.

5.2.5.12 Sampling Method Table (DMSS0465). Screen DMSS0465 is used to maintain the Sampling Method table.

5.2.5.13 Treatment Procedure Table (DMSS0466). Screen DMSS0466 is used to maintain the Treatment Procedure table.

\subsubsection{Sample Management Screens}

The screens described in this section are utilized by the Sample Operations function.

5.2.6.1 Sample Management Menu. The function of this menu is to allow the user to select the sample management activity to be performed. This screen is 
generated upon selection of "Sample Management" from the "WRAP 1 DMS User Menu" screen. The selections available from this menu include:

- Chain of Custody

- Sample Analysis Request

- Waste Designation

- Worksheet Data Entry

- Sample Management and Chain of Custody

- Sample Labels

- Sample/Bottle Tracking

- Purge Port/Transfer Pig Location.

5.2.6.2 Sample Data (DMSS0501). This screen allows the user to obtain a sample and document the relevant chain of custody data such as sampler, source of the sample, purge port into which the sample was placed, date and time of sampling, etc. This screen is generated upon selection of "Sample Data" from any of the following screens:

- LLW Non-Compliant Packet

- LLW RWM Repackaging

- TRU RWM Non-Compliant Packet

- TRU RWM Repackaging.

5.2.6.3 Electronic Chain of Custody (DMSS0502). This screen allow the user to update the electronic chain of custody form as custody of a sample, purge port, or sample pig is transferred from one user to another. This record will be maintained for the life of the sample from the time it is obtained to the time it is disposed of. The $1 \mathrm{ab}$ will be treated as a single custodian for the purpose of the WRAP 1 facility tracking since they will maintain their own internal tracking system. This screen will also allow the user to enter specific data related to the handling of the samples.

5.2.6.4 Field Screening (DMSSO503). This screen provides the operator with a means to perform field screening in the RWM gloveboxes and record the applicable data upon completion of those tasks.

5.2.6.5 Sample Analysis Request (DMSS0504). This screen provides for the definition of the items being sampled, the applicable sample/bottle numbers, and analyses available for the sample. The screen will allow the user to review the various analyses and choose those which are applicable for the sample in question.

5.2.6.6 Waste Designation (DMSS0505). This screen will allow the user to update the applicable packet waste descriptions and designation codes in the WRAP 1 DMS database according to the results of the field screening analyses. This screen is generated upon selection of "Waste.Designation" from the "Sample Management" menu.

5.2.6.7 Worksheet Data Entry (DMSS0506). This screen will allow the user to specify treatment instructions and identify them with a treatment process number. The instructions will be developed by the facility chemist based on the results of sample analyses for the parent items. Upon completion of the worksheet definition, the waste packets will be scheduled for processing, transferred to the glovebox, and the worksheet instuctions displayed on the DMS monitor mounted on the back of the RWM gloveboxes. This screen is 
generated upon selection of "Worksheet Data Entry" from the "Sample Management" menu.

5.2.6.8 Sample Management and Chain of Custody (DMSS0507). This screen will allow the user to update the $C O C$ form and to enter sample management data such as priority for processing, safety hazards, etc. Documentating the shipment of the COC samples is also performed from this form. This screen is generated upon selection of "Sample Management/COC" from the "Sample Management" menu.

5.2.6.9 Sample Labels (DMSSO508). This screen will allow the user to select specific sample lables to be printed out on a sample management bar code printer. This screen is generated upon selection of "Sample Labels" from the "Sample Management" menu.

5.2.6.10 Sample/Bottle Tracking (DMSS0509). This screen will allow the user to track the status of samples/bottles generated in the WRAP facility. When lab results are available and the sample/bottle is returned to WRAP for final disposal, this screen will be used to document that status on the DMS. This screen is generated upon selection of "Sample/Bottle Tracking" from the "Sample Management" menu.

5.2.6.11 Purge Port/Transfer Pig Location (DMSS0510). This screen will allow the user to update sample purge port and transfer pig locations in the DMS database as these containers are removed from the Process Area into Sample Management and as they are returned from the labs to the Sample Management Area. There is no PCS interface in Sample Management to provide this location update. This screen is generated upon selection of "Purge Port/Transfer Pig" from the "Sample Management Menu" screen.

\subsubsection{Shipping Screens} function.

The screens described in this section are utilized by the Shipping

5.2.7.1 Shipping Menu. The function of this menu is to allow the user to select the shipping activity to be performed. This screen is generated upon selection of "Shipping" from the "WRAP I DMS User Menu" screen. The

selections available from this menu include:

- Loading Dock Shipping Data

- Loading Dock Container Shipping

- TRUPACT Cask Loading/Certification

- TRUPACT Shipping Documentation.

5.2.7.2 Loading Dock Shipping Data (DMSS0601). The function of this screen is to generate the shipping papers and documentation required to send a shipment of empty drums, waste drums, or waste boxes out of the facility through the loading dock. The PINs for which data is recalled or entered will be found on a pick list based on the shipping schedule. The screen will prompt the user for any additional data required to complete the appropriate shipping forms. The user will be allowed to reroute drums back through the process to collect missing data. The forms to be completed and printed from this screen include: 
- Uniform Hazardous Waste Manifest (UHWM)

- Radioactive Shipment Record (RSR)

- Solid Waste Storage/Disposal Record (SWSDR).

5.2.7.3 Loading Dock Container Shipping (DMSS0602). The function of this screen is to allow the user assemble a set of containers for shipment out of the WRAP 1 facility through the loading dock. This screen will display a list of PINs scheduled for shipment and allow the user to perform and check off the following items and activities required to ship those containers:

- Retrieve the containers from storage to the loading dock.

- Scan the containers and compare them to the shipping schedule and prepared paperwork.

- Update container location.

- Authorize shipment.

- Update SWITS.

5.2.7.4 TRUPACT Cask Loading/Certification (DMSSO603). The function of this screen is to support the loading of the assembled 14 pack of TRU drums or 2 TRU SWBs into a particular TRUPACT II shipping cask. The screen will have the applicable shipping/payload assembly data entered. The screen will be printed and taken to the TRUPACT loading bay where the data will be manually recoreded on the screen print. The data sheet will then be taken back to a DMS terminal for entry into the DMS. Approval to ship the TRUPACTs will be documented via this screen.

5.2.7.5 TRUPACT Shipping Documentation (DMSS0604). The function of this screen is to allow the user to print the applicable TRUPACT shipping documentation to support the shipment of TRUPACTs from the WRAP 1 facility. As the final WIPP requirements, data format, and method of data transmittal has not been defined at this time, the details of this screen are TBD. This screen will also provide for a data upload to SWITS upon actual shipment of the TRUPACTs.

\subsubsection{System Administration Tables}

These screens are used to maintain the WRAP 1 DMS Administration Tables. These tables are used to maintain the error messages, system status, users, procedures, reports, security, and system bulletins. All of these tables are accessed through the System Administration menu.

5.2.8.1 Error Message Table (DMSS0701). This screen is used to maintain the Error Message table. The Error Message Table contains a 11 error and information messages that pop up as windows for the user. This includes information messages that display in the status line at the bottom of the screen.

5.2.8.2 User Table (DMSS0702). This screen is used to maintain the User Table. The User table contains information specific to a user such as User ID, logon date, and terminal type. Most of the user fields are not currently used by the DMS, but are included for possible future use. 
5.2.8.3 Role Table (DMSS0703). This screen is used to maintain the Role table. Roles must be added to this table before they can be assigned to users.

5.2.8.4 Screen Table (DMSSO704). This screen is used to maintain the Screen table. This table contains an entry for all the DMS screens. Screens need to be added to this table before they can be linked to roles in the Role Screen table.

5.2.8.5 Report Table (DMSS0705). This screen is used to maintain the Report table.

5.2.8.6 User Role Table (DMSS0708). This screen is used to assign roles to users.

5.2.8.7 Role Screen Table (DMSS0709). This screen is used to define which screens a role has access to and whether the access is for update or read only.

5.2.8.8 Field Help Table (DMSS0710). This screen is used to maintain the Field Help table. This table consists of the table name, field name, data type, and description.

5.2.8.9 Form Help Table (DMSS0711). This screen is used to maintain the Form Help Table. The table consists of the form name and description.

\subsubsection{Report Screens}

The screens described in this section support the Reports function. In addition, WRAP 1 DMS reports are available from applicable screens in the modules these reports support.

5.2.9.1 Reports Menu. The function of this screen is to allow the user to directly request any WRAP 1 DMS report.

\subsubsection{Process Routing and Pick Lists Screens}

The screens described in this section are utilized by the Process Routing and Pick Lists function.

5.2.10.1 Pick List Menu. The function of this screen is to allow the user to select the pick list management activity to be performed. The selections available from this menu include:

- Download Processing List

- Process Pick List

- AS/RS Storage Pick List

- AS/RS Shipping Pick List

- TRUPACT Assembly Pick List.

This screen is generated upon selection of "Pick Lists" from the "WRAP 1 DMS User Menu" screen. 
WHC-SD-W026-SDD-001, Rev. 2

5.2.10.2 Processing List Additions (DMSSO901). This screen is used by WRAP 1 scheduling to enter the drum information and processing sequence for a shipment into the DMS. Information from SWOC and the generators is used by the WRAPl schedulers to compile this information and schedule waste to be processed. When appropriate, WRAP 1 scheduling appends this 1 ist to the end of the current process 1ist. The user will enter container package ID, route code, sample flag, compliant flag, and profile ID. The user will have the ability to reorder and commit the list. This screen is generated upon selection of "Processing List Additions" from the "Pick List Menu" screen.

5.2.10.3 Process List (DMSSO902). The function of this screen is to allow the user to transfer processing pick lists from the WRAP 1 DMS to the PCS for incorporation into the PCS processing pick list as facility equipment becomes available. The user will have the ability to reorder the list according to the changing needs of the facility. This screen is generated upon selection of "Process List" from the "Pick List Menu" screen.

5.2.10.4 AS/RS Storage Pick List (DMSS0903). The function of this screen is to allow the user to store a drum in the AS/RS. Storage occurs from the transfer car.

Storage from the transfer car will occur when a drum reaches the end of the discharge conveyor. This screen will display the waste characteristics of the drum PIN on the discharge conveyor and a list of drums with similar characteristics on partially filled pallets in the AS/RS. The user will then select a PIN on partially filled pallet on which to place the discharged drum. This PIN is placed on the AS/RS retrieval via transfer car pick list and the pallet containing that PIN is retrieved. The drum is transferred from the discharge conveyor to the pallet on the transfer car by a jib crane and the pallet is stored in the AS/RS. Drum location information in the WRAP 1 DMS is updated. This screen is generated upon selection of "AS/RS Storage Pick List" from the "Pick List Menu" screen.

5.2.10.5 AS/RS Shipping Pick List Screen (DMSSO904). The function of this screen is to allow the user to group a set of drums into a shipment from the loading dock and assign a shipment ID\# to the set. This screen provides the capability to ship drums from the WRAP 1 facility for any reason including Head Gas sampling and a LLW Burial. This list is uploaded to the PCS when all the necessary information for all drums in the shipment has been compiled and a truck has been scheduled to pick up the shipment. This screen is generated upon selection of "AS/RS Shipping Pick List" from the "Pick List Menu" screen.

5.2.10.6 TRUPACT Assemb1y Pick List (DMSS0905). The function of this screen is to allow the user to establish a sequence for retrieval of the drums from the AS/RS via the transfer stand for TRUPACT Assembly.. This list is uploaded to the PCS when all the necessary information for all drums in the shipment has been compiled and a truck has been scheduled to pick up the shipment. After the TRUPACT assembly drums are retrieved from the AS/RS for assembiy into payloads on the stretch wrapper, the operator will review this screen to identify those drums which have been assembled into the payload under construction. The operator may verify this by noting the updated locations on the screen (from TPSTAND to ACCVYR). This screen is generated upon selection of "TRUPACT Assembly Pick List" from the "Pick List Menu" screen. 
WHC-SD-W026-SDD-001, Rev. 2

\subsubsection{Facility Inventories Screen} function.

The screens described in this section support the Facility Inventories

5.2.11.1 Radiologic Inventory Sumary (DMSS1101). The function of this screen is to allow the user to display, update, and print the current radiologic inventory for the entire Facility, the TRU glovebox, and the RWM glovebox along with the limits associated with each area. This screen is generated upon selection of "Radiologic Inventory Summary" from the "Facility Metrics and Inventories Menu" screen.

5.2.11.2 Container Location and Relationships (DMSS1102). The function of this screen is to allow the user to modify the facility location records for any given waste container being processed in the WRAP 1 facility. This screen is generated upon selection of "Container Location and Relationships" from the "Facility Metrics and Inventories Menu" screen.

\subsubsection{Process Data Review Screens} data.

The screens described in the following sections are utilized to review

5.2.12.1 Processed Waste NDA Data Review (DMSS1201). This screen is utilized by the User to review NDA data associated with waste drums which are "processed" in the WRAP I facility. The function of this screen is to allow the user to select a specific product drum assay for review for those drums leaving the Processing Area. This screen is generated upon selection of "Processed Waste NDA Data Review" from the "Process Data Review" menu.

5.2.12.2 Waste Puck MDA Data Review (DMSS1202). This screen is utilized by the User to review NDA data associated with individual waste pucks which comprise a product drum generated in the Process Area LLW Glovebox. This screen is generated upon selection of the "Compacted Drum Data" button from the "Processed Waste NDA Data Review" screen.

5.2.12.3 Verification NDA Data Review (DMSS1211). This screen is utilized by the User to review NDA data associated with waste drums which are not "processed" in the WRAP 1 facility. User will have the capability to select specific assays performed in WRAP for data review. This screen is generated upon selection of "Verification NDA Data Review" from the "Process Data Review" menu.

5.2.12.4 Certification \& Verification NDA Data Review (DMSS1212). The function of this screen is to allow the user to compare NDA data provided by the waste generators against NDA data generated in the WRAP facility. This screen is generated upon selection of "Compare Certification and Verification Data" button from the "Verification NDA Data Review" screen.

5.2.12.5 Processed Waste Data Review a Modification (DMSS1221). The function of this screen is to allow the user to review and modify data for a specific product drums leaving the Processing Area. This screen is generated upon selection of "Processed Waste Data Review and Modification" from the "Process Data Review" menu. 
5.2.12.6 Verification Data Review (DMSS1231). The function of this screen is to allow the user to review and modify data for a specific drum that has only undergone NDE and NDA exams in WRAP. Only WRAP generated data will be modified from this screen. Revised SWITS data may also be downloaded from this screen. This screen is generated upon selection of "Verification Data Review" from the "Process Data Review" menu.

\subsubsection{Activity Comment Screen (DMSS1301)}

This screen is utilized by the User to generate or review activity comments against waste containers processed in WRAP. This screen may be accessed from any WRAP DMS screens using a "fast access" function.

\subsection{REPORTS}

Reporting encompasses a11 required preprogrammed and preformatted WRAP 1 DMS reports. All reporting functions assume that all the data $p 1$ aced into databases in any input function is available at reporting time. Appendix B provides an outline of the projected WRAP 1 reporting menu and provides definition for those reports that will be required to support initial WRAP 1 operations. Appendix $B$ will be updated as additional report requirements are defined by the WRAP 1 Operations groups.

\subsection{DATA DETAIL DESIGN}

The design details for each object are incorporated into the Data Dictionary (Appendix C) and the object model diagrams (Appendices D-G). 
WHC-SD-W026-SDD-001, Rev. 2

This page intentionally left blank. 


\subsection{REFERENCES}

BNFL, 1994, Waste Receiving and Processing Facility Drum NDA Integrated Assembly - Interface Definition Document, Rev. 0, British Nuclear Fuels Ltd., Sellafield, Seascale, Cumbria, United Kingdom.

IEEE, 1989, IEEE Recommended Practice for Software Design Descriptions, ANSI/IEEE Standard 1016-1987, IEEE, New York, New York.

IEEE, 1989, IEEE Standard Glossary of Software Engineering Technology, ANSI/IEEE Standard 729-1983, New York, New York.

SII, 1995, Waste Receiving and Processing (WRAP) Facility Plant Management System - Network Communications Protocol Definition Document, Rev. 3.1, systems Interface, Inc., Bothe11, Washington.

WHC, 1989, Hazardous Waste Management, WHC-CM-5-16, Westinghouse Hanford Company, Richland, Washington.

WHC, 1990, Quality Assurance Manua7, WHC-CM-4-2, Westinghouse Hanford Company, Richland, Washington.

WHC, 1993, Hanford Site Solid Waste Acceptance Criteria, WHC-EP-0063-4, Westinghouse Hanford Company, Richland, Washington.

WHC, 1994, Waste Receiving and Processing Module 1 Operating Plan, WHC-SD-W026-SD-001, Rev. 0, Westinghouse Hanford Company, Richland, Washington.

WHC, 1994, WRAP 1 Computer Interface Definition Document, WHC-SD-W026-CSWD-001, Rev. 0, Westinghouse Hanford Company, Richland, Washington.

WHC, 1996, WRAP I Data Management System Software Requirements Specification, WHC-SD-CSRS-001, Rev. 1, Westinghouse Hanford Company, Richland, Washington.

\subsection{Trademarks}

1. Oracle is a trademark of Oracle Corporation, World Headquarters, 500 Oracle Parkway, Redwood Shores, CA 94063 
WHC-SD-W026-SDD-001, Rev. 2

\subsection{Trademarks}

1. Oracle is a trademark of Oracle Corporation, World Headquarters, 500 Oracle Parkway, Redwood Shores, CA 94063

2. X-Windows is a trademark of Massachusetts Institute of Technology

3. IBM is a registered trademark of International Business Machines Corporation

4. Hewlett-Packard is a trademark of Hewlett-Packard Corporation

5. UNIX is a trademark licensed exclusively through $X / 0$ pen Company Ltd.

6. Microsoft is a registered trademark of Microsoft Corporation

7. Pro-C is a trademark of Oracle Corporation

8. SQL*Reports is a trademark of Oracle Corporation

9. SQL*Net is a registered trademark of Oracle Corporation

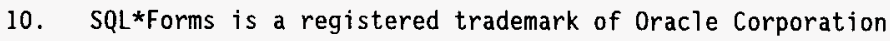


WHC-SD-W026-SDD-001, Rev. 2

APPENDIX A

SCREEN DESIGN DETAILS

$A-i$ 
WHC-SD-W026-SDD-001, Rev. 2

This page intentionally left blank. 
WHC-SD-W026-SDD-001, Rev. 2

\section{CONTENTS}

DMS Screen Hierarchy ....................A-1

\section{FIGURES}

A-1. WRAP 1 DMS Main Menu Screen. ............. A-7

A-2. DMSS0101 Container Recceiving Screen. . . . . . . . . . . A-8

A-3. DMSS0102 Bar Code Generator Screen. . . . . . . . . . . . . A-9

A-4. DMSS0201 NDE Screen. . . . . . . . . . . . . . . . . A-10

A-5. DMSS0201 NDE Screen Container and Content Record

(WASTE) Screen Pop-Up. ............... . . . . . . .

A-6. MDSS0201 NDE Screen Physical Component Screen Pop-Up. . . . . . . A-12

A-7. DMSS0201 NDE Screen Radioactive Waste Container Detail Record

Screen. . . . . . . . . . . A-13

A-8. DMSSO202 NDA Screen. . . . . . . . . . . . . . . . A-14

A-9. DMSS0202 NDA Screen NDA Results Screen Pop-Up......... A-15

A-10. DMSSO202 NDA Screen NDAISO Display Screen Pop-Up . . . . . . . A A-16

A-11. DMSS0311 LLW Glovebox Drum Status at Entry Screen . . . . . . . . A-17

A-12. DMSS0312 LLW Sorting Table Screen . . . . . . . . . . . . . . . A-18

A-13. DMSSO312 LLW Sorting Table Screen LLW Non-Compliant Screen

Pop-Up . . . . . . . . . . . . . . A-19

A-14. DMSSO312 LLW Sorting Table Screen Chemical Component Screen

Pop-Up . . . . . . . . . . . . . . . . . . . .

A-15. DMSS0312 LLW Sorting Table Screen Physical Component Screen

Pop-Up . . . . . . . . . . . . . A-21

A-16. DMSS0312 LLW Sorting Table Screen NDE Comment Screen Pop-Up . . A A-22

A-17. DMSS0315 LLW Exit Glovebox Screen . . . . . . . . . . . . . . A-23

A-18. DMSS0321 LLW RWM Waste Sorting Screen. . . . . . . . . . . . . A A-24

A-19. DMSS0322 LLW RWM Waste Repackaging Screen. . . . . . . . . . . A-25

A-20. DMSS0323 LLW RWM Compliant Waste Loadout Screen. . . . . . . . . . A-26

A-21. DMSS0324 LLW RWM Treatment Item Assembly ('Packets' Selected). . . A-27

A-22. DMSS0324 LLW RWM Treatment Item Assembly ('Samples' Selected). . A-28

A-23. DMSS0325 LLW RWM Processing Instructions Screen. . . . . . . . . A-29

A-24. DMSS0326 LLW RWM Treatment Screen. . . . . . . . . . . . . A-30

A-25. DMSS0328 LLW RWM Treated Waste Loadout Screen. . . . . . . . . . . A-31

A-26. DMSS0331 TRU Glovebox Drum Status at Entry Screen. . . . . . A A-32

A-27. DMSS0332 TRU Sorting Table Screen. . . . . . . . . . . . . A-33

A-28. DMSS0332 TRU Sorting Table Screen TRU Non-Compliant Packet

Pop-Up. . . . . . . . . . . . . . . . . . . . A-34

A-29. DMSS0333 TRU Chemical Composition Screen. . . . . . . . . . A-35

A-30. OMSS0334 TRU Physical Components Screen. . . . . . . . . A-36

A-31. DMSS0335 TRU Exit Glovebox Screen. . . . . . . . . . . . . . A-37

A-32. DMSS0341 TRU RWM Waste Sorting Screen. . . . . . . . . . . A-38

A-33. DMSS0342 TRU RWM Waste Repackaging Screen. . . . . . . . . . . . . A-39

A-34. DMSS0343 TRU RWM Compliant Waste Loadout Screen. . . . . . A-40

A-35. DMSS0344 TRU RWM Treatment Item Assembly Screen

('Packets' Selected). . . . . . . . . . . . . A-41

A-36. DMSS0344 TRU RWM Treatment Item Assembly Screen

('Samples' Selected). 
A-37. DMSS0345 TRU RWM Processing Instructions Screen. . . . . . . . . . A-43

A-38. DMSS0346 TRU RWM Treatment Screen. . . . . . . . . . . . . . . . A-44

A-39. DMSS0348 TRU RWM Treated Waste Loadout Screen. . . . . . . . . . . A-45

A-40. DMSSO452 Location Table Screen . . . . . . . . . . . . . . . . . A-46

A-41. DMSS0454 Profile/Profile Isotope Screen . . . . . . . . . . . A-47

A-42. DMSSO455 Route Description Table Screen . . . . . . . . . . . . . A-48

A-43. DMSS0456 Shipping Pick List Type Screen . . . . . . . . . . . . . A-49

A-44. DMSS0457 SIE Isotope Name Screen . . . . . . . . . . . . . . A-50

A-45. DMSS0458 TRU Container Code Table Screen . . . . . . . . . . . . A-51

A-46. DMSS0459 Field Analysis Type Screen . . . . . . . . . . . . . A-52

A-47. DMSS0460 Material Screen. . . . . . . . . . . . . . . . . . A-53

A-48. DMSS0461 WRAP Miscellaneous Table Screen . . . . . . . . . . . A-54

A-49. DMSS0462 Laboratory Analysis Screen . . . . . . . . . . . . . . A-55

A-50. DMSS0463 Sample Container Screen . . . . . . . . . . . . . . . A-56

A-51. DMSS0464 Sample Matrix Screen . . . . . . . . . . . . . . . . A-57

A-52. DMSS0465 Sampling Method Screen . . . . . . . . . . . . A-58

A-53. DMSS0466 Treatment Procedure Table Screen . . . . . . . . . . . . A-59

A-54. DMSS0501 Lab Sample Acquisition Screen. . . . . . . . . . . . . . A-60

A-55. DMSSO502 Chain of Custody Screen. . . . . . . . . . . . A-61

A-56. DMSS0503 Field Screening Screen. . . . . . . . . . . . . . . . . . A-62

A-57. DMSS0504 Laboratory Sample Analys is Request Screen. . . . . . . . A-63

A-58. DMSS0505 Packet Waste Designation Screen. . . . . . . . . . . . . A-64

A-59. DMSS0506 Worksheet Data Entry Screen. . . . . . . . . . . . . . . A-65

A-60. DMSS0506 Worksheet Data Entry Screen Select Packets For

Treatment Pop-Up. . . . . . . . . . . . . . A-66

A-61. DMS50506 Worksheet Data Entry Screen Select Samples For 1. . . A-67

A-62. DMSS0507 Sample Management and COC Screen. . . . . . . . . . . A-68

A-63. DMSS0507 Sample Management and COC Screen

COC Sample Selection Pop-Up. . . . . . . . . . . . . A-69

A-64. DMS50508 Sample Bottle Labels Screen. . . . . . . . . . . . . . . A-70

A-65. DMSS0509 Samples/Bottle Tracking Data Screen. . . . . . . . . . A-71

A-66. DMS50510 Purge Port/Transfer Pig Location Screen. . . . . . . . . A-72

A-67. DMSS0511 Samples Returned From Lab Screen. . . . . . . . . . . . . A-73

A-68. DMSS0601 Loading Dock Shipping Data Screen. . . . . . . . . . . . A-74

A-69. DMSS0602 Loading Dock Container Shipping Screen . . . . . . . . . A-75

A-70. DMS50603 TRUPACT Cask Loading/Certification Screen. . . . . . . . A-76

A-71. DMS50604 TRUPACT Shipping Documentation Screen. . . . . . . . . . A-77

A-72. DMSS0605 Loading Dock Box and Empty Container Shipping Screen - A-78

A-73. DMSS0701 Error Message Table Screen . . . . . . . . . . . . . . A-79

A-74, DMSS0702 User Table Screen . . . . . . . . . . . . . . . . . . A-80

A-75. DMSS0703 Role Table Screen . . . . . . . . . . . . . . . . . . . . A-81

A-76. DMSS0709 Role Screen Table Screen . . . . . . . . . . . . . . . A-82

A-77. DMS50708 User Role Table Screen . . . . . . . . . . . . . . . . . A-83

A-78. DMSS0704 Screen Table Screen . . . . . . . . . . . . . . . . . . . A-84

A-79. DMSS0901 Process List Additions Screen . . . . . . . . . . . . . . A-85

A-80. DMSS0902 Process List Screen . . . . . . . . . . . . . . . . . . A-86

A-81. DMSS0903 AS/RS Storage Pick List Screen . . . . . . . . . . . . . A-87

A-82. DMSS0904 AS/RS Shipping Pick List Screen . . . . . . . . . . . . . A-88

A-83. DMSS0905 TRUPACT Assembly List Screen . . . . . . . . . . . . . A-89

A-84. DMSS0906 Box/Empty Drum Shipping Pick List Screen . . . . . . . . A-90

A-85. DMSS1101 Radiologic Inventory Summary Screen . . . . . . . . . . . A-9l

A-86. DMSS1102 Container Location and Relationships Screen. . . . . . . A-92

A-87. DMSS1201 Process Waste NDA Data Review and Modification Screen . . A-93

A-88. DMSS1202 Compacted Drum NDA Data Review Screen. . . . . . . . . . A-94 
A-89. DMSS1211 Verification NDA Data Review Screen. . . . . . . . . . . A-95

A-90. DMSS1212 Certification/Verification NDA Data Review Screen. . . . A-96

A-91. DMSS1221 Processed Waste Data Review \& Mod. Screen . . . . . . . . A-97

A-92. DMSS1221 Processed Waste Data Review \& Mod. Screen Applicable

MSDS Screen Pop-Up . . . . . . . . . . . . . . . . . . . . A-98

A-93. DMSS1221 Processed Waste Data Review \& Mod. Screen Chemical Component Screen Pop-Up . . . . . . . . . . . . . . . . . . . A-99

A-94. DMSS1221 Processed Waste Data Review \& Mod. Screen Container Relationship (CONREL) Screen Pop-Up . . . . . . . . . . A-100

A-95. DMSS1221 Processed Waste Data Review \& Mod. Screen Hazardous Waste Container Detail Record (HAZDETAIL) Screen Pop-Up . . . A-101

A-96. DMSS1221 Processed Waste Data Review \& Mod. Screen Package Dangerous Waste Numbers Record Screen Pop-Up . . . . . . . . . A-102

1-97. DMSS1221 Processed Waste Data Review \& Mod. Screen Radioactive Isotope Quantity (ISOQTY) Record Screen Pop-Up . . . . . . . . A-103

A-98. DMSS1221 Processed Waste Data Review \& Mod. Screen Physical Component Screen Pop-Up ................. A-104

A-99. DMSS1221 Processed Waste Data Review \& Mod. Screen Radioactive Waste Container Detail Record Screen Pop-Up . . . . . . . . . A-105

A-100. DMSS1221 Processed Waste Data Review \& Mod. Screen Container and Content Record (WASTE) Screen . . . . . . . . . . A-106

A-101. DMSS1231 Waste Verification Data Review Screen. . . . . . . . A-107

A-102. DMSS1301 Activity Comment Screen. . . . . . . . . . . A-108 
WHC-SD-W026-SDD-001, Rev. 2

This page intentionally left blank. 
WHC-SD-W026-SDD-001, Rev. 2

DMS SCREEN HIERARCHY

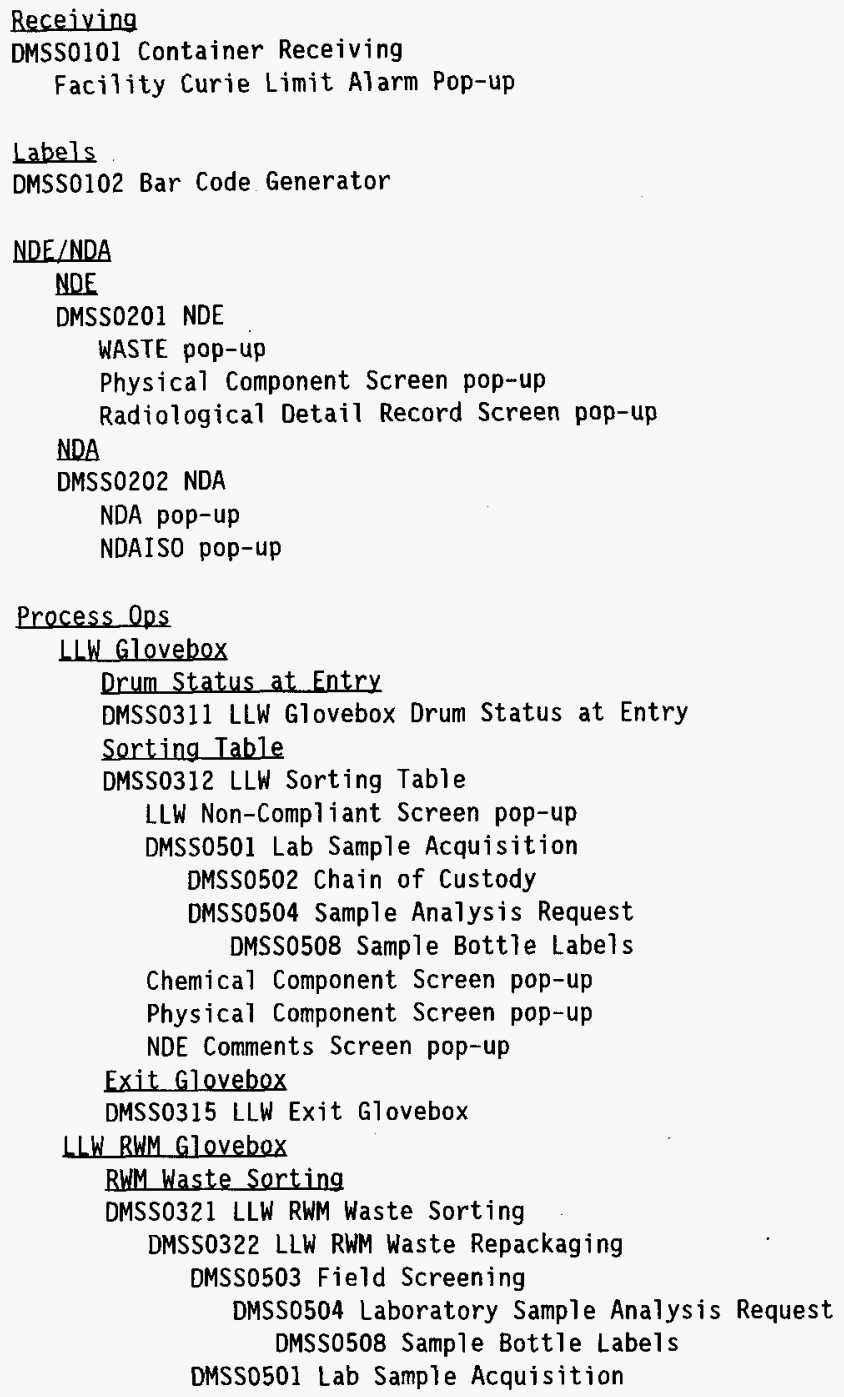


DMSS0502 Chain of Custody

DMSS0504 Sample Analysis Request

DMSS0508 Sample Bottie Labels

DMSS0323 LLW RWM Compliant Waste Loadout

Physical Component Screen pop-up

RWM Compliant Loadout

DMSS0323 LLW RWM Compliant Waste Loadout

Physical Component Screen pop-up

RWM Treatment

DMSS0324 LLW RWM Treatment Item Assembly

DMSS0325 LLW RWM Processing Instructions (RWM glovebox monitor)

DMSS0326 LLW RWM Treatment

DMSS0323 LLW RWM Compliant Waste Loadout

Physical Component Screen pop-up

DMSS0328 LLW RWM Treated Waste Loadout

Physical Component Screen pop-up

Chemical Component Screen pop-up

RWM Treated Loadout

DMSS0328 LLW RWM Treated Waste Loadout

Physical Component Screen pop-up

Chemical Component Screen pop-up

IRU Glovebox

IRU Entry

DMSS0331 TRU Glovebox Drum Status at Entry

IRU Sorting

DMSS0332 TRU Sorting Table

TRU Non-Compliant Packet pop-up

DMSS0501 Lab Sample Acquisition

DMSS0504 Sample Analysis Request

DMSS0508 Sample Bottle Labels

DMSS0502 Chain of Custody

DMSS0333 TRU Chemical Composition

DMSS0334 TRU Physical Components

DMSS0334 TRU Physical Components

DMSS0333 TRU Chemical Compostion

NDE Comments Screen pop-up

IRU Exit

DMSSO335 TRU Exit

IRU RWM Glovebox

RWM Waste Sorting

DMSS0341 TRU RWM Waste Sorting

DMSS0342 TRU RWM Repackaging

DMSS0503 Field Screening

DMSS0504 Laboratory Sample Analysis Request

DMSS0508 Sample Bottle Labels 


\section{DMSS0501 Lab Sample Acquisition \\ DMSS0502 Chain of Custody \\ DMSS0504 Sample Analysis Request \\ DMSS0508 Sample Bottle Labels \\ DMSS0343 TRU RWM Compliant Waste Loadout \\ Physical Component Screen pop-up}

BWM Compliant Leadout

DMSS0343 TRU RWM Compliant Waste Loadout

Physical Component Screen pop-up

\section{IRU Treatment}

DMSS0344 TRU RWM Treatment Item Assembly

DMSS0345 TRU RWM Processing Instructions (RWM glovebox monitor)

DMSS0346 RHM Treatment

DMSS0343 TRU RWM Compliant Waste Loadout

Physical Component Screen

DMSS0348 TRU RWM Treated Waste Loadout

Physical Component Screen

Chemical Component Screen

Sample Mgmt

Internal Chain of Custody

DMSS0502 Chain of Custody

Sample Analys is Request

DMSS0504 Laboratory Sample Analysis Request

DMSS0503 Field Screening

DMSS0508 Sample Bottle Labels

Waste Designation

DMSS0505 Packet Waste Designation Request

HDET pop-up

Chemical Component Screen pop-up

MSDS Data pop-up

Worksheet Entry

DMSS0506 Worksheet Data Entry

DMSS0505 Packet Waste Designation

Select Packets for Treatment pop-up

Select Samples for Treatment pop-up

HDET pop-up

Chemical Component Screen pop-up

MSDS Data pop-up

External Chain of Custody

DMSS0507 Sample Management and COC

COC Sample Selection pop-up

Sample Labels

DMSS0508 Sample Bottle Labels 
WHC-SD-W026-SDD-001, Rev. 2

Sample Tracking

DMSS0509 Sample/Bottle Tracking Data

Purge Port Lecation

DMS50510 Purge Port/Transfer Pig Location

Returned Samples

DMSS0511 Samples Returned From Lab

Datą Review

Processed Waste NDA Data

DMSS1201 Processed Waste NDA Data Review and Modification DMSS1202 Compacted Drum NDA Data Review

Physical Component Screen pop-up

RADDETAIL pop-up

ISOQTY pop-Up

Verification NDA Data

DMSS1211 Verification of NDA Data for new1y generated waste RADDETAIL pop-up

Physical Component Screen pop-up

DMSS1212 Certification and Verification NDA Data Review

Processed Waste Data Review

DMSS1221 Processed Waste Data Review and Modification

DMSS0505 Waste Packet Designation

APPMSDS pop-up

Chemical Component Screen pop-up

CONREL pop-Up

HDET pop-up

ISOQTY pop-up

Physical Component Screen pop-up

RADDETAIL pop-up

WASTE pop-up

Verification Data Review

DMSS1231 Verification Data Review

\section{Shipoing}

Loading Dock Shipping

DMSS0601 Loading Dock Shipping Data

RSR pop-up

LLWSDR pop-up

RMWAS pop-up

UHWM pop-up

Loading Dock Container

DMSSO602 Loading Dock Container Shipping

IRU Waste Shipping

DMSSO603 TRUPACT Cask Loading/Certification 
IRUPACT Documentation

DMSS0604 - TRUPACT Shipping Documentation

Box and Empty Drum Shipping

DMSS0605 - Loading Dock Box and Empty Drum Container Shipping

\section{Pick List}

Process List Additions

DMSS0901 Process List Additions

Process List

DMSS0902 Process List

AS/RS Storage Pick List

DMSS0903 AS/RS Storage Pick List

AS/RS Shipping Pick List

DMSS0904 AS/RS Shipping Pick List

IRUPACT Assembly List

DMSS0905 TRUPACT Assembly List

Box/Empty Drum Shipping Pick List

DMSS0906 - Box/Empty Drum Shipping Pick List

Activity Comment

DMSS1301 Activity Comment

Rad Inv

Radiological Inventory

DMSS1101 Radiologic Inventory Summary

Container Location

DMSS1102 Container Location and Relationships

\section{Reports}

(TBD)

Iable Maint

Location

DMSS0452 Location Table

Profile Isotopic

DMSS0454 Profile/Profile Isotopic

Route Desc

DMSS0455 Route Description Table

Shipping Pick List Tvpe

DMSS0456 Shipping Pick List Type

SIE Isotopic Name

DMSS0457 SIE Isotope Name

IRU Container code

DMSS0458 TRU Container Code Table 


\author{
Field Analysis Type \\ DMSS0459 Field Analysis Type \\ Material \\ DMSS0460 Material \\ WRAP Misc. Code \\ DMSS0461 WRAP Miscellaneous Table \\ Laboratory Analysis \\ DMSS0462 Laboratory Analys is \\ Sample Container \\ DMSS0463 Sample Container \\ Sample Matrix \\ DMSS0464 Sample Matrix \\ Sampling Method \\ DMSS0465 Sampling Method \\ Ireatment Procedure \\ DMSS0466 Treatment Procedure
}

Admin

Error Message Table

DMSS0701 Error Message Table

User Table

DMSS0702 User Table

Role Screen Table

DMSS0709 Role Screen Table

Report Table

DMSS07xx Report Table

Role Table

DMSSO703 Role Table

User Role Table

DMSS0708 User Role Table

Screen Table

DMSS0704 Screen Table

Field Help Table

DMSS07xx Field Help Table

Form Help Table

DMSS07xx Form Help Table

New User Setup

DMSS07xx New User Setup 


$$
\text { WHC-SD-W026-SDD-001, Rev. } 2
$$

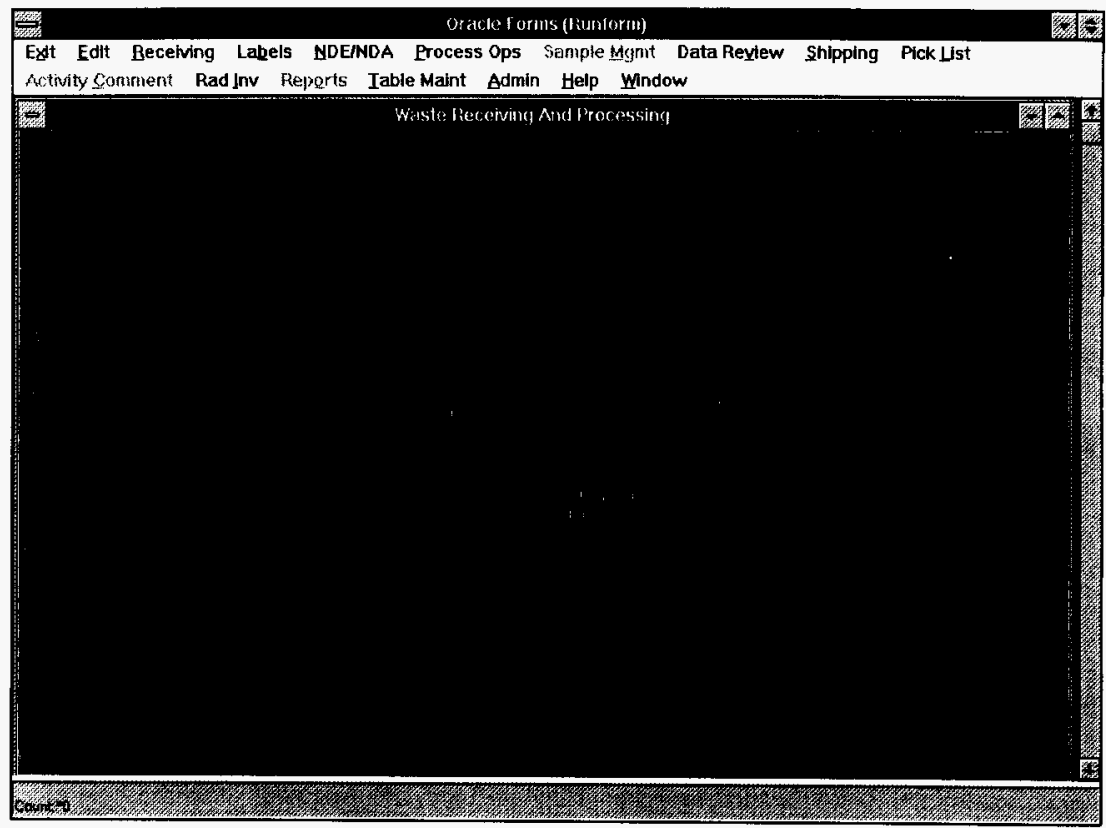

Figure A-1. WRAP 1 DMS Main Menu Screen. 
WHC-SD-W026-SDD-001, Rev. 2

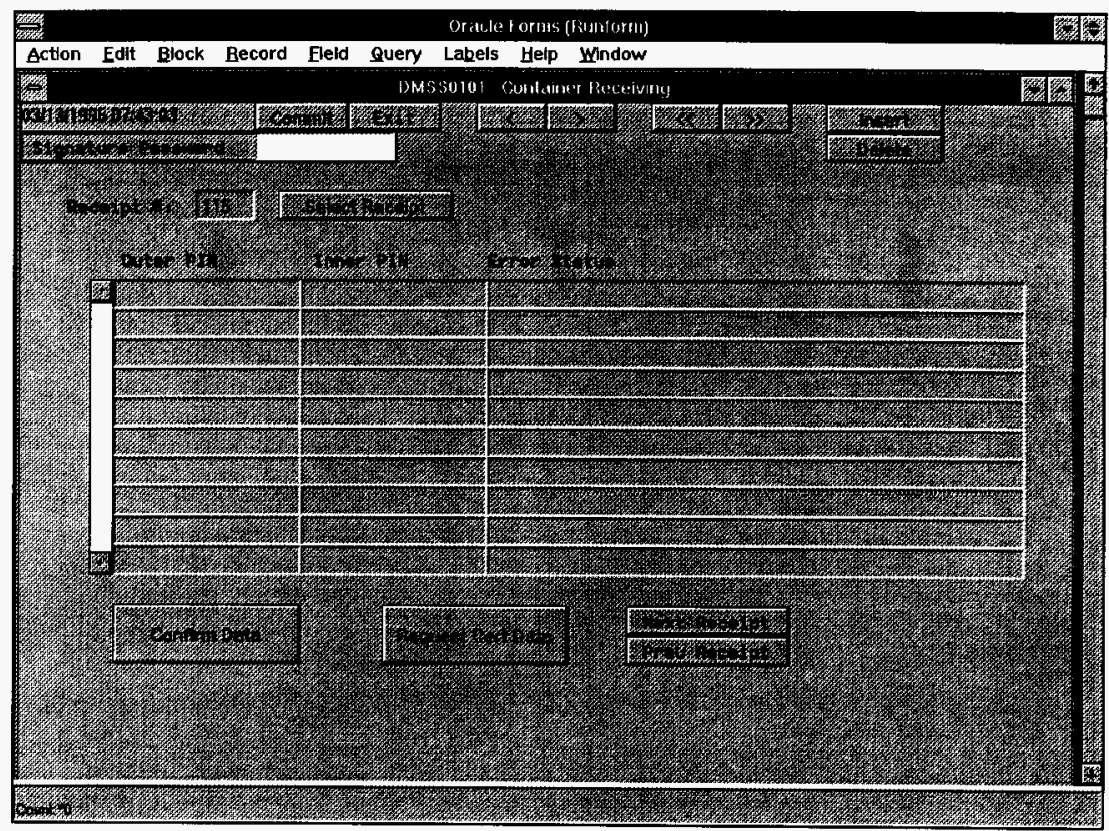

Figure A-2. DMSS0101 Container Recceiving Screen. 
WHC-SD-W026-SDD-001, Rev. 2

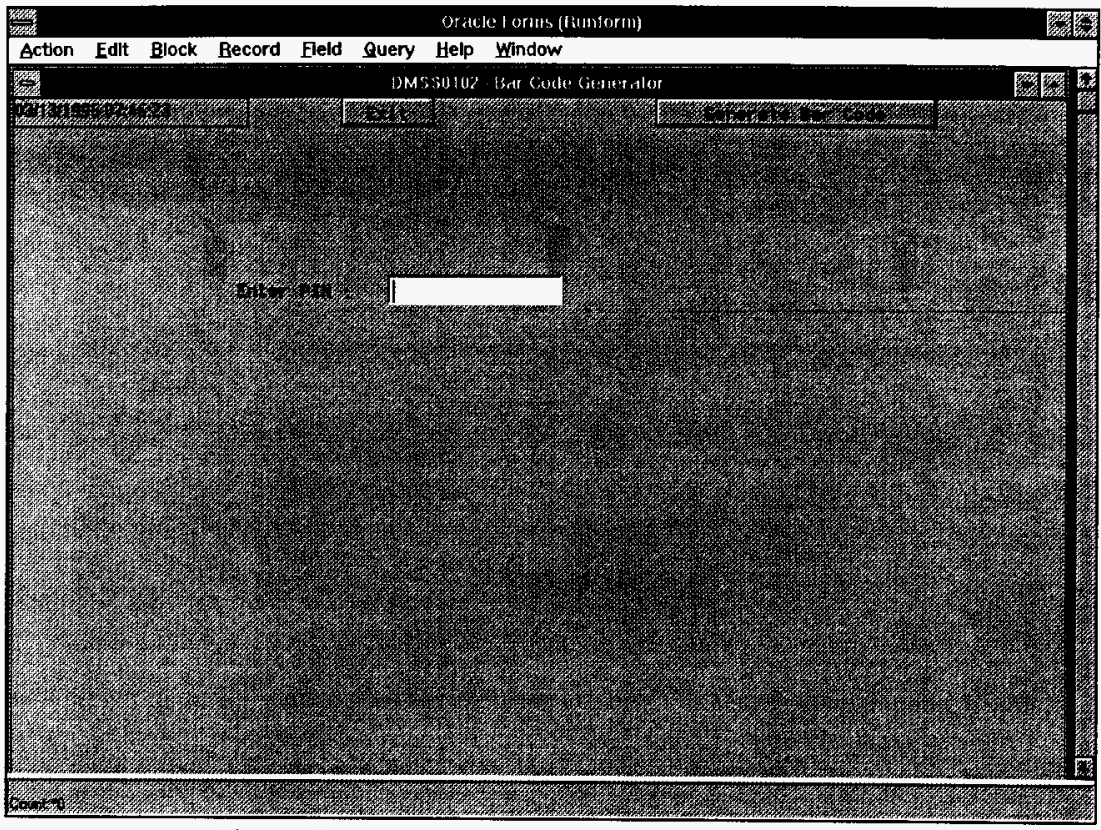

Figure A-3. DMSS0102 Bar Code Generator Screen. 
WHC-SD-W026-SDD-001, Rev. 2

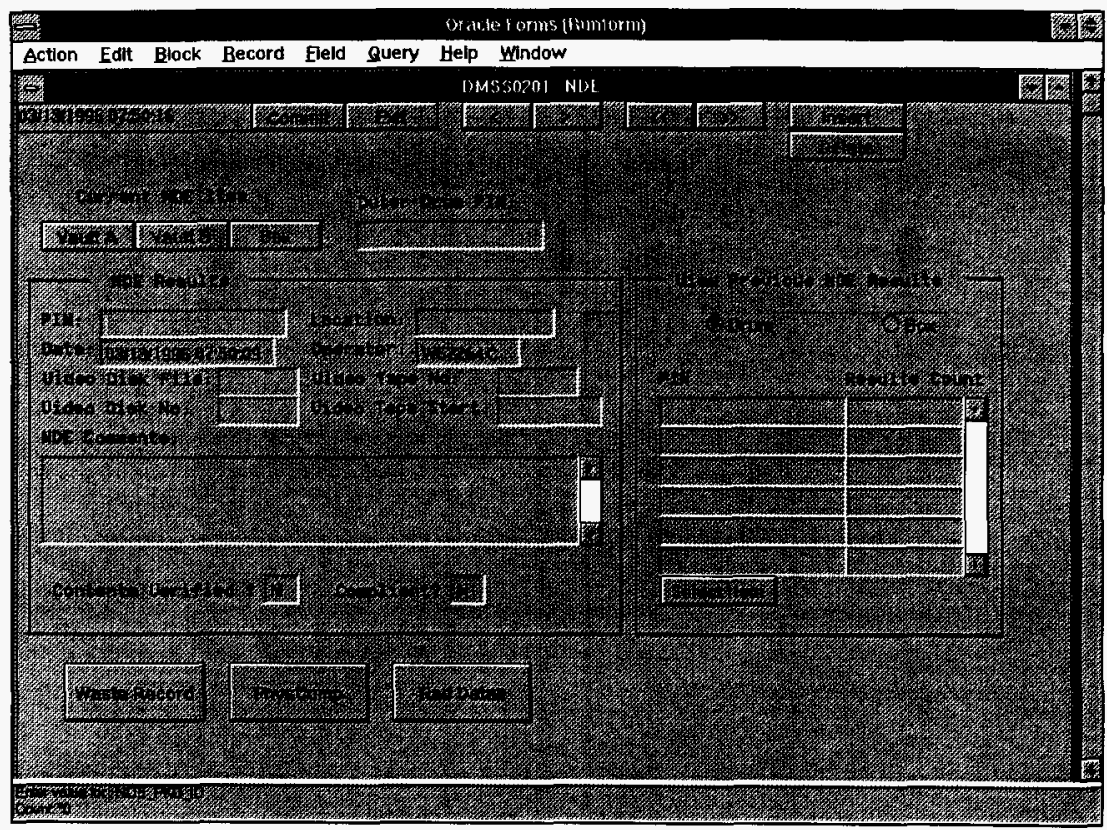

Figure A-4. DMSS0201 NDE Screen. 
WHC-SD-W026-SDD-001, Rev. 2

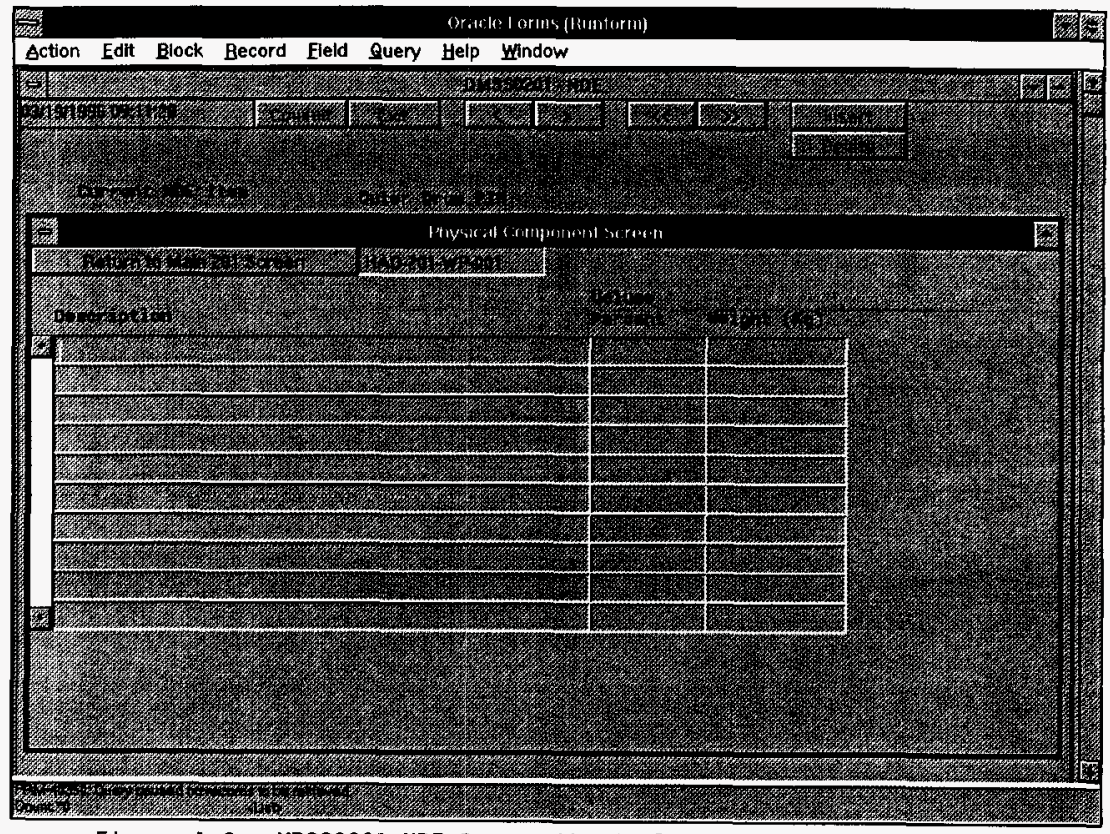

Figure A-6. MDSS0201 NDE Screen Physical Component Screen Pop-Up. 
WHC-SD-W026-SDD-001, Rev. 2

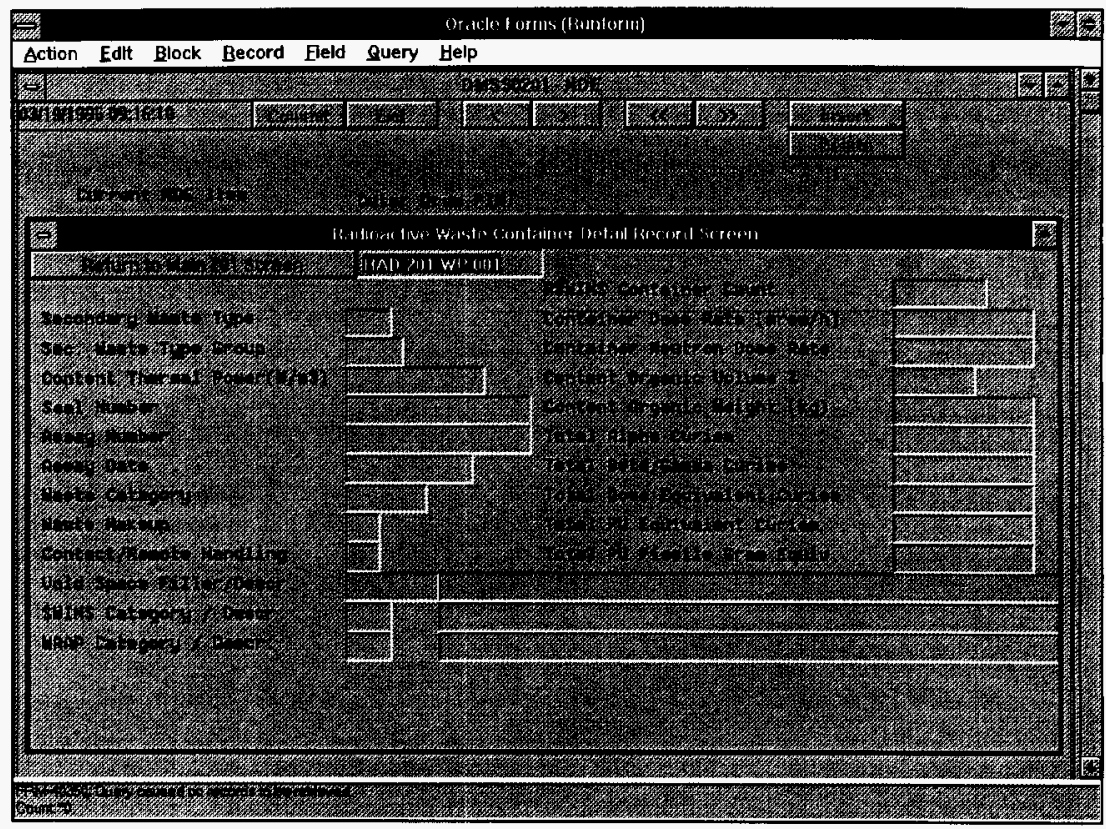

Figure A-7. DMSS0201 NDE Screen Radioactive Waste Container Detail Record Screen. 
WHC-SD-W026-SDD-001, Rev. 2

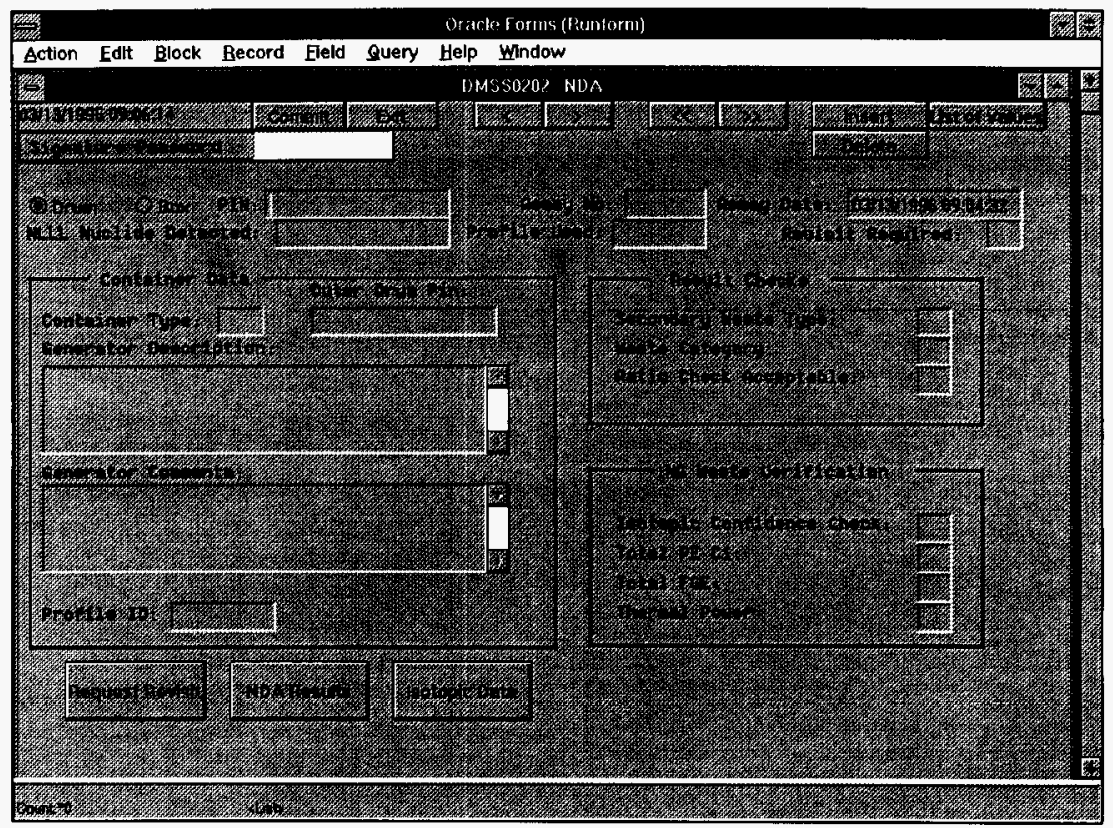

Figure A-8. DMSS0202 NDA Screen. 
WHC-SD-W026-SDD-001, Rev. 2

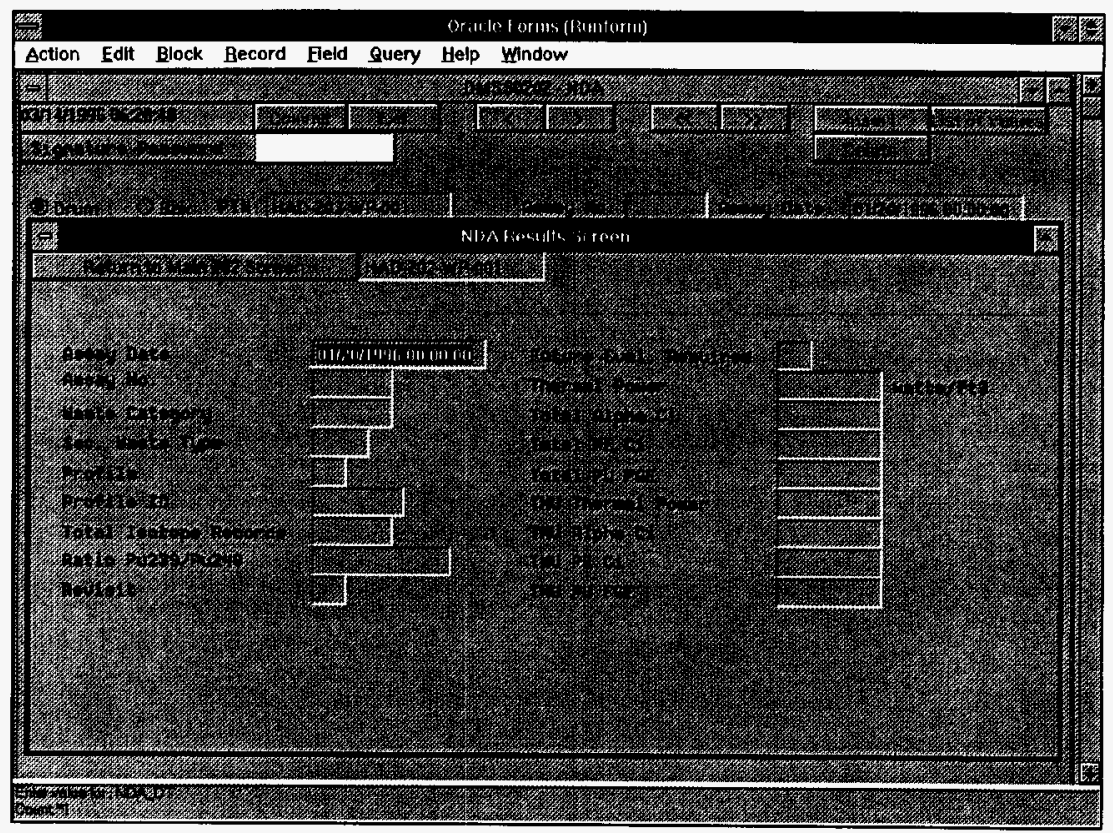

Figure A-9. DMSS0202 NDA Screen NDA Results Screen Pop-Up. 


\section{WHC-SD-W026-SDD-001, Rev. 2}

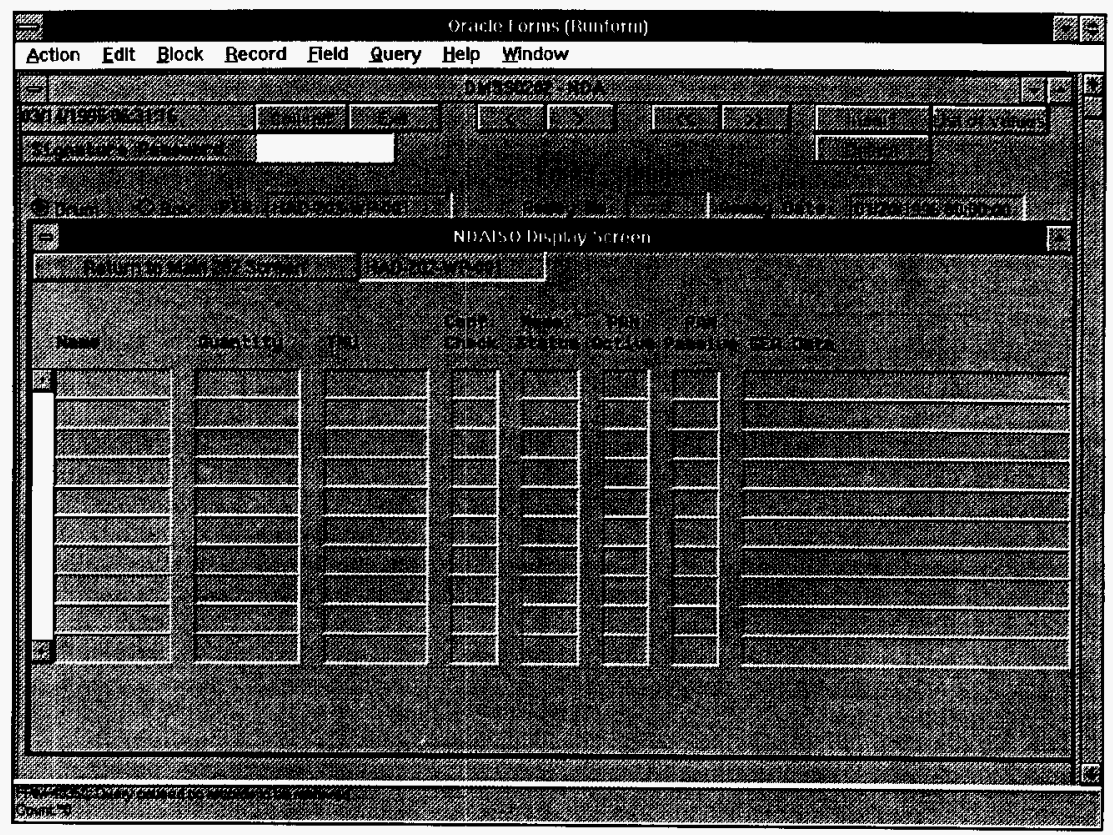

Figure A-10. DMSS0202 NDA Screen NDAISO Display Screen Pop-Up. 
WHC-SD-W026-SDD-001, Rev. 2

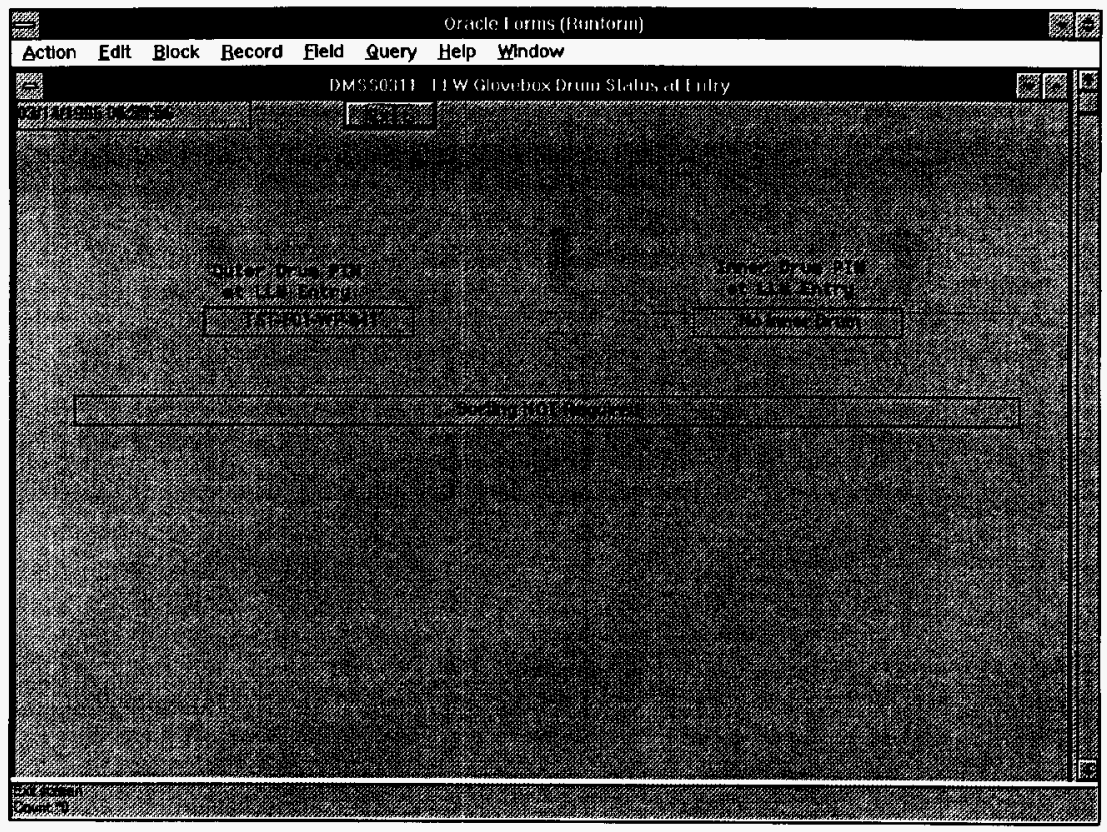

Figure A-11. DMSS0311 LLW Glovebox Drum Status at Entry Screen. 


\section{WHC-SD-W026-SDD-001, Rev. 2}

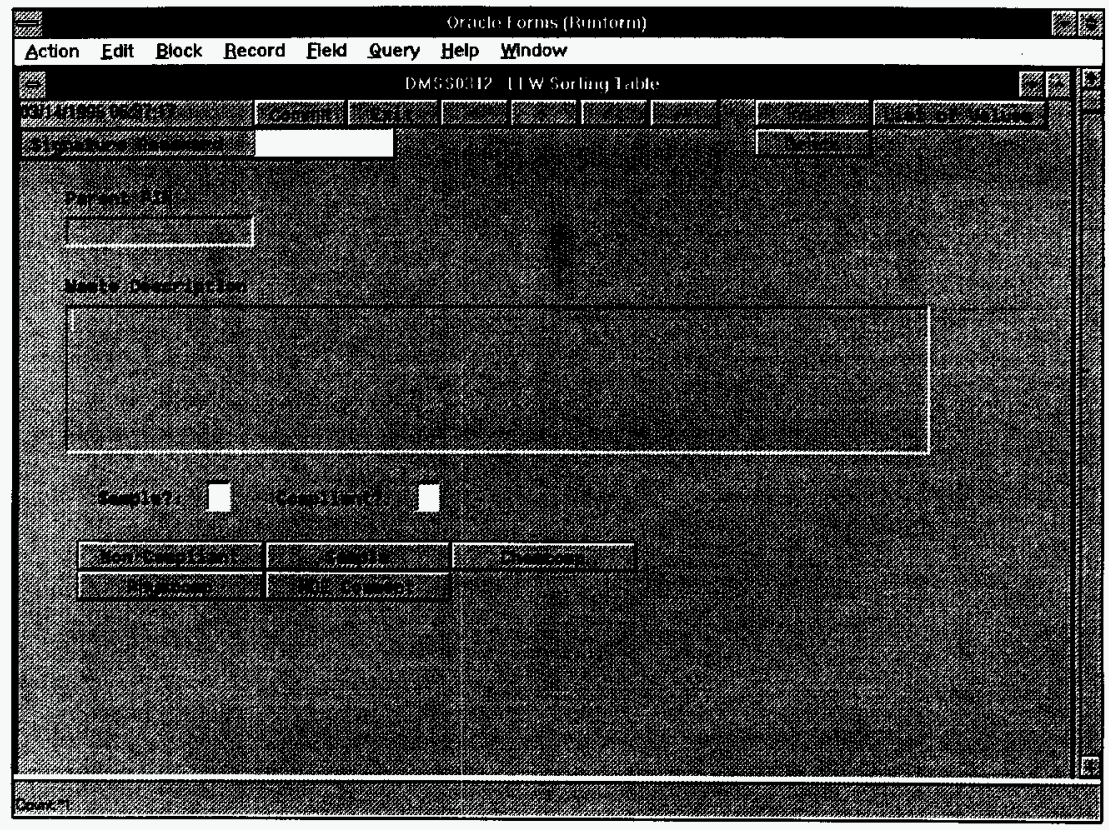

Figure A-12. DMSS0312 LLW Sorting Table Screen. 
WHC-SD-W026-SDD-001, Rev. 2

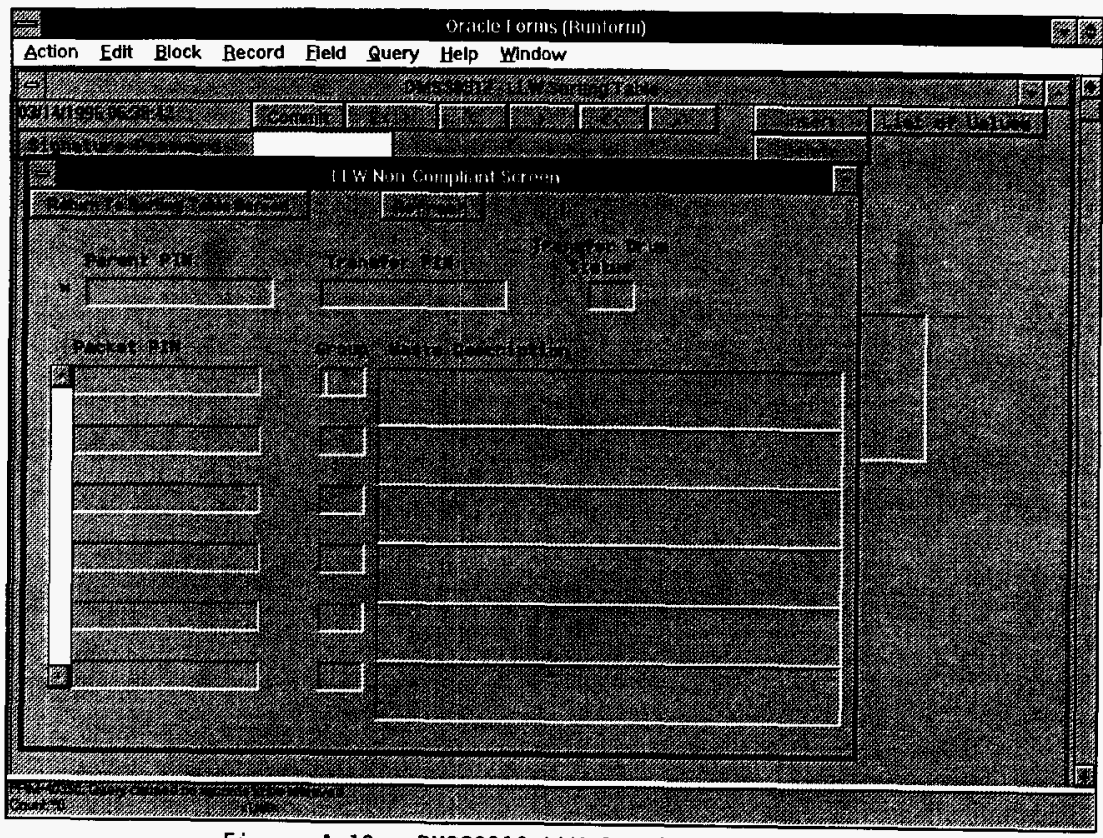

Figure A-13. DMSS0312 LLW Sorting Table Screen

LLW Non-Comp 1 ant Screen Pop-Up. 
WHC-SD-W026-SDD-001, Rev. 2

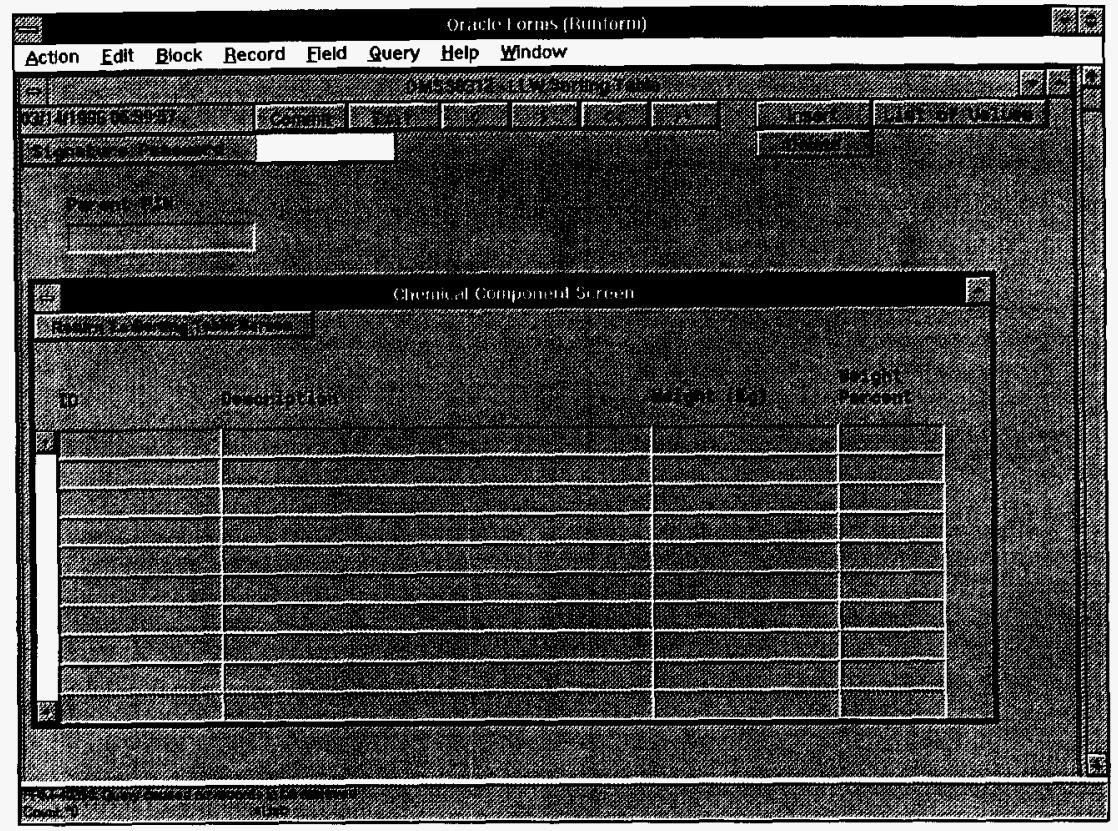

Figure A-14. DMSS0312 LLW Sorting Table Screen Chemical Component Screen Pop-Up. 


$$
\text { WHC-SD-W026-SDD-001, Rev. } 2
$$

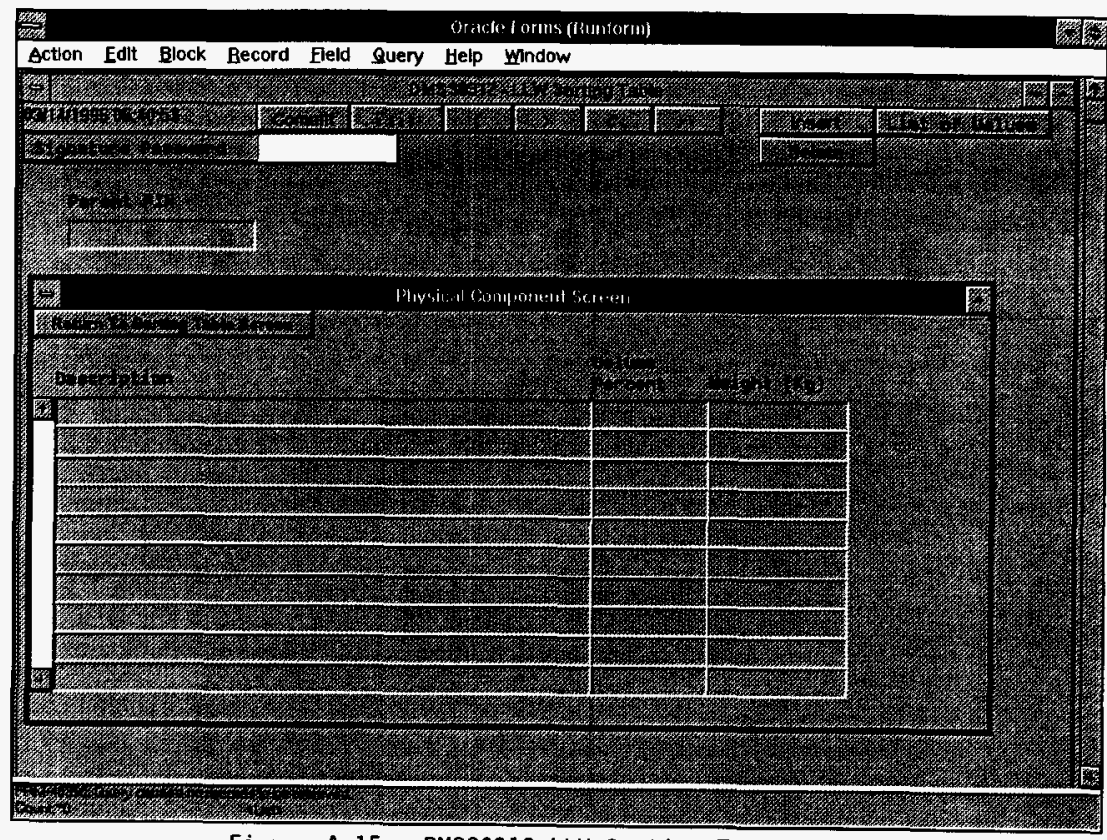

Figure A-15. DMSS0312 LLW Sorting Table Screen Physical Component Screen Pop-Up. 
WHC-SD-W026-SDD-001, Rev. 2

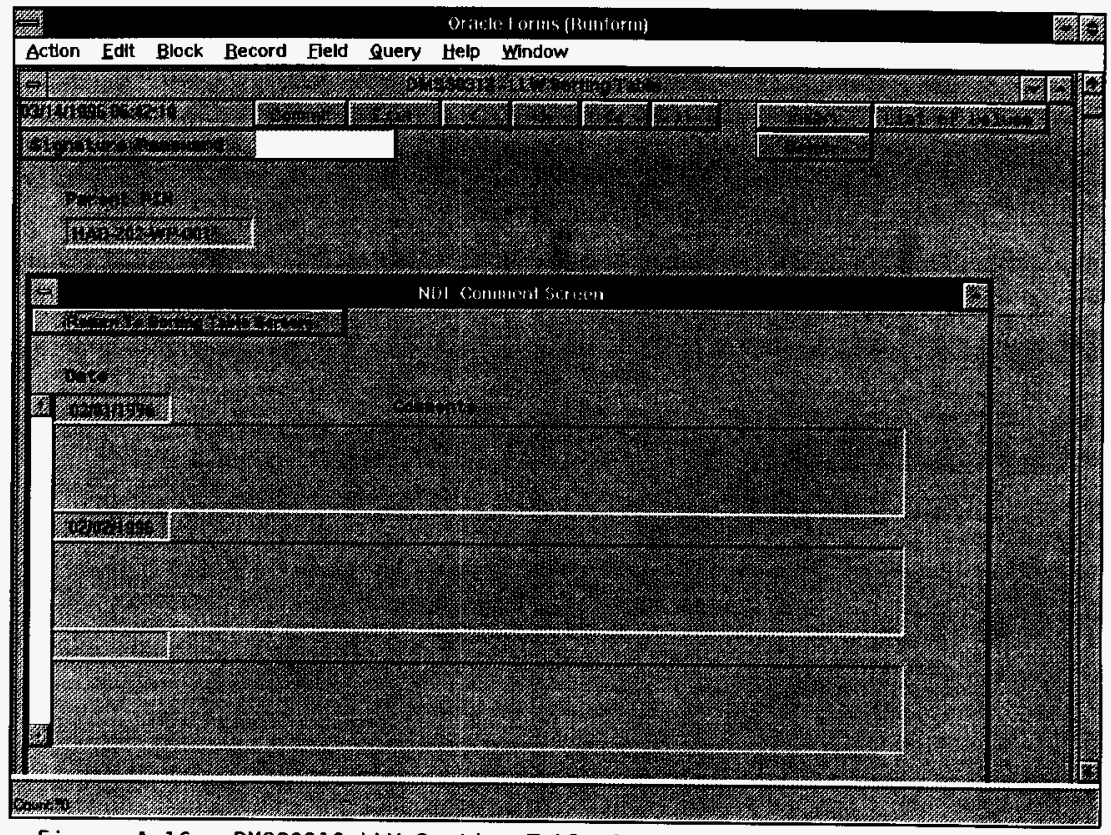

Figure A-16. DMSS0312 LLW Sorting Table Screen NDE Comment Screen Pop-Up. 
WHC-SD-W026-SDD-001, Rev. 2

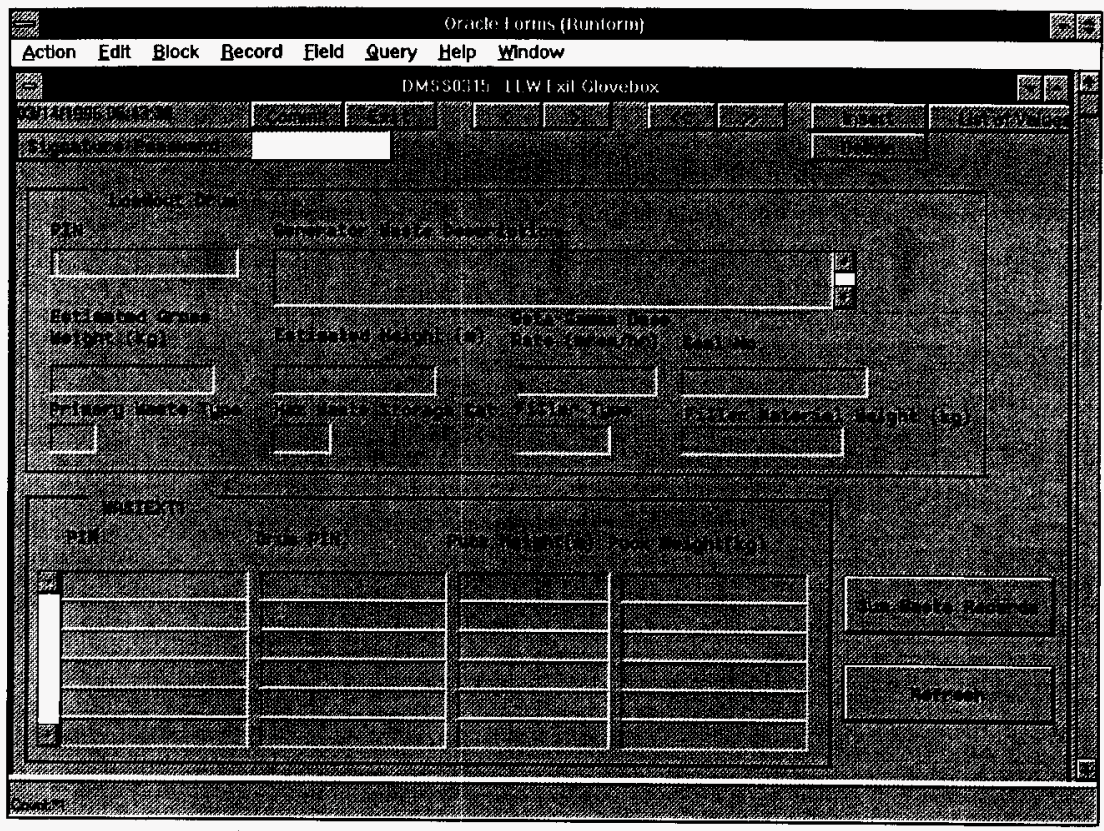

Figure A-17. DMSS0315 LLW Exit Glovebox Screen. 
WHC-SD-W026-SDD-001, Rev. 2

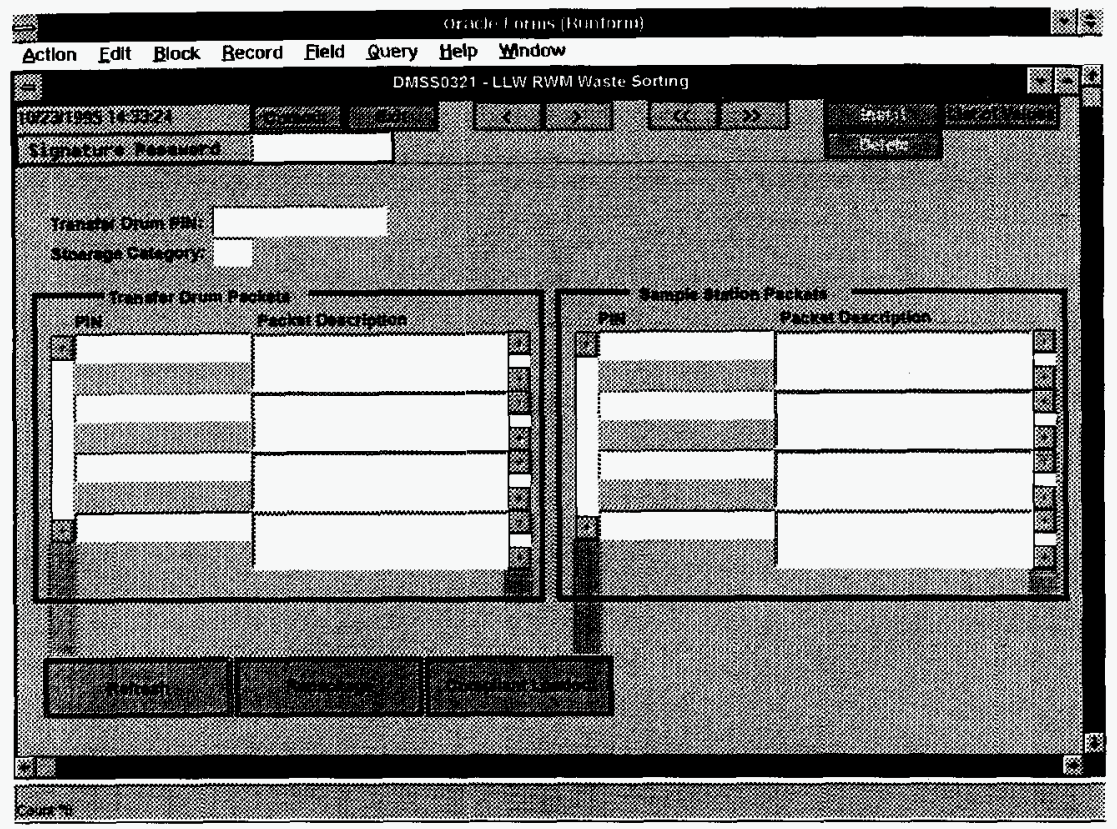

Figure A-18. DMSS0321 LLW RWM Waste Sorting Screen. 
WHC-SD-W026-SDD-001, Rev. 2

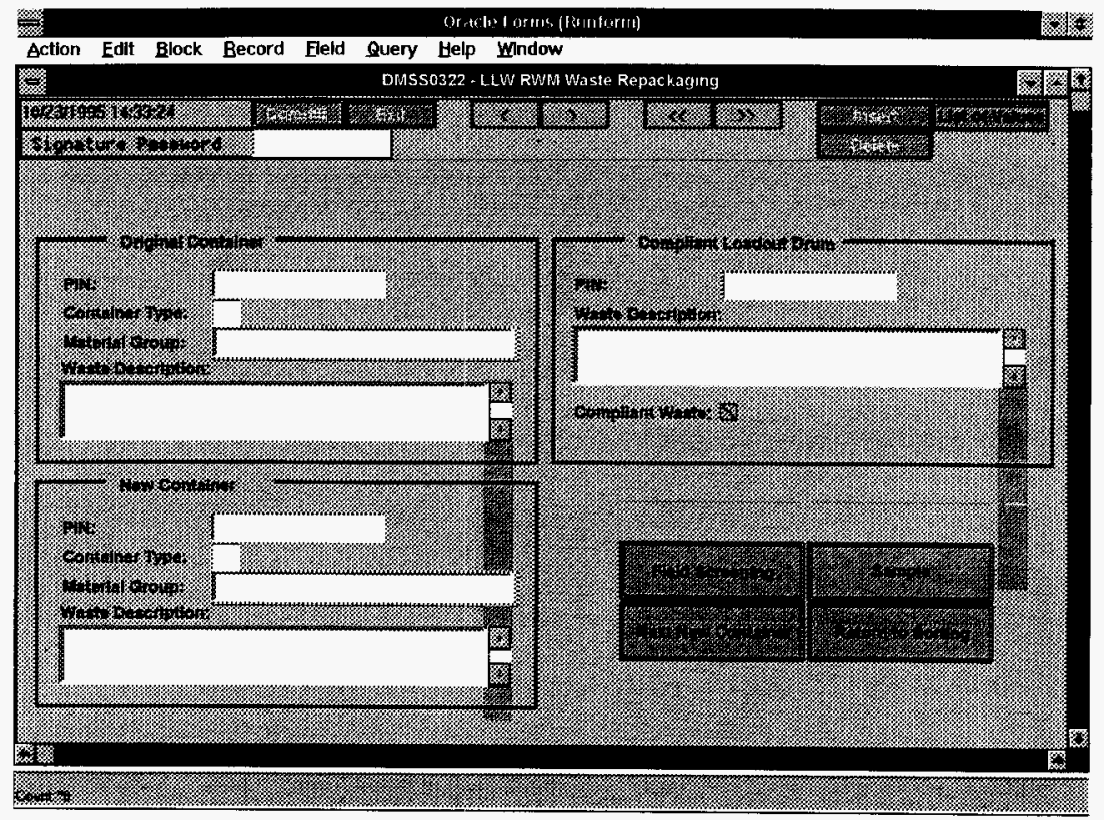

Figure A-19. DMSS0322 LLW RWM Waste Repackaging Screen. 
WHC-SD-W026-SDD-001, Rev. 2

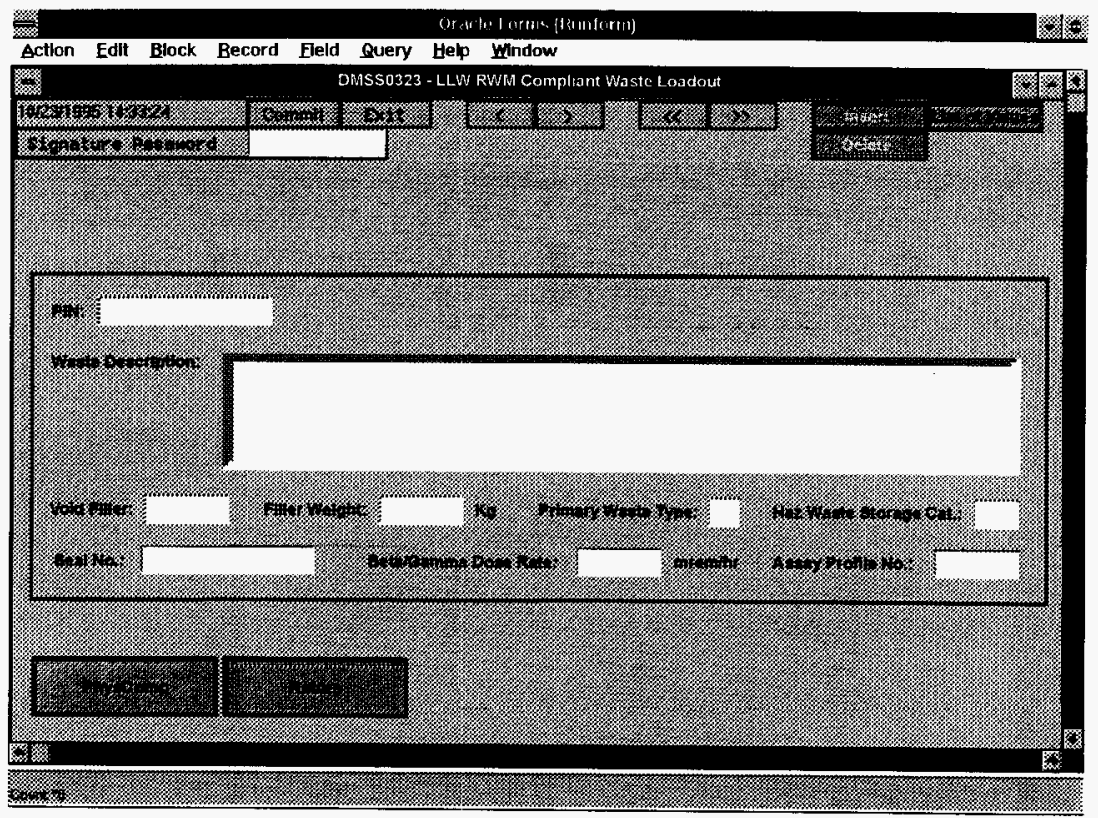

Figure A-20. DMSS0323 LLW RWM Compliant Waste Loadout Screen. 
WHC-SD-W026-SDD-001, Rev. 2

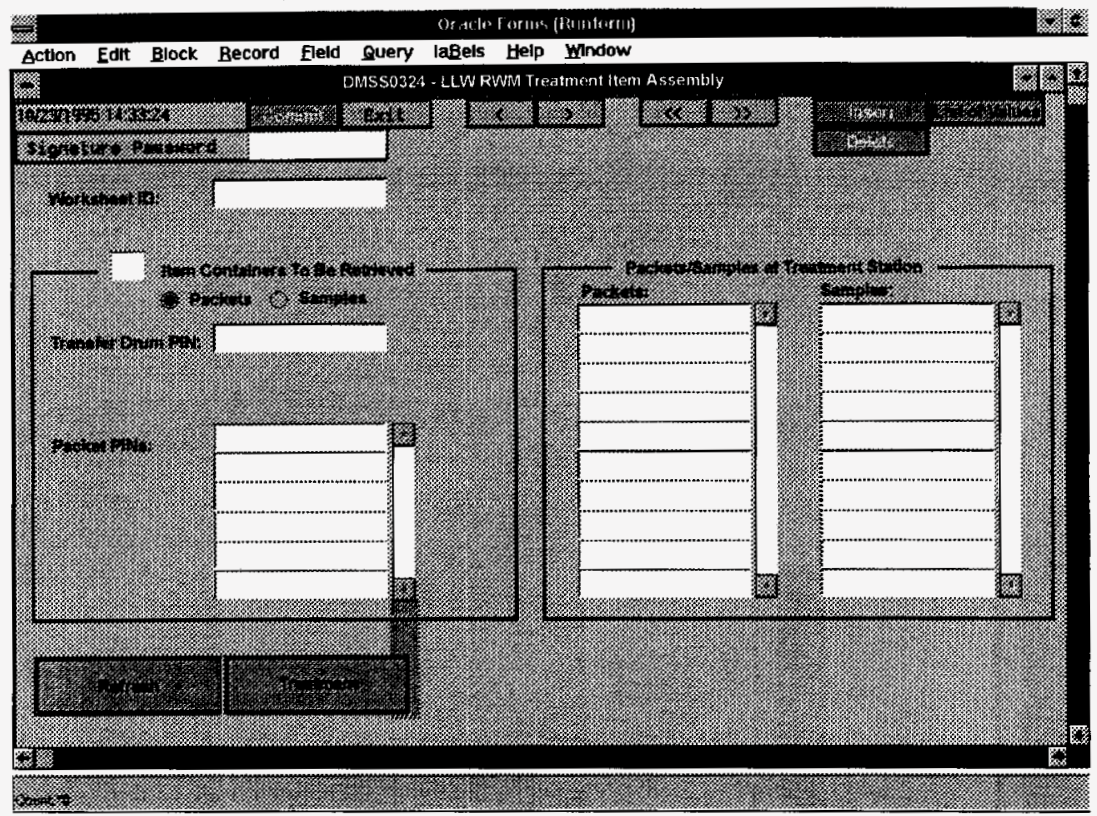

Figure A-21. DMS50324 LLW RWM Treatment Item Assembly ('Packets' Selected). 
WHC-SD-W026-SDD-001, Rev. 2

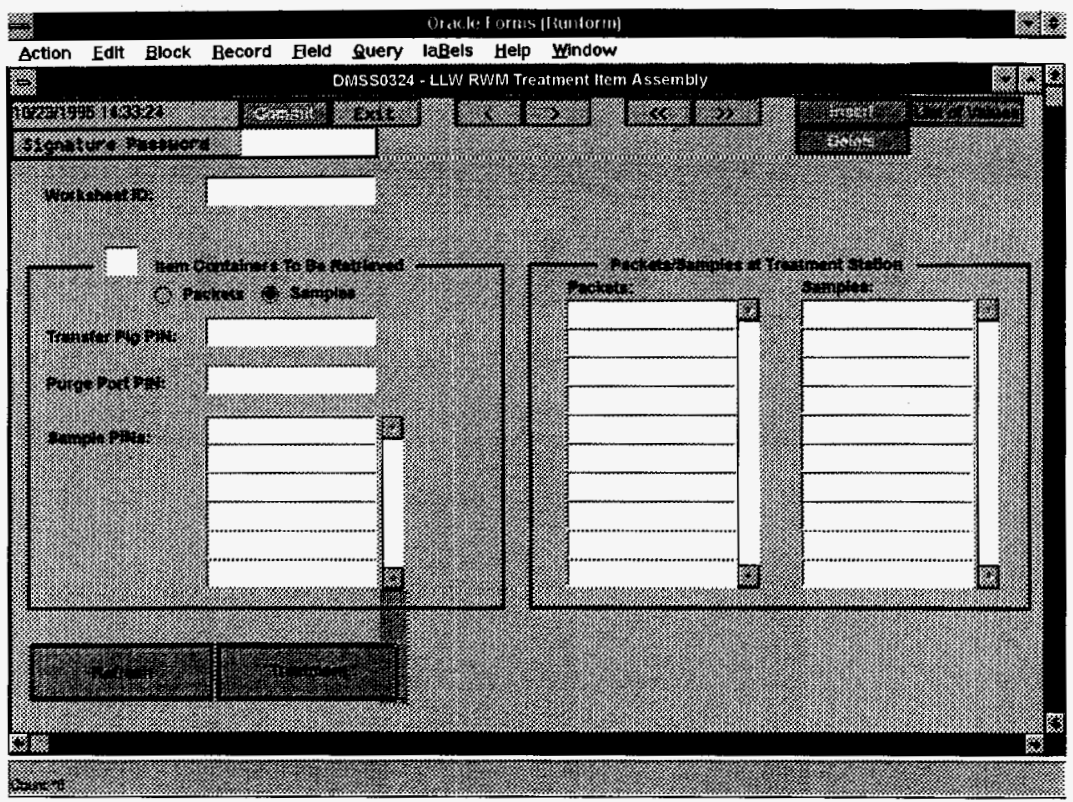

Figure A-22. DMSS0324 LLW RWM Treatment Item Assembly ('Samples' Selected). 


\section{WHC-SD-W026-SDD-001, Rev. 2}

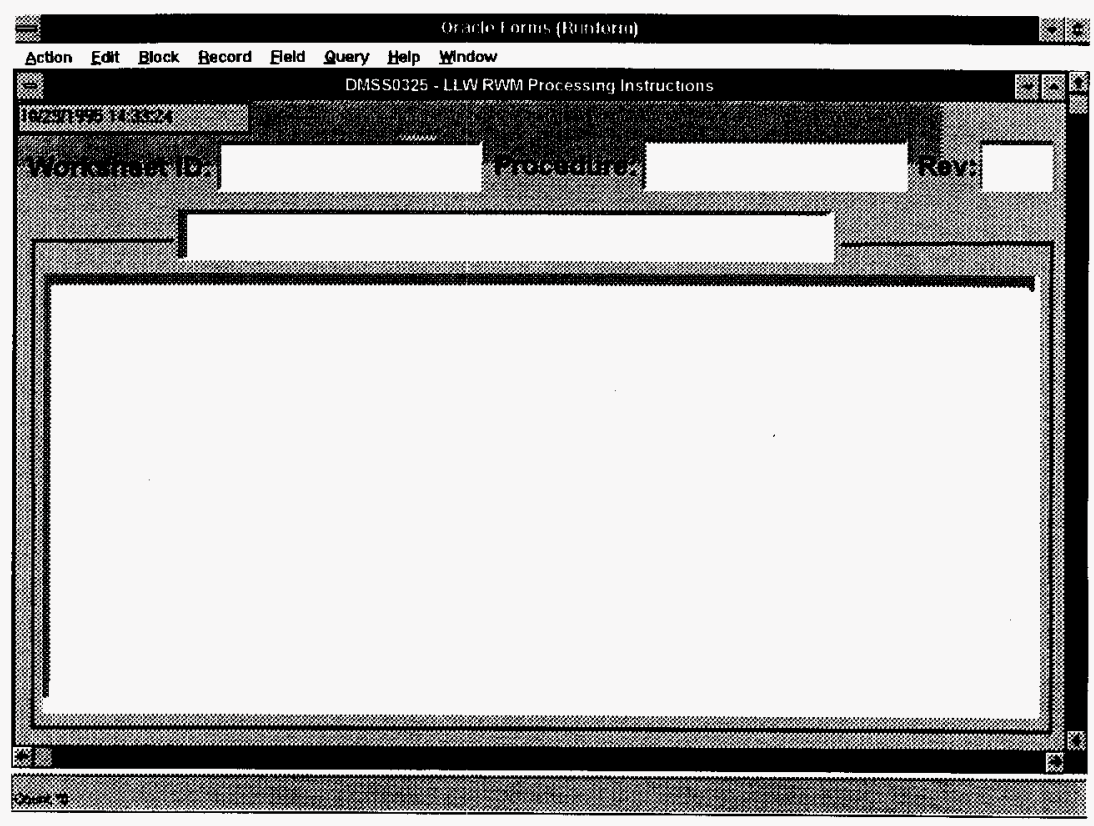

Figure A-23. DMSS0325 LLW RWM Processing Instructions Screen. 
WHC-SD-W026-SDD-001, Rev. 2

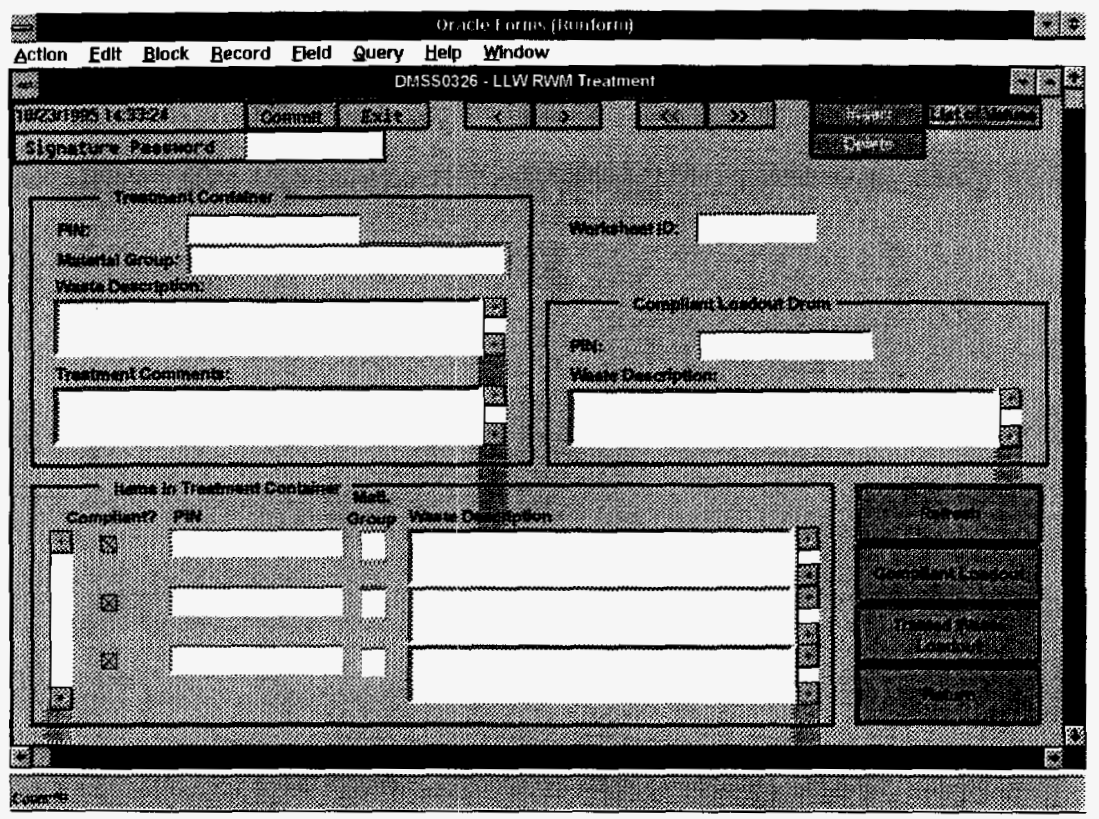

Figure A-24. DMSS0326 LLW RWM Treatment Screen. 
WHC-SD-W026-SDD-001, Rev. 2

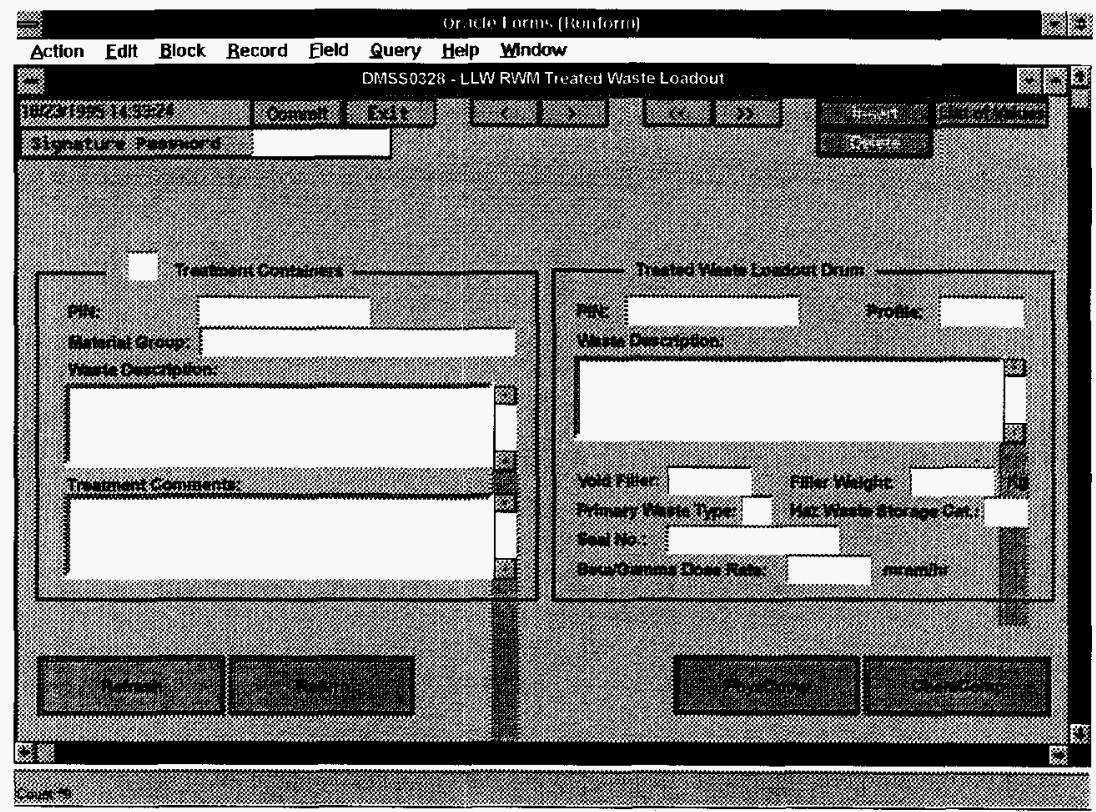

Figure A-25. DMSS0328 LLW RWM Treated Waste Loadout Screen. 
WHC-SD-W026-SDD-001, Rev. 2

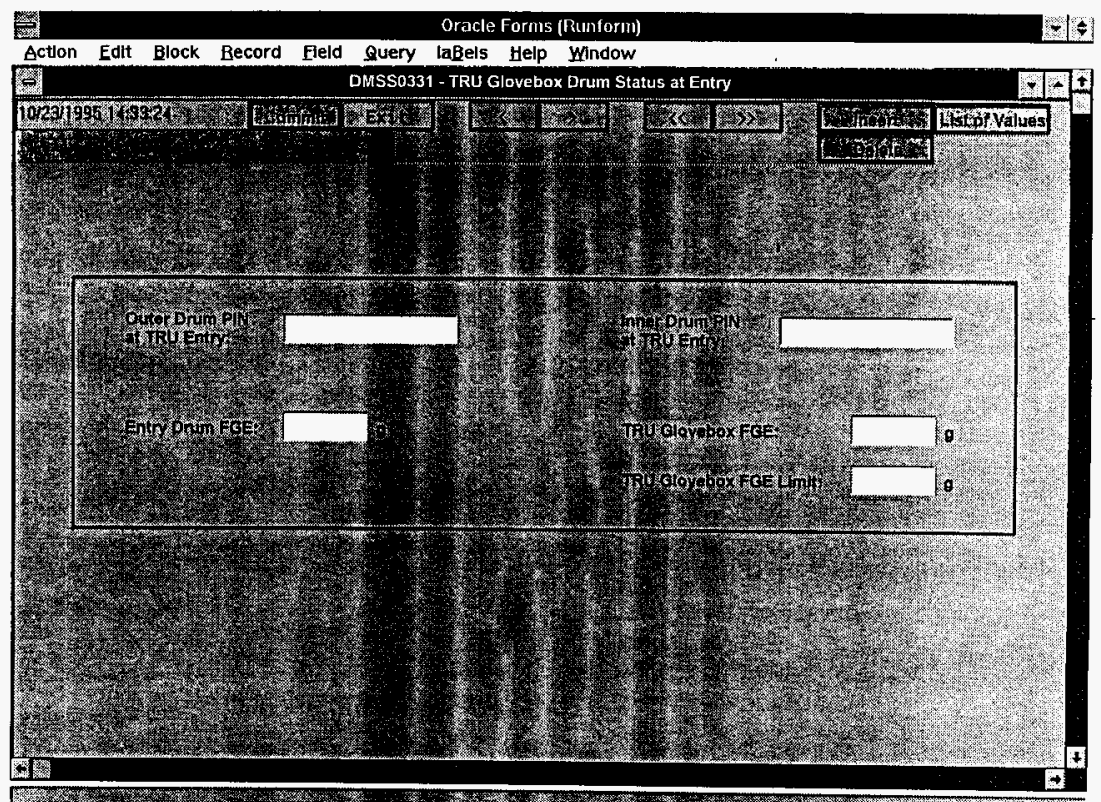

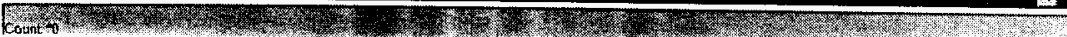

Figure A-26. DMSS0331 TRU Glovebox Drum Status at Entry Screen. 


$$
\text { WHC-SD-W026-SDD-001, Rev. } 2
$$

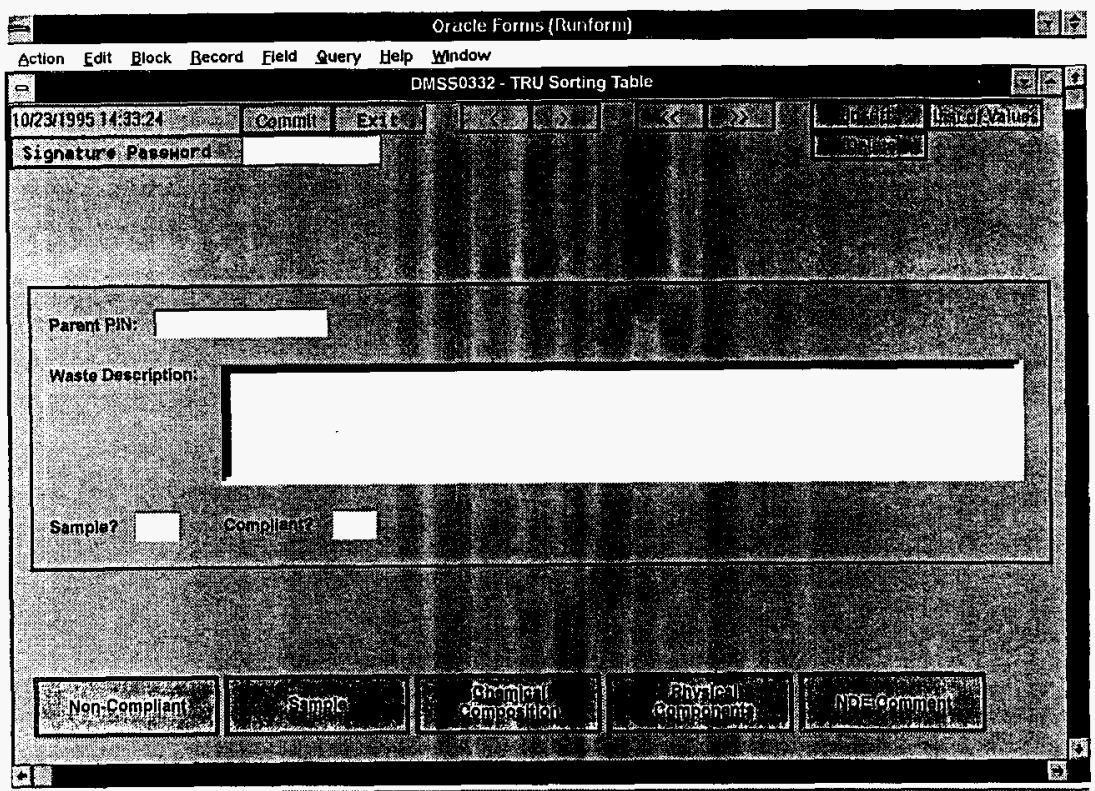

6oun 6 r

Figure A-27. DMSS0332 TRU Sorting Table Screen. 


$$
\text { WHC-SD-W026-SDD-001, Rev. } 2
$$

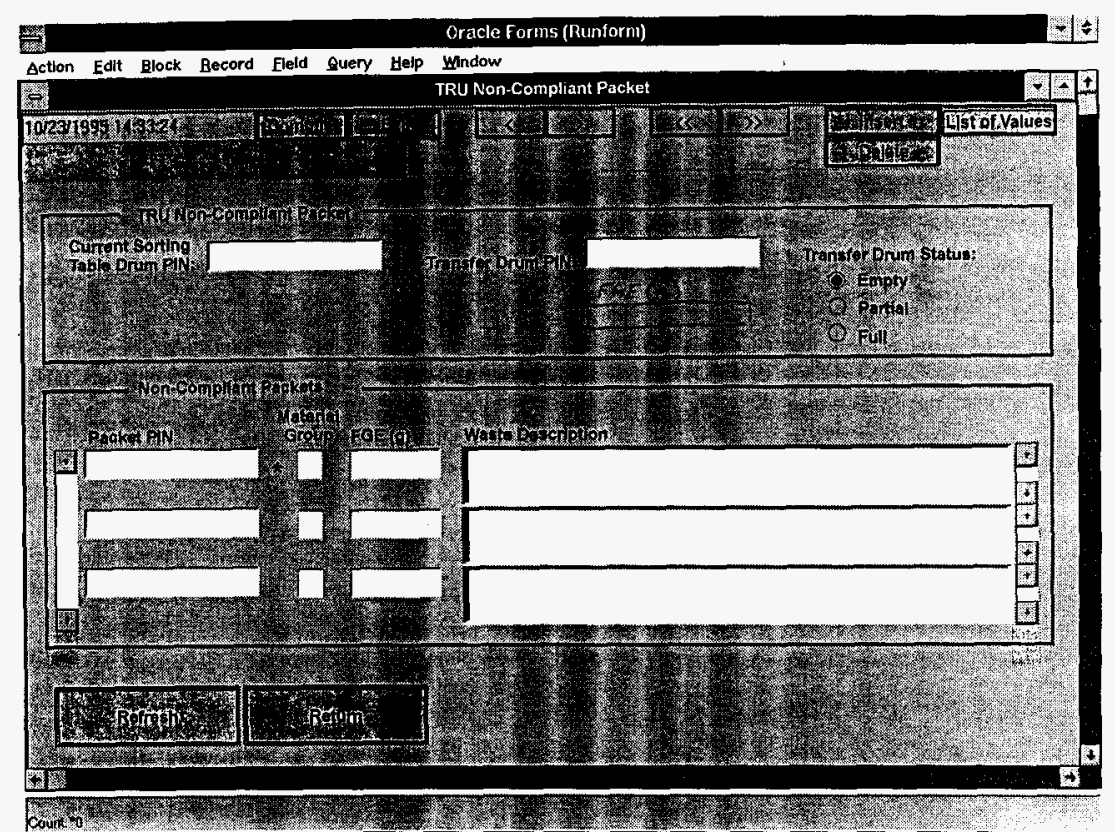

Figure A-28. DMSS0332 TRU Sorting Table Screen TRU Non-Compli iant Packet Pop-Up. 
WHC-SD-W026-SDD-001, Rev. 2

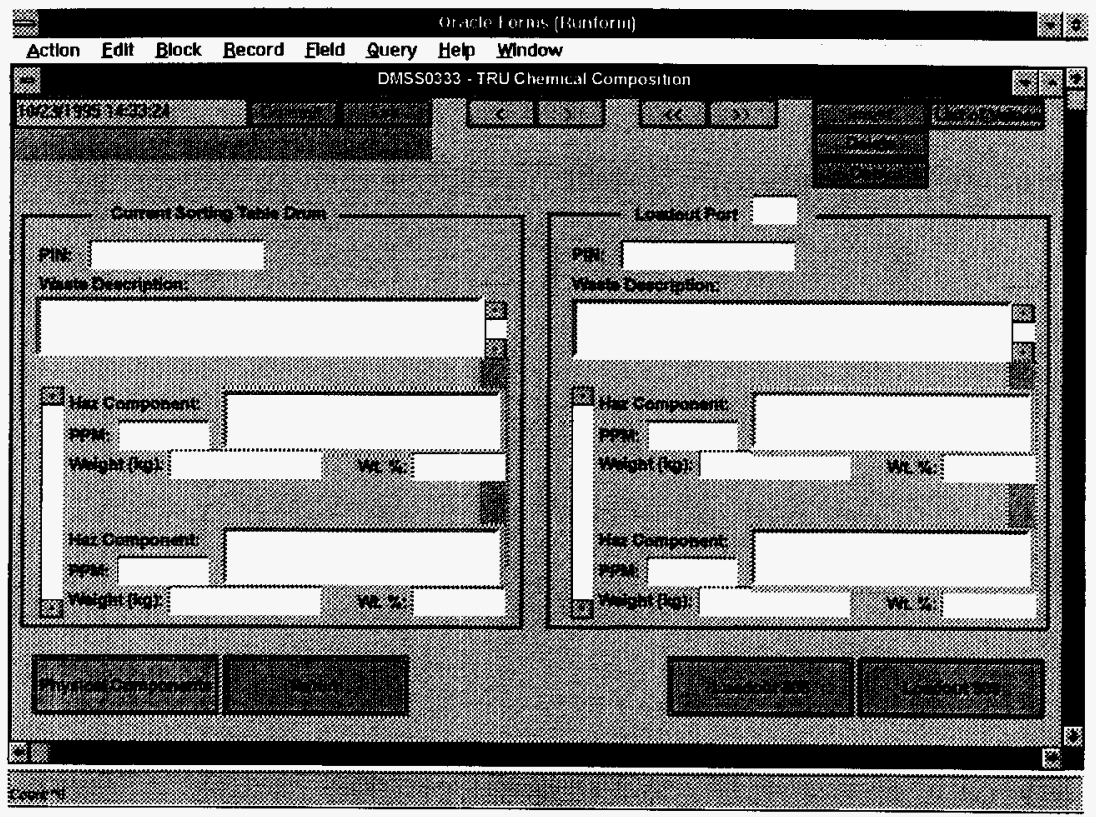

Figure A-29. DMSS0333 TRU Chemical Composition Screen. 
WHC-SD-W026-SDD-001, Rev. 2

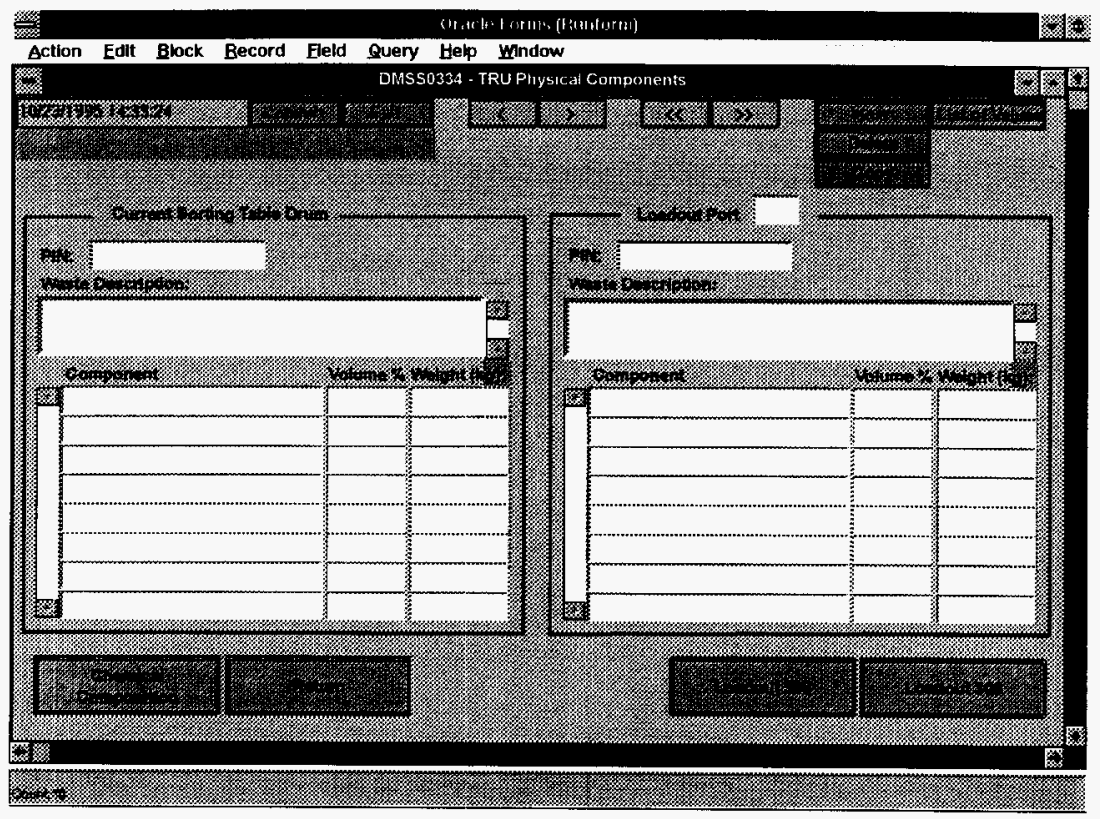

Figure A-30. DMSS0334 TRU Physical Components Screen. 


$$
\text { WHC-SD-W026-SDD-001, Rev. } 2
$$

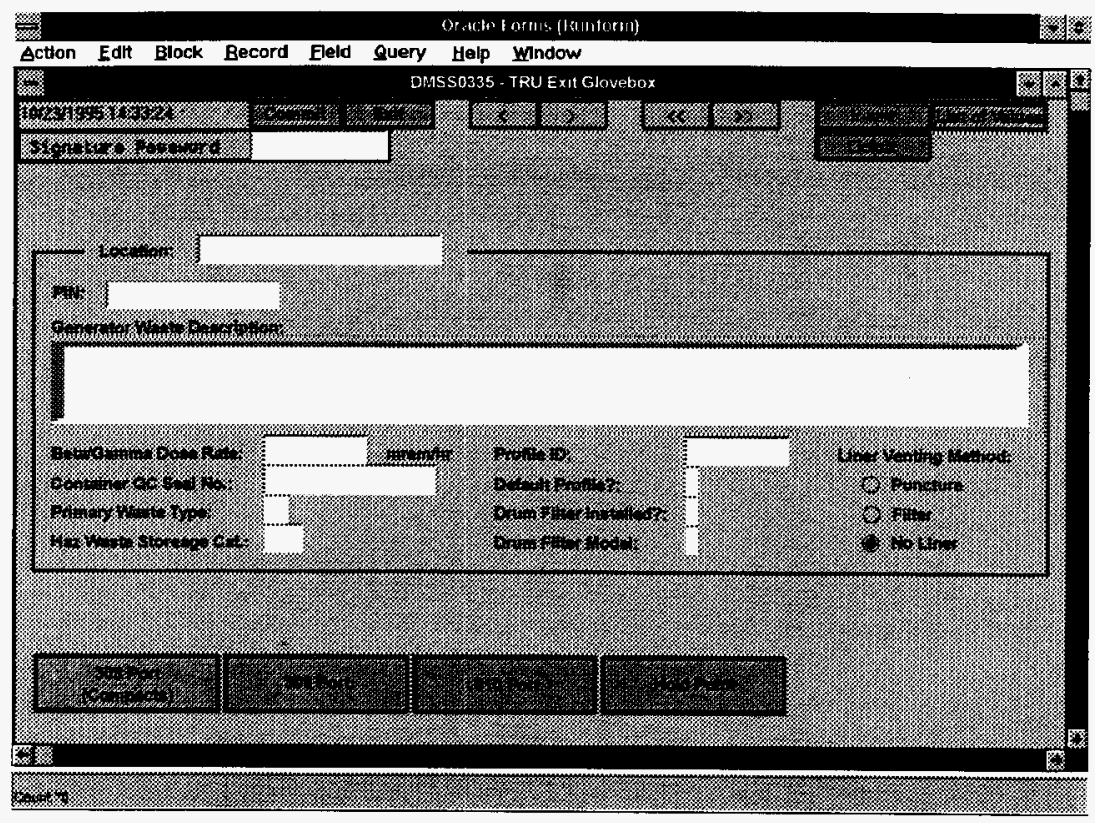

Figure A-31. DMSS0335 TRU Exit Glovebox Screen. 


$$
\text { WHC-SD-W026-SDD-001, Rev. } 2
$$

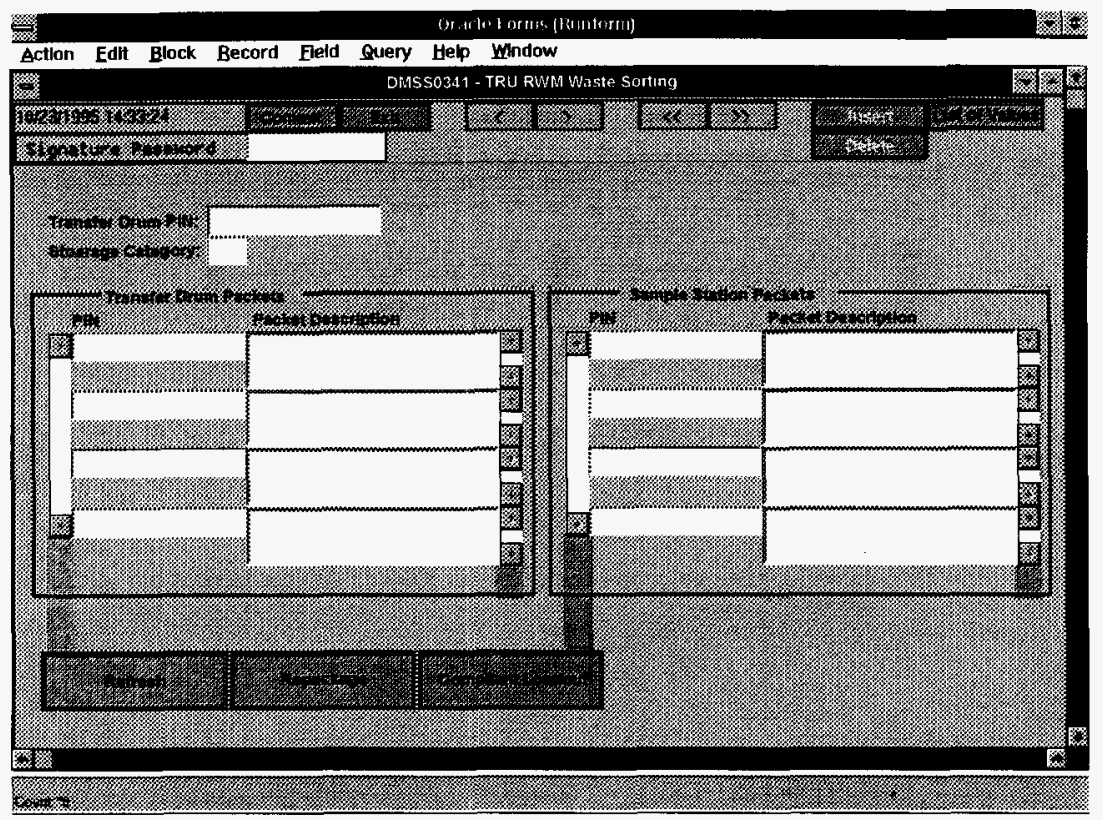

Figure A-32. DMSS0341 TRU RWM Waste Sorting Screen. 
WHC-SD-W026-SDD-001, Rev. 2

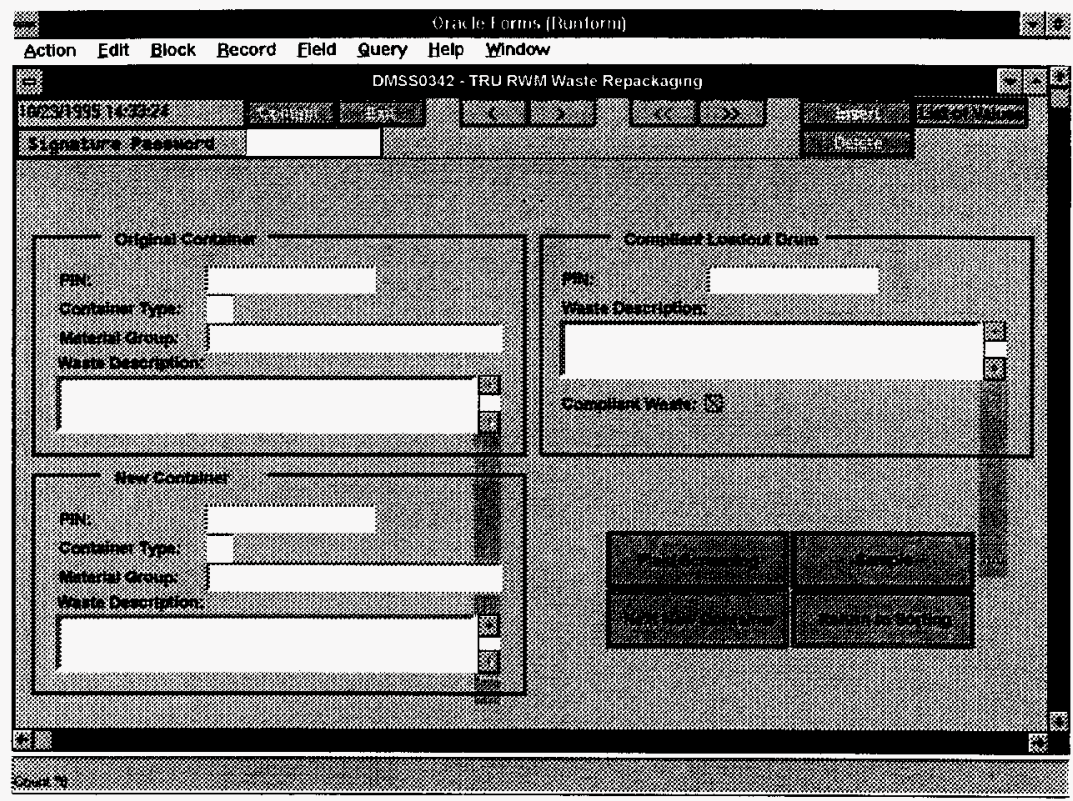

Figure A-33. DMSS0342 TRU RWM Waste Repackaging Screen. 
WHC-SD-W026-SDD-001, Rev. 2

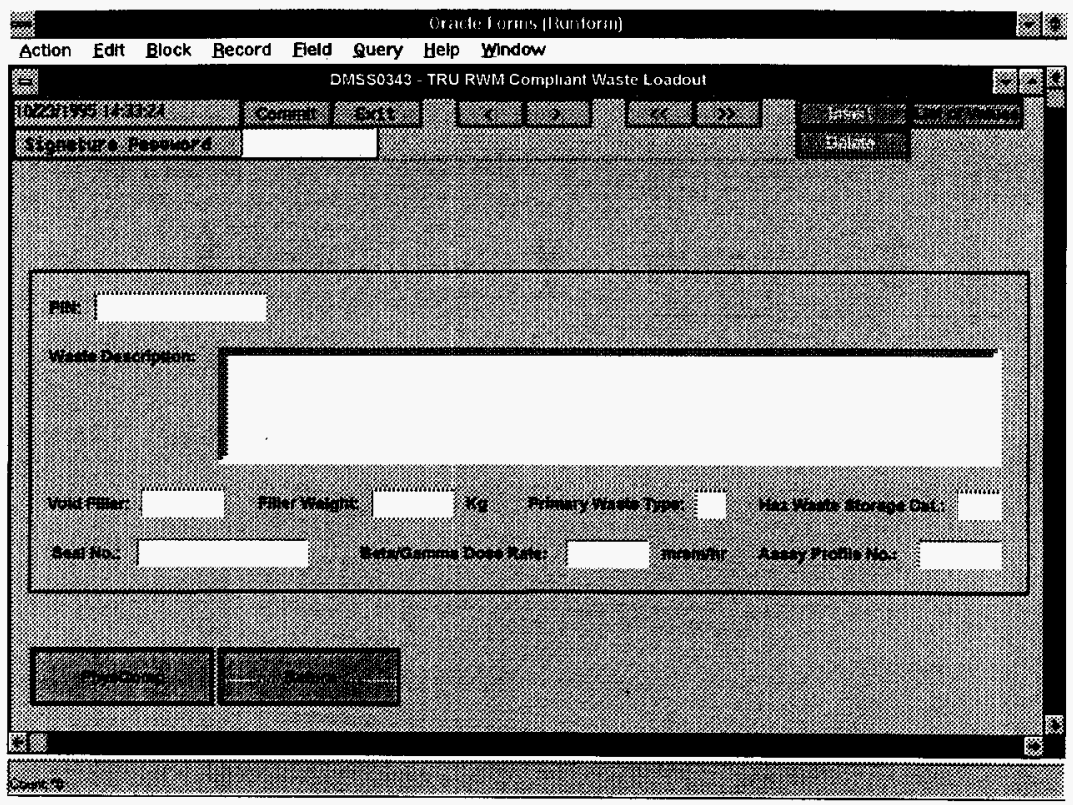

Figure A-34. DMSS0343 TRU RWM Compliant Waste Loadout Screen. 
WHC-SD-W026-SDD-001, Rev. 2

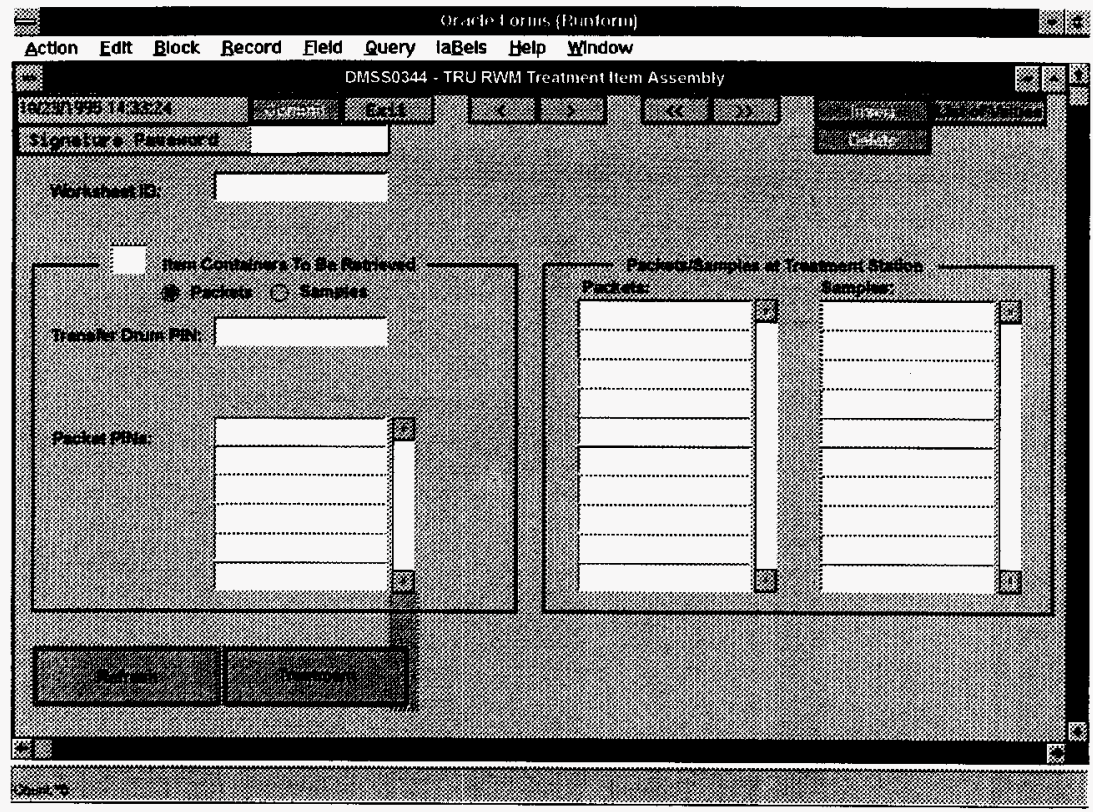

Figure A-35. DMSS0344 TRU RWM Treatment Item Assembly Screen

('Packets' Selected). 
WHC-SD-W026-SDD-001, Rev. 2

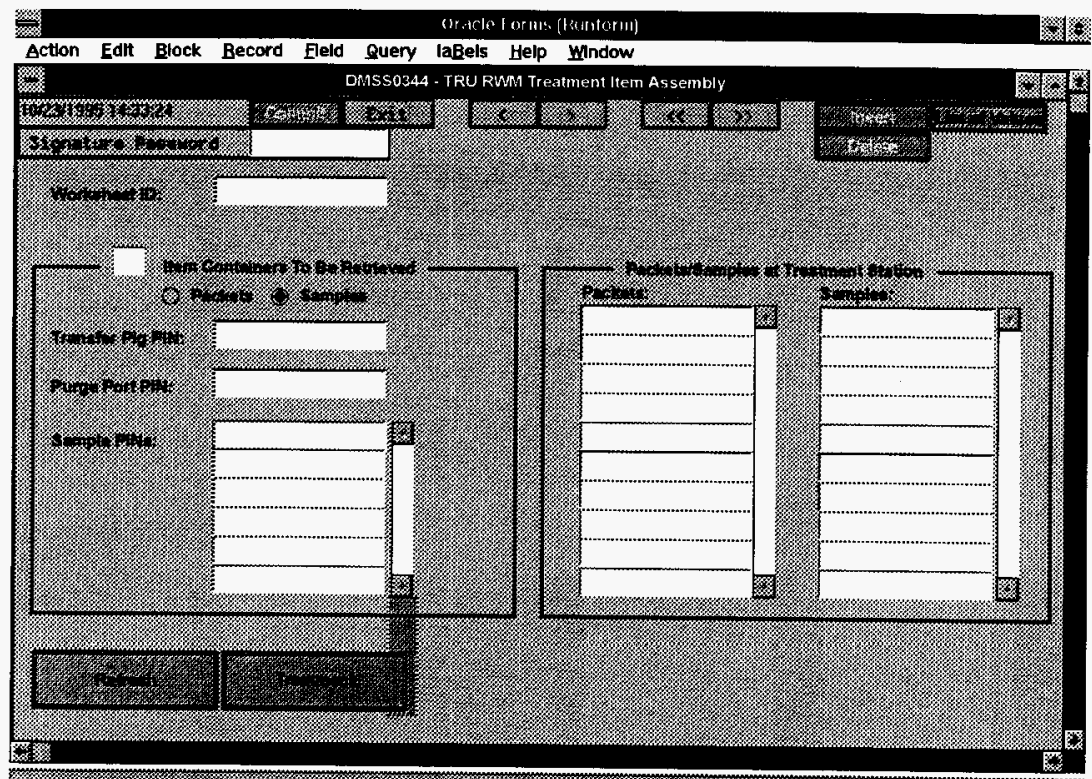

2.

Figure A-36. DMSS0344 TRU RWM Treatment Item Assembly Screen

('Samples' Selected). 
WHC-SD-W026-SDD-001, Rev. 2

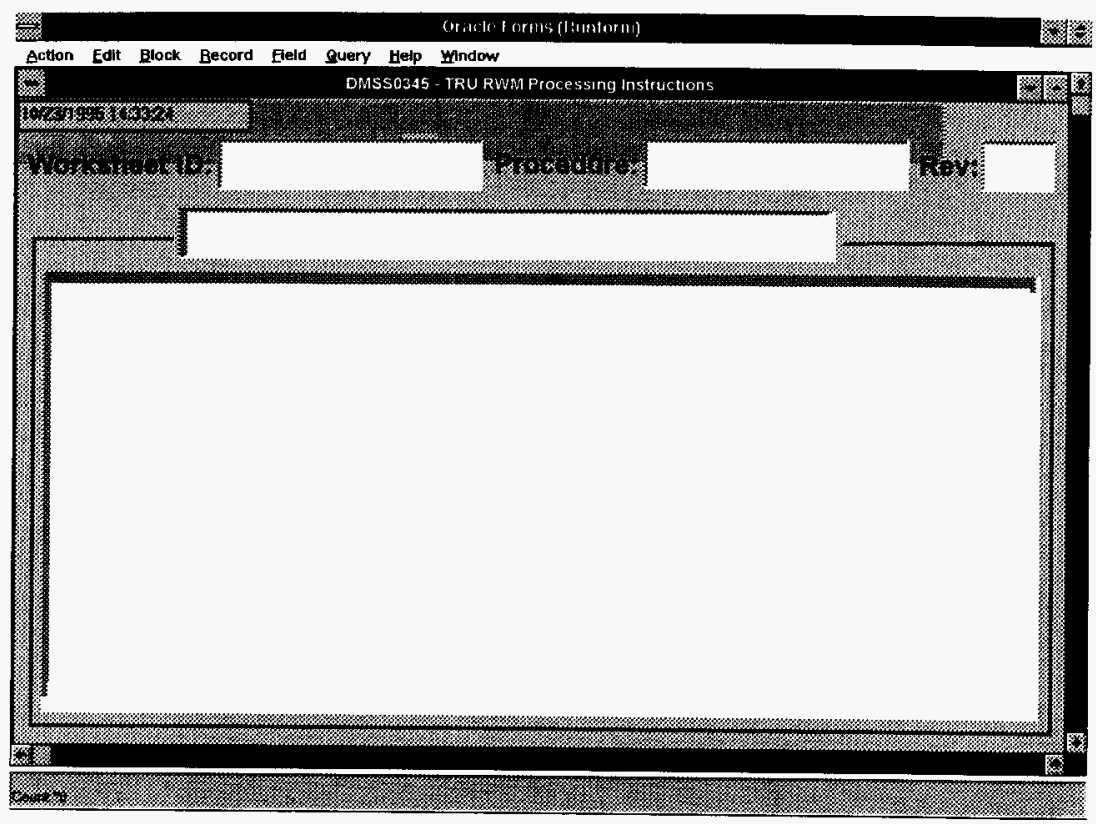

Figure A-37. DMSS0345 TRU RWM Processing Instructions Screen. 


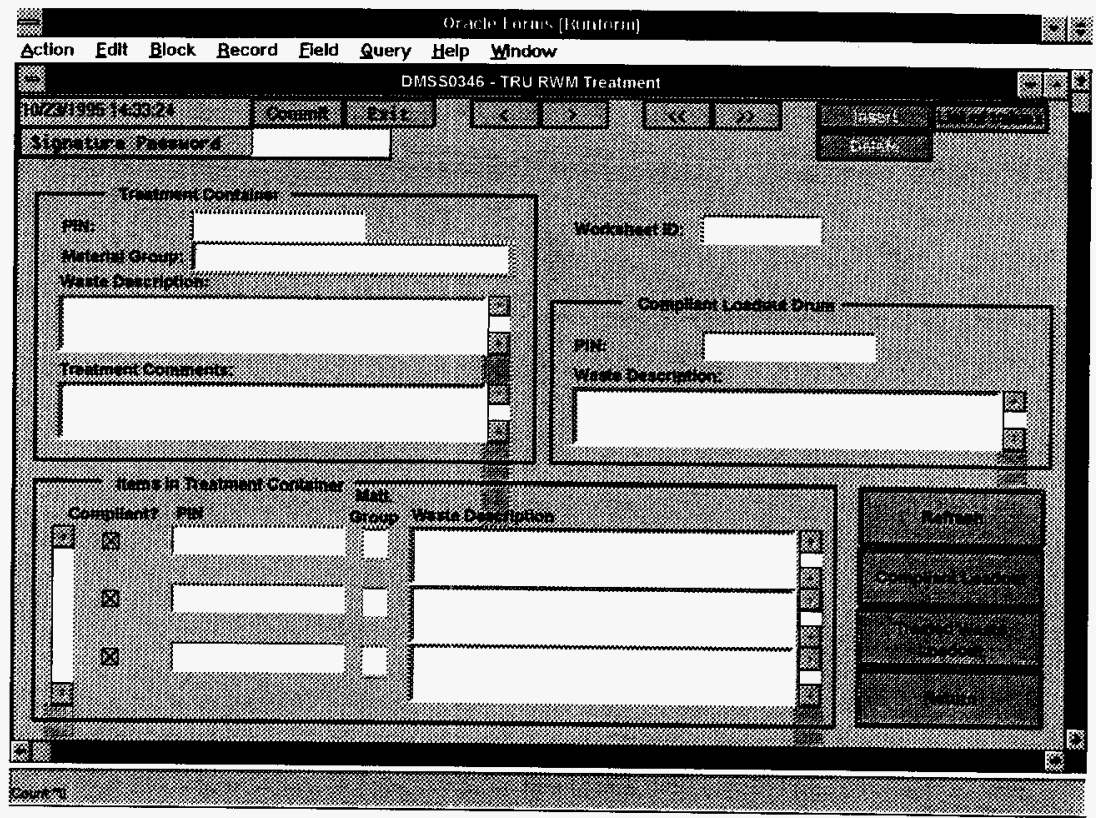

Figure A-38. DMSS0346 TRU RWM Treatment Screen. 
WHC-SD-W026-SDD-001, Rev. 2

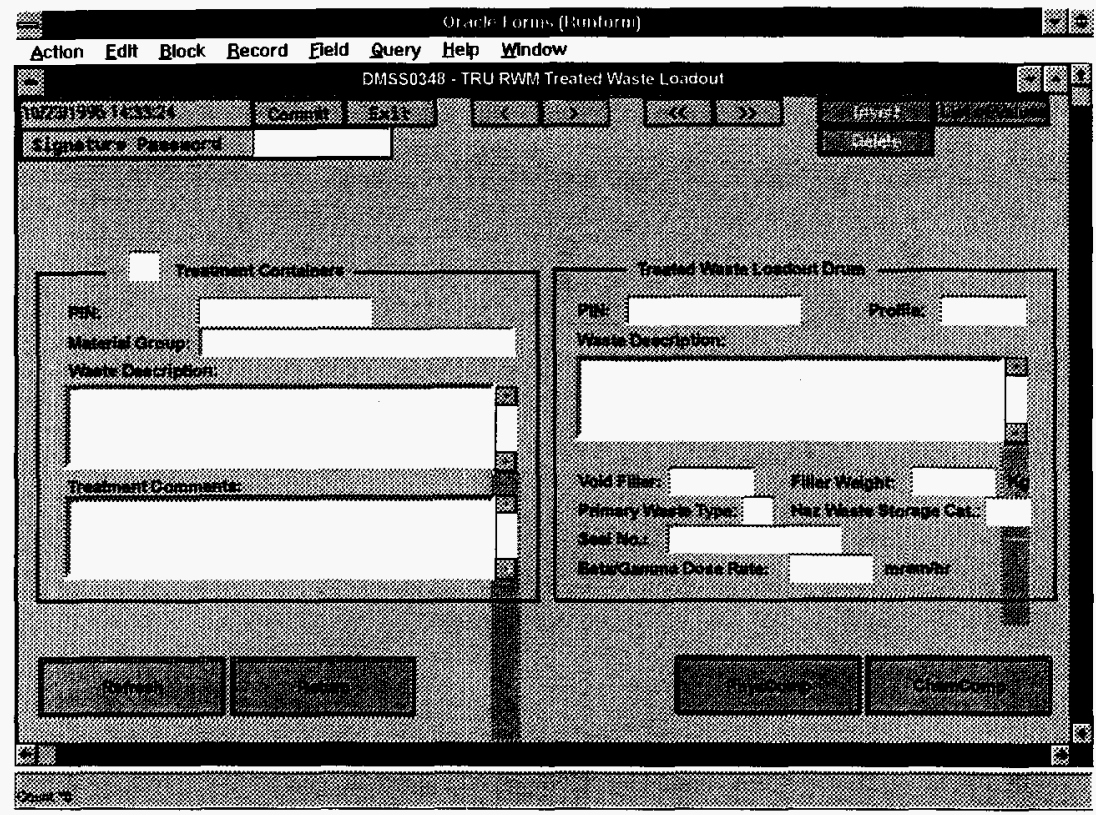

Figure A-39. DMSS0348 TRU RWM Treated Waste Loadout Screen. 


\section{WHC-SD-W026-SDD-001, Rev. 2}

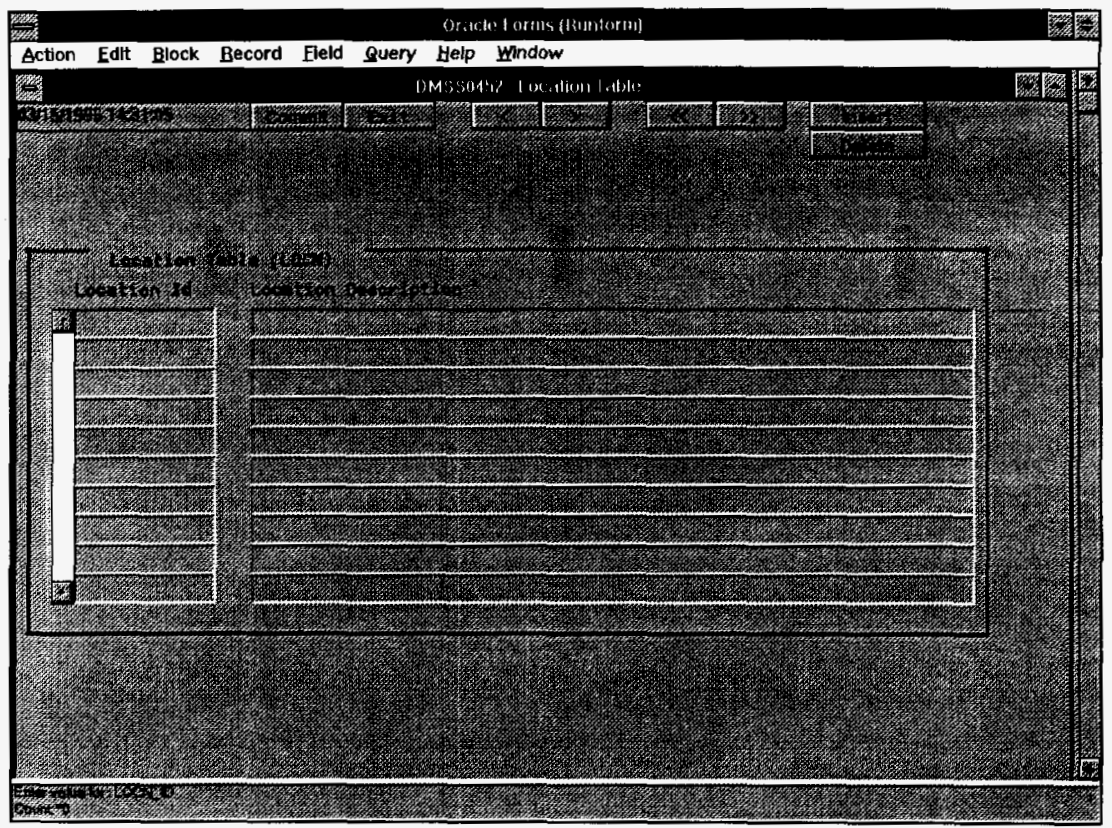

Figure A-40. DMSS0452 Location Table Screen. 
WHC-SD-W026-SDD-001, Rev. 2

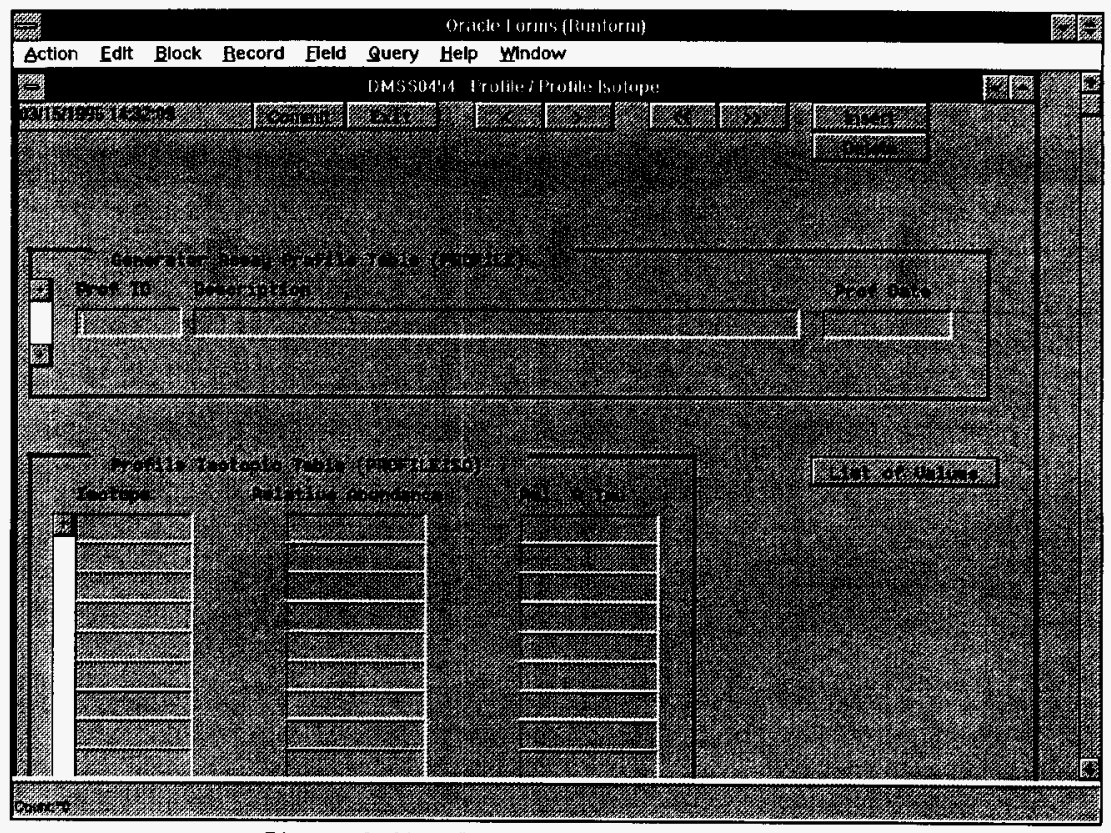

Figure A-41. DMSS0454 Profile/Profile Isotope Screen. 
WHC-SD-W026-SDD-001, Rev. 2

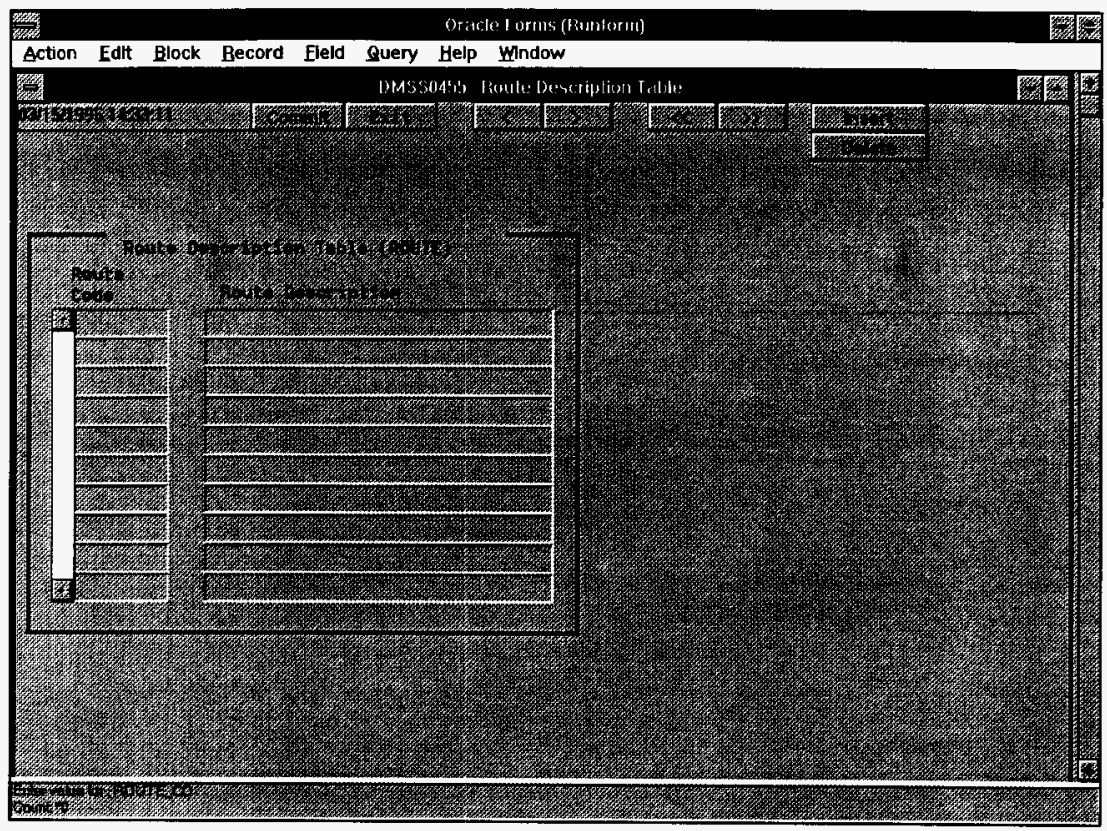

Figure A-42. DMSS0455 Route Description Table Screen. 
WHC-SD-W026-SDD-001, Rev. 2

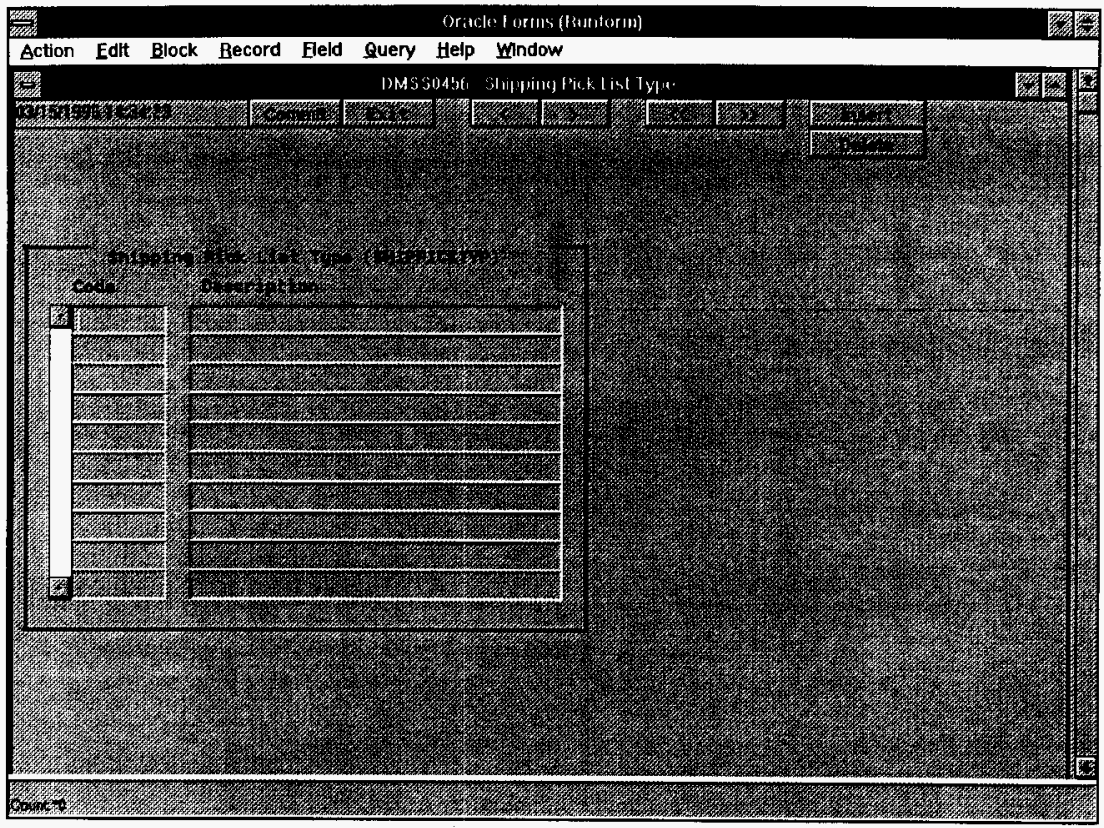

Figure A-43. DMSS0456 Shipping Pick List Type Screen. 
WHC-SD-W026-SDD-001, Rev. 2

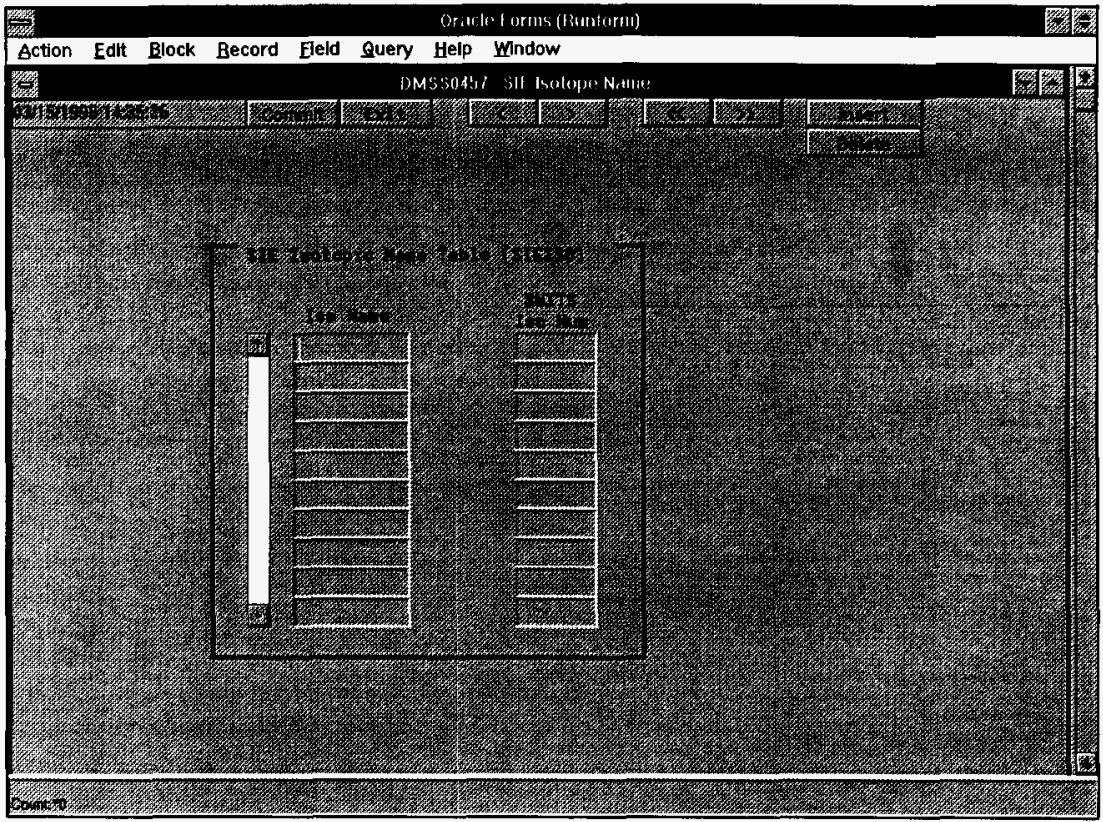

Figure A-44. DMSS0457 SIE Isotope Name Screen. 
WHC-SD-W026-SDD-001, Rev. 2

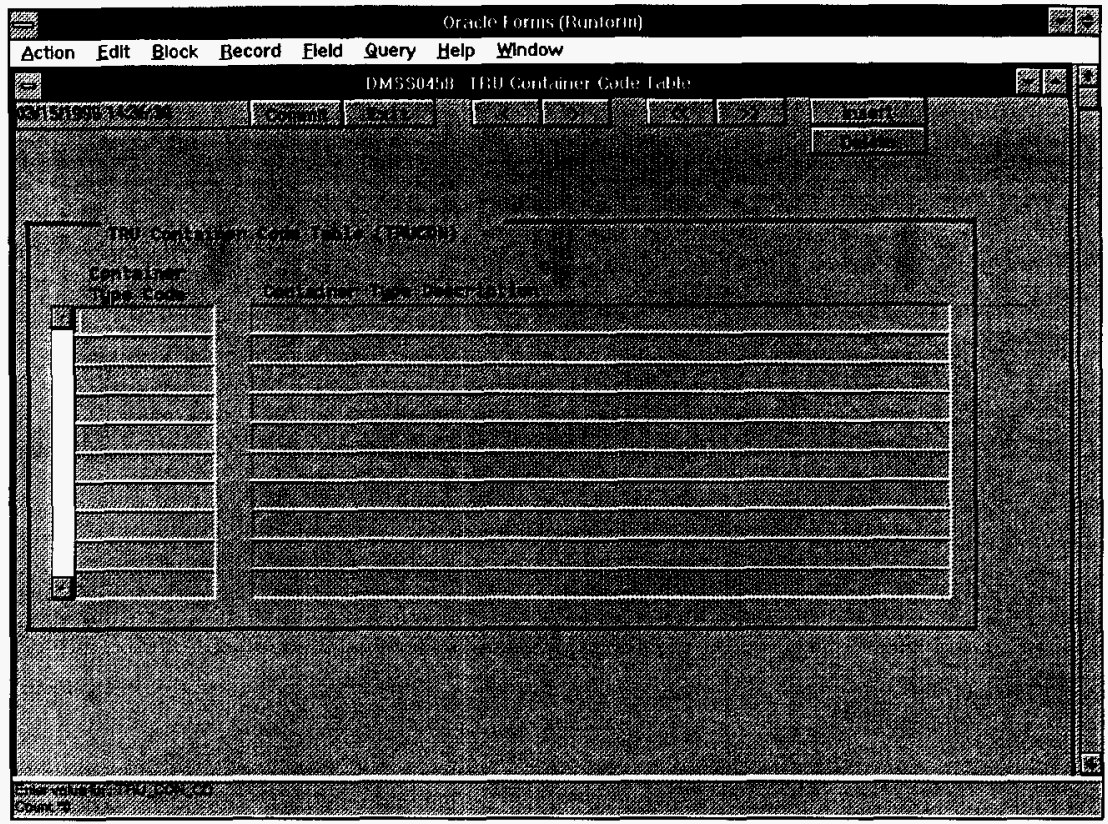

Figure A-45. DMSS0458 TRU Container Code Table Screen. 
WHC-SD-W026-SDD-001, Rev. 2

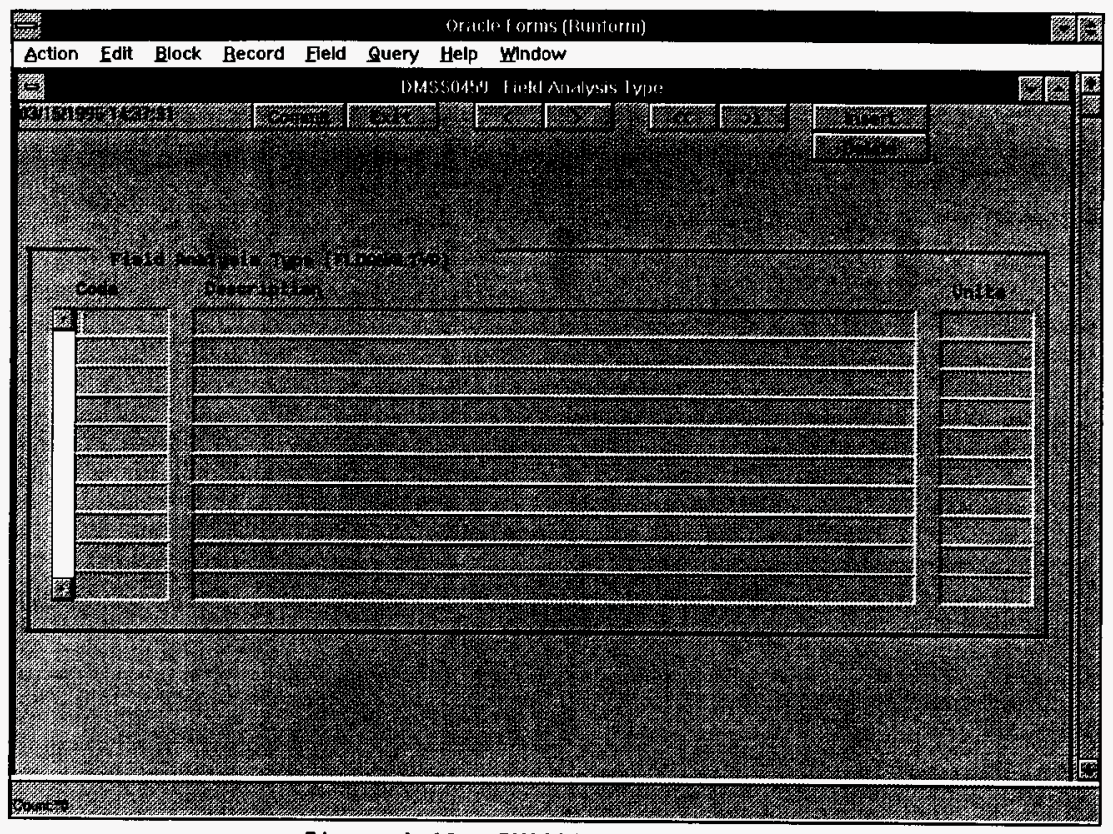

Figure A-46, DMSS0459 Field Analysis Type Screen. 
WHC-SD-W026-SDD-001, Rev. 2

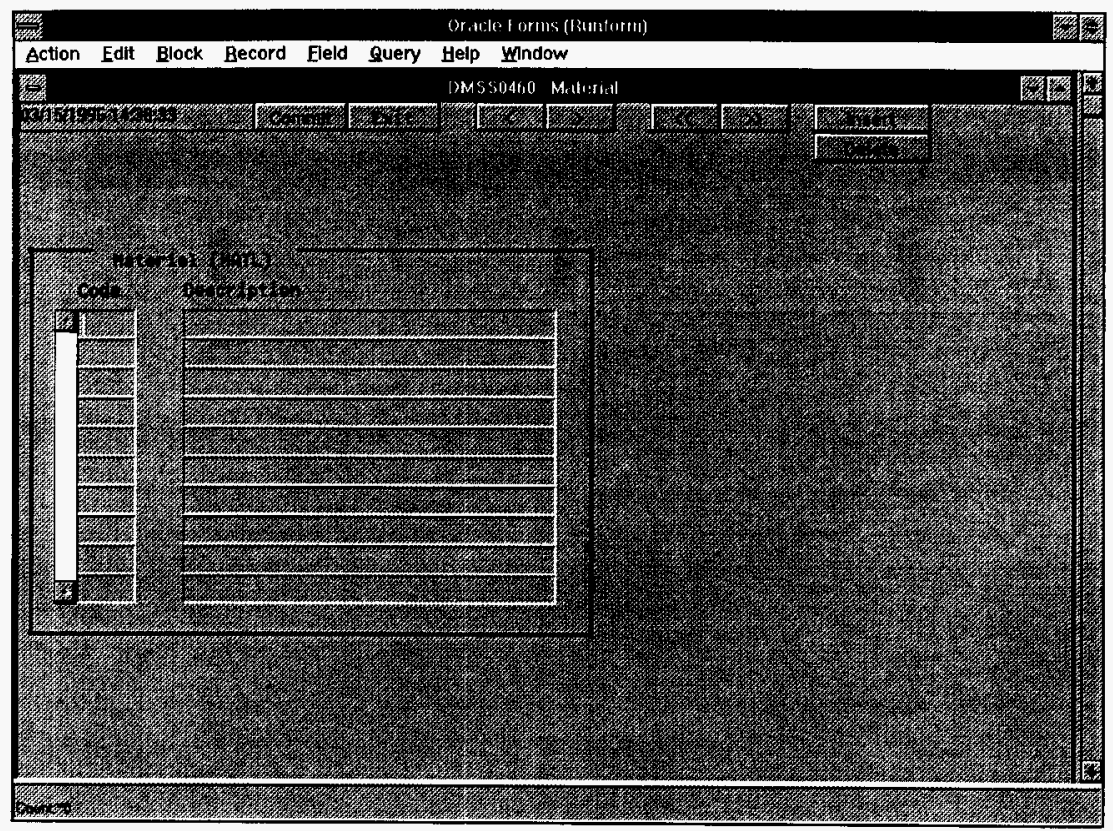

Figure A-47. DMSS0460 Material Screen. 


$$
\text { WHC-SD-W026-SDD-001, Rev. } 2
$$

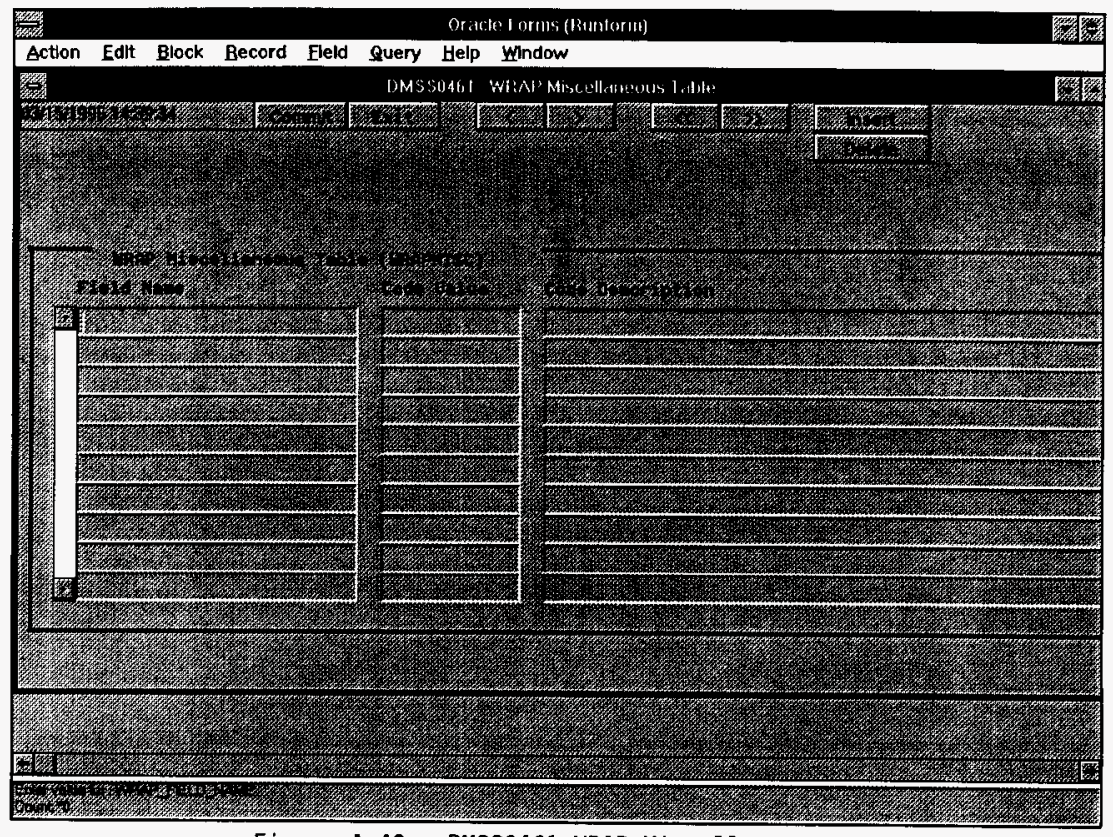

Figure A-48. DMSS0461 WRAP Miscellaneous Table Screen. 
WHC-SD-W026-SDD-001, Rev. 2

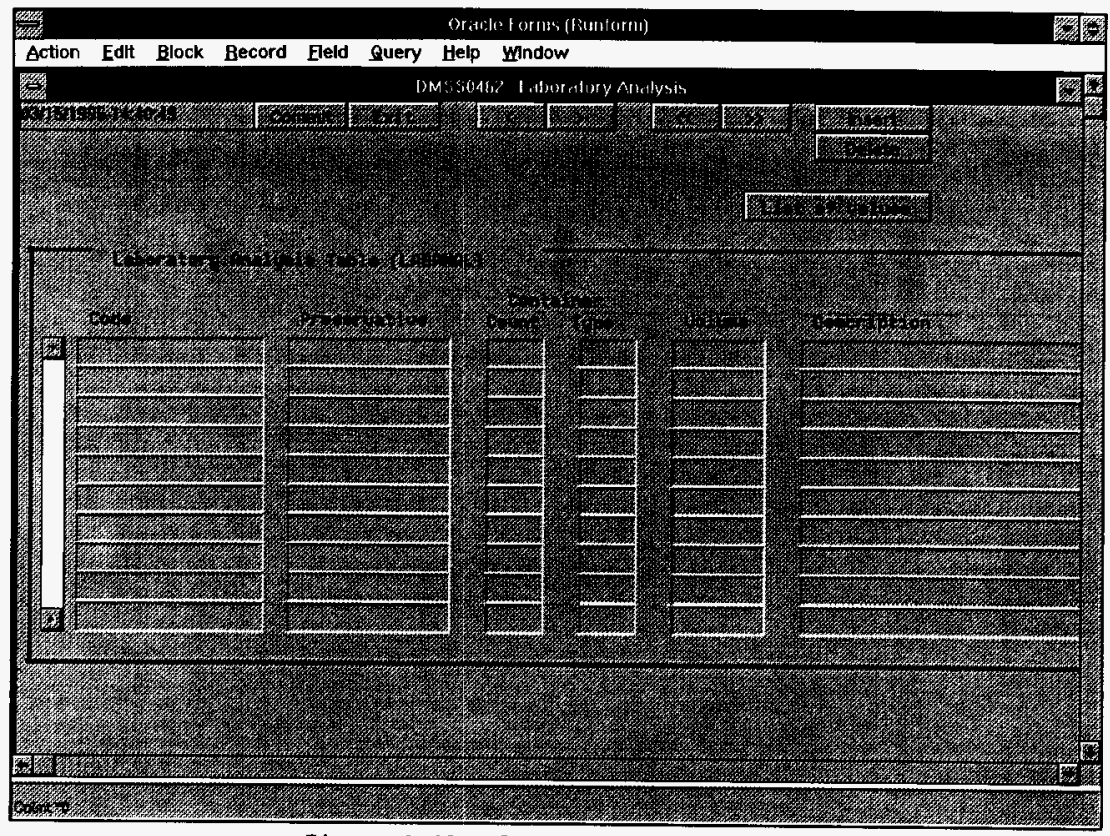

Figure A-49. DMSSO462 Laboratory Analys is Screen. 


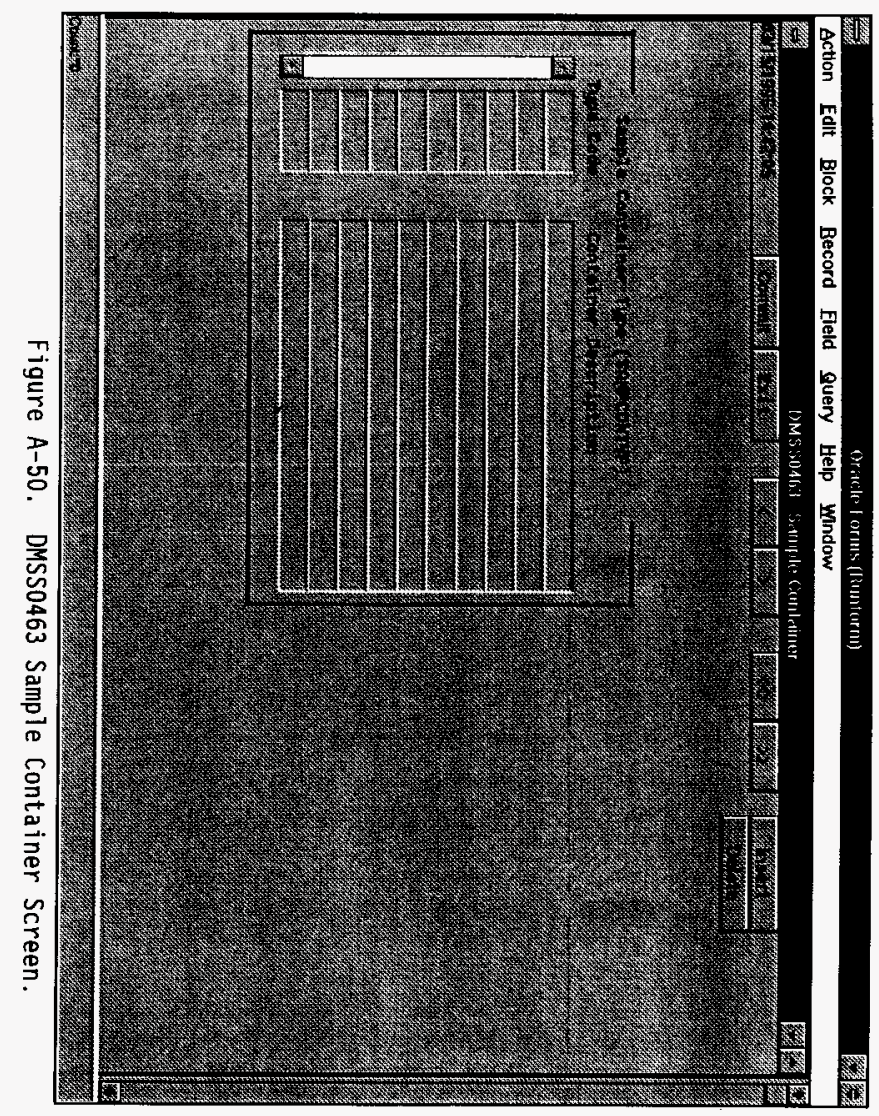

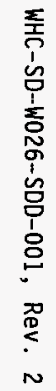


WHC-SD-W026-SDD-001, Rev. 2

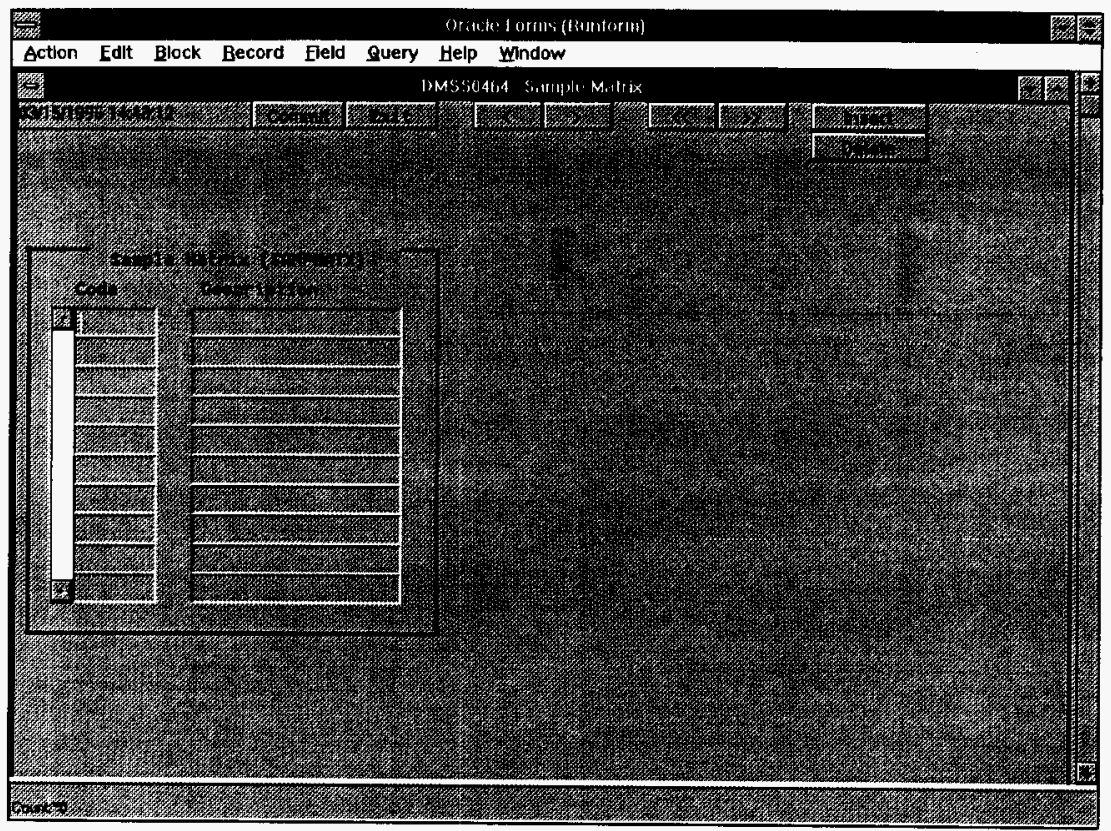

Figure A-51. DMSS0464 Sample Matrix Screen. 


$$
\text { WHC-SD-W026-SDD-001, Rev. } 2
$$

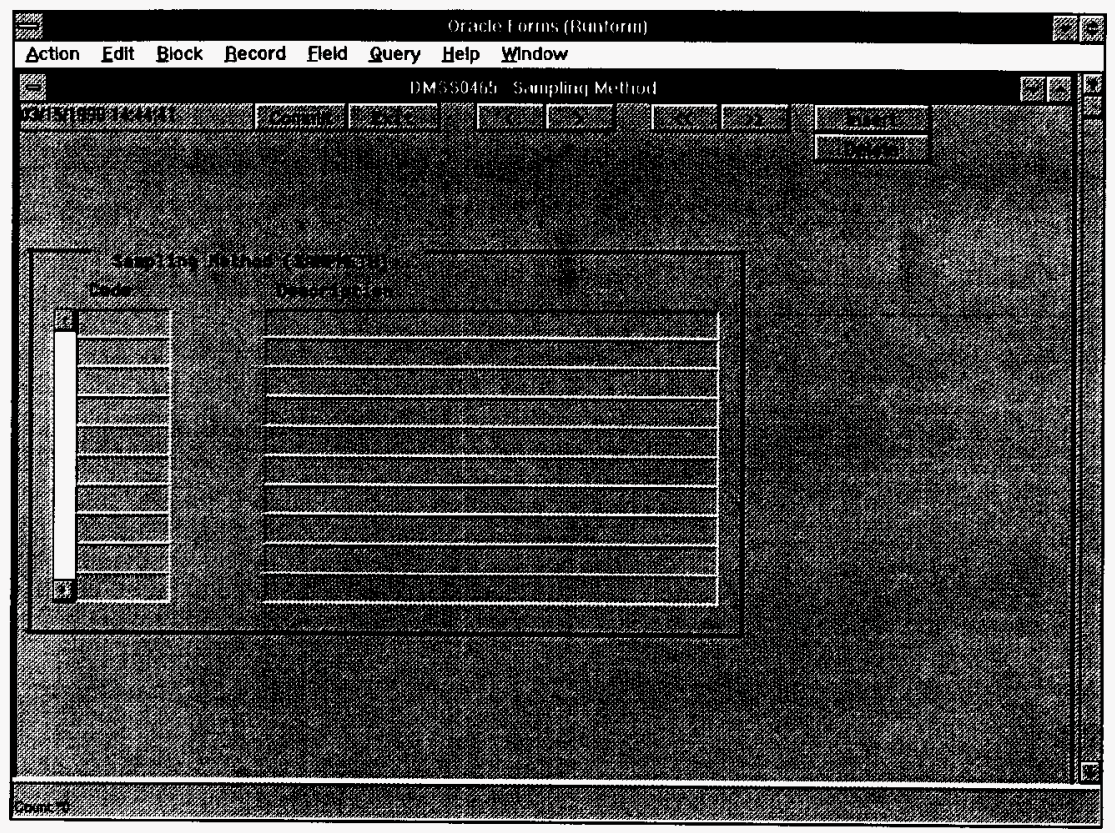

Figure A-52. DMSS0465 Sampling Method Screen. 


\section{WHC-SD-W026-SDD-001, Rev. 2}

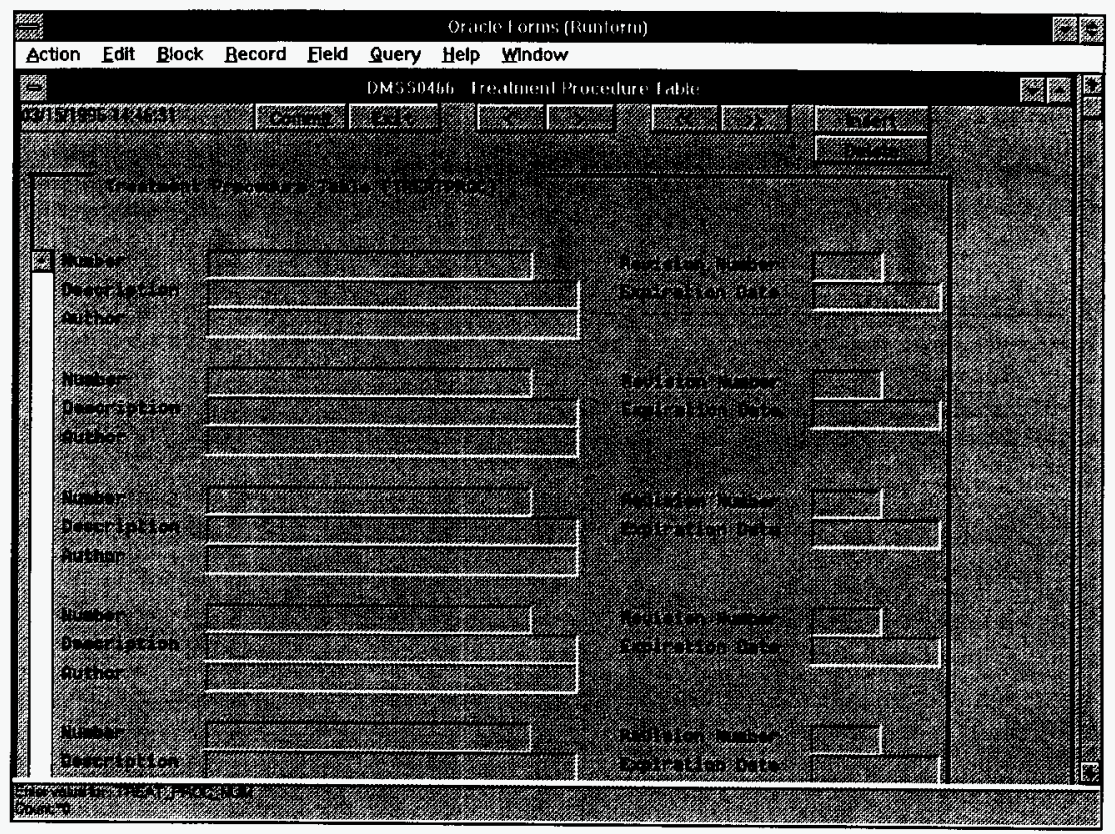

Figure A-53. DMSS0466 Treatment Procedure Table Screen. 


$$
\text { WHC-SD-W026-SDD-001, Rev. } 2
$$

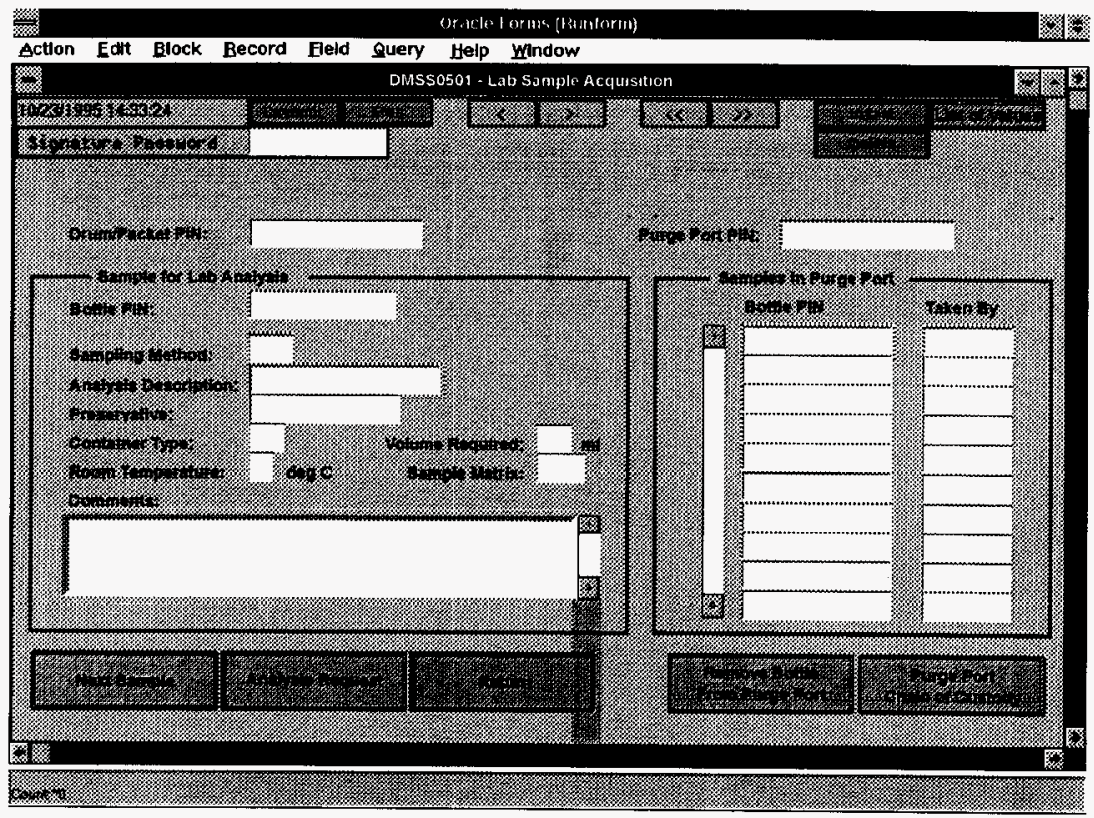

Figure A-54. DMSS0501 Lab Sample Acquisition Screen. 
WHC-SD-W026-SDD-001, Rev. 2

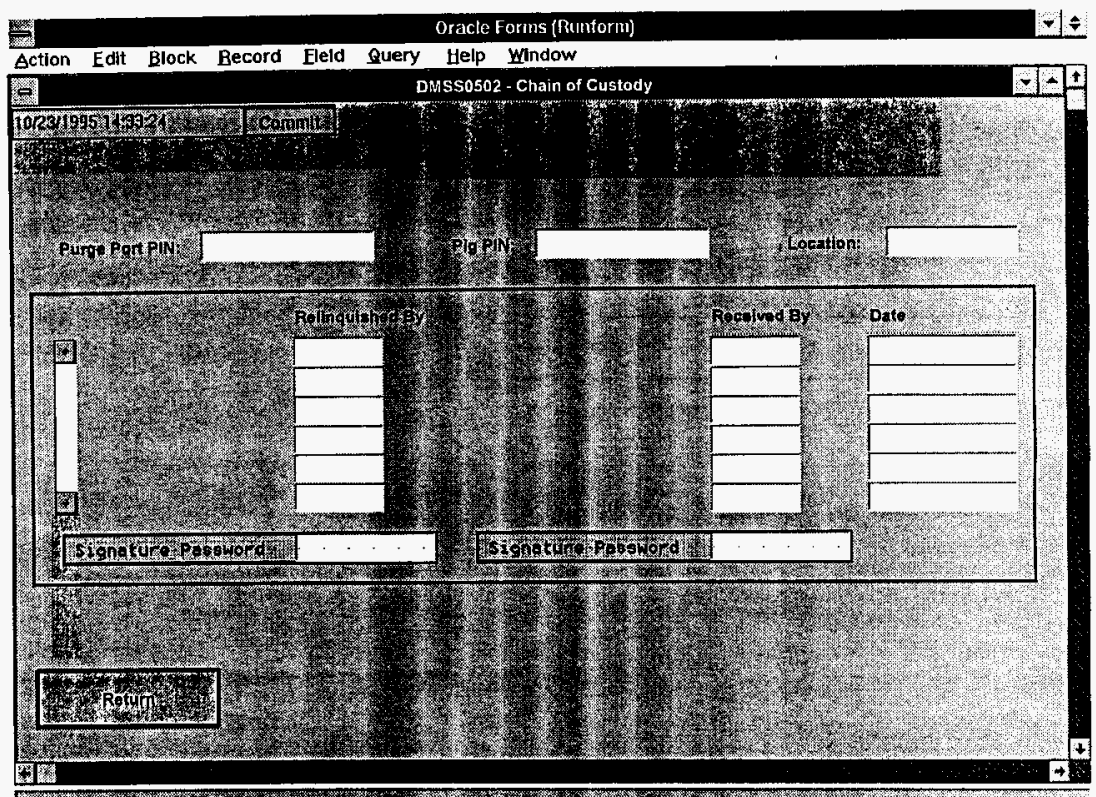

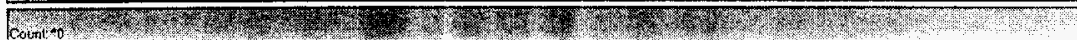

Figure A-55. DMSS0502 Chain of Custody Screen. 


$$
\text { WHC-SD-W026-SDD-001, Rev. } 2
$$

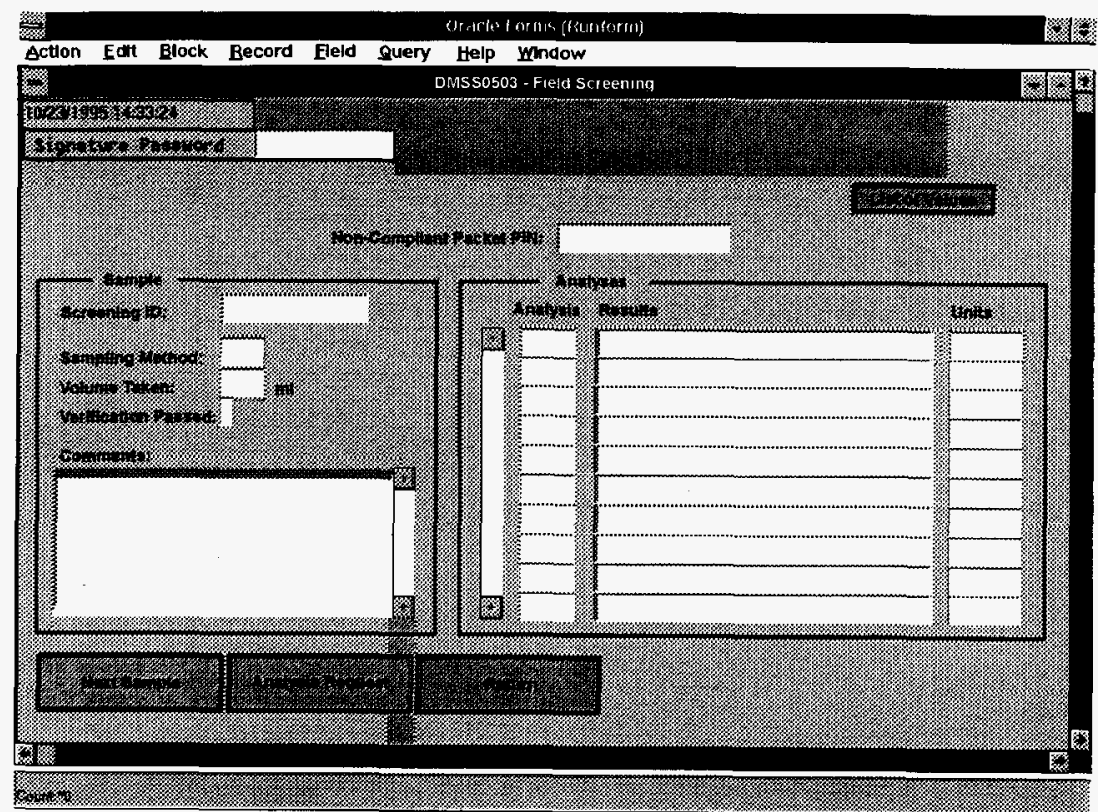

Figure A-56. DMSS0503 Field Screening Screen. 
WHC-SD-W026-SDD-001, Rev. 2

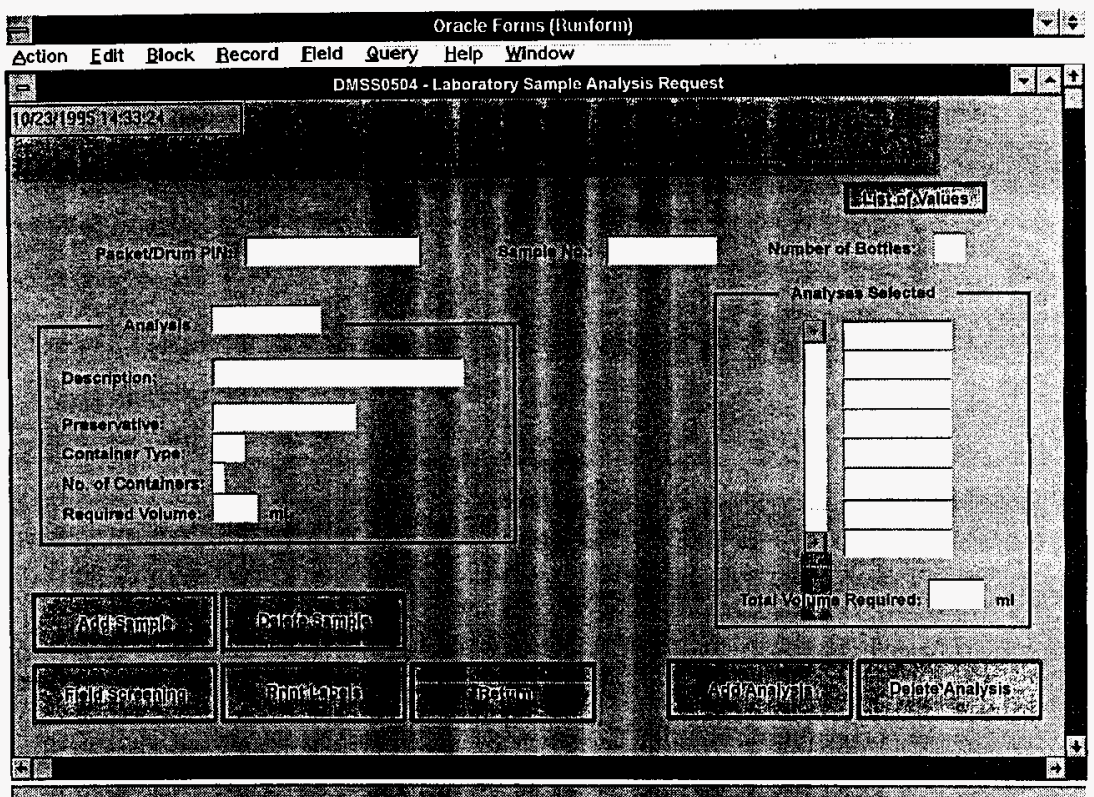

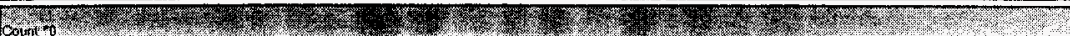

Figure A-57. DMSS0504 Laboratory Sample Analysis Request Screen. 


$$
\text { WHC-SD-W026-SDD-001, Rev. } 2
$$

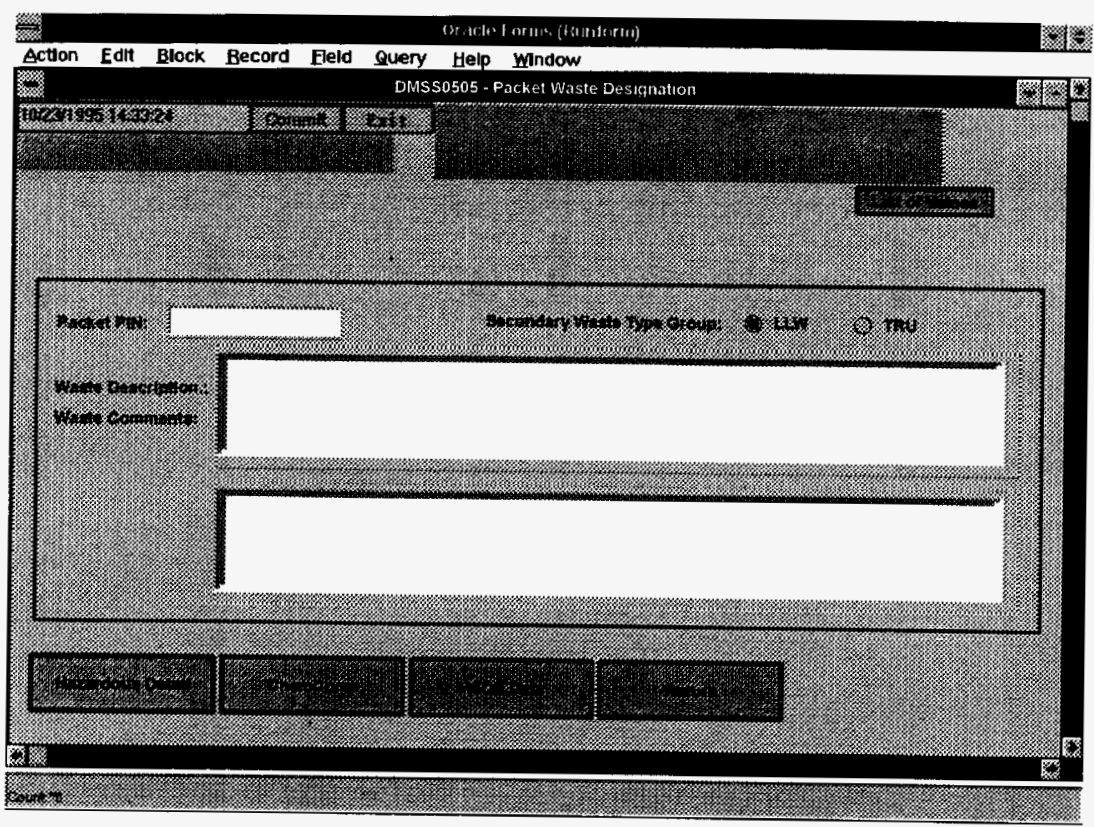

Figure A-58. DMSS0505 Packet Waste Designation Screen. 
WHC-SD-W026-SDD-001, Rev. 2

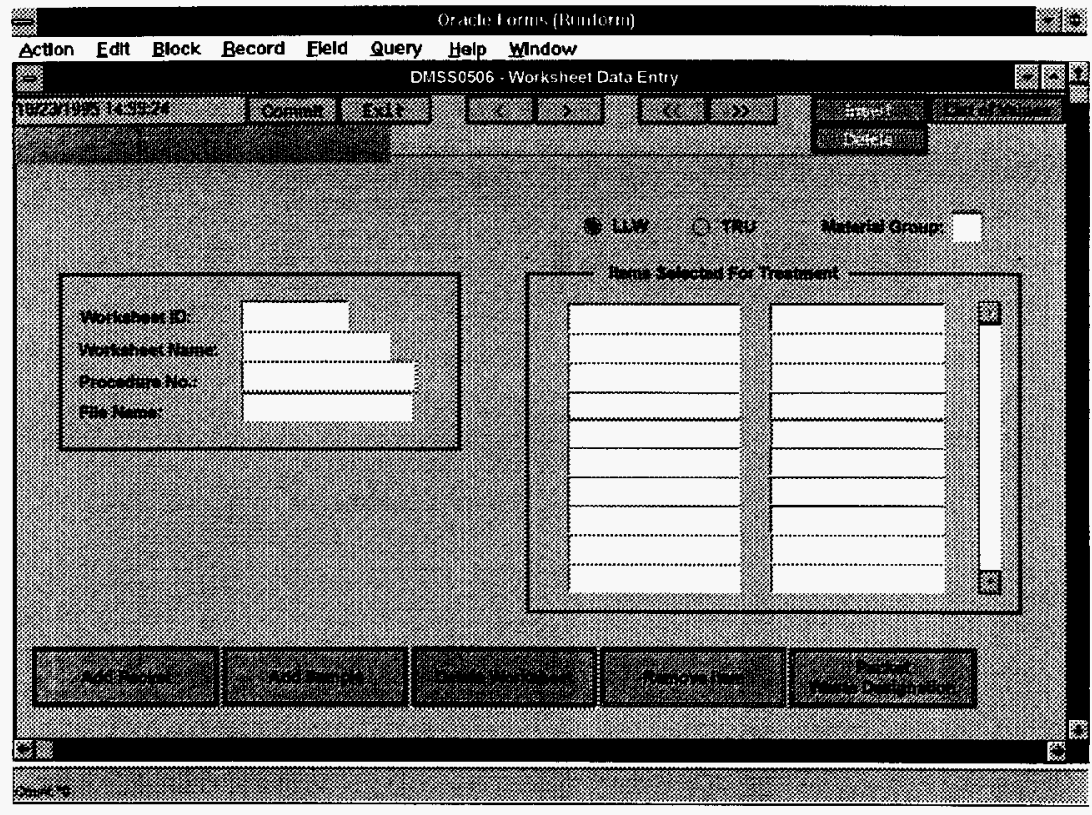

Figure A-59. DMSS0506 Worksheet Data Entry Screen. 
WHC-SD-W026-SDD-001, Rev. 2

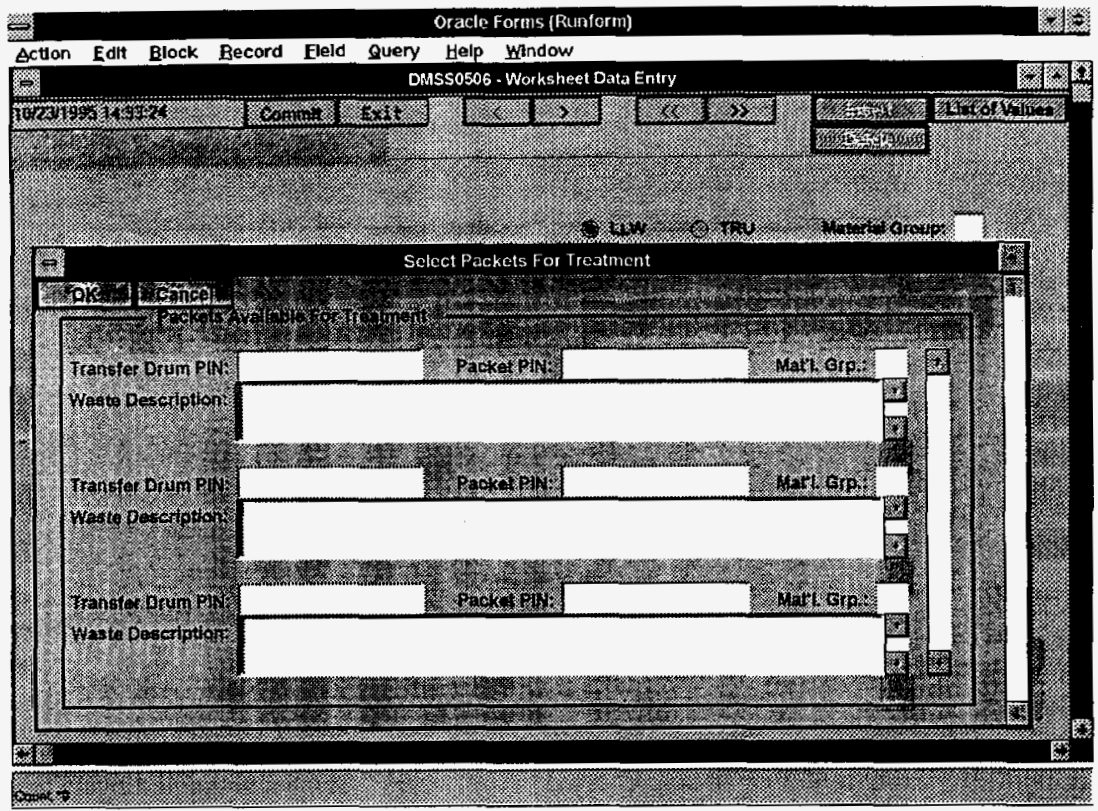

Figure A-60. DMSS0506 Worksheet Data Entry Screen Select Packets For Treatment Pop-Up. 


\section{WHC-SD-W026-SDD-001, Rev. 2}

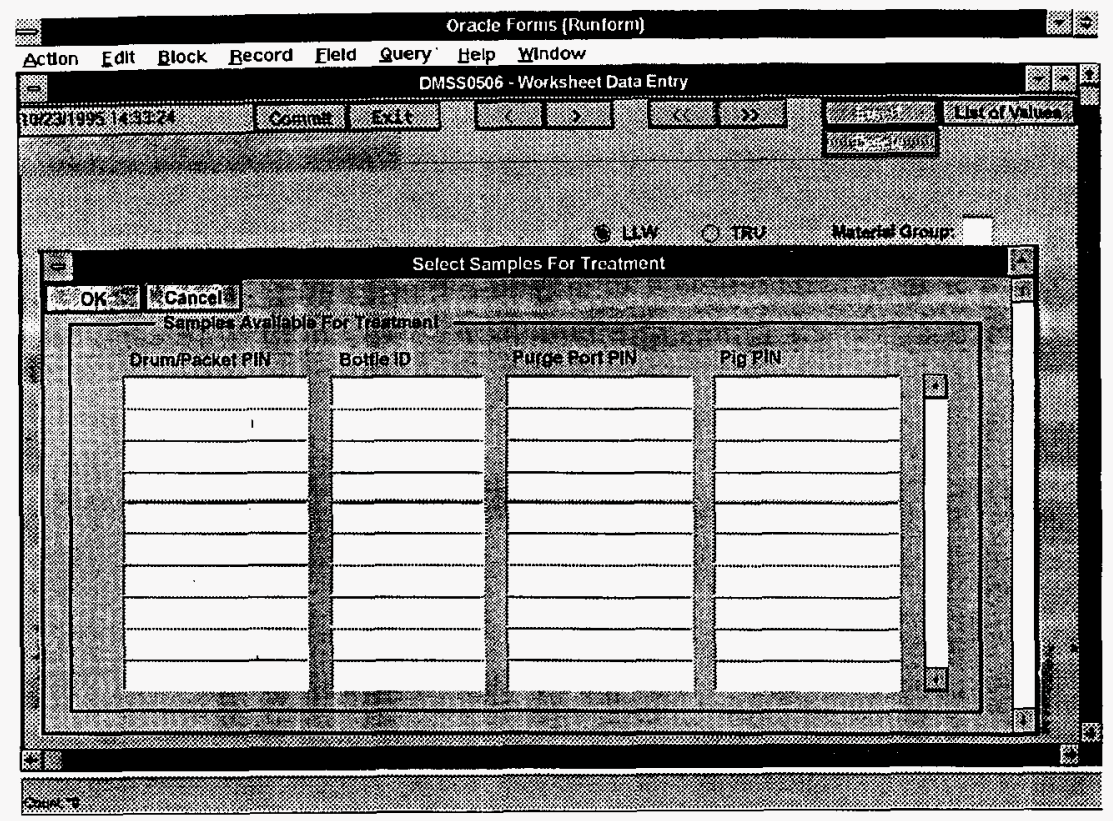

Figure A-61. DMSS0506 Worksheet Data Entry Screen Select Samples For Treatment Pop-Up. 
WHC-SD-W026-SDD-001, Rev. 2

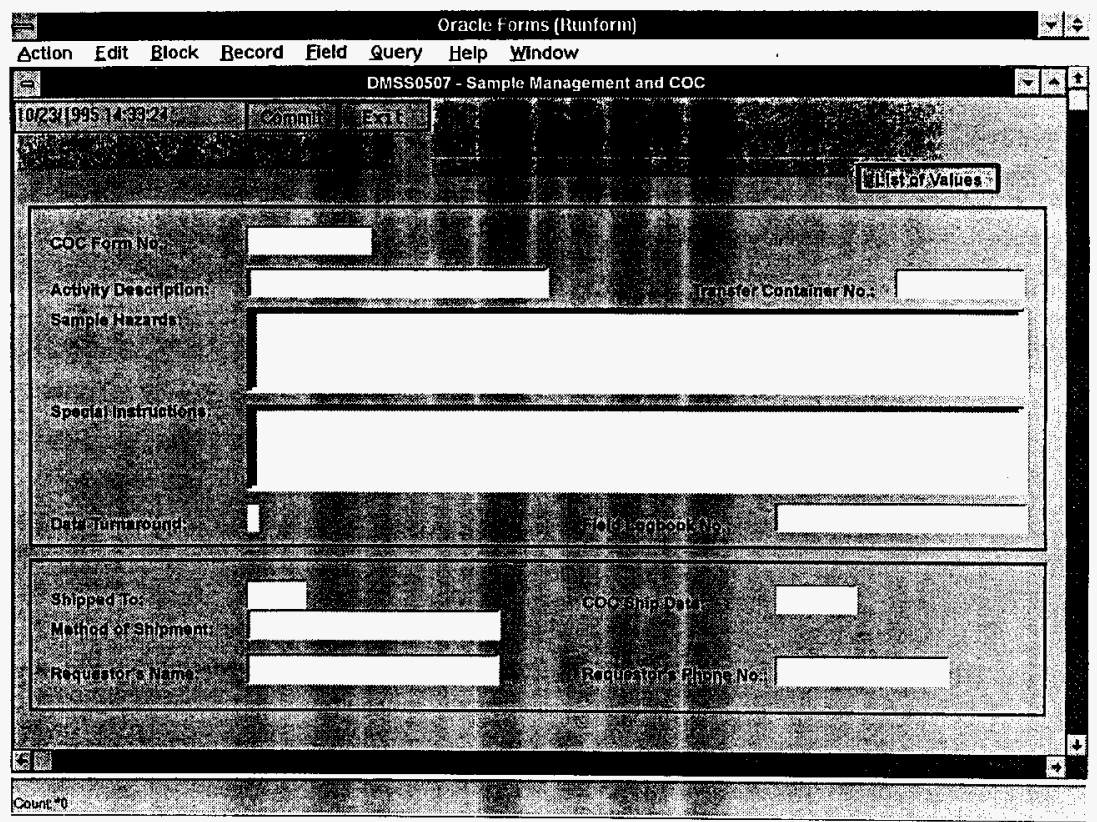

Figure A-62. DMSS0507 Sample Management and COC Screen. 
WHC-SD-W026-SDD-001, Rev. 2

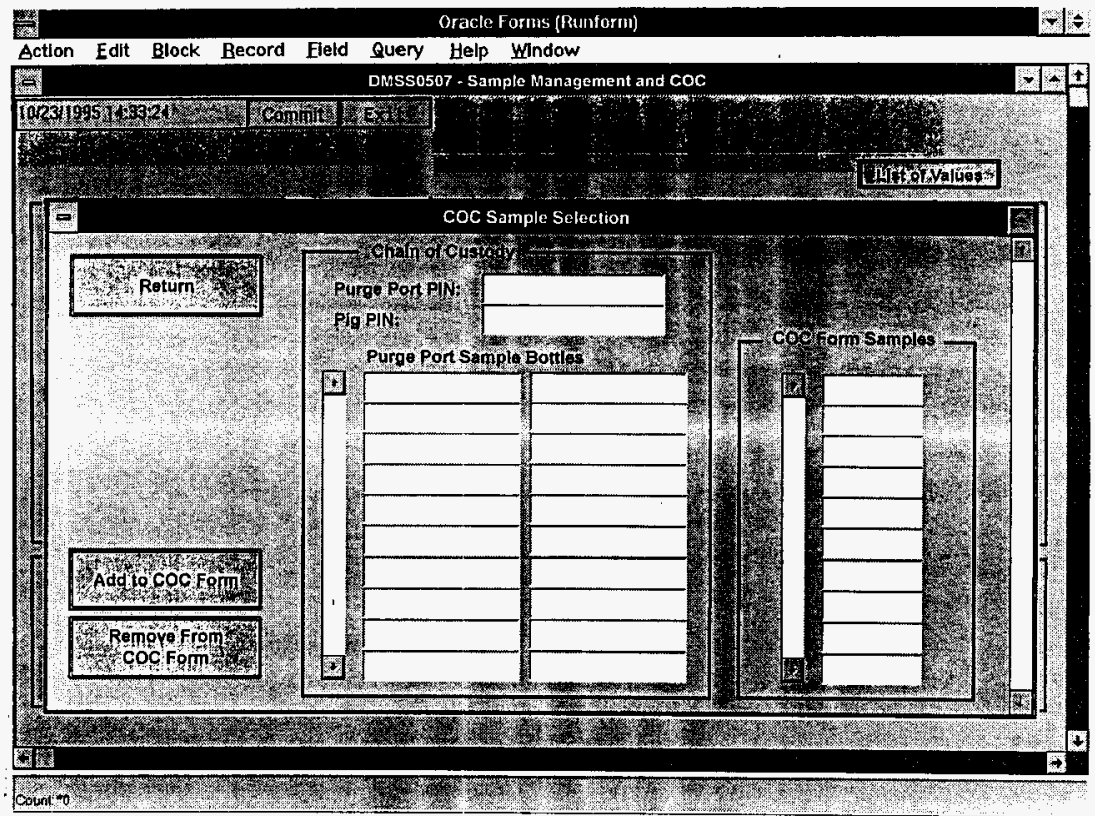

Figure A-63. DMSSO507 Sample Management and COC Screen COC Sample Selection Pop-Up. 


\section{WHC-SD-W026-SDD-001, Rev. 2}

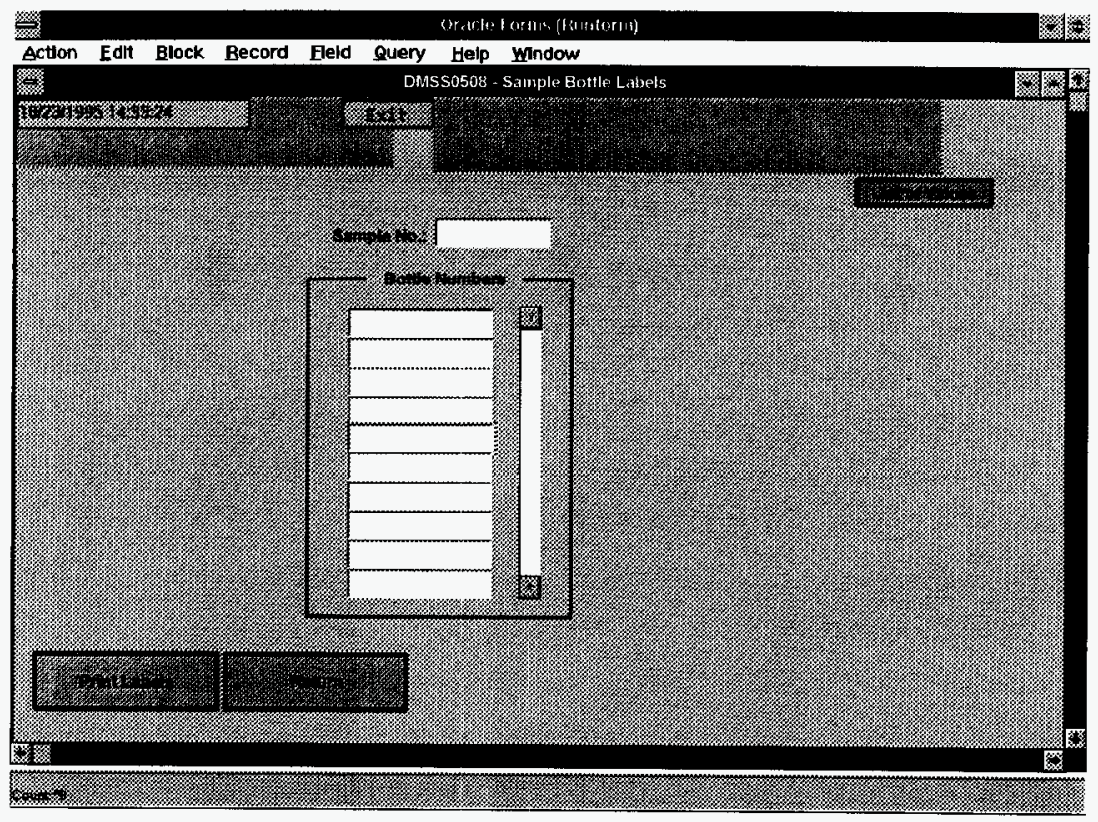

Figure A-64. DMSS0508 Sample Bottle Labels Screen. 
WHC-SD-W026-SDD-001, Rev. 2

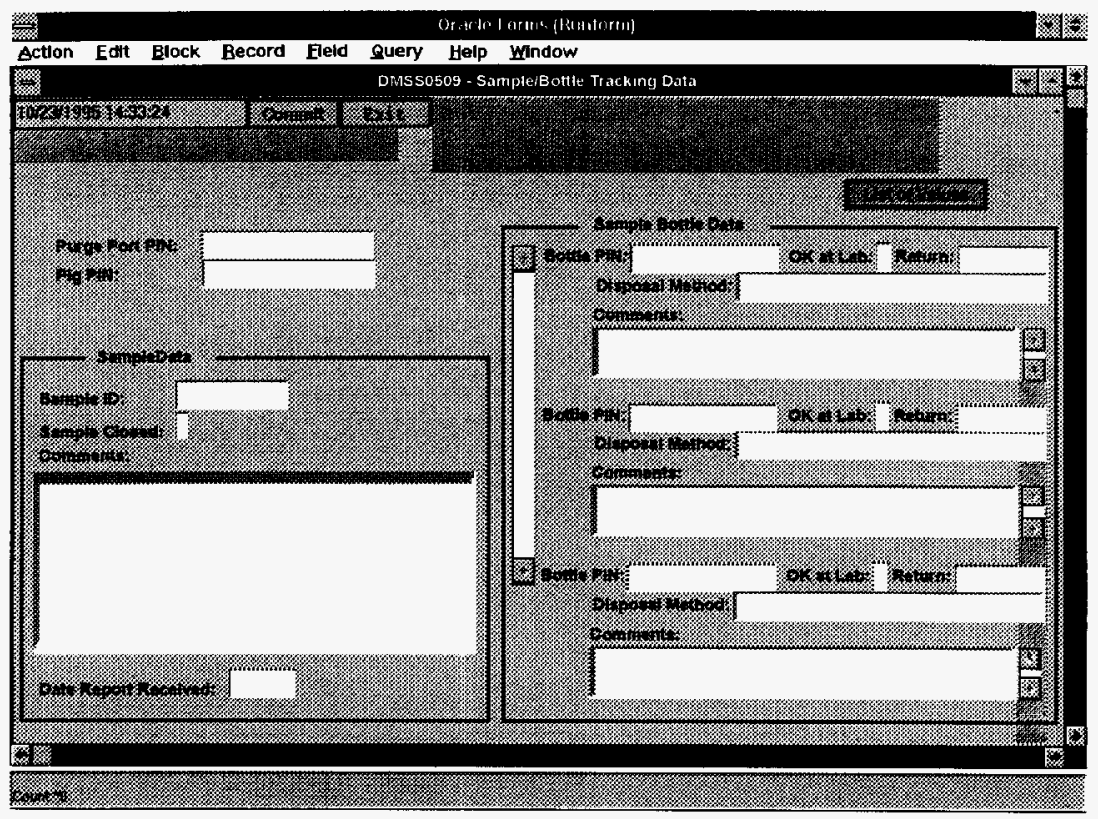

Figure A-65. DMSS0509 Samples/Bottle Tracking Data Screen. 
WHC-SD-W026-SDD-001, Rev. 2

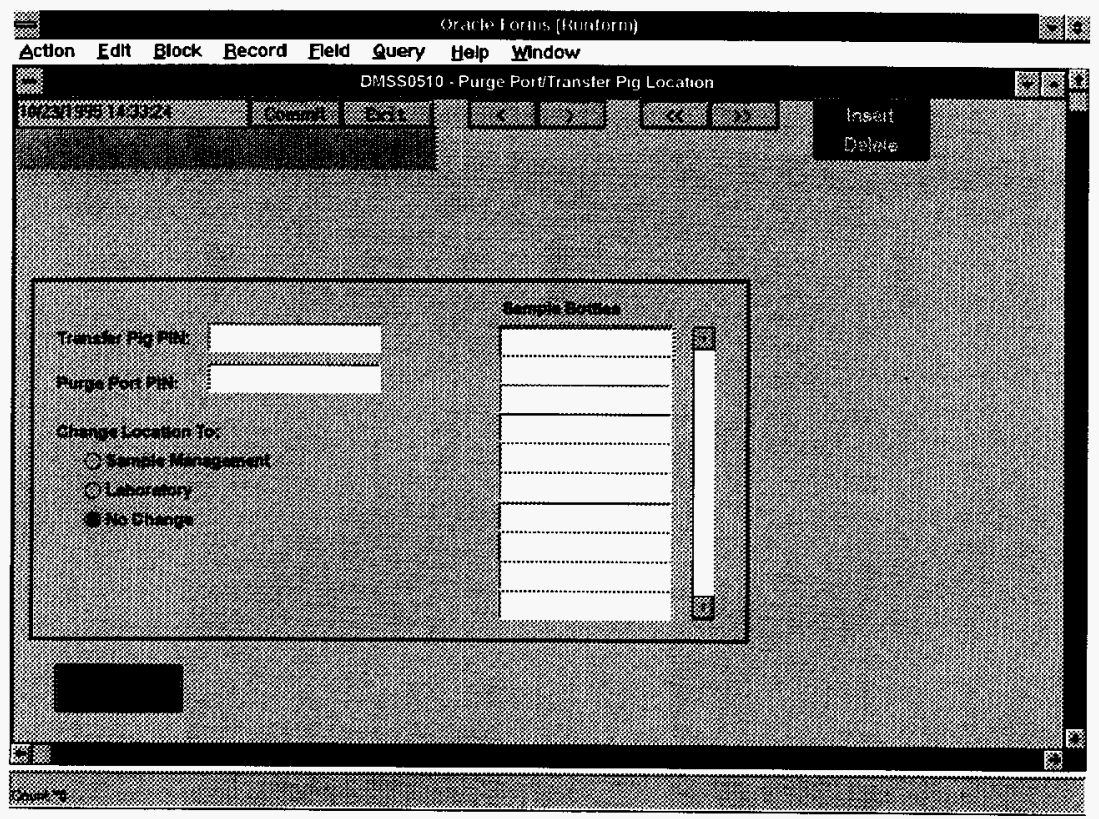

Figure A-66. DMSS0510 Purge Port/Transfer Pig Location Screen. 
WHC-SD-W026-SDD-001, Rev. 2

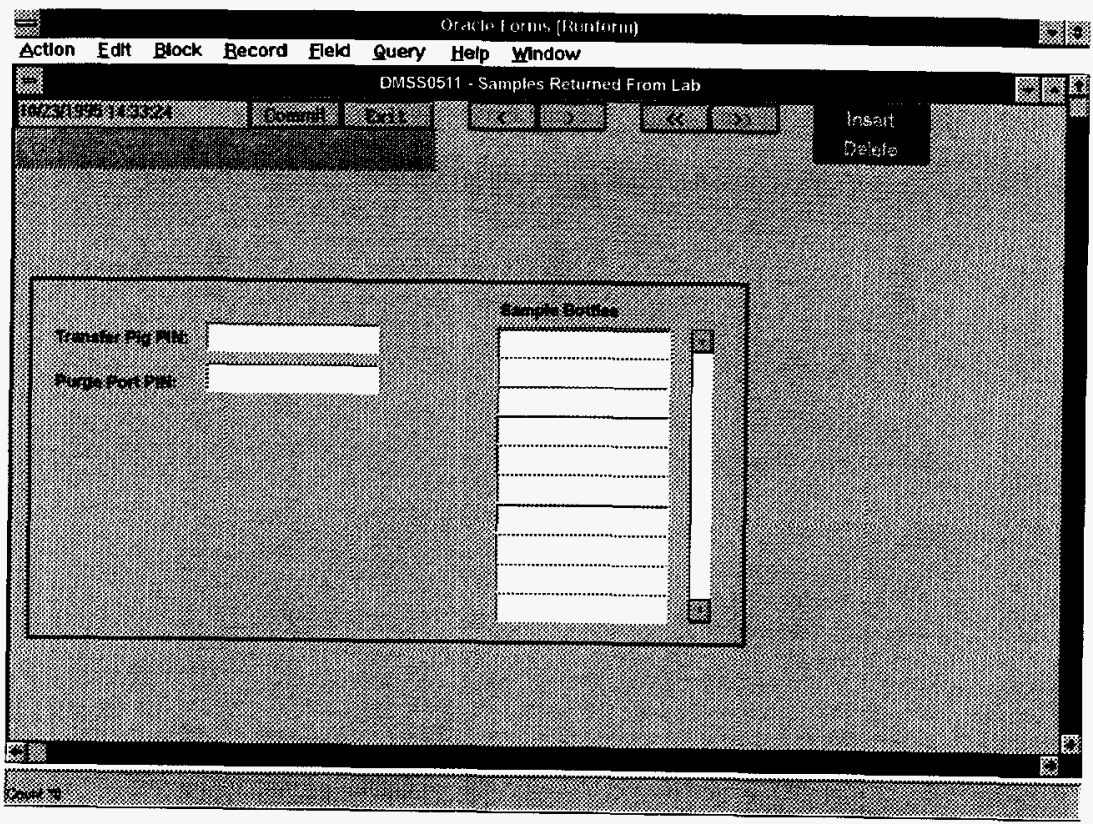

Figure A-67. DMSS0511 Samples Returned From Lab Screen. 
WHC-SD-W026-SDD-001, Rev. 2

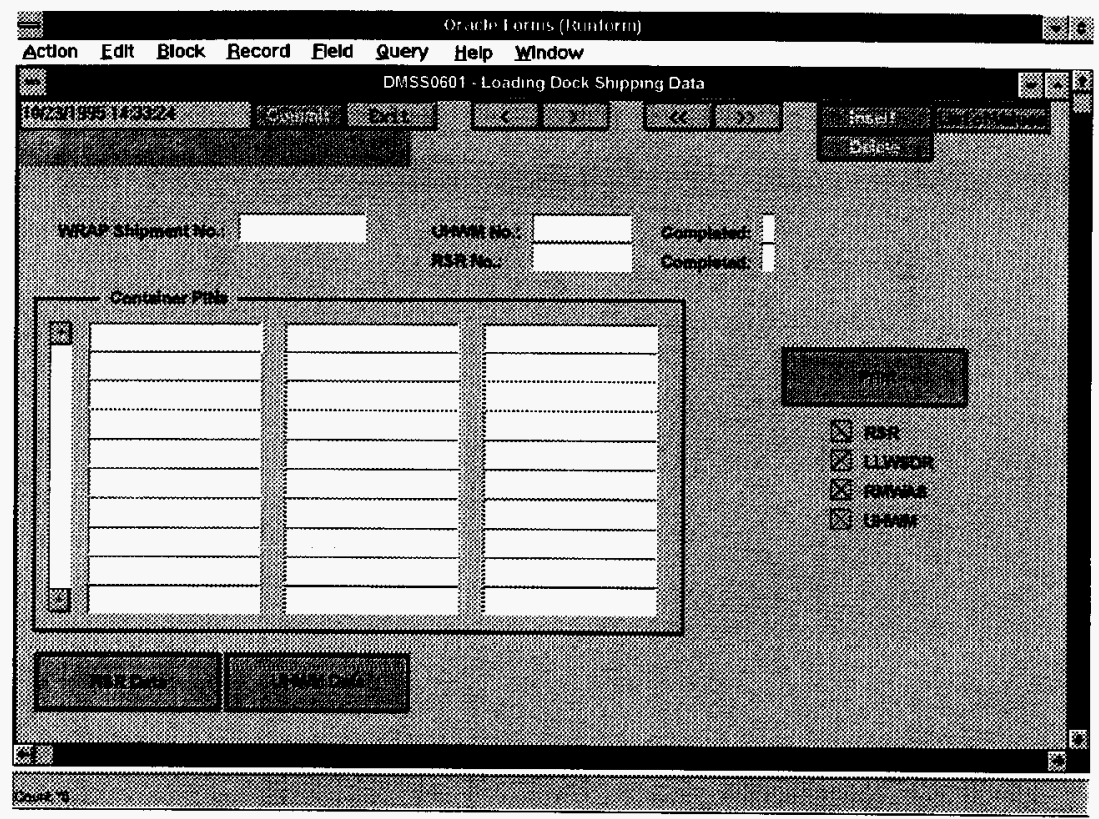

Figure A-68. DMSS0601 Loading Dock Shipping Data Screen. 
WHC-SD-W026-SDD-001, Rev. 2

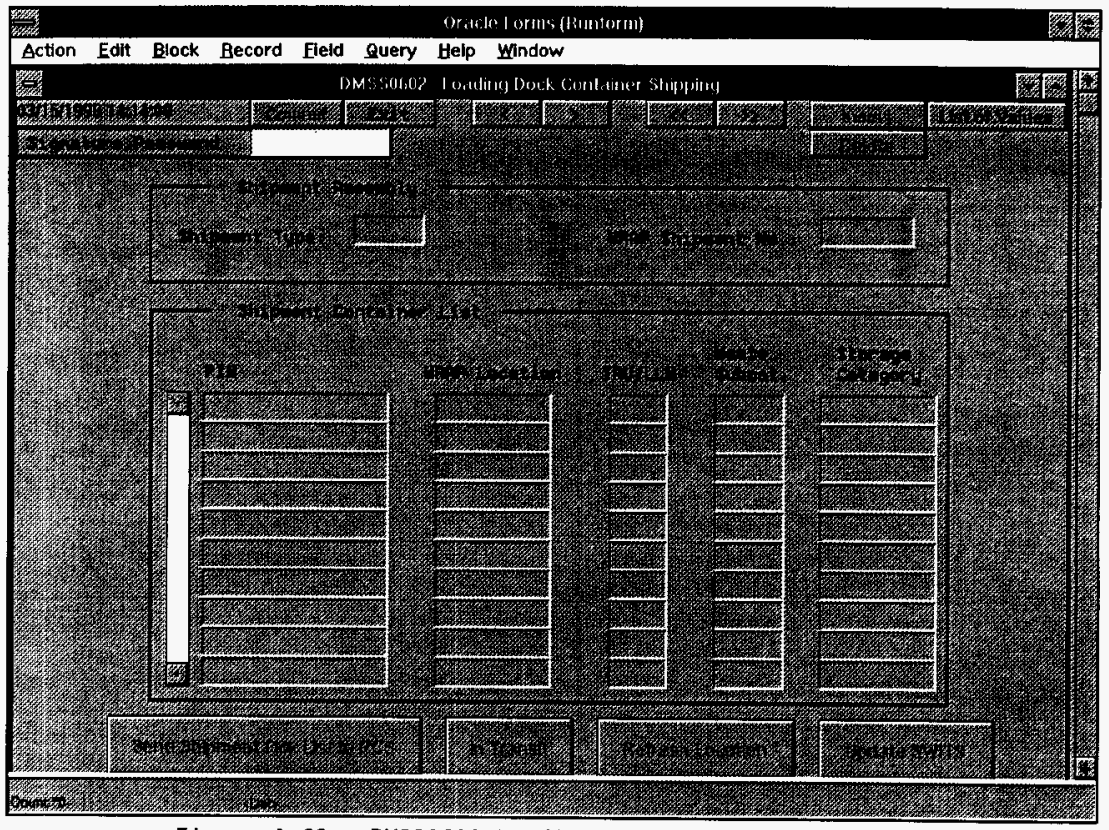

Figure A-69. DMSS0602 Loading Dock Container Shipping Screen. 
WHC-SD-W026-SDD-001, Rev. 2

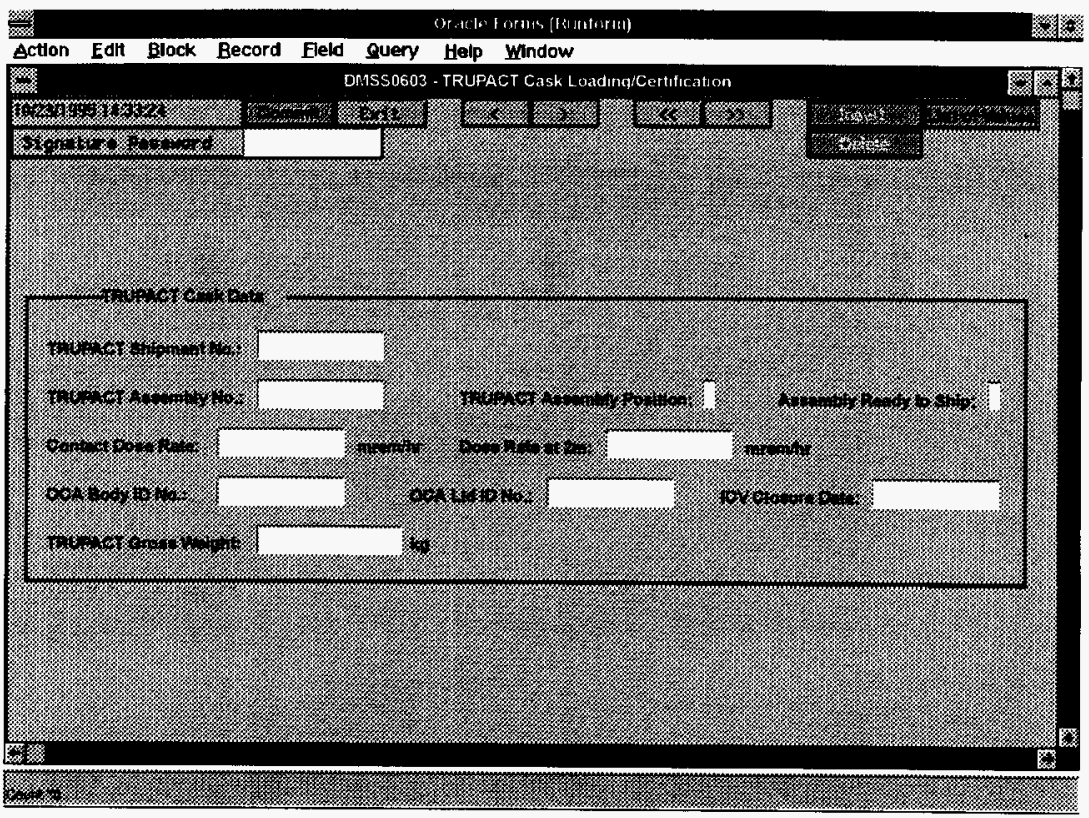

Figure A-70. DMSS0603 TRUPACT Cask Loading/Certification Screen. 
WHC-SD-W026-SDD-001, Rev. 2

(To Be Defined)

Figure A-71. DMSS0604 TRUPACT Shipping Documentation Screen. 
WHC-SD-W026-SDD-001, Rev. 2

(To Be Defined)

Figure A-72. DMSS0605 Loading Dock Box and Empty Container Shipping Screen. 
WHC-SD-W026-SDD-001, Rev. 2

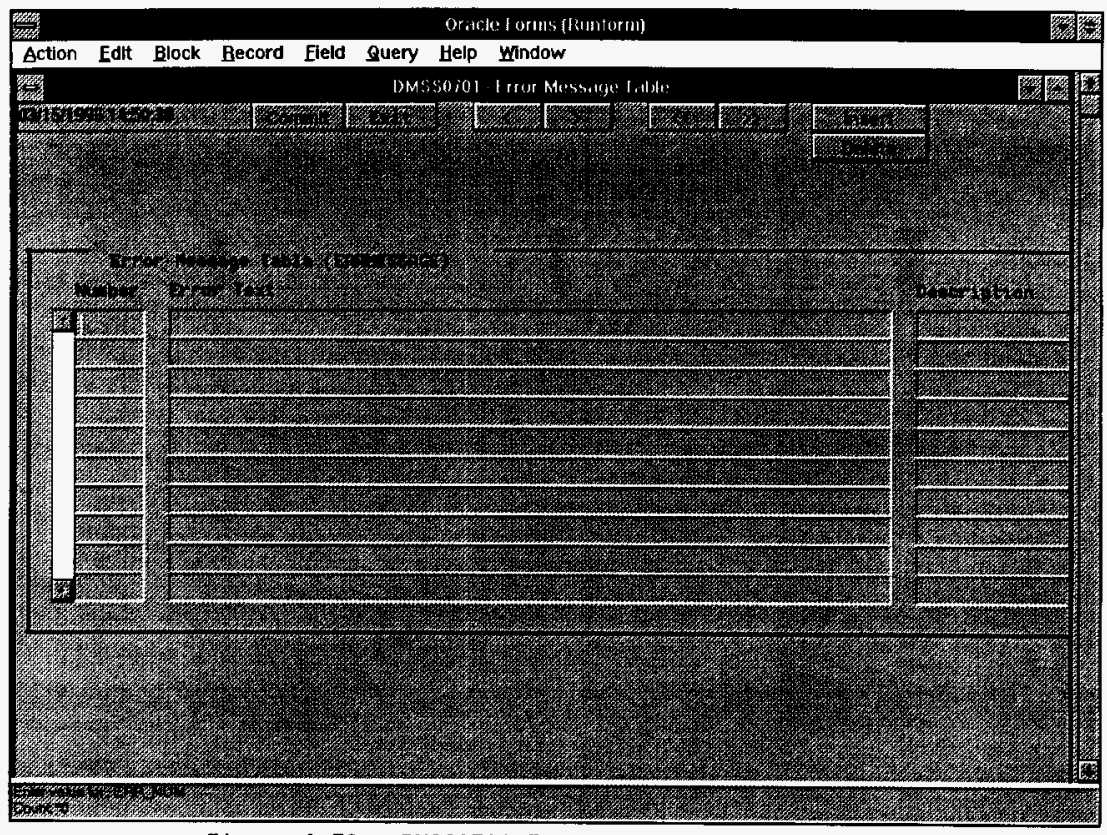

Figure A-73. DMSS0701 Error Message Table Screen. 
WHC-SD-W026-SDD-001, Rev. 2

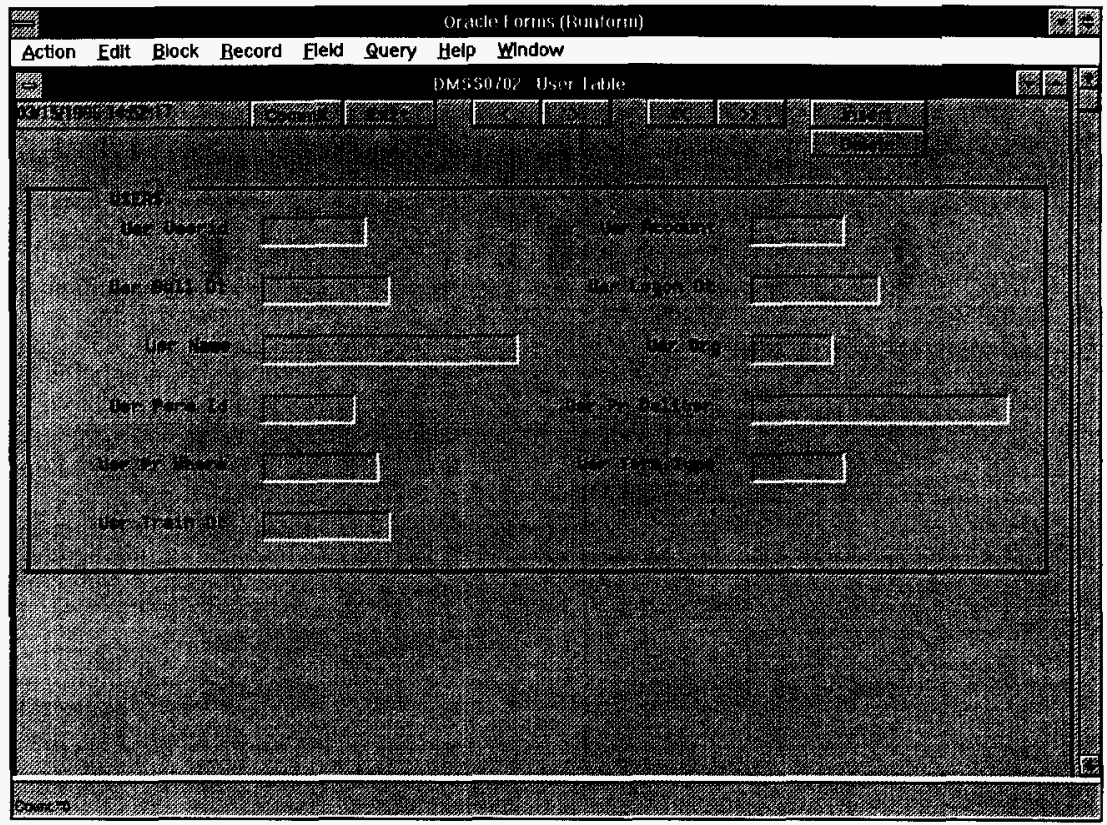

Figure A-74. DMSS0702 User Table Screen. 
WHC-SD-W026-SDD-001, Rev. 2

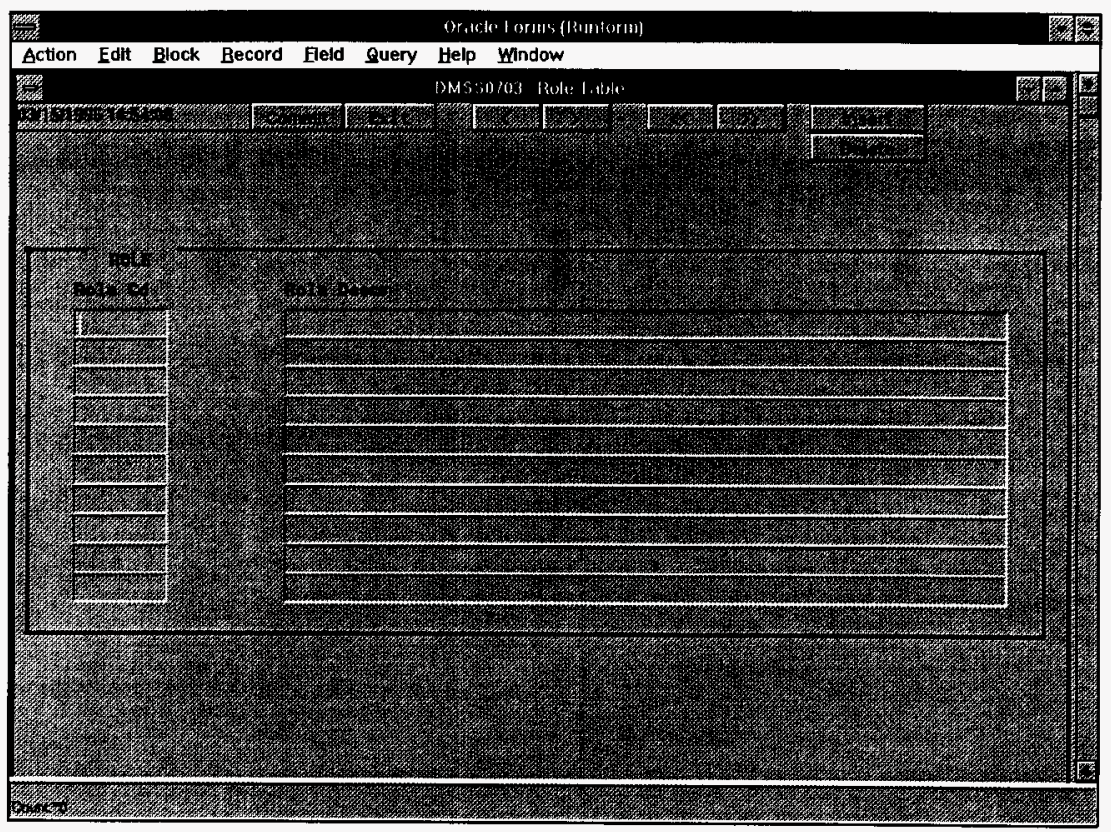

Figure A-75. DMSS0703 Role Table Screen. 
WHC-SD-W026-SDD-001, Rev. 2

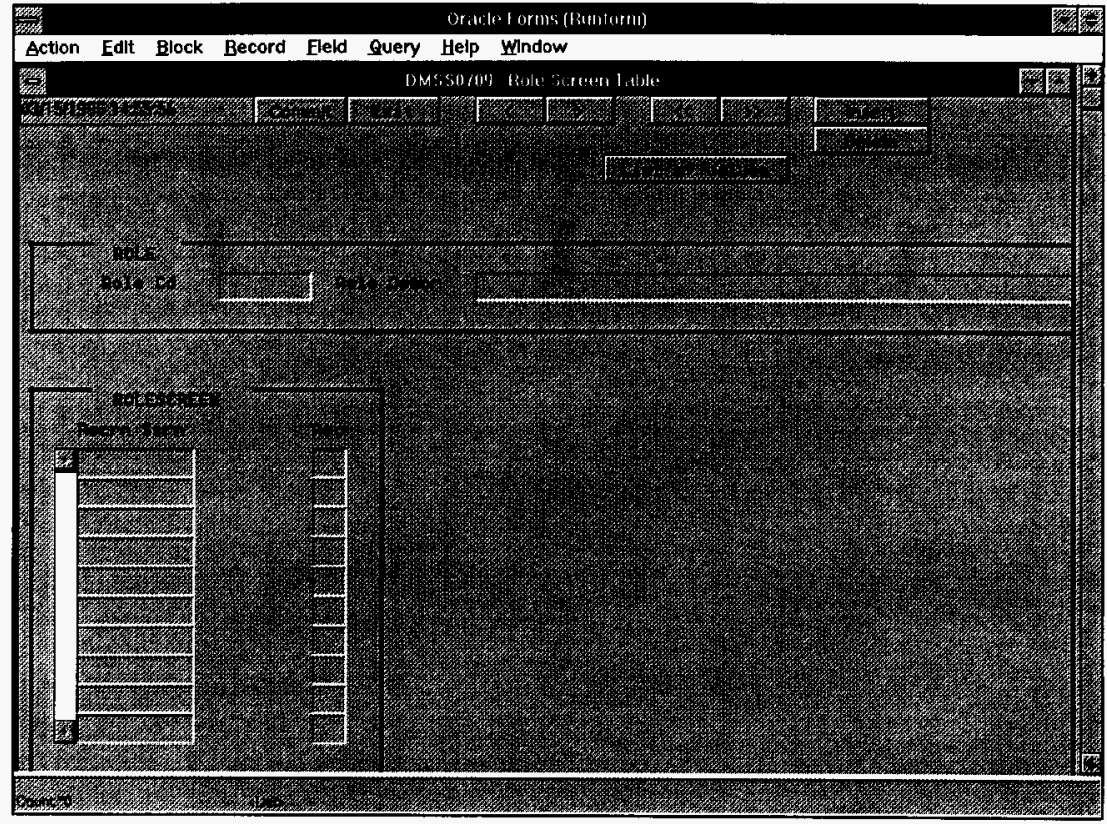

Figure A-76. DMSS0709 Role Screen Table Screen. 
WHC-SD-W026-SDD-001, Rev. 2

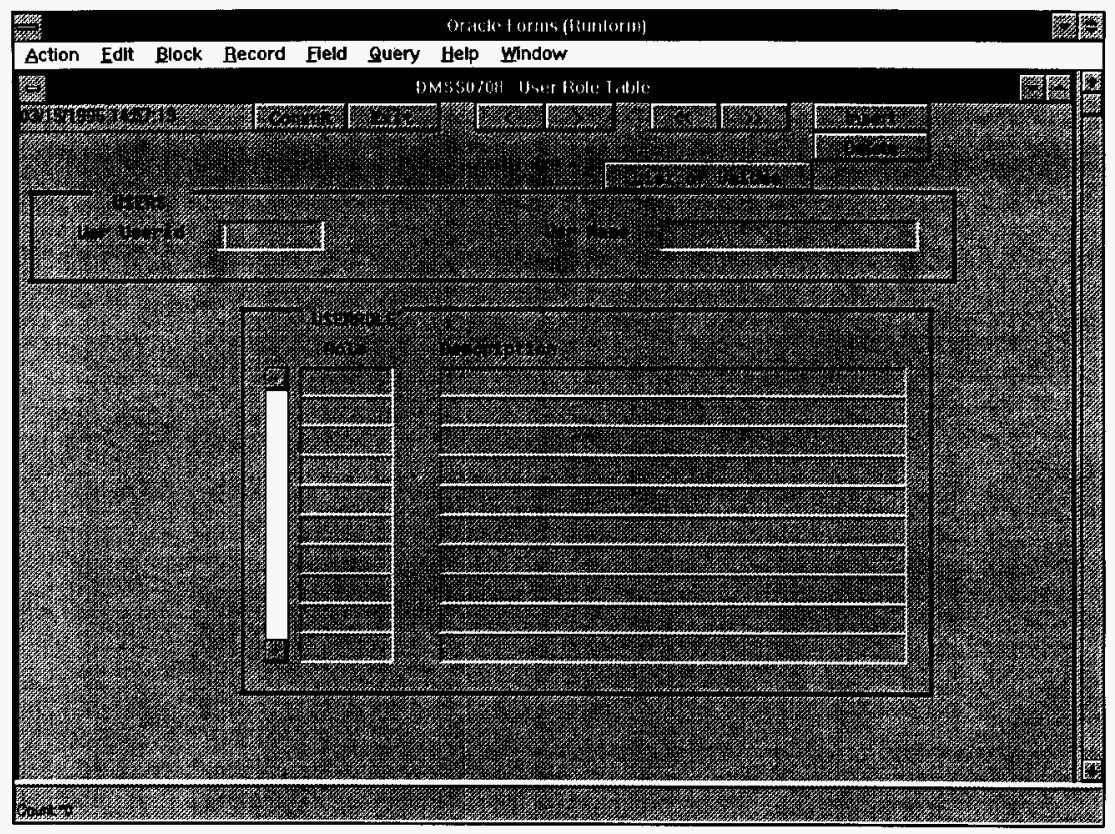

Figure A-77. DMSS0708 User Role Table Screen. 
WHC-SD-W026-SDD-001, Rev. 2

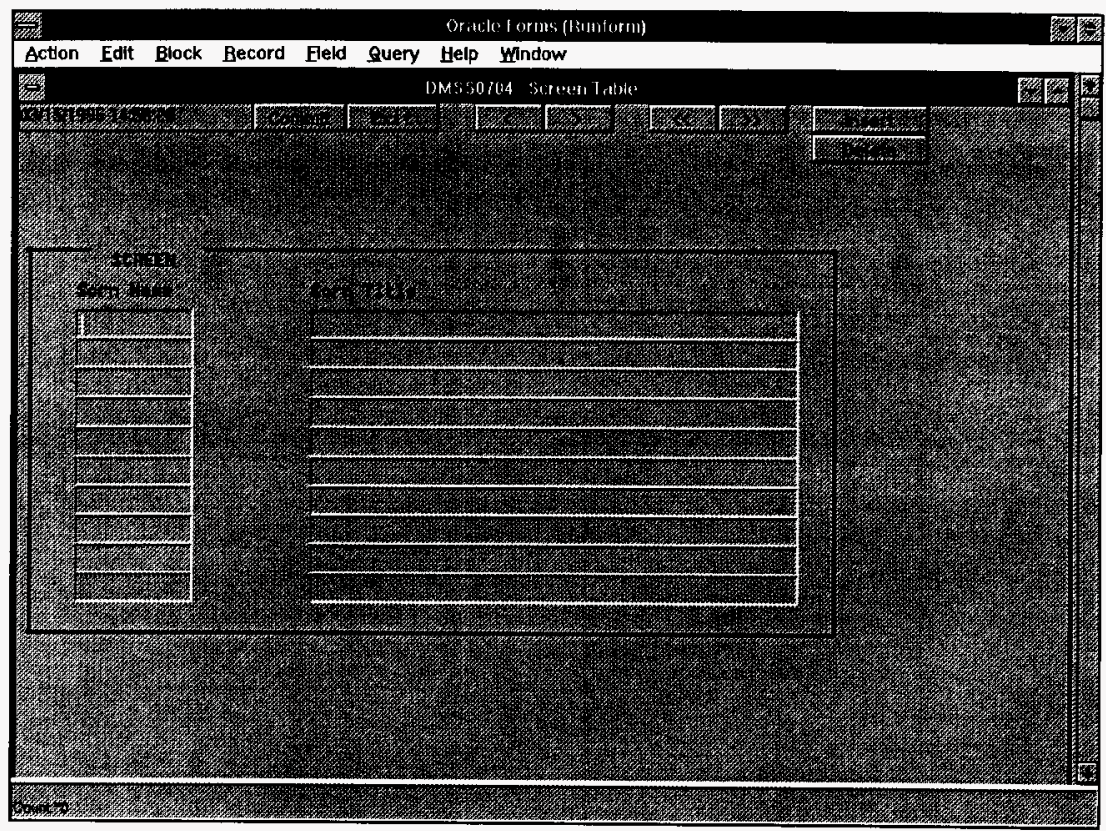

Figure A-78. DMSS0704 Screen Table Screen. 
WHC-SD-W026-SDD-001, Rev. 2

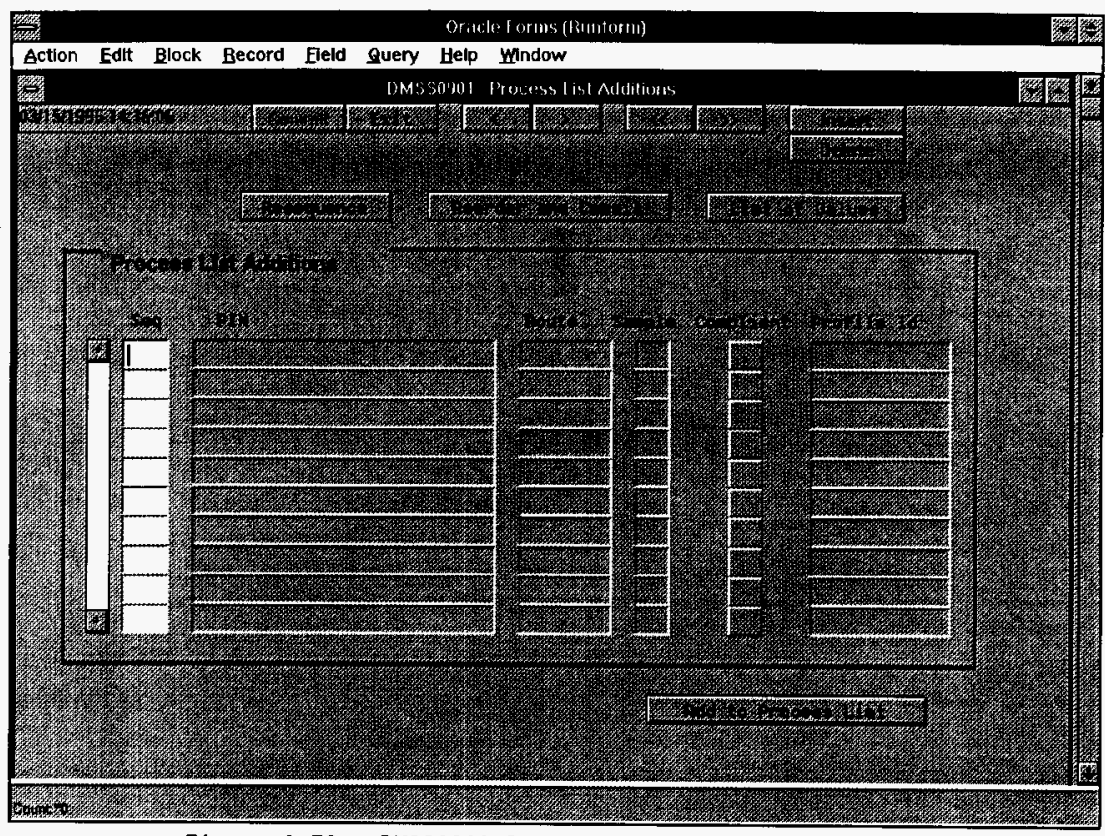

Figure A-79. DMSS0901 Process List Additions Screen. 
WHC-SD-W026-SDD-001, Rev, 2

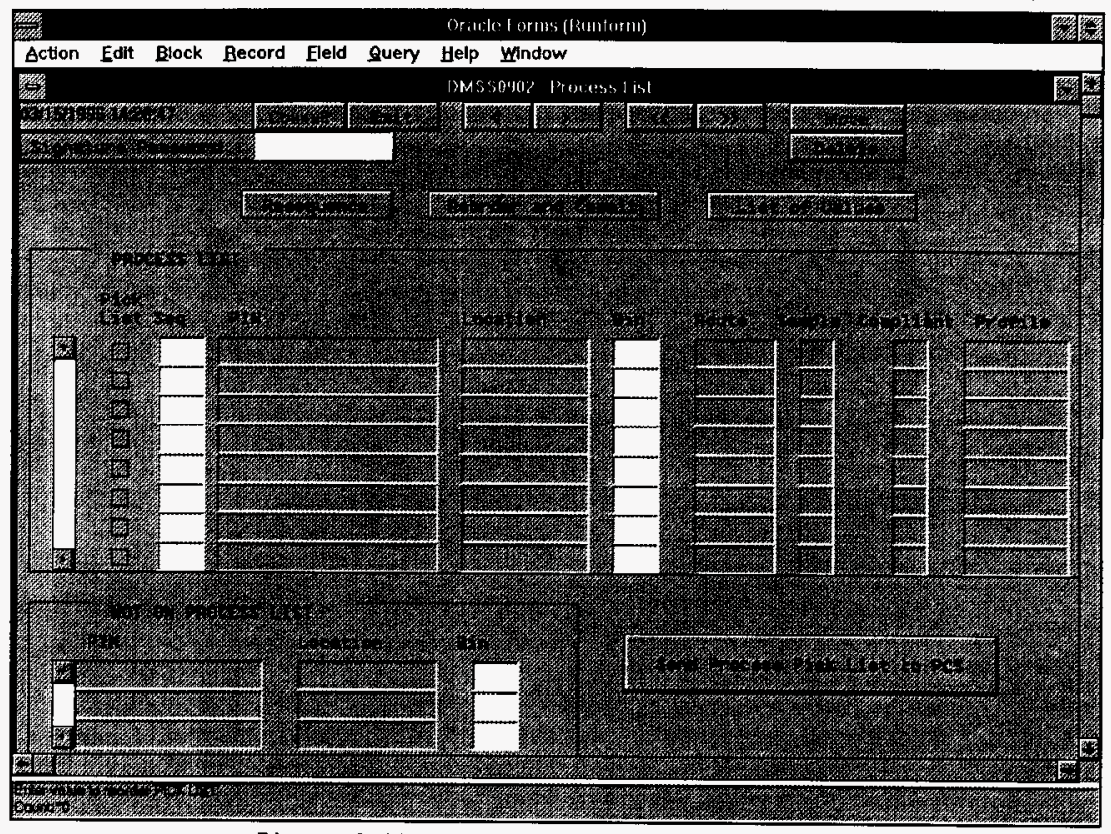

Figure A-80. DMSS0902 Process List Screen. 
WHC-SD-W026-SDD-001, Rev. 2

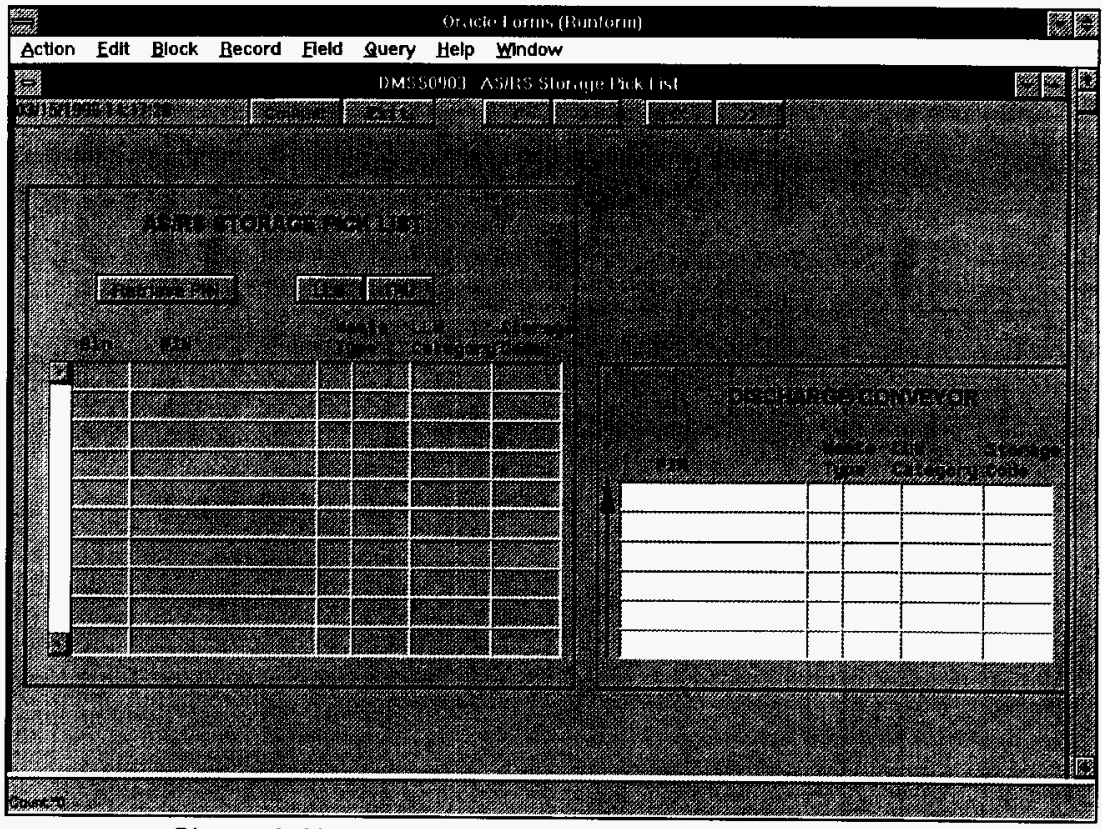

Figure A-81. DMSS0903 AS/RS Storage Pick List Screen. 
WHC-SD-W026-SDD-001, Rev. 2

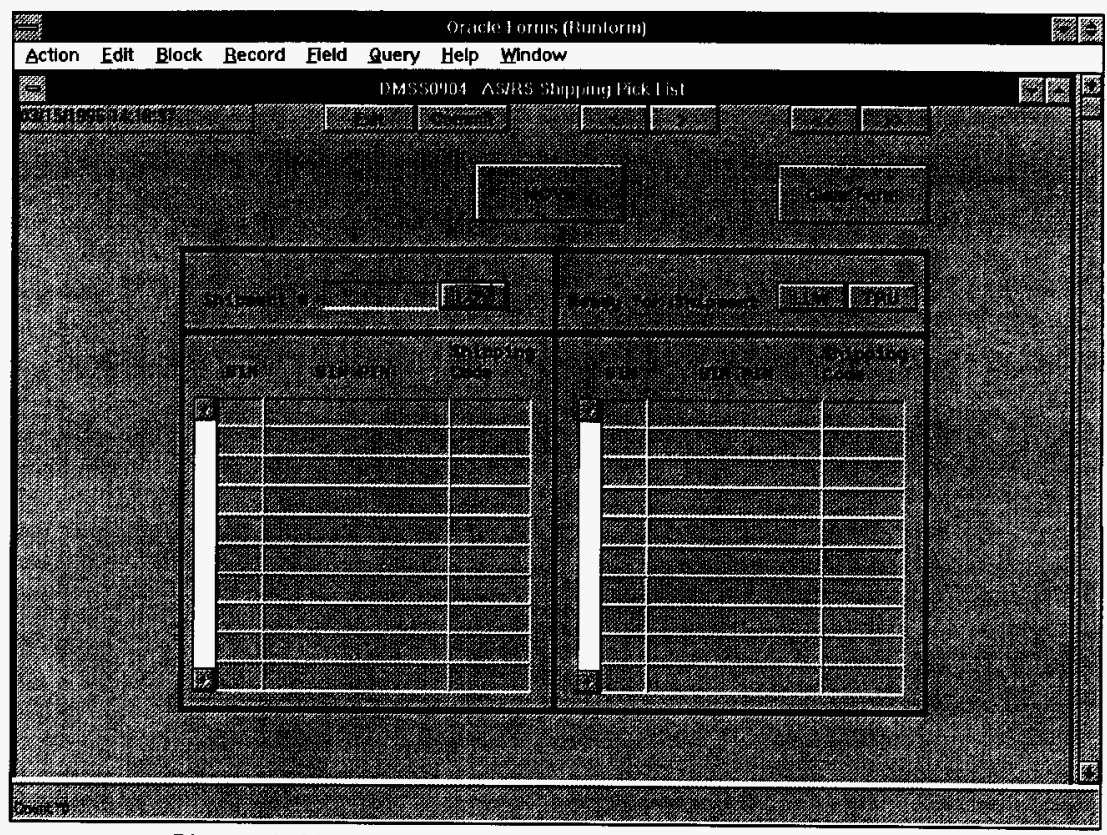

Figure A-82. DMSS0904 AS/RS Shipping Pick List Screen. 
WHC-SD-W026-SDD-001, Rev. 2

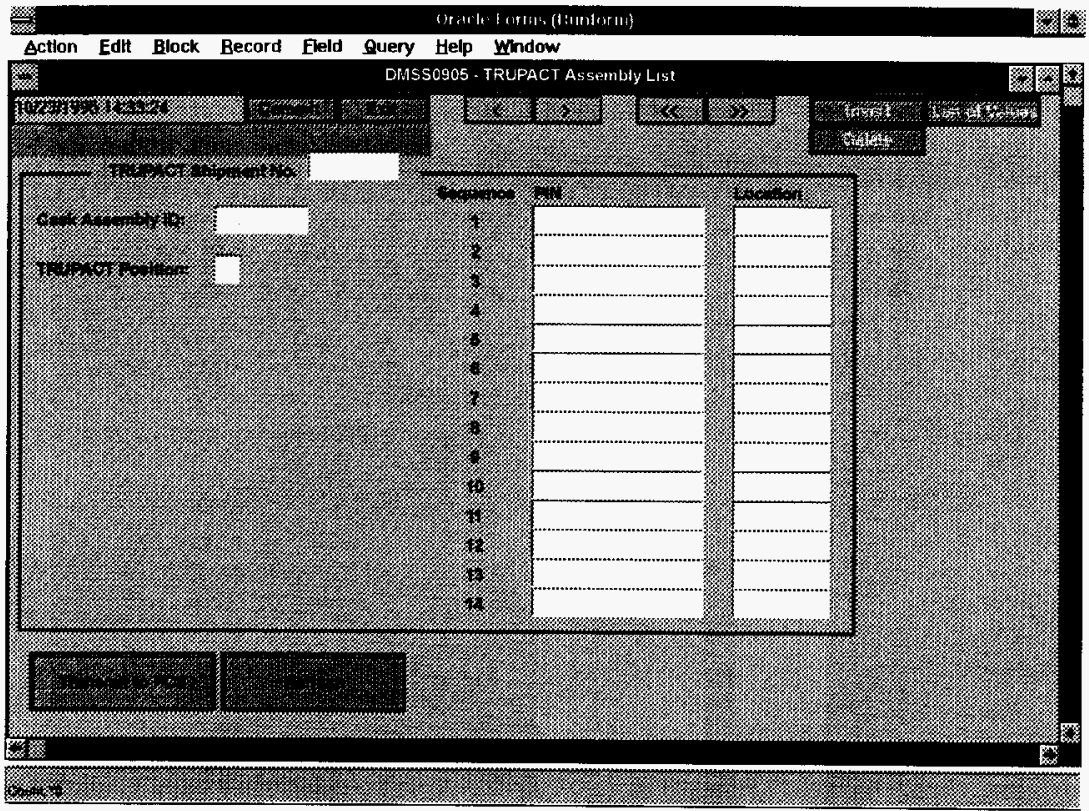

Figure A-83. DMSS0905 TRUPACT Assembly List Screen. 
WHC-SD-W026-SDD-001, Rev. 2

(To Be Defined)

Figure A-84. DMSS0906 Box/Empty Orum Shipping Pick List Screen. 


\section{WHC-SD-W026-SDD-001, Rev. 2}

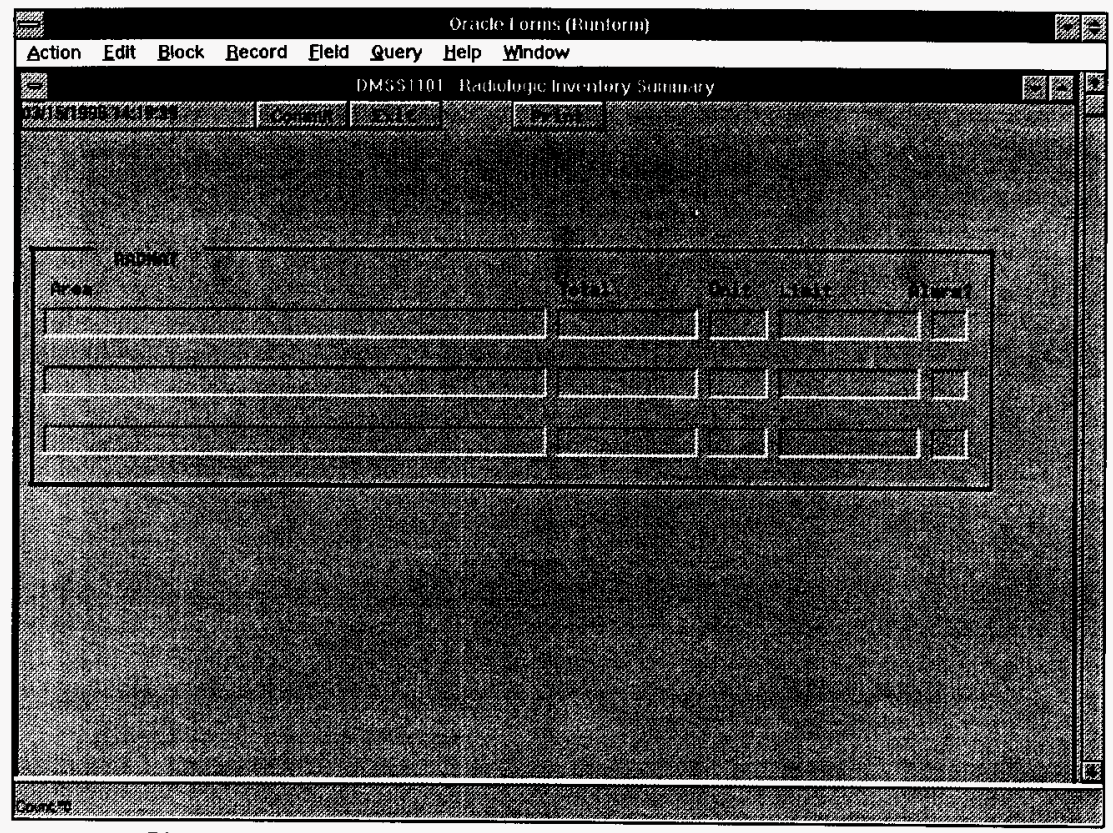

Figure A-83. DMSS1101 Radiologic Inventory Summary Screen. 


$$
\text { WHC-SD-W026-SDD-001, Rev. } 2
$$

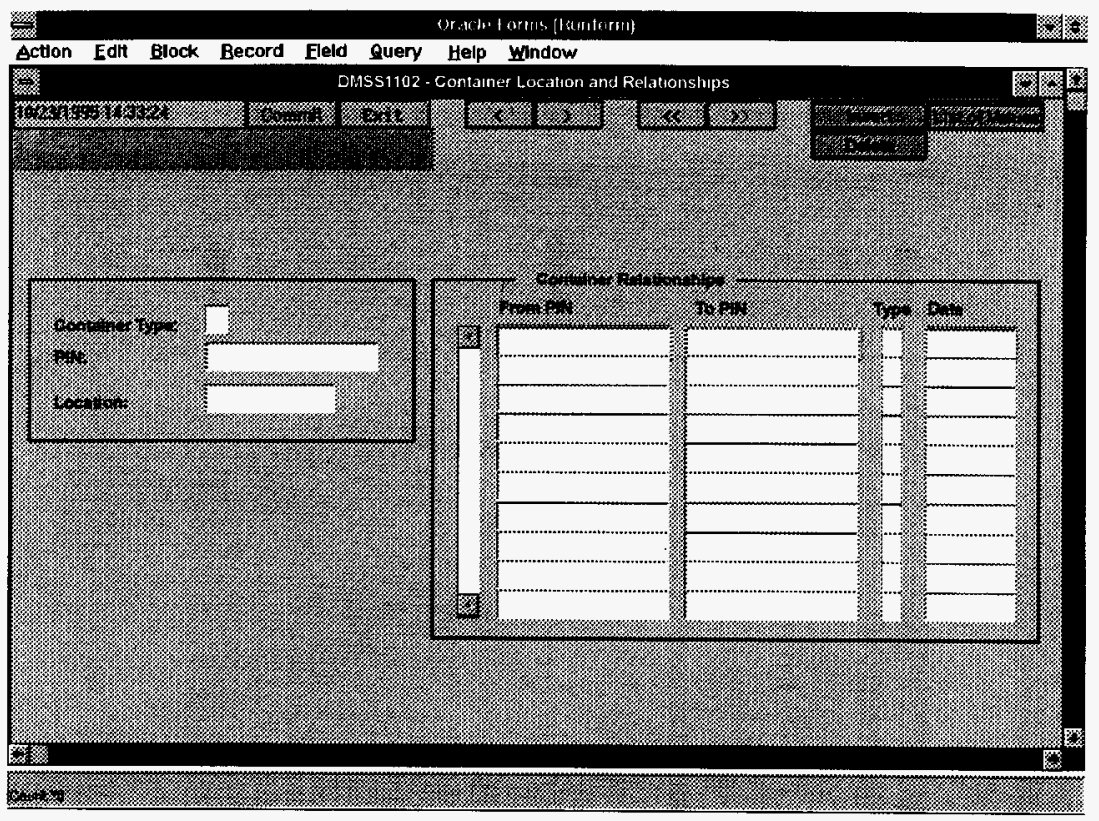

Figure A-86. DMSS1102 Container Location and Relationships Screen. 


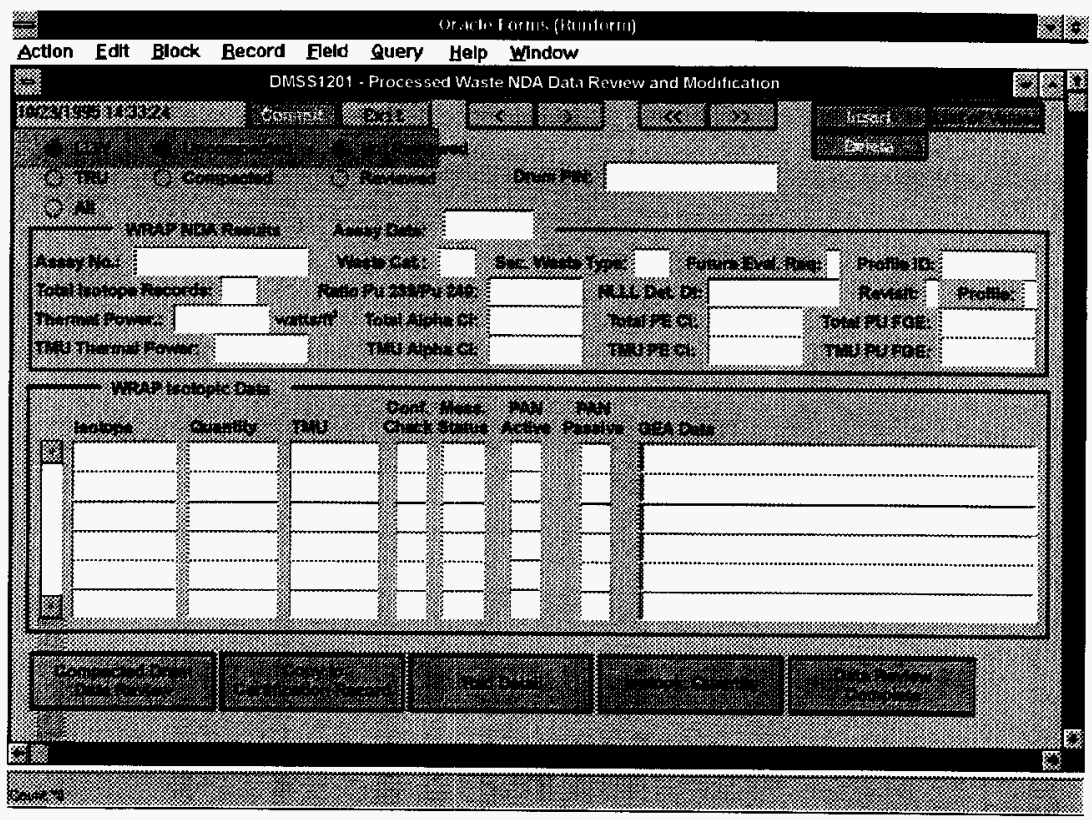

Figure A-87. DMSS1201 Process Waste NDA Data Review and Modification Screen. 
WHC-SD-W026-SDD-001, Rev. 2

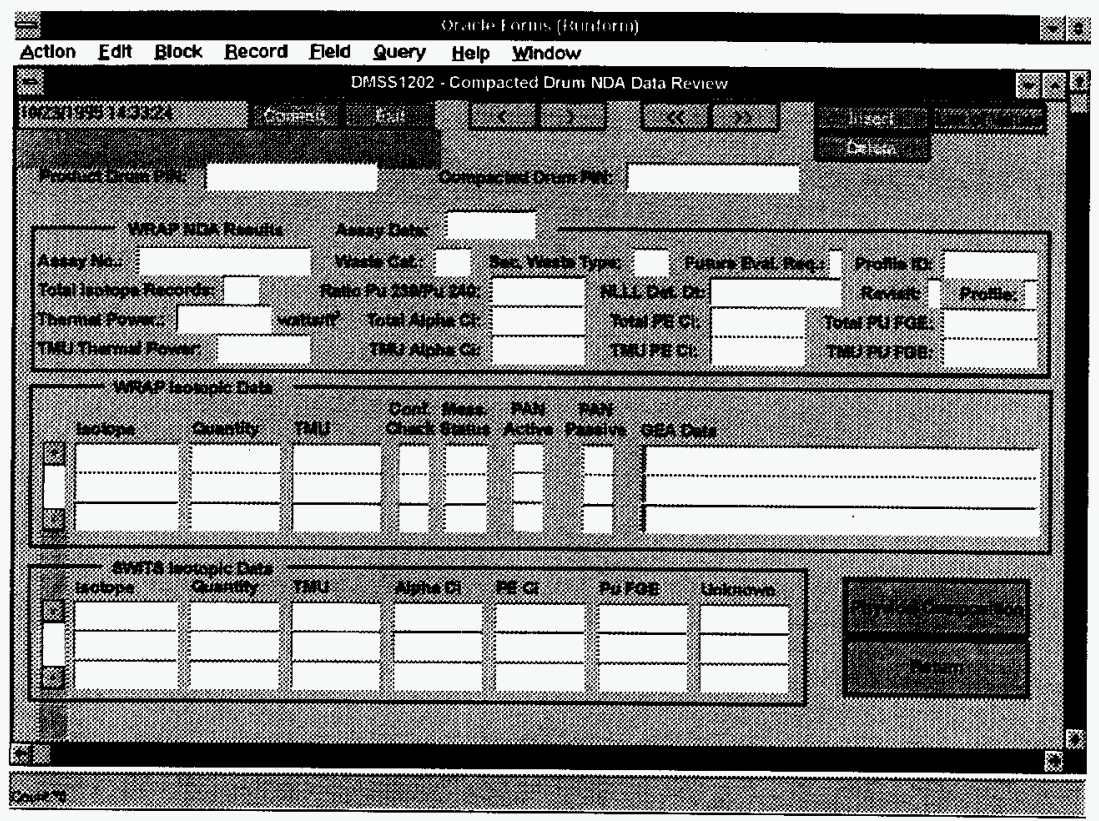

Figure A-88. DMSS1202 Compacted Drum NDA Data Review Screen. 
WHC-SD-W026-SDD-001, Rev. 2

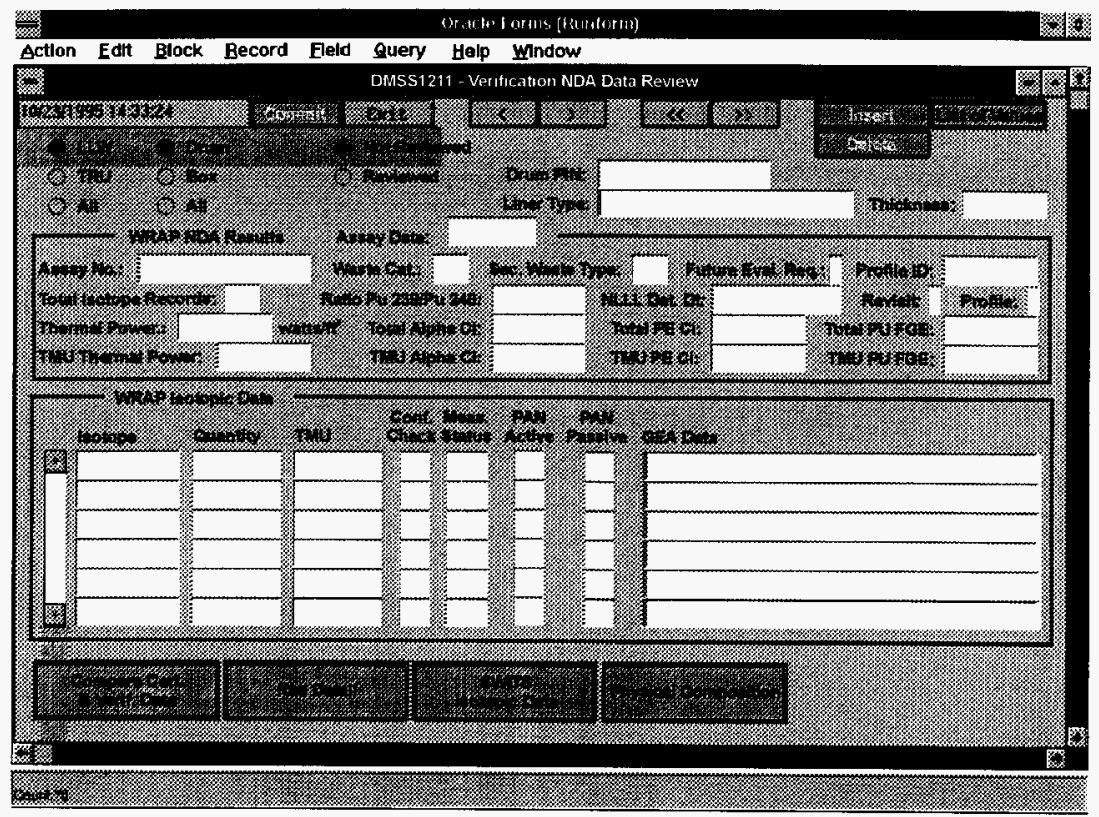

Figure A-89. DMSS1211 Verification NDA Data Review Screen. 
WHC-SD-W026-SDD-001, Rev. 2

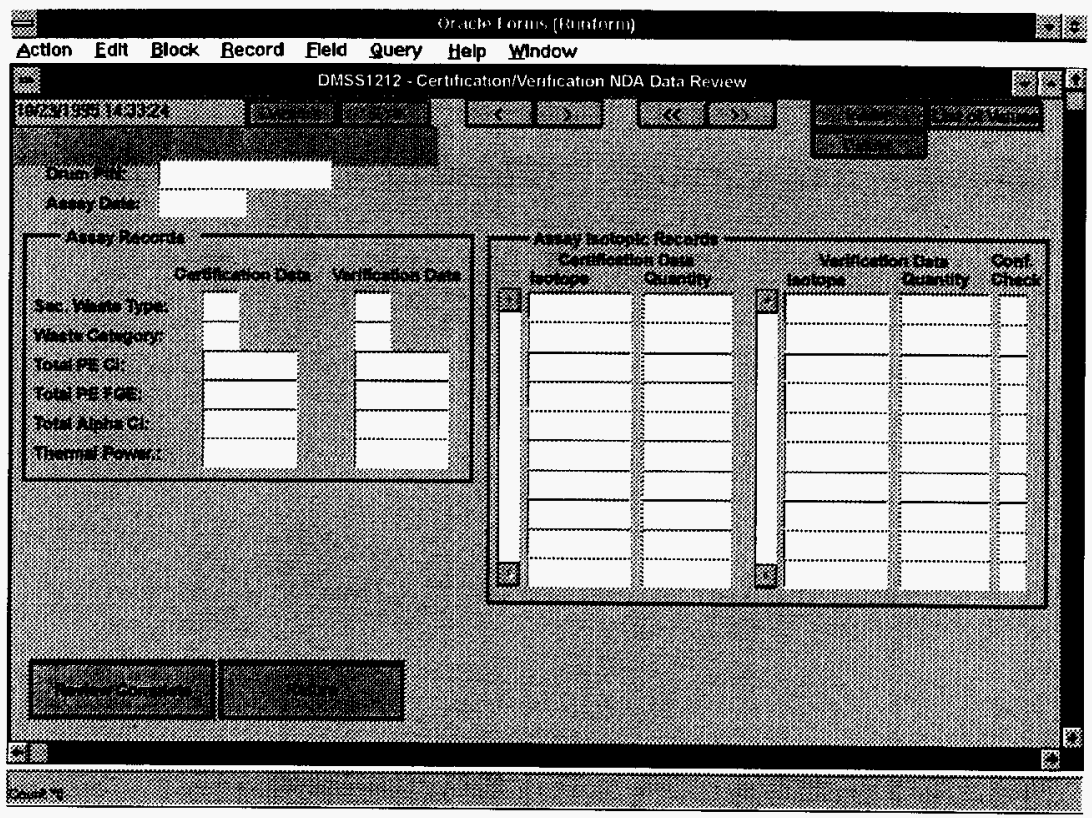

Figure A-90. DMS\$1212 Certification/Verification NDA Data Review Screen. 
WHC-SD-W026-SDD-001, Rev. 2

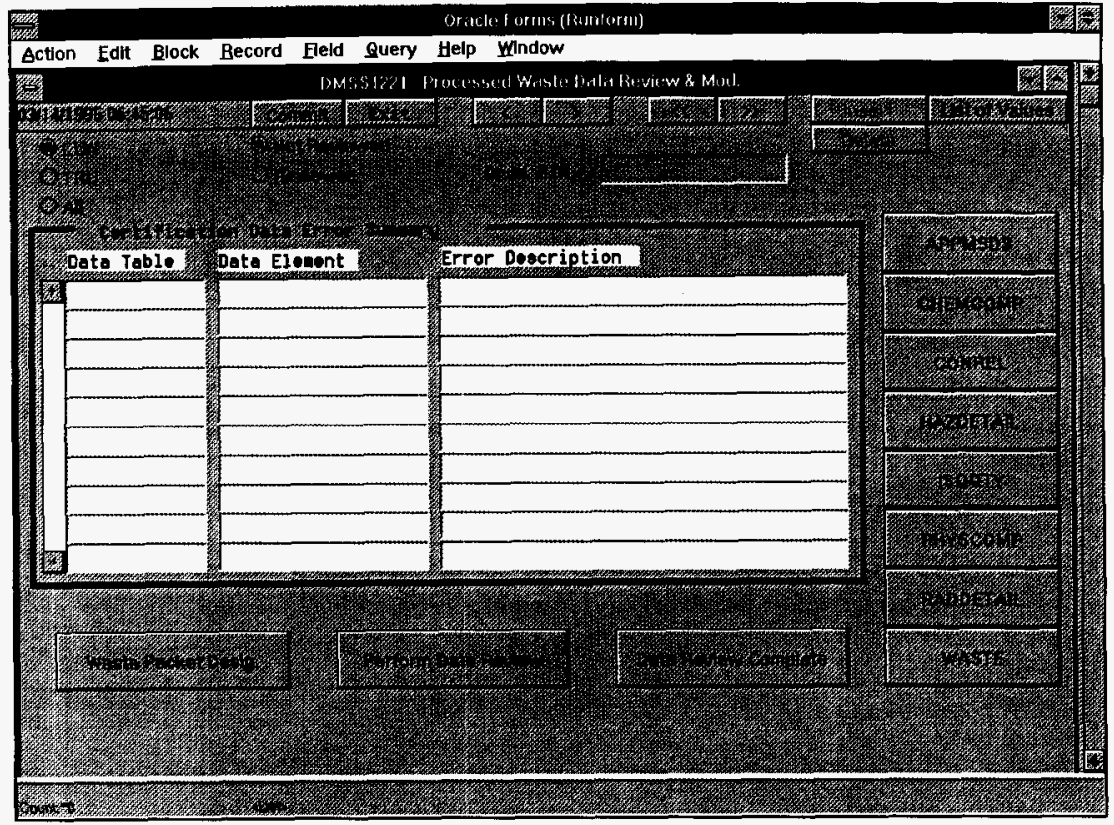

Figure A-91. DMSS1221 Processed Waste Data Review \& Mod. Screen. 


\section{WHC-SD-W026-SDD-001, Rev. 2}

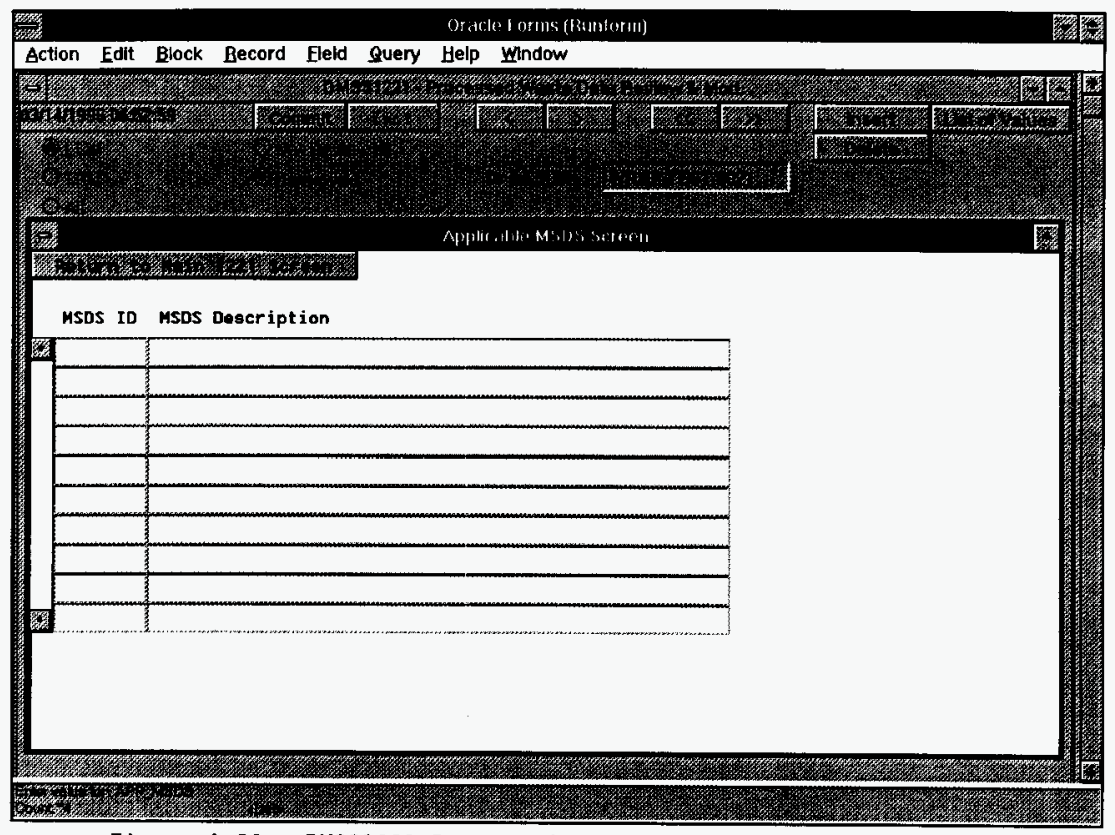

Figure A-92. DMSS1221 Processed Waste Data Review \& Mod. Screen Applicable MSDS Screen Pop-Up. 


$$
\text { WHC-SD-W026-SDD-001, Rev. } 2
$$

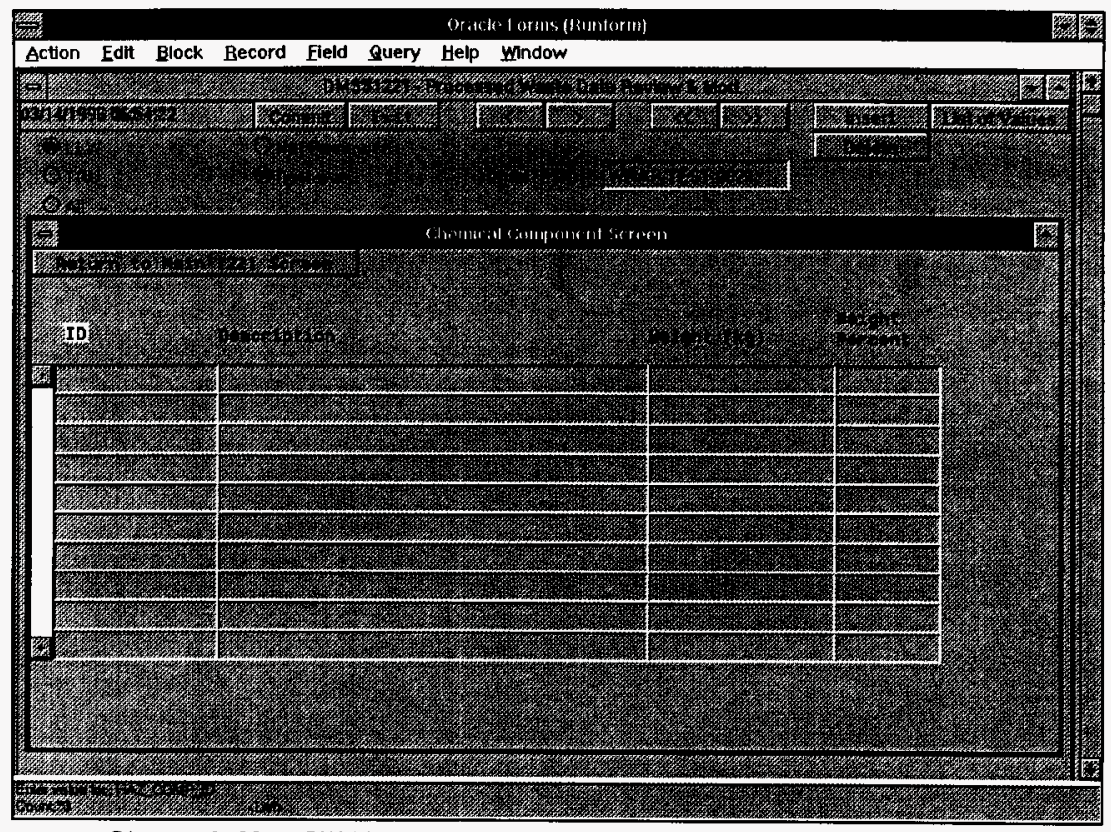

Figure A-93. DMSS1221 Processed Waste Data Review \& Mod. Screen Chemical Component Screen Pop-Up. 


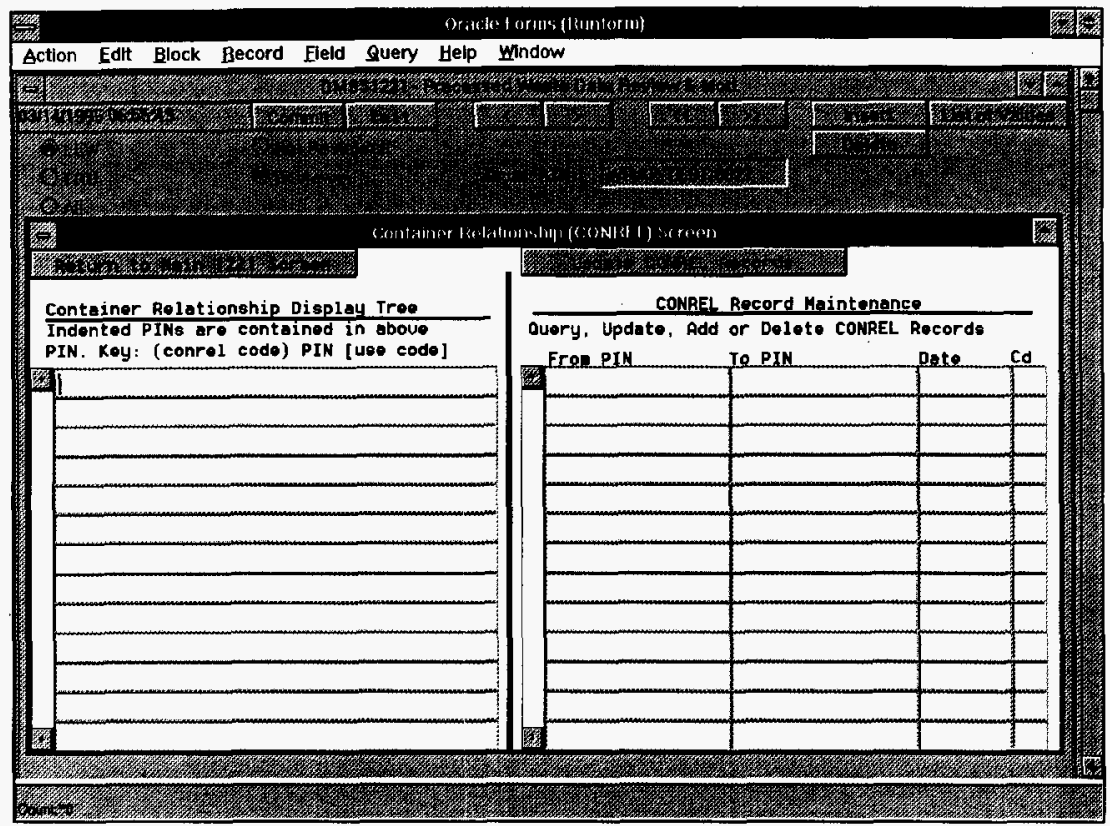

Figure A-94. DMSS1221 Processed Waste Data Review \& Mod. Screen Container Relationship (CONREL) Screen Pop-Up. 


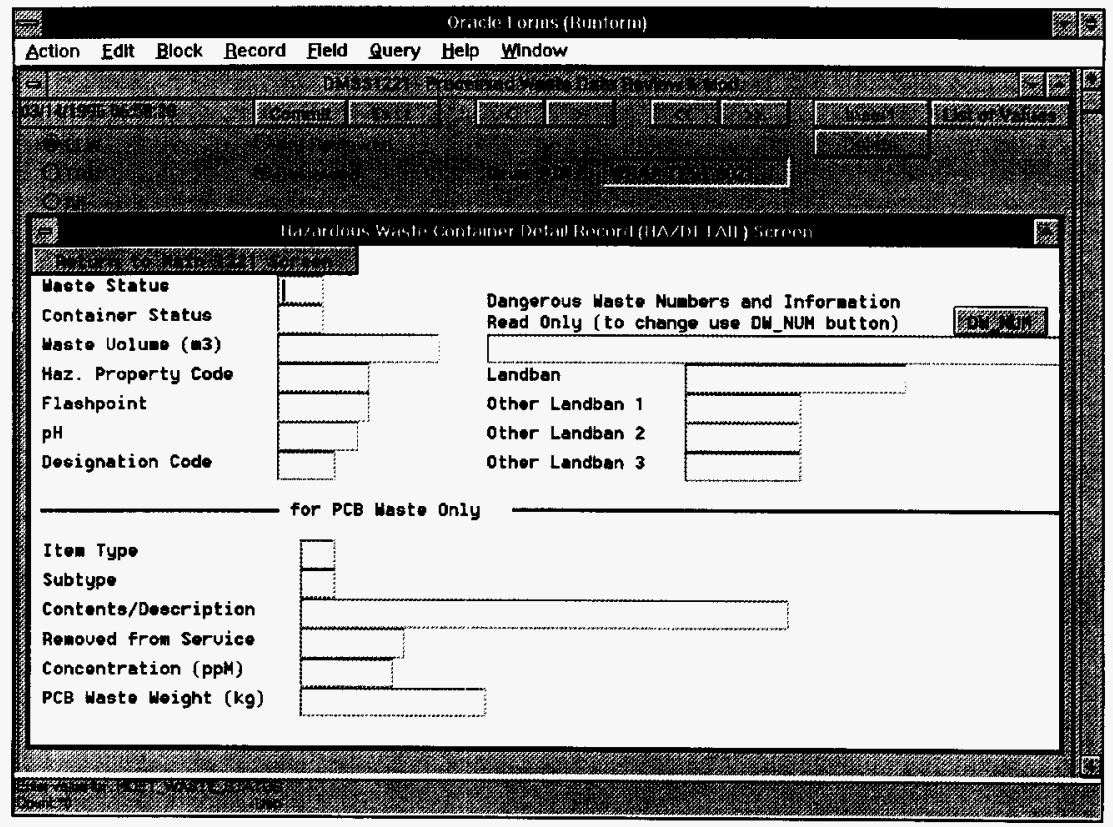

Figure A-95. DMSS1221 Processed Waste Data Review \& Mod. Screen Hazardous Waste Container Detail Record (HAZDETAIL) Screen Pop-Up. 
WHC-SD-W026-SDD-001, Rev. 2

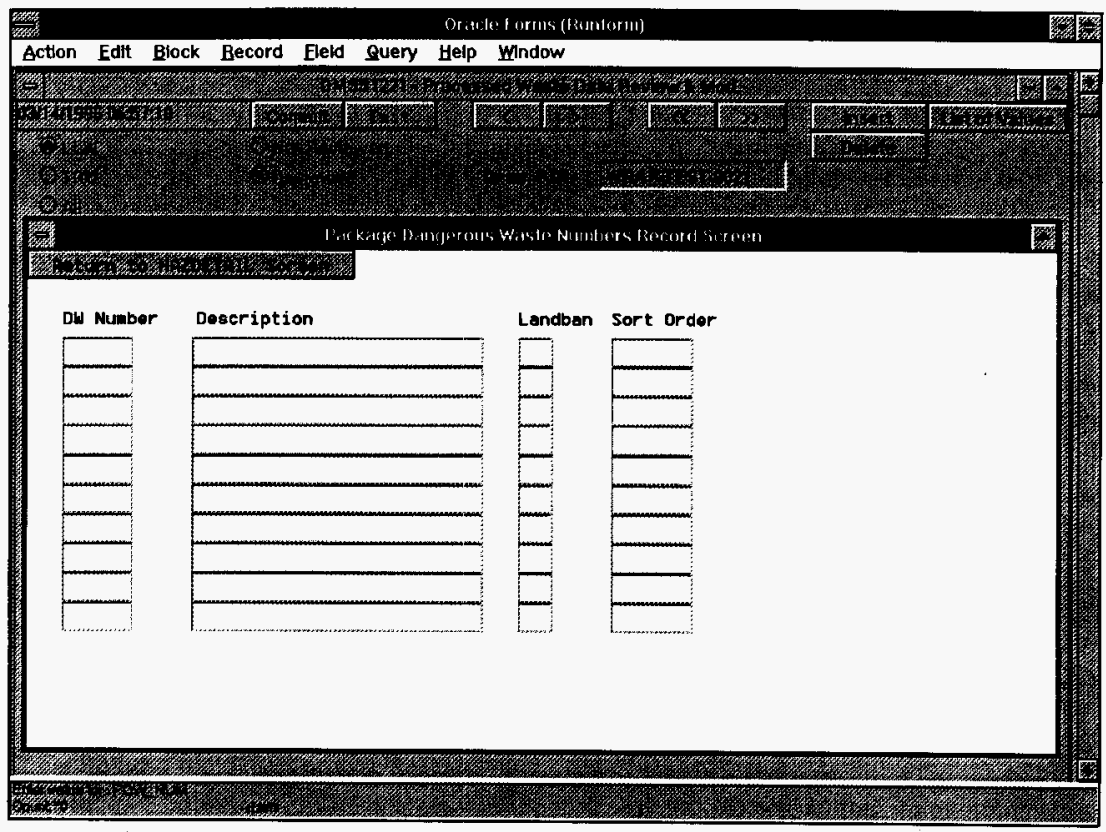

Figure A-96. DMSS1221 Processed Waste Data Review \& Mod. Screen Package Dangerous Waste Numbers Record Screen Pop-Up. 


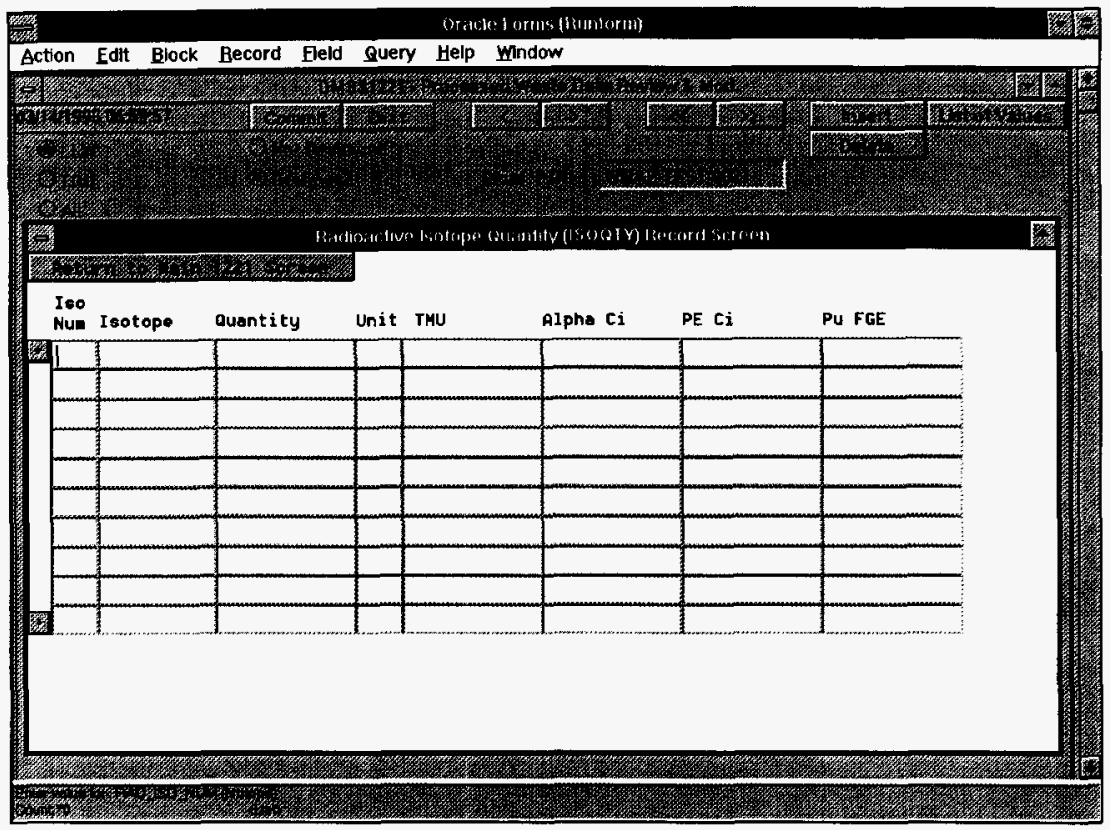

Figure A-97. DMSS1221 Processed Waste Data Review \& Mod. Screen Radioactive Isotope Quantity (ISOQTY) Record Screen Pop-Up. 


$$
\text { WHC-SD-W026-SDD-001, Rev. } 2
$$

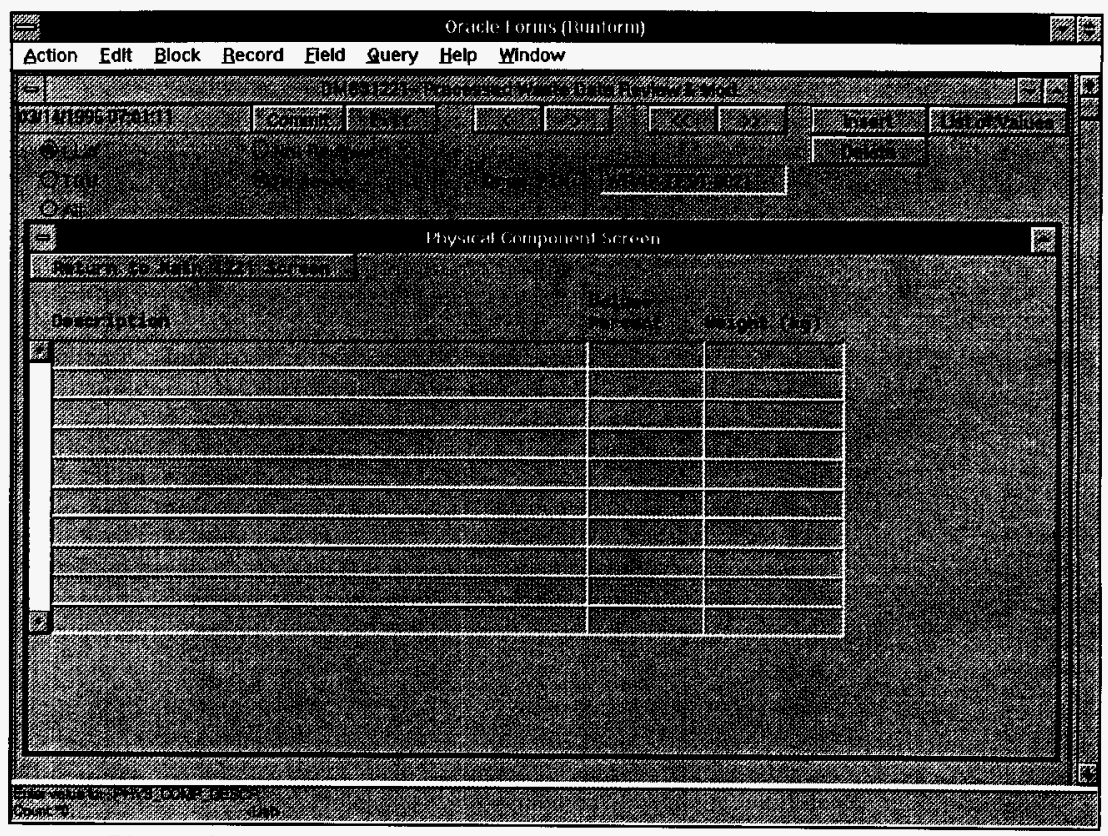

Figure A-98. DMSS1221 Processed Waste Data Review \& Mod. Screen Physical Component Screen Pop-Up. 


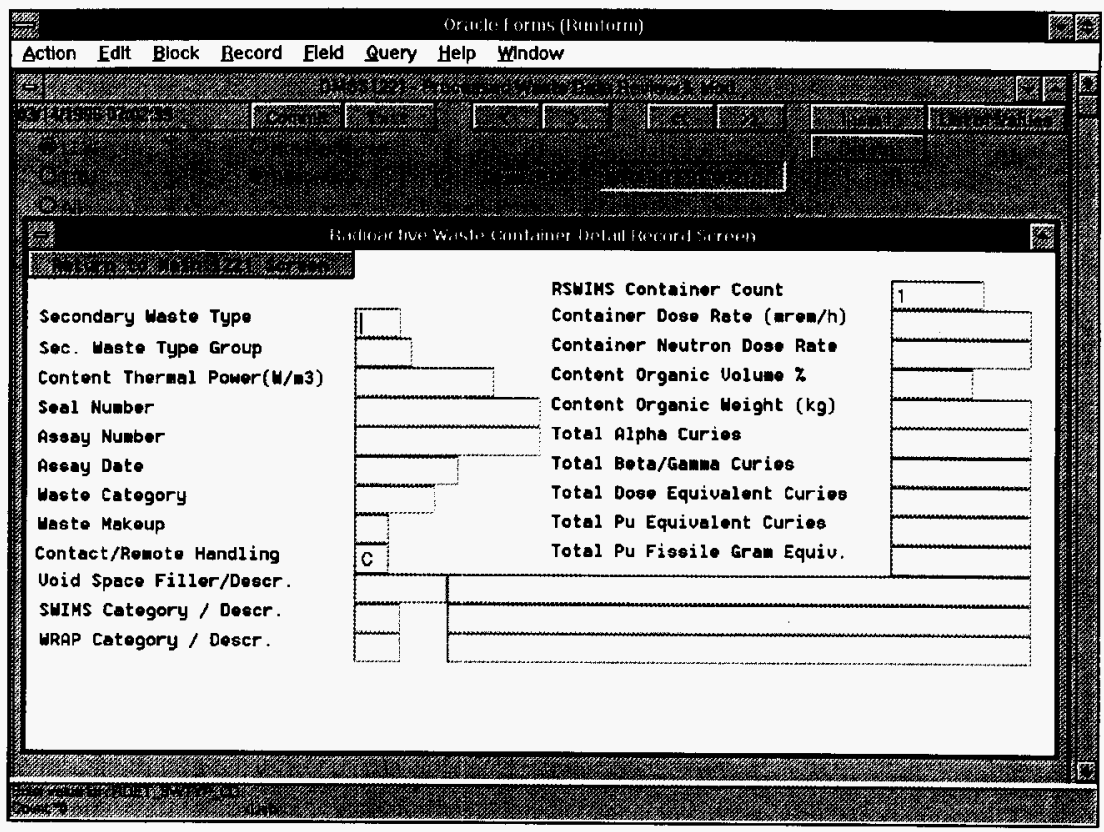

Figure A-99. DMSS1221 Processed Waste Data Review \& Mod. Screen Radioactive Wate Container Detail Record Screen Pop-Up. 


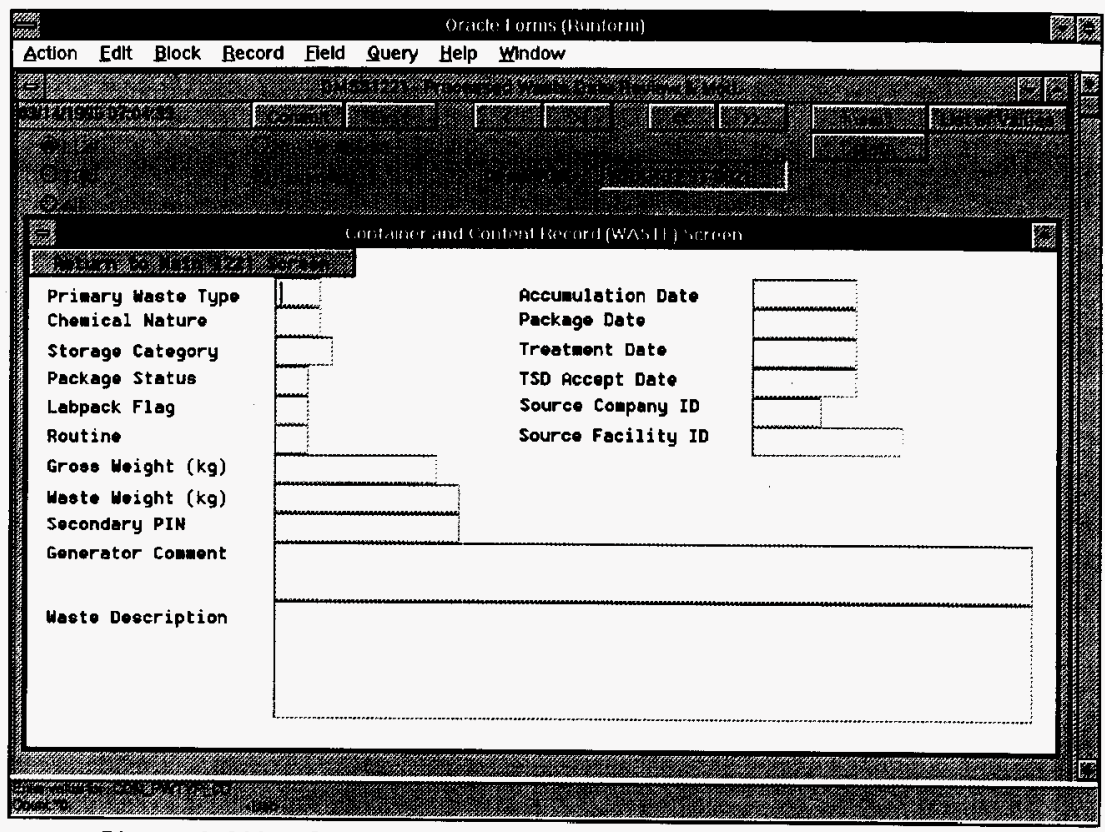

Figure A-100. DMSS1221 Processed Waste Data Review \& Mod. Screen Container and content Record (WASTE) Screen. 


$$
\text { WHC-SD-W026-SDD-001, Rev. } 2
$$

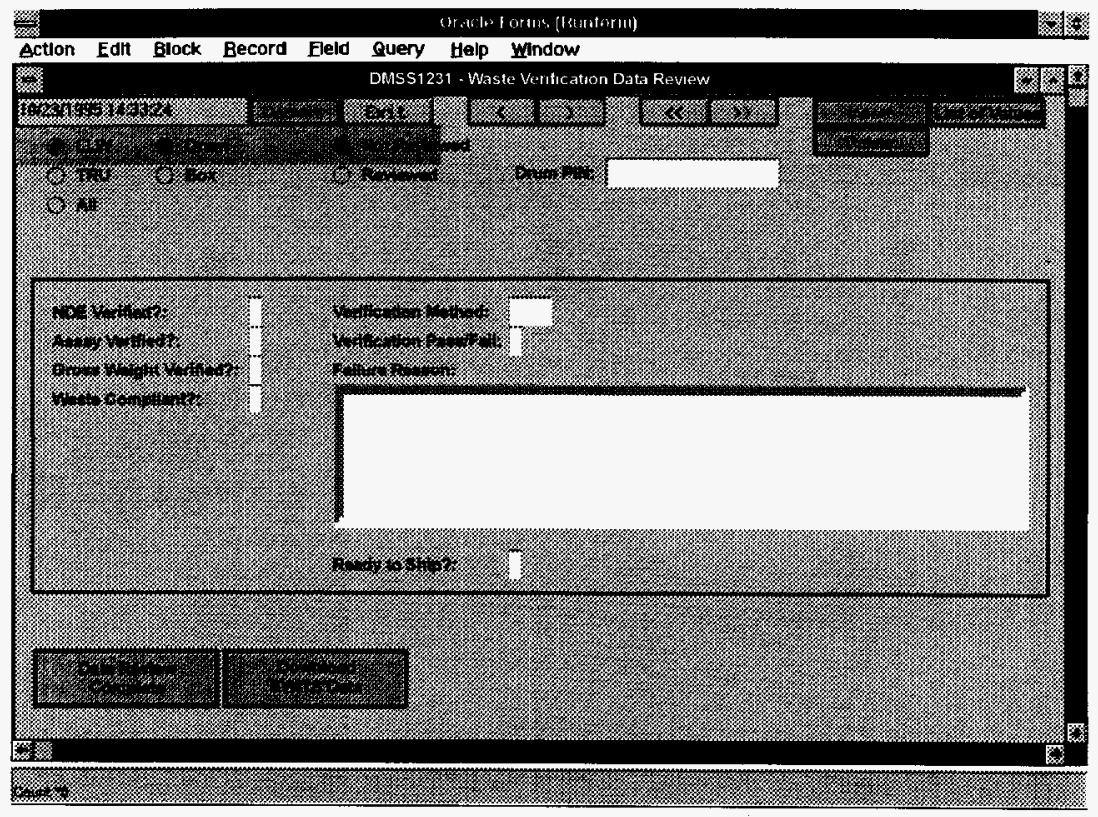

Figure A-101. DMSS1231 Waste Verification Data Review Screen. 
WHC-SD-W026-SDD-001, Rev. 2

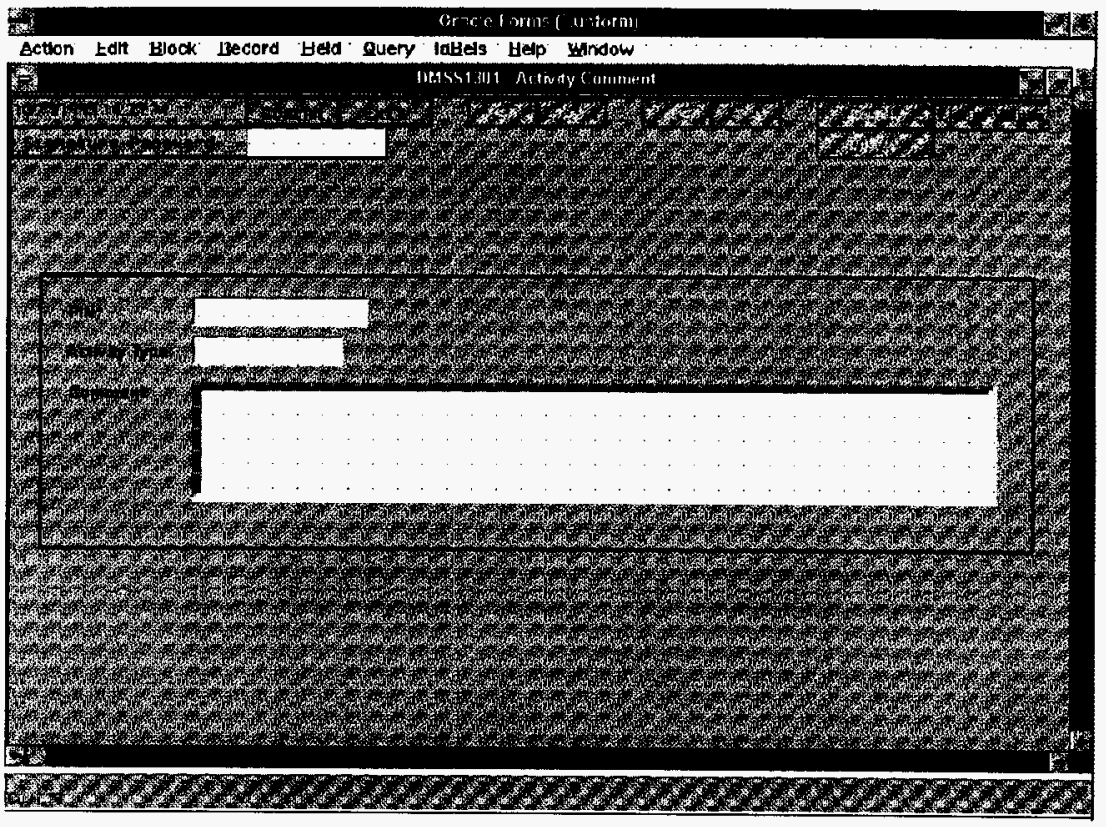

Figure A-102. DMSS1301 Activity Comment Screen. 
WHC-SD-W026-SDD-001, Rev. 2

APPENDIX B

REPORT DESIGN DETAILS

B- $i$ 
WHC-SD-W026-SDD-001, Rev. 2

This page intentionally left blank. 


\section{DMS REPORT HIERARCHY}

1.0 Receiving

DMSROIXX

2.0 NDE/NDA

DMSRO2XX

3.0 Process 0ps

LLW Glovebox

DMSR031X

LLW RWM Glovebox

DMSR032X

TRU Glovebox

DMSR033X

TRU RWM Glovebox

DMSR034X

Misc Processing Reports

DMSS0351 Transfer Drum Status Report

4.0 Table Maint

DMSR04XX

5.0 Sample Mamt

DMSR0501 Open Sample Status Detail Report

$6.0 \quad$ Shipping

9.0 Pick List

DMSR09XX

10.0 Process Route

DMSSR10XX

11.0 Facility Metrics

DMSR1101 Empty Container Inventory Report

DMSR1102 Building Inventory Report

DMSR1103 Waste Package Location History Report

DMSRI104 WRAP Processing Report

12.0 Process Data Review

DMSR1201 Container Listing Report for Package ID 


\subsection{Transfer Drum Status Report (DMSR0351)}

The Transfer Drum Status Report (DMSR0351) provides an inventory of all WRAP 1 transfer drums used to transfer waste between the Processing Area gloveboxes. The status of the drums (i.e. transfer drum ful1, partially full, or empty) is provided along with drum PIN, and inner package PINs. A sample report layout is shown below.

Report Data Element Name

Waste Type

Drum status

Package ID

WRAP Location

Location Date

Inner Package PINs
DMS Database Data Element Name

CON PWTYP CD and RDET_SWTYP_GROUP CONEXT CNTNR STATUS

CON PKG $\bar{G}$ ID

CONLOC [OCN ID

CONLOC DT

CONR_FROM_PKG_ID
Sort Sequence:

User Queries:

Data Selects:

Schedule:

Frequency :

Vol ume :

Totals:

Break Groups:

Page Break:

Requestor/0rg Name:

Special Form/Font:

Report Distribution:

Programmer Notes:
CONEXT_CNTNR_STATUS, CON_PKG_ID

Waste Type (as input by user), default = all

CONEXT_USE_CD = "TD"

N/A

As required

1-5 pages

Containers per status (Empty, partially fu11, fu11) and facility total

Group 1: CONEXT_CNTNR_STATUS

As required

TBD

hpstd

TBD

CONLOC_DT for current CONLOC_LOCN_ID is displayed 
WHC-SD-W026-SDD-001, Rev. 2

DMSR0351

URAP 1 Data Mangenent System

$M M / O D / Y Y$

$\mathrm{HH}: \mathrm{MH}$

Transfer Drum Status Report

page: 1

Primary Waste Type: $X X$

Secondary Waste Type: XXX

\begin{tabular}{|c|c|c|c|c|c|}
\hline $\begin{array}{l}\text { Drum } \\
\text { Status }\end{array}$ & Package ID & $\begin{array}{l}\text { Drum } \\
\text { Location }\end{array}$ & $\begin{array}{l}\text { Location } \\
\text { Date }\end{array}$ & $\begin{array}{l}\text { Location } \\
\text { Time }\end{array}$ & $\begin{array}{l}\text { Inner } \\
\text { Package ID }\end{array}$ \\
\hline$x$ & $x x x x x x x x x x x x x x x x$ & $x x x x x x x x x x$ & $M M / D D / Y Y$ & HH:MM:SS & 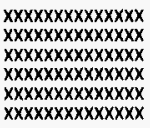 \\
\hline$x$ & $x \times x \times x \times x \times x x x x x \times x$ & $x x x x x x x x x x x$ & $M M / D D / Y Y$ & $H H: M M: S S$ & 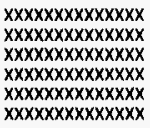 \\
\hline$x$ & $x x x x x x x x x x x x x x x$ & $x \times x \times x \times x \times x \times x \times X$ & $M H / D D / Y Y$ & $H H: M M: S S$ & 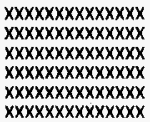 \\
\hline
\end{tabular}

Container status subtotal: 9999

Facility total: 9999

Transfer Drum Status Report (DMSR0351) 


\subsection{Open Sample Status Detail Report (DMSR0501)}

The Open Sample Status Detail Report (DMSR0501) lists all open samples for the WRAP 1 facility. Report is printed by package/drum identification (parent article that the sample was taken from) in ascending order. The sample information and related dates are given for each sample. A sample report layout is provided below.

Report Data Element Name DMS Database Data Element Name

Package ID

Sample ID

Sample Date

Sample Taken By

Sent to Lab

Lab ID

Analysis Returned

Comments

Sort Sequence:

User Queries:

Data Selects:

Schedule:

Frequency:

Volume:

Totals:

Break Group:

Page Break:

Requestor/Org Name: TBD

Special Form/Font: hplsc

Report Distribution: TBD

Programmer Notes: N/A

None

TBD

TBD
SAMREL PKG ID
SAM SAMMPLE ${ }^{-}$ID
SAM TAKEN DT
SAM TAKEN ${ }^{-}$BY
COC SHIP $\bar{D} T$
$\mathrm{COC}^{-} \mathrm{LAB}$ ID
SAM REPŌRT DT
SAM COMMENTS

SAMREL_PKG_ID, SAM_SAMPLE_ID ascending

None, default to WRAP 1 users

SAM_CLOSED_FLAG $=$ ' $N$ '

As Required (weekly)

SAMREL_PKG_ID

As Required 


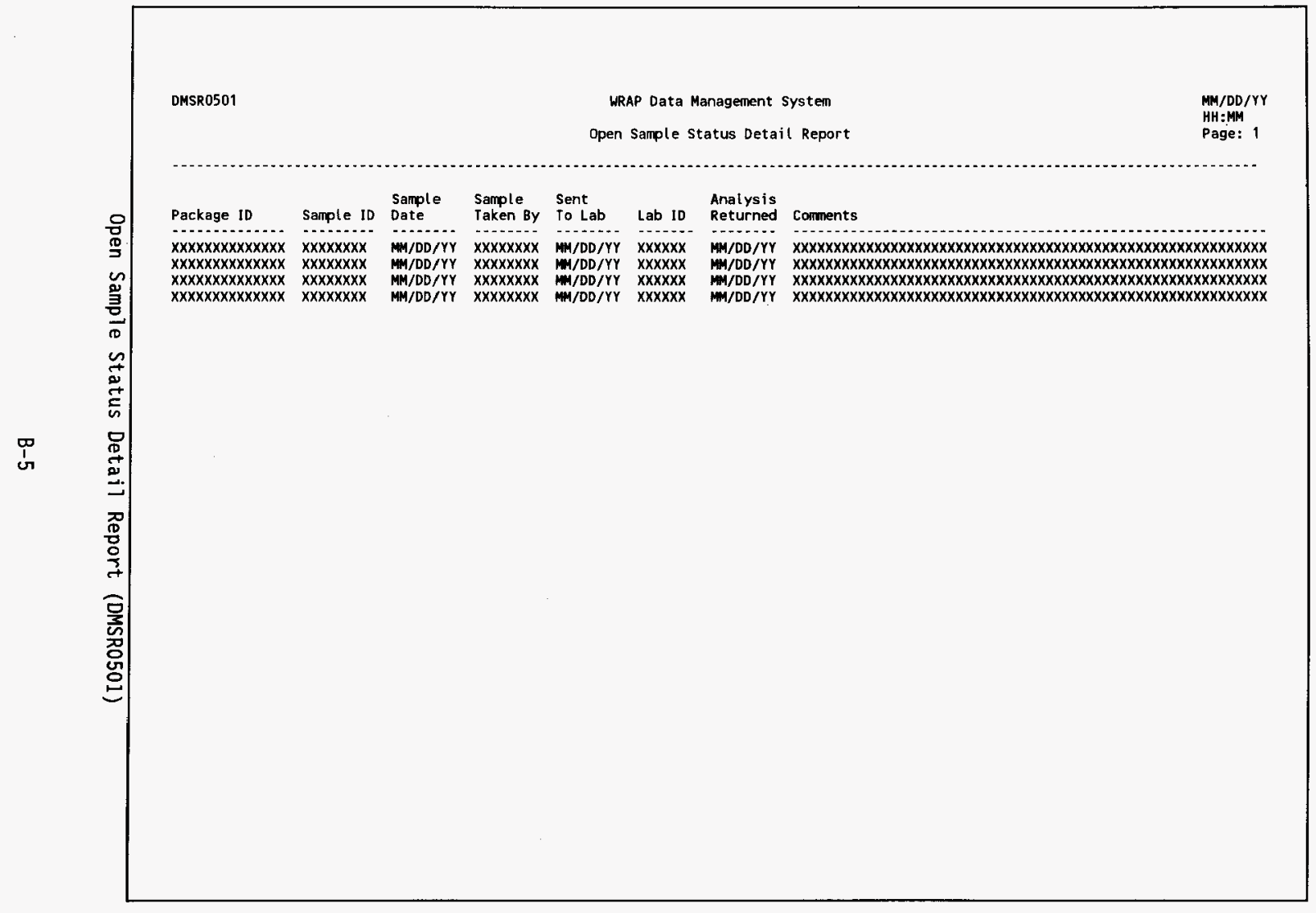


WHC-SD-W026-SDD-001, Rev. 2

\subsection{Empty Container Inventory Report (DMSR1101)}

The Empty Container Inventory Report (DMSR1101) provides an inventory of empty or used-empty containers located within the WRAP facility. A sample report layout is shown below.

Report Data Element Name

Cont Type

Container Size

Package ID

Facility Recipt Date

WRAP Location

\section{DMS Database Data Element Name}

CON CNTYP CD

CON $^{-}$SIZE DESCR

CON ${ }^{-}$PKG ID

CONEOC DT for CONLOC LOCN ID = "RECKCK" or ("LLW ENTRY or

"TRU ENTRY") if 1ater than "RECDCK" CONLŌC LOCN ID
Sort Sequence:

User Queries:

Data Selects:

Schedule:

Frequency:

Volume:

Totals:

Break Groups:

Page Break:

Requestor/Org Name:

Special Form/Font:

Report Distribution:

Programmer Notes:
CON_CNTYP_CD, CON_SIZE_DESCR

CONLOC_LOCN_ID (default is all WRAP locations)

CONEXT_USE_CD = "EC" or CONEXT_CNTNR_STATUS = "E"

$N / A$

As Required

1-5 pages

Containers per type/size combination within Facility

Group 1: CONLOC LOCN ID

Group 2: CON_CNTYP_CD, CON_SIZE_DESCR

as required

TBD

hpstd

TBD

Use of the journaling/archiving functionality will be required to support the "Facility Receipt Date" 
WHC-SD-W026-SDD-001, Rev. 2

\begin{tabular}{|c|c|c|c|c|c|}
\hline \multicolumn{2}{|c|}{ DMSR 1101} & \multicolumn{3}{|c|}{$\begin{array}{l}\text { WRAP } 1 \text { Data Mangement System } \\
\text { Empty Container Inventory Report } \\
\text { Facility Location : XXXXXXXXX }\end{array}$} & $\begin{array}{l}\text { MM/DD/YY } \\
\text { HH:MM } \\
\text { page: } 1\end{array}$ \\
\hline \begin{tabular}{l} 
Cont \\
Type \\
\hdashline$x \times x$
\end{tabular} & $\begin{array}{l}\text { Container size } \\
x x x x x x x x x x x x x x x\end{array}$ & 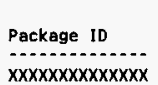 & $\begin{array}{l}\text { Facility } \\
\text { Receipt Dt } \\
\text { MM/DD/YY }\end{array}$ & \begin{tabular}{l} 
Facility \\
Location \\
\hdashline$x x x x x x x x x x$
\end{tabular} & \\
\hline$x x x x$ & $x x x x x x x x x x x x x x x x$ & $x \times x \times x \times x)(x \times x \times x \times x \times x$ & $M A / D D / Y Y$ & $x X X X X X X X X X X X$ & \\
\hline$x x x x x$ & $x x x x x x x x x x x x x x x x x$ & $X X X X X X X X X X X X X X X X X X$ & $M M / D D / Y Y$ & $x y x x x y x x x x x$ & \\
\hline$x x x x$ & 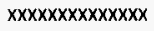 & $x x X X X X X X X X X X X X X X X$ & $M M / D D / Y Y$ & $y X X X X X X X X X X$ & \\
\hline$x x x x$ & $X X X X X X X X X X X X X X X X X X$ & $X X X X X X X X X X X X X X X X X$ & $M M / D D / Y Y$ & XXXXXXXXXXXX & \\
\hline$x x x x$ & $X X X X X X X X X X X X X X X X X$ & $X X X X X X X X X X X X X X X X X$ & $M M / D D / Y Y$ & $X X X X X X X X X X X$ & \\
\hline$x x x x$ & $x \times x \times x \times x \times x \times x \times x \times x \times x x$ & $X X X X X X X X X X X X X X X X X$ & $M M / D D / Y Y$ & $x x x x x x x x x x$ & \\
\hline \multicolumn{6}{|c|}{$\begin{array}{l}\text { Container type/size rotal: } 9999 \\
\text { Facility total: } 9999\end{array}$} \\
\hline
\end{tabular}

Empty Container Inventory Report (DMSR1101) 


\subsection{Building Inventory Report (DMSR1102)}

The Building Inventory Report (DMSR1102) provides building inventory by storage category, location, and waste type. The user enters the location and Storage Category on which the report is to be prepared. A sample report layout is shown below.

Report Data Element Name

Facility Location

Storage Category

Container Use Code

Category Description

Container Type Code

Total Number of Containers

Package ID. Number

Waste Type
DMS Database Data Element Name

CONLOC LOCN ID

CON SCĀT $\mathrm{CD}^{-}$

CONEXT USE CD

SCAT CATTEGÖRY

CON CNTYP CD

count (CON PKG ID)

CON PKG ID ${ }^{-}$

CON_PWTYP_CD and RDET_SWTYP_GROUP
Sort Sequence:

User Queries:

Data Selects:

Schedule:

Volume:

Frequency:

Vol ume :

Totals:

Page Break:

Requestor/Org Name:

Special Form/Font: $\quad$ hp304

Report Distribution: TBD

Programmer Notes:

$N / A$

TBD

TBD
CONLOC_LOCN_ID, CON_SCAT_CD, CONEXT_USE_CD, CON_PKG_ID

CONLOC LOCN ID, default = all WRAP 1 locations

CON SCATT CD, default $=$ a 11 CON SCAT CDS CONEXT_US̄EECD

A11 WRAP 1 containers

Approximately 1 to 30 pages

CON_PKG_ID by CONLOC_LOCN_ID \& CON SCAT CD

Containers by location

Category description in header left blank if Storage Category is not filled in by user 
WHC-SD-W026-SDD-001, Rev. 2

\begin{tabular}{|c|c|c|c|c|c|c|}
\hline DMSR 1102 & \multicolumn{5}{|c|}{$\begin{array}{l}\text { Building Inventory Report: } \\
\text { for WRAP Location: } X X X X X X X X X X X X \\
\text { for Storage Category: } X X X X X X X X X \\
\text { for Container Use Code: } X X\end{array}$} & $\begin{array}{l}\text { MM/DD/YY } \\
\text { HH:MM } \\
\text { Page: } 1\end{array}$ \\
\hline \multicolumn{7}{|c|}{ Total for Facility/Ouadrant: 99999} \\
\hline $\begin{array}{l}\text { Category } \\
\text { Description } \\
x \times x \times x \times x \times x \times x\end{array}$ & $\operatorname{cxxxxxxxx}$ & $\begin{array}{l}\text { Total N } \\
\text { of Cont } \\
99999\end{array}$ & $\begin{array}{l}\text { nber } \\
\text { iners }\end{array}$ & & & \\
\hline $\begin{array}{l}\text { Container } \\
\text { Location } \\
x \times x \times x \times x \times x \times\end{array}$ & \begin{tabular}{l} 
Storage \\
Category \\
\hdashline$x \times x \times x \times x \times$
\end{tabular} & $\begin{array}{l}\text { Container } \\
\text { Use Code } \\
\text { Xx }\end{array}$ & $\begin{array}{l}\text { Package ID. } \\
\text { Number } \\
x \times x \times x \times x x x \times x x x x\end{array}$ & $\begin{array}{l}\text { Conta iner } \\
\text { Type Code } \\
\text { XX }\end{array}$ & 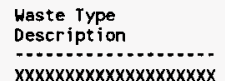 & \\
\hline 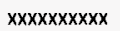 & $x x x x x x x x$ & $x x$ & $x x x x x x x x x x x x x x$ & $x x$ & 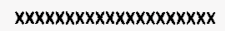 & \\
\hline$x x x x x \times x \times x x$ & $x x x x x x x x$ & $x x$ & $x \times x x x x x x x x x x x x$ & $x \mathbf{x}$ & $x x x x x x x x x x x x x x x x x x x x x$ & \\
\hline$x x \times x \times x x x x x$ & $x x x x x x x x$ & $\mathbf{x x}$ & $x x x x x x x x x x x x x x x$ & $\mathbf{x x}$ & 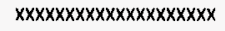 & \\
\hline
\end{tabular}

Building Inventory Report (DMSR1102)

\subsection{Waste Package Location History Report (DMSR1103)}

The Waste Package Location History Report (DMSR1103) provides a history of the relocation of a specific waste package within the WRAP facility. The history will include the locations, date/time.

\section{Report Data Element Name}

Package ID

WRAP Location

WRAP Relocation Date

\section{DMS Database Data Element Name}

CONLOC PKG ID

CONLOC ${ }^{-}$LOCN ID

CONLOC $-\mathrm{DT}$

Sort Sequence: $\quad$ CONOC_DT

User Queries: CONLOC_PKG_ID

Data Selects: Al1 CONLOC_LOCN_ID for input PIN

Schedule: $\quad$ N/A

Frequency: As Required 
Volume:

1 page

Totals:

$N / A$

Break Groups:

$N / A$

Page Break:

As Required

Requestor/Org Name: TBD

Special Form/Font: hpstd

Report Distribution: TBD

Programmer Notes: Use of the journaling/archiving functionality will be required to support the Location History function

\begin{tabular}{|c|c|c|c|}
\hline DMSR 1103 & \multicolumn{2}{|c|}{$\begin{array}{l}\text { WRAP I Data Mangement System } \\
\text { Waste Container Locati on History Report } \\
\text { Waste Container ID : } X X X X X X X X X X X X X X X\end{array}$} & $\begin{array}{l}M M / D D / Y Y \\
H H: M M \\
\text { page: } 1\end{array}$ \\
\hline \begin{tabular}{l} 
Facility \\
Location \\
\hdashline$X X X X X X X X X X$ \\
$X X X X X X X X X X$ \\
$X X X X X X X X X X$ \\
$X X X X X X X X X X$ \\
$X X X X X X X X X X$ \\
$X X X X X X X X X X$ \\
$X X X X X X X X X X$ \\
$X X X X X X X X X X$ \\
$X X X X X X X X X X$ \\
$X X X X X X X X X X$ \\
$X X X X X X X X X X$ \\
$X X X X X X X X X X$ \\
$X X X X X X X X X X$ \\
$X X X X X X X X X X$ \\
$X X X X X X X X X X X$
\end{tabular} & $\begin{array}{l}\text { Relocation } \\
\text { Date } \\
-M M / D D / Y Y \\
M M / D D / Y Y \\
M M / D D / Y Y \\
M M / D D / Y Y \\
M M / D D / Y Y \\
M M / D D / Y Y \\
M M / D D / Y Y \\
M M / D D / Y Y \\
M M / D D / Y Y \\
M M / D D / Y Y \\
M M / D D / Y Y \\
M M / D D / Y Y \\
M M / D D / Y Y \\
M M / D D / Y Y \\
M N / D D / Y Y \\
M M / D D / Y Y\end{array}$ & 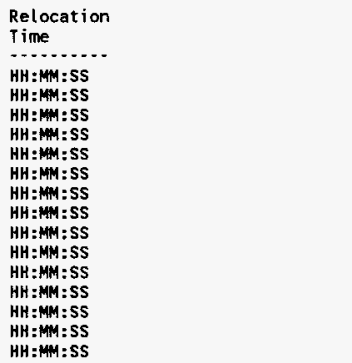 & \\
\hline
\end{tabular}

Waste Container Location History Report (DMSR1103) 


\subsection{WRAP Processing Report (DMSR1104)}

The WRAP Processing Report (DMSR1104) summarizes the number of containers received, verified, processed. The summary is keyed by primary and secondary waste type and provides a subtotal for each waste type and a total of all container in each category for a given time period. A sample report layout is shown below.

Report Data Element Name
Container Use Code
Waste Type
Package ID
Facility Receipt Date
Processed Date
Shipped Date
Certified/Verified

\section{DMS Database Data Element Name} CONEXT USE CD CON PWTYP $\bar{C} D$ and RDET_SWTYP_GROUP CON PKG ID CONLOC DT for CONLOC_LOCN_ID = "RECDCK" CON_ACCUM DT, "AIRCVYR_A3" or "AI RCVYR $\bar{B} 1$ " (see notes below) CON_SHIP_DT VER_PASS
Sort Sequence:

User Queries:

Data Selects:

Schedule:

Frequency:

Volume:

Totals:

Break Groups:

Page Break:

Requestor/Org Name:

Special Form/Font:

Report Distribution

Programmer Notes:
Primary sort by CONEXT_USE CD and Waste Type, if not specified, secondary sōrt by VER_PASS

CONEXT_USE_CD and Waste Type

CONEXT USE CD = "PD", "BX", "WP" "WV"). Time frame bounded by "Report Period Start" and "Report Period End" dates specified by the user.

$N / A$

TBD

TBD

Containers Received, Processed, Shipped, and Verified

Group 1: Waste type, CONEXT_USE_CD

Waste Type and as required

TBD

hpstd

TBD

Provide al1 CON PKG ID records with dates between those specified by the user in the report header.

If the "WV" or "BX" use codes are specified, no processed dates will be displayed. If the "WP" use code is specified, no shipped date or certified date will be displayed. The 
processed date should be set $=$ CONLOC DT for CONLOC LOCN ID = "AIRCVYR A3" or "AIRCVYYR Bl"

- If the "PD"- use code is specified, no receipt date will be displayed. The processed date should be set = CON ACCUM DT

- Use of the journaling/archiving functionality will be required to support the "Facility Receipt Date"

DMSR1104

WRAP 1 Data Mangenent System

WRAP Processing Report
$M M / D D / Y Y$

$H H: M M$

page: 1

Report Period Start: MM/DO/YY

Report Period End: $M M / D D / Y Y$

Container Use Code ( $B X, W N$, or $P D$ ) : XX

Waste Type (CON_PWTYP_CD and RDET_SWTYP_GROUP: XXXXXXX

\begin{tabular}{|c|c|c|c|c|c|c|}
\hline $\begin{array}{l}\text { Container } \\
\text { Use Code }\end{array}$ & $\begin{array}{l}\text { Waste } \\
\text { Type }\end{array}$ & Package ID & $\begin{array}{l}\text { Facility } \\
\text { Receipt Dt }\end{array}$ & $\begin{array}{l}\text { Processed } \\
\text { Date }\end{array}$ & $\begin{array}{l}\text { Shipped } \\
\text { Date }\end{array}$ & $\begin{array}{l}\text { Certified/ } \\
\text { Verified }\end{array}$ \\
\hline$x x$ & $x \times x x x x$ & $x x x \times x \times x \times x \times x x x x x$ & $M M / D D / Y Y$ & MM/DD/YY & $M M / D D / Y Y$ & $x$ \\
\hline$x x$ & $x x x x x x$ & 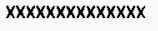 & $M M / D D / Y Y$ & MM/DD/YY & $M M / D D / Y Y$ & $x$ \\
\hline$x x$ & $x \times x x x x$ & $x X X X X X X X X X X X X X X$ & $M M / D D / Y Y$ & $M M / D D / Y Y$ & $M M / D D / Y Y$ & $x$ \\
\hline
\end{tabular}

Container use code, waste type, received subtotal: 9999

Container use code, waste type, processed subtotal: 9999

Container use code, waste type, shipped subtotal: 9999

Container use code, waste type, certified subtotal: 9999

Container use code total: 9999

WRAP Processing Report (DMSR1104) 


\subsection{Container Listing Report for Package ID (DMSR1201)}

The Container Listing Report for Package ID (DMSR1201) produces a complete list of all the data elements pertaining to an individual CON PKG ID. The selection screen permits any combination of selection data includíng:

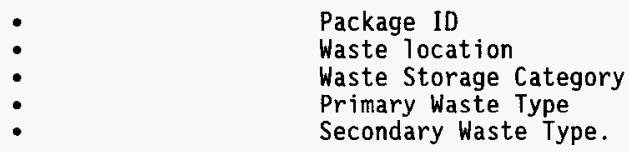

Entry of any or all of the input parameters will cause the report program to select only data that matches user input. A sample report layout is shown in below.

Report Data Element Name

Package ID

SDAR Approval Number

Primary Waste Type

Accumulation Date

Packaged Date

Package Status

Certification Date

Physical State Code

Chemical Nature Code

SWIMS Waste Description Code

Backlog Flag

Secondary Waste Type Code

Secondary Waste Group

Waste Type Description

Container Type Code

/ Description

\% Organic Volume

Container volume (meters)

Waste Wt. $(\mathrm{kg})$

Organic Wt $(\mathrm{kg})$

Container Empty Tare Wt.

Container Total Wt. (kg)

Labpack Flag

Container Contents
DMS Database Data Element Name

CON PKG ID

RDET SDĀR APPRV NUM

CON PWTYP CD

$\mathrm{CON}^{-}$ACCUM ${ }^{-} \mathrm{DT}$

CON ${ }^{-}$PKG DT

CON-PKG ${ }^{-}$STATUS

RDET CERT DT

CON PHYS STATE CD

CON ${ }^{-}$CHEM NATURE CD

RDET SWIMSS CD

CON BAACKLO $\bar{G}$ FLAG

RDET SWTYP $\bar{C} D$

RDET ${ }^{-}$SWTYP' GROUP

-- Cālculated

CON CNTYP CD

CON SIZE DESCR

RDET̄ORGÄNIC_VOL_PCT

CON CNTR VOL

CON WASTE WGT

RDETT ORGANIIC WGT

(kg) CON TARE WGT

CON ${ }^{-}$GROS $\bar{S}$ WGT

CON ${ }^{-}$LABPAC̄K FLAG

CON_GENER_WĀSTE_DESCR

Generator Information:

Generating Company

/ Company Title

Company Type

Organization

Source Facility

Charge Code

Generator Comments

$$
\begin{aligned}
& \text { CON SRCE CMPNY_ID } \\
& --\bar{C} \text { alcuTated - } \\
& \text { CON_SRCE_CMPNY_TYPE } \\
& \text { CON SRCE_ORG } \\
& \text { CON_SRCE_FACIL_ID }
\end{aligned}
$$

CON SRCE CHRG CD

CON_GENER_COMMTENT 


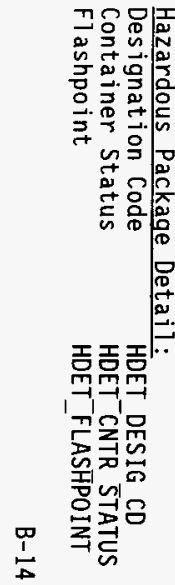

DMSR 1201

WRAP Data Management System

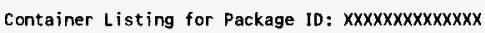

$M M / D D / Y Y$

HH:MM

Package ID: $X X X X X X X X X X X X X X X$ SDAR Approval \#: $X X X X X X X X X X X X X$

Primary Haste Type: $X X \quad$ Accumulation Date: $1 / D O / Y Y$

Package Status: $X$ Certification Date: $X Y / D O / Y Y$

SWIMS Waste Description Code: $X X$ Data Qual ity Code: $X X$

Backlog Flag: $X$

Secondary Waste Type Code: $x x$ Secondary Haste Group: $X x$

Container Type Code / Description: XX / Xxxxxxxxxxxxx

Container Volume (meters): 9999999.999

Conta iner Empty Iare Wt.(kg): 9999999.999

Labpack $F$ lag: $x$

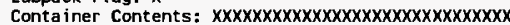

Generator Information: XXXXXXXXXXXXXXXXX

Generating Company: $X X X X X X X / X X X X X X X X X X X X X X X X X X X X X X X X X X X X X X X X X X X X X$ Company Type: $X X X$

Organization: 99999 Source Facility: $x x x x x x x x$ charge Code: $x x x x$

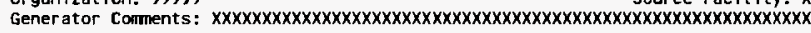

Packaged Date: MM/DD/YY

Chemical Nature Code: $X X$

Hazardous Package Detail: XXXXXXXXXX
Designation Code: $X X$ Container status: $X X$
$\mathrm{pH}$ Value: 9999
Container Status: XX Flashpoint: 9999
Hazardous Waste Volume: 999999
DW Waste $\#: x x x x$
Other Landban \#1: $\mathrm{XX}$
other Landban $\# 2$ : $X X$
Hazardous Properties Cd: $x x$ Waste Status: $x X$
Other Landban $\# 3: x x$

* Organic Volume: 999

Radioactive Package Detail:

Total Alpha (Ci): 999999999 Total Beta-Gamma (Ci): 9999999999

Ttotal Pu Equivalent ( $\mathrm{C}$ i): 9999999999 Total PU-FGE: 9999999999

Neutron Dose Rate: 9999999999 Thermal Power (w/Cu.m.): 9999999999

Dose Rate: 9999999999

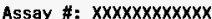

Seal \#: $\mathbf{x X X X X X X X X X X X X X X X}$

Current Location Information:

TSO Accept Date: MM/DD/YY Area: $x x x x x$ Facility ID: $x x x x x x$

Storage Category: $\mathrm{xxX}$

Content WRAP Category: $x x$ Waste Make- up Code: $x x$ void Code: $x x$ 
Repackaging History

Current Container Previous Container(s) Relation Cd Date Repackaged Action Taken

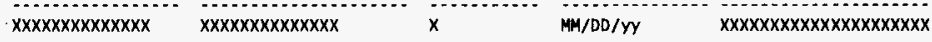

Isotope Information:

Isotope Number Isotope Name Alpha Ci PE-Ci Isotope Activity Unit

$\begin{array}{llllllll}999 & \text { XXXXXXXXXXXXXXXXXX } & 999999999999 & 999999999999 & 999999999999 & 9999999999999999 & 0.120\end{array}$

Hezardous chemical Components:

Component 10 component Text $\quad$ PPM Weight (kg) Height \% EPCRA

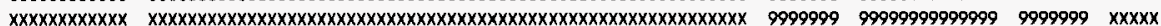

Physical Components:

Content Description Volume \% Weight $(\mathrm{kg})$

XXXXXXXXXXXXXXXXXXXXXXXXXXXXXXX 9999999999999999999

Manifest/Shipping Information:

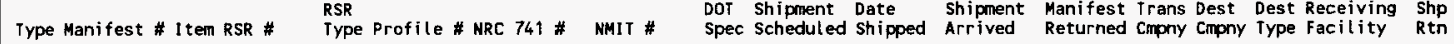

Shipment Manifest Trans Dest Dest Receiving Shp 


$\begin{array}{ll}\text { Hazardous Properties Cd HDET_HAZPROP_CD } \\ \text { pH Value } & \text { HDET_PH } \\ \text { Hazardous Waste Volume } & \text { HDET_WASTE VOL } \\ \text { Waste Status } & \text { HDET_WASTE_STATUS } \\ \text { DW Waste \# } & \text { HDET_DW NUM } \\ \text { Landban } & \text { HDET_LANDBAN } \\ \text { Other Landban \#1 } & \text { HDET_OTHER_LANDBAN_1 } \\ \text { Other Landban \#2 } & \text { HDET_OTHER_LANDBAN_2 } \\ \text { Other Landban \#3 } & \text { HDET_OTHER_LANDBAN_3 }\end{array}$

Radioactive Package Detail:

\begin{tabular}{|c|c|}
\hline $\begin{array}{l}\text { Total Alpha (Ci) } \\
\text { Total Beta-Gamma (Ci) } \\
\text { Dose Rate } \\
\text { Content WRAP Category } \\
\text { Total Pu Equivalent (Ci } \\
\text { Total Pu-FGE } \\
\text { Assay Number } \\
\text { Waste Make-up Code } \\
\text { Neutron Dose Rate } \\
\text { Thermal Power (w/cubic } \\
\text { Seal Number } \\
\text { Void Code }\end{array}$ & 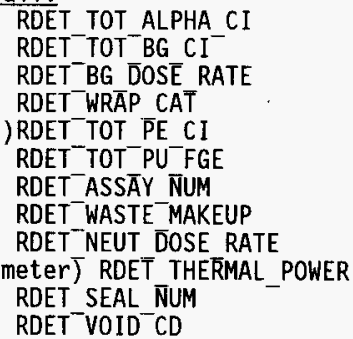 \\
\hline
\end{tabular}

Current Location Information:

$\begin{array}{ll}\text { TSD Accept Date } & \text { CON_TSD ACCEPT_DT } \\ \text { Area } & \text { CON_LOCN FACIL-AREA } \\ \text { Facility ID } & \text { CON }^{-} \text {LOCN FACIL_ID } \\ \text { Storage Category } & \text { CON_SCAT_CD }^{-}\end{array}$

Repackaging History:

Current Container

Previous Container(s)

Date Repackaged

CONR TO PKG ID

CONR ${ }^{-}$FRŌM_PKG ID

CONR ${ }^{-} D T$

Container Relationship

CONR_REL_CD

Isotope Information:

Isotope Number

I sotope Name

RAD ISO NUM

Alpha Ci

PE-Ci

PU-FGE

Isotope Activity

Unit

ISO NAME

RAD ALPHA CI

$\mathrm{RAD}^{-} \mathrm{PE} \mathrm{CI}^{-}$

$\mathrm{RAD}^{-} \mathrm{PU}-\mathrm{FGE}$

$\mathrm{RAD}^{-} \mathrm{QTY}$

ISO_UNIT

Hazardous Chemical Components:

\begin{tabular}{ll}
\hline Component ID & HAZ COMP ID \\
Component Text & HAZ_COMP-TEXT \\
PPM & HAZ_COMP-PPM \\
Weight $(\mathrm{kg})$ & HAZ_COMP-WGT \\
Weight $\%$ & HAZ_COMP-WGT PCT \\
EPCRA & HAZ_EPCRA_FLAG
\end{tabular}

Physical Components: Content Description

PHYS COMP DESCR 
$\begin{array}{ll}\text { Volume } \% & \text { PHYS COMP VOL_PCT } \\ \text { Weight }(\mathrm{kg}) & \text { PHYS_COMP_WGT }^{-}\end{array}$

Manifest/Shipping Information:

Type

Manifest Number

Item Number

RSR Number

RSR Type

Profile Number

NRC 741 Number

NMIT Number

DOT Specification

Shipment Scheduled

Date Shipped

Manifest Returned

Transportation Company

Transportation Type

Destination Company

Destination Type

Receiving Facility

Shipment Return

Sort Sequence:

User Queries:

Data Selects:

Schedule:

Frequency:

Volume :

Totals:

Break Groups:

Page Break:

Requestor/Org Name: TBD

Special Form/Font: hp310

Report Distribution: TBD

Programmer Notes: N/A

TBD

TBD
SHPMNT MFST TYPE_CD

SHPHST $^{-}$MFST $^{-}$NUM

SHPITM-ITEM-NUM

SHPHST ${ }^{-}$RSR N NUM

SHPMNT ${ }^{-}$RSR $^{-}$TYPE

SHPITM-PROFILE NUM

SHPHST $^{-} 741$ NUM $^{-}$

SHPHST $^{-}$NMIT NUM

CON DOT SPEC

SHPMNT SCHED DT

SHPMNT ${ }^{-}$SHIP DT

SHPMNT ${ }^{-}$MFST $^{-}$RET DT

SHPMNT_TRANSP_CMPNY ID

SHPMNT ${ }^{-}$TRANSP- ${ }^{-}$CMPNY $^{-}$TYPE

SHPMNT_OFFSITE CMPNY ID

SHPMNT ${ }^{-}$OFFS ITE ${ }^{-}$CMPNY $^{-}$TYPE

SHPMNT'RECV FAC IL_ID

SHPHST_RETUR̄N

CON_PKG_ID

CON_PKG_ID

As defined above

2 pages per CON_PKG_ID (Could be as many as 200 to 300 containers for some runs)

total HAZ_COMP_WGT, total PHYS_COMP_WGT

As Required 
WHC-SD-W026-SDD-001, Rev. 2

This page intentionally left blank. 
WHC-SD-W026-SDD-001, Rev. 2

APPENDIX C

DATA DICTIONARY

C $-i$ 
WHC-SD-W026-SDD-001, Rev. 2

This page intentionally left blank. 
WHC-SD-W026-SDD-001, Rev. 2

\section{CONTENTS}

C.0 DATA DICTIONARY . . . . . . . . . . . . . . . . . . C-1

C.1 DATA ELEMENT LIST . . . . . . . . . . . . . . . . C-5

C.1.1 Data Record Tables.............. . C-5

C.1.2 Data Look-Up Tables . . . . . . . . . . . . . . . C-19

C.2 DMS DATA ELEMENT DESCRIPTIONS ............. . C-27

C.2.1 Data Record Tables Element Descriptions . . . . . . . C-27

C.2.2 Data Look-Up Tables Element Descriptions . . . . . . C-105

C.3 MISCELLANEOUS CODE DEFINITIONS . . . . . . . . . . . . c c-134

C.4 "ONE-PAGER" DATA ElEMENT LIST . . . . . . . . . . . . . . c-135

\section{TABLES}

C-1. DMS Data Records and Lookup Tables .............. C-1

C-2. Miscellaneous Codes. .................... C-134

C-3. WRAP Miscellaneous Codes. . . . . . . . . . . . . . . . c-134 
WHC-SD-W026-SDD-001, Rev. 2

This page intentionally left blank. 


\section{C.0 DATA DICTIONARY}

The Data Dictionary describes the data elements that make up the DMS database. The data elements are grouped into records of related data. In the front of a data name, an [*] indicates a unique key for the record in which the data element occurs, a [•] indicates a foreign key to which the data element refers, and a [U] indicates a unique non-key index. An [R] following the data element size and type indicates that data is required in that element (the element value cannot be null).

Table C-1 summarizes the WRAP 1 DMS data records, along with the phase in which each is planned for implementation, DMS or SWITS origin, and whether the record is journalled. Section C.I lists the data elements included in each data record and look-up data table and provides the name and size for each data element. Section C.2 contains definitions of each of the data elements.

Table C-1. DMS Data Records and Lookup Tables.

\begin{tabular}{|c|c|c|c|c|c|c|c|}
\hline \multirow[b]{2}{*}{ Record Name } & \multirow{2}{*}{$\begin{array}{l}\text { Database } \\
\text { Table Name }\end{array}$} & \multicolumn{2}{|c|}{$\begin{array}{l}\text { Table } \\
\text { Origin }\end{array}$} & \multicolumn{3}{|c|}{$\begin{array}{c}\text { DMS Devel. } \\
\text { Phase }\end{array}$} & \multirow[b]{2}{*}{ Journal } \\
\hline & & SWITS & DMS & 1 & 2 & 3 & \\
\hline \multicolumn{8}{|c|}{ Data Record Tables } \\
\hline Activity Comment Record & ACTCOM & & $x$ & & $x$ & & \\
\hline Applicable MSDS & APPMSDS & $x$ & & $x$ & & & $X$ \\
\hline Bin List & BIN & & $x$ & $x$ & & & \\
\hline Bottle Data Record & BOTTLE & & $x$ & & $x$ & & $x$ \\
\hline Bottle Analysis Record & BOTANAL & & $x$ & & $x$ & & \\
\hline $\begin{array}{l}\text { Hazardous Chemical Component } \\
\text { Record }\end{array}$ & CHEMCOMP & $x$ & & $x$ & & & $X$ \\
\hline Chain of Custody & $\operatorname{coc}$ & & $x$ & & $x$ & & $x$ \\
\hline Chain of Custody Transfer & COCXFR & & $x$ & & $x$ & & \\
\hline Communication Table & $\begin{array}{l}\text { COMMUNICATIO } \\
\text { N_TABLE }\end{array}$ & & $x$ & $x$ & & & \\
\hline Container Location & CONLOC & & $x$ & $x$ & & & $X$ \\
\hline Container Relationship Record & CONREL & $x$ & & $x$ & & & $x$ \\
\hline Container Treatment & CONTREAT & & $x$ & & $x$ & & \\
\hline Discharge Conveyor List & DISCHARGE & & $x$ & $x$ & & & \\
\hline
\end{tabular}


WHC-SD-W026-SOD-001, Rev. 2

\begin{tabular}{|c|c|c|c|c|c|c|c|}
\hline \multirow[b]{2}{*}{ Record Name } & \multirow{2}{*}{$\begin{array}{l}\text { Database } \\
\text { Table Name }\end{array}$} & \multicolumn{2}{|c|}{$\begin{array}{l}\text { Table } \\
\text { Origin }\end{array}$} & \multicolumn{3}{|c|}{$\begin{array}{l}\text { DMS Deve1. } \\
\text { Phase }\end{array}$} & \multirow[b]{2}{*}{ Journal } \\
\hline & & SWITS & DMS & 1 & 2 & 3 & \\
\hline Field Screening Record & FIELDSCRN & & $x$ & & $x$ & & \\
\hline Field Analysis & FIELDANAL & & $x$ & & $x$ & & . \\
\hline $\begin{array}{l}\text { Hazardous Waste Container } \\
\text { Detail Record }\end{array}$ & HAZDETAIL & $x$ & & $x$ & & & $x$ \\
\hline $\begin{array}{l}\text { Radioactive Isotope Quantity } \\
\text { Record }\end{array}$ & ISOQTY & $x$ & & $x$ & & & $x$ \\
\hline Metrics Record & METRICS & & $x$ & & $x$ & & \\
\hline Message Log Record & MSGLOG & & $x$ & $x$ & & & \\
\hline NDA Assay Results & NDA & & $x$ & $x$ & & & \\
\hline NDA Assay Isotopic Records & NDAISO & & $x$ & $x$ & & & \\
\hline NDE Results & NDE & & $x$ & $x$ & & & \\
\hline Not Process List & NOTPROCLIST & & $x$ & $x$ & & & \\
\hline Not Ship Pick List & NOTSHIPPICK & & $x$ & $x$ & & & \\
\hline Isotopic Distribution & PAM & & $x$ & & & $x$ & \\
\hline $\begin{array}{l}\text { Payload Container } \\
\text { Certification Record }\end{array}$ & PAYLOAD & & $x$ & & & $x$ & $X$ \\
\hline $\begin{array}{l}\text { Payload Assembly } \\
\text { Certification Record }\end{array}$ & PAYLOADASBLY & & $x$ & & & $x$ & $x$ \\
\hline Physical Component Record & PHYSCOMP & $X$ & & $x$ & & & $x$ \\
\hline $\begin{array}{l}\text { Package Dangerous Waste } \\
\text { Numbers Records }\end{array}$ & PKGDW & $x$ & & $x$ & & & $x$ \\
\hline Process Pick List & PROCLIST & & $x$ & $X$ & & & \\
\hline Processing Add List & PROCADD & & $X$ & $x$ & & & $X$ \\
\hline $\begin{array}{l}\text { Radioactive Waste Container } \\
\text { Detail Record }\end{array}$ & RADDETAIL & $X$ & & $x$ & & & $x$ \\
\hline Radiologic Material Inventory & RADMAT & & $x$ & $x$ & & & $x$ \\
\hline Receiving Display Record & RECDISP & & $X$ & $X$ & & & \\
\hline Sample Bottle Location & SAMLOC & & $x$ & & $x$ & & $x$ \\
\hline Sample Data Record & SAMPLE & & $x$ & & $x$ & & $x$ \\
\hline $\begin{array}{l}\text { Sample Data Relationship } \\
\text { Record }\end{array}$ & SAMREL & & $x$ & & $x$ & & $x$ \\
\hline Sample Analysis Request & SAR & & $x$ & & $x$ & & $x$ \\
\hline
\end{tabular}


WHC-SD-W026-SDD-001, Rev. 2

\begin{tabular}{|c|c|c|c|c|c|c|c|}
\hline \multirow[b]{2}{*}{ Record Name } & \multirow{2}{*}{$\begin{array}{l}\text { Database } \\
\text { Table Name }\end{array}$} & \multicolumn{2}{|c|}{$\begin{array}{l}\text { Table } \\
\text { Origin }\end{array}$} & \multicolumn{3}{|c|}{$\begin{array}{l}\text { DMS Deve1. } \\
\text { Phase }\end{array}$} & \multirow[b]{2}{*}{ Journal } \\
\hline & & SWITS & DMS & 1 & 2 & 3 & \\
\hline Shipment History Record & SHIPHIST & $x$ & & $\mathrm{x}$ & & & \\
\hline Shipment Item Record & SHYPITEM & $x$ & & $x$ & & & \\
\hline Shipment Record & SHIPMENT & $x$ & & $x$ & & & \\
\hline Shipping Pick List & SHIPPICK & & $x$ & $x$ & & & \\
\hline TRUPACT Shipping Record & TRUSHIP & & $x$ & & & $x$ & \\
\hline Container and Content Record & WASTE & $x$ & & $x$ & & & $x$ \\
\hline $\begin{array}{l}\text { Container \& Content Extension } \\
\text { Record }\end{array}$ & WASTEXT & & $x$ & $x$ & & & $x$ \\
\hline Treatment Worksheet & WORKSHEET & & $x$ & & $x$ & & \\
\hline Verification & VERIFCATION & $x$ & & & $x$ & & $x$ \\
\hline Worksheet Item & WORKITEM & & $x$ & & $x$ & & $x$ \\
\hline WRAP Shipment & SHIPWRAP & & $x$ & $x$ & & & $x$ \\
\hline \multicolumn{8}{|c|}{ Data Look-Up Tables } \\
\hline Miscellaneous Code Table & CODECHECK & $x$ & & $x$ & & & \\
\hline Company Table & COMPANY & $x$ & & $x$ & & & \\
\hline Container Size Table & CONSIZE & $x$ & & $x$ & & & \\
\hline Container Type Table & CONTYPE & $x$ & & $x$ & & & \\
\hline Field He1p Table & DATADICT & & $x$ & $x$ & & & \\
\hline $\begin{array}{l}\text { DOT Container Specification } \\
\text { Table }\end{array}$ & DOTSPEC & $x$ & & $x$ & & & \\
\hline Dangerous Waste Number Table & DWNUM & $x$ & & $x$ & & & \\
\hline Error Message Table & ERRMESSAGE & & $x$ & $x$ & & & \\
\hline Facility Table & FACILITY & $x$ & & $x$ & & & \\
\hline Field Analysis Type Table & FLDANALTYP & & $x$ & & $x$ & & \\
\hline Form Help Table & FORMHELP & & $x$ & $x$ & & & \\
\hline $\begin{array}{l}\text { Hazardous Chemical Component } \\
\text { Table }\end{array}$ & HAZ'COMP & $x$ & & $x$ & & & \\
\hline Isotope Table & ISOTOPE & $x$ & & $x$ & & & \\
\hline Laboratory Table & LAB & $\bar{x}$ & & & $x$ & & \\
\hline Laboratory Analysis Table & LABANAL & & $x$ & & $x$ & & \\
\hline
\end{tabular}


WHC-SD-W026-SDD-001, Rev. 2

\begin{tabular}{|c|c|c|c|c|c|c|c|}
\hline \multirow[b]{2}{*}{ Record Name } & \multirow{2}{*}{$\begin{array}{l}\text { Database } \\
\text { Table Name }\end{array}$} & \multicolumn{2}{|c|}{$\begin{array}{l}\text { Table } \\
\text { Origin }\end{array}$} & \multicolumn{3}{|c|}{$\begin{array}{l}\text { DMS Deve1. } \\
\text { Phase }\end{array}$} & \multirow[b]{2}{*}{ Journal } \\
\hline & & SWITS & DMS & 1 & 2 & 3 & \\
\hline Location Table & LOCN & & $x$ & $x$ & & & \\
\hline Material Table & MATL & & $x$ & $x$ & & & \\
\hline Material Safety Data Sheets & MSDS & $x$ & & $x$ & & & \\
\hline Person Table & PERSON & & $x$ & $x$ & & & \\
\hline $\begin{array}{l}\text { Physical Component } \\
\text { Description Table }\end{array}$ & PHYSDESC & $x$ & & $x$ & & & \\
\hline Package Status Table & PKGSTAT & $x$ & & $x$ & & & \\
\hline Primary Waste Type Code Table & PRIWASTYPE & $x$ & & $x$ & & & \\
\hline Generator Assay Profile Table & PROFILE & & $x$ & $x$ & & & \\
\hline Profile Isotopic Table & PROFILEISO & & $x$ & $x$ & & & \\
\hline Report Table & REPORTABLE & & $x$ & $x$ & & & \\
\hline Role Table & ROLE & & $x$ & $x$ & & & \\
\hline $\begin{array}{l}\text { Role Screen Relationship } \\
\text { Table }\end{array}$ & ROLESCREEN & & $x$ & $x$ & & & \\
\hline Route Description Table & ROUTE & & $x$ & $x$ & & & \\
\hline Sample Container Type & SAMYPCONTYP & & $x$ & & $x$ & & \\
\hline Sample Matrix Table & SAMPMATX & & $x$ & & $x$ & & \\
\hline Sampl ing Method & SAMPMETH & & $x$ & & $x$ & & \\
\hline Screen Table & SCREEN & & $\bar{x}$ & $x$ & & & \\
\hline $\begin{array}{l}\text { Secondary Waste Type Code } \\
\text { Table }\end{array}$ & SECWASTYPE & $x$ & & $x$ & & & \\
\hline Shipping Pick List Type & SHIPPICKTYP & & $x$ & $x$ & & & \\
\hline SIE Isotopic Name Table & SIEISO & & $x$ & $x$ & & & \\
\hline State Table & STATE & $x$ & & $x$ & & & \\
\hline Storage Category Table & STIORAGECAT & $x$ & & $x$ & & & \\
\hline Treatment Procedure & TREATPROC & & $x$ & & $x$ & & $x$ \\
\hline TRUCON Code Table & TRUICON & & $x$ & & & $x$ & \\
\hline TRU Shipping Category Table & TRUSHIPCAT & & $x$ & & & $x$ & \\
\hline TSD Facility Table & TSIDFACIL & $x$ & & $x$ & & & \\
\hline User Role Relationship Table & USERROLE & & $x$ & $x$ & & & \\
\hline
\end{tabular}




\begin{tabular}{|c|c|c|c|c|c|c|c|}
\hline \multirow[b]{2}{*}{ Record Name } & \multirow{2}{*}{$\begin{array}{l}\text { Database } \\
\text { Table Name }\end{array}$} & \multicolumn{2}{|c|}{$\begin{array}{l}\text { Table } \\
\text { Origin }\end{array}$} & \multicolumn{3}{|c|}{$\begin{array}{c}\text { DMS Devel. } \\
\text { Phase }\end{array}$} & \multirow[b]{2}{*}{ Journal } \\
\hline & & SWITS & DMS & 1 & 2 & 3 & \\
\hline User Table & USERS & & $x$ & $x$ & & & \\
\hline User Signature Password & USERSIGNPASS & & $x$ & $x$ & & & \\
\hline WRAP Miscellaneous Table & WRAPMISC & & $x$ & $x$ & & & \\
\hline
\end{tabular}

\section{1 DATA ELEMENT LIST}

Section C.1.1 lists SWITS data records and data elements that appear appropriate for use in the DMS database along with those SWITS data records that have added DMS data elements and new DMS data records. Tables which are journalled are identified. The data records are listed alphabetically by data record name. Section C.1.2 lists the SWITS and DMS look-up tables in alphabetical order. In both these sections, new DMS data records and added DMS data elements are indicated by bold type.

\section{C.1.1 Data Record Tables}

\section{Activity Comment Record (ACTCOM)}

This table will track those data elements which will be used to record operator comments against specific waste containers and processing activities.

Activity Package ID

Activity Date

Activity Code

Activity Comment

Activity Operator ID
-*ACT_PKG ID
*ACT ${ }^{-} D T$
$A C T^{-} C D$
ACT COMMENTS
- ACT OP_ID

VARCHAR2(14) R

DATE

VARCHAR2 (10)

VARCHAR2 (255)

VARCHAR2 (7)

Applicable MSDS (APPMSDS) - SWITS Data Record (Journal) This table lists any Material Safety Data Sheets which apply to chemicals referenced in the Hazardous Chemical Component table.

Applicable Package ID Number

Applicable MSDS

*APP PKG ID

-*APP'MSDS (MSDS_ID)
VARCHAR2 (14) $R$ VARCHAR2 (6) $R$

\section{Bin List (BIN)}

This table is used to track the waste drums to specific AS/RS Bin locations.

Bin Number

Bin Package ID
*BIN NUM

U॰*BIN_PKG_ID
VARCHAR2 (3) $R$ VARCHAR2(14) R 
Bottle Data Record (BOTTLE)

(Journa1)

This table is used to track the bottle containers of a sample from the

time of sampling through disposal.

Bottle ID

Bottle Sample ID

Bottle Comments

Bottle Disposed By

Bottle Disposal Date

Bottle Disposal Method

Bottle OK at Laboratory

Bottle Returned to Package

Bottle Return Date

$\begin{array}{ll}\text { *BOT_BOTTLE_ID } & \text { VARCHAR2 }(12) R \\ \text {-BOT-SAMPLE-ID } & \text { VARCHAR2 (8) R R R } \\ \text { BOT-COMMENTS } & \text { VARCHAR2 (255) } \\ \text { BOT-DISP BY } & \text { VARCHAR2 (15) } \\ \text { BOT-DISP-DT } & \text { DATE } \\ \text { BOT-DISP-METHOD } & \text { VARCHAR2 (25) } \\ \text { BOT-OK AT LAB } & \text { VARCHAR2 (1) } \\ \text { BOT-RETURN TO PKG } & \text { VARCHAR2 (1) } \\ \text { BOT_RETURN-DT } & \text { DATE }\end{array}$

Bottle Analysis Record (BOTANAL)

This table is used to record the analyses requested for and performed on each sample bottle.

Bottle Analysis Bottle ID

Bottle Analysis Analysis Code

Bottle Analysis Requested Flag

Bottle Analysis Performed Flag

$\begin{array}{lll}\text { •*BOTANAL_BOTTLE ID } & \text { VARCHAR2 (12) } & R \\ \text { •*BOTANAL_ANAL CD } & \text { VARCHAR2 (8) } & R \\ \text { BOTANAL_REQUEST_FLAG } & \text { VARCHAR2 (1) } \\ \text { BOTANAL_PERFORM_FLAG } & \text { VARCHAR2 (1) }\end{array}$

Hazardous Chemical Component Record (CHEMCOMP) - SWITS Data Record (Journal) This table identifies all chemical component names which may be used in describing hazardous and mixed waste.

Hazardous Package ID

Hazardous Chemical Component ID

Hazardous Chemical Component Parts

Per Million

Hazardous Chemical Component Text

Hazardous Chemical Component Weight
-*HAZ PKG ID
- *HAZ COMP ID
$\mathrm{HAZ}_{-}^{-} \mathrm{COMP}_{-}^{-} \mathrm{PPM}$
$\operatorname{VARCHAR2(14)~} R$
$\operatorname{VARCHAR2(12)~R~}$
$\operatorname{VARCHAR2}(7)$

HAZ COMP TEXT

HAZ $^{-}$COMP $^{-}$WGT

HAZ_COMP_WGT_PCT

HAZ_EPCRA_FLAG
VARCHAR2 (70)

$\operatorname{NUMBER}(12,4)$

$\operatorname{VARCHAR} 2(7)$

$\operatorname{VARCHAR2}(1)$

Hazardous Chemical Component Emergency

Planning and Community Right-to-know

Act (EPCRA) Flag

Chain of Custody (COC)

(Journal)

This table contains information about the Chain of Custody for laboratory samples.

COC Form ID

COC Bill of Lading/Air Bill Number

COC Ice Chest ID Number

COC Possible Sample Hazard Remarks

COC Laboratory ID

COC Log ID

COC Method of Shipment

COC Company Contact

COC Project Designation

COC Offsite Property Number

COC SAF Number

COC Shipment Date

COC Special Handling or Storage

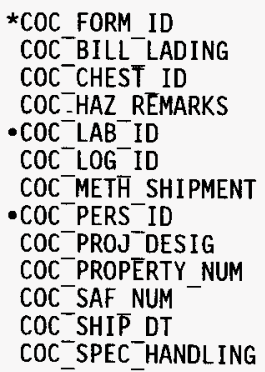

VARCHAR2 (10) $R$

NUMBER (25)

VARCHAR2 (11)

VARCHAR2 (255)

VARCHAR2 (6)

VARCHAR2 (20)

VARCHAR2 (20)

VARCHAR2 (6)

VARCHAR2 (25)

NUMBER (14)

NUMBER (10)

DATE

VARCHAR2 (255) 
WHC-SD-W026-SDD-001, Rev. 2

COC Special Instructions

COC SPEC INSTRUCTION

VARCHAR2 (255)

COC Data Turnaround

COC $^{-}$TURN'AROUND

VARCHAR2 (1)

Chain of Custody Transfer (COCXFR)

This table provides the fields required to maintain an electronic chain of possession for samples within a purge port.

COC Transfer Pkg ID

-*COCXFR PKG ID

*COCXFR DT

VARCHAR2 (14) $R$

COC Transfer Date

- COCXFR RECVD BY OP ID VARCHAR2 (6)

COC Transfer Received By Operator

-COCXFR_RELIN_BY_OP_ID VARCHAR2(6)

Communication Table (COMMUNICATION TABLE)

This table is used for communication between DMSCOM and SQL*FORMS programs.

Communication From

Communication To

Communication Message ID

Communication Message Text

Communication Priority

Communication Date

COMM FROM
COMM-TO
COMM-MSG_ID
COMM-MSG TEXT
COMM-PRIORITY
COMM-DT

VARCHAR2 (8)

VARCHAR2 (8)

VARCHAR2 (20)

VARCHAR2 (80)

NUMBER(3)

DATE

Container Location (CONLOC)

(Journal)

This table is used to record the current location of specific containers within WRAP.

Container Package ID

Container Location Date

Container Location ID

$$
\begin{aligned}
& \text { *CONLOC_PKG_ID } \\
& \text { CONLOC_DT - } \\
& \text { CONLOC_LOCN_ID }
\end{aligned}
$$

VARCHAR2 (14) $R$

DATE

VARCHAR2 (10)

Container Relationship Record (CONREL) - SWITS Data Record

(Journal)

This table permits the system to track the separating, repackaging, and combining of containers. It identifies the source CONTAINER occurrence and the resulting CONTAINER occurrence. Through this entity, an unlimited number of combinations and recombinations of containers can be tracked.

Container Relationship From Package ID **CONR FROM PKG ID

Container Relationship To Package ID

Container Relationship Date

Container Relationship Code

-*CONR ${ }^{-}$TO PKG ID

*CONR DT

CONR_REL_CD

VARCHAR2 (14) $R$

VARCHAR2(14) $R$

DATE

VARCHAR2 (1)

\section{Container Treatment (CONTREAT)}

This data record provides the data required to relate a specific treatment worksheet to the applicable waste container to be treated.

Container Treatment Package ID

Container Treatment Date

Container Treatment Comments

Container Treatment User ID

Container Treatment Worksheet ID
**CONTREAT PKG ID

*CONTREAT DT CONTREAT ${ }^{-}$COMMENT

- CONTREAT USER ID

CONTREAT_WS_ID
VARCHAR2(14) $R$

DATE

VARCHAR2 (255)

VARCHAR2 ( 7$)$

VARCHAR2 (8) 
Discharge Conveyor List (DISCHARGE)

This table is used to track the drums (by position) which are located on

the WRAP 1 Discharge conveyor in the S\&R Area.

Discharge Conveyor Sequence Number

*DISCHARGE SEQ NUM

NUMBER(12) R

Discharge Conveyor Package ID

-DISCHARGE_PKG_ID

VARCHAR2 (14)

Field Screening Record (FIELDSCRN)

This record is used to record data associated with the field screening activities in the gloveboxes.

Field Screening Container ID Number

Field Screening ID

Field Screening Comments

Field Screening Date

Field Screening Location

Field Screening Person

Field Screening Sample Volume

Field Screening Sampling Method code

Field Screening Verification Pass Flag

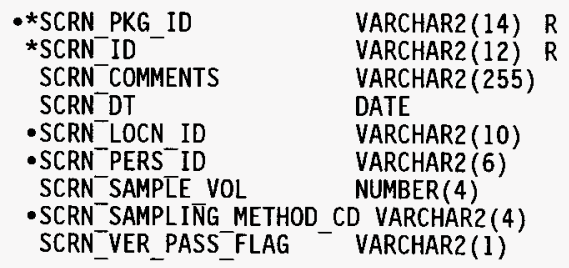

\section{Field Analysis (FIELDANAL)}

This record is used to record the data associated with each analysis performed during field screening activities.

Field Analysis Screening ID

Field Analysis Code

Field Analysis Results
$\bullet *$ FIELD SCRN ID
* FIELD FAT CD
FIELD RES

Hazardous Waste Container Detail Record (HAZDETAIL) - SWITS Data Recotdournal) This is a one-to-one entity, a single occurrence being present for those containers that hold hazardous or mixed waste. The entity is not required for containers holding only radioactive waste.

Hazardous Detail Package ID

Hazardous Detail Container Status

Hazardous Detail Designation Code

Hazardous Detai1 Dangerous Waste Number

Hazardous Detail Flashpoint

Hazardous Detail Hazardous Property Codes

Hazardous Detail Individual DOT ID Number

Hazardous Detail Individual Not 0therwise Specified Description

Hazardous Detail Individual Shipping Name

Hazardous Detail Land Banned

Hazardous Detail Other Land Banned 1

Hazardous Detail Other Land Banned 2

Hazardous Detail Other Land Banned 3

Hazardous Detail PCB Description

Hazardous Detail PCB Parts Per Million

Hazardous Detail PCB Removed Date

Hazardous Detai1 PCB Sub-Type
-*HDET PKG ID

HDET ${ }^{-}$CNTR STATUS

HDET ${ }^{-}$DESIG $\bar{G}$ CD

HDET_DW_NUM

HDET FLASHPOINT

HDET $^{-}$HAZPROP CD

HDET_IND_DOT_ID_NUM

HDET_IND_NOS_DESCR

HDET_IND_SHIP_NAME

HDET LANDBAN

HDET OTHER LANDBAN 1

HDET $^{-}$OTHER LANDBAN ${ }^{-} 2$

HDET-OTHER LANDBAN ${ }^{-} 3$

HDET ${ }^{-} P C B$ DESCR

HDET $^{-}{ }^{-}{ }^{-} B^{-}$PPM

HDET $^{-}$PCB - REMOVED DT

HDET_PCB SUBTYPE
VARCHAR2 (12) $R$

VARCHAR2 (4) $R$

VARCHAR2 (30)

VARCHAR2 (14) $R$

VARCHAR2 (2)

VARCHAR2 (3)

VARCHAR2 (85)

VARCHAR2 (6)

VARCHAR2 (6)

VARCHAR2 (5)

VARCHAR2 (60)

VARCHAR2 (80)

VARCHAR2 (17)

VARCHAR2 (8)

VARCHAR2 (8)

VARCHAR2 (8)

VARCHAR2 (40)

VARCHAR2 (6)

DATE

VARCHAR2 (1) 
WHC-SD-W026-SDD-001, Rev. 2

Hazardous Detail PCB Type

Hazardous Detail PCB Weight

Hazardous Detail PH

Hazardous Detail Waste Status

Hazardous Detail Waste Volume

\author{
HDET PCB TYPE \\ HDET ${ }^{-}$PCB-WGT \\ HDET $^{-}$PH \\ HDET WASTE STATUS \\ HDET_WASTE_VOL
}

VARCHAR2 (1)

NUMBER $(12,4)$

VARCHAR2 (5)

VARCHAR2 (2)

$\operatorname{NUMBER}(10,4)$

Radioactive Isotope Quantity Record (ISOQTY) - SWITS Data Record

(Journa1)

The radioactive isotopes present in a container are identified through

this table. For each isotope present, one occurrence of this entity will exist.

Radioactive Package ID

Radioactive Isotope Number

Radioactive Alpha CI

Radioactive PE CI

Radioactive PU FGE

Radioactive Quantity

Radioactive Qty Total Meas. Uncertainty

Radioactive Unknown

$*$ RAD_PKG ID
$*$ RAD-ISO-NUM
RAD_ALPHA_CI
RAD-PE_CI
RAD_PU FGE
RAD_QTY
RAD_QTY TMU
RAD_UNKNONN

VARCHAR2 (14) R $\operatorname{NUMBER}(3) \quad R$

FLOAT

FLOAT

FLOAT

FLOAT

FLOAT

FLOAT

\section{Metrics Record (METRICS)}

Table for recording waste container data changes within the WRAP facility. The data contained in this table will be used to generate facility metrics reports.

Metric Package ID

Metric Date

Metric Assay Verified $\mathrm{Flag}$

Metric Compliant Flag

Metric Hazardous Materials Ver. Flag

Metric Location

Metric NDE Verified Flag

Metric Secondary Waste Group

Metric Container Use Code

Metric Waste Category

Metric WRAP Status Code

\begin{tabular}{|c|c|}
\hline $\begin{array}{l}\text { *MET_PKG_ID } \\
\text { *MET_DT - } \\
\text { MET_ASSAY VER FLAG } \\
\text { MET_COMPLIANT-FLAG } \\
\text { MET_HAZ VER_FLAG } \\
\text { MET_LOCN ID- } \\
\text { MET_NDE VER FLAG } \\
\text { MET_SWTYP GROUP } \\
\text { MET_USE CD } \\
\text { MET_WASTE CAT } \\
\text { MET-WRAP STAT CD }\end{array}$ & $\begin{array}{l}\text { VARCHAR2 (14) } \\
\text { DATE } \\
\text { VARCHAR2 (1) } \\
\text { VARCHAR2 (1) } \\
\text { VARCHAR2 (1) } \\
\text { VARCHAR2 (10) } \\
\text { VARCHAR2 (1) } \\
\text { VARCHAR2 (2) } \\
\text { VARCHAR2 (2) } \\
\text { VARCHAR2 (5) } \\
\text { VARCHAR2 (2) }\end{array}$ \\
\hline
\end{tabular}

Message Log Record (MSGLOG)

History table for intersystem message headers used whenever communication occurs between the DMS and other WRAP systems (PCS, SIE, BWAS).

Message Log Date

Message Log Error

Message Log General Type

Message Log Sequence Number

Message Log Specific Type

Message Log Stringl-ASCII

Message Log String2-HEX

MSGLOG_DT
MSGLOG-ERROR FLAG
MSGLOG_GEN TYPE
MSGLOG_SEQ-NUM
MSGLOG-SPEC TYPE
MSGLOG-STRING
MSGLOG STRING2

DATE

VARCHAR2 (2)

VARCHAR2 (8)

VARCHAR2 (4)

VARCHAR2 (4)

VARCHAR2 (2000)

LONG RAW 
NDA Assay Results (NDA)

This record is used to record the assay data that is generated by an assay performed in the WRAP 1 facility.

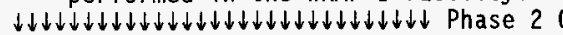

NDA Package ID

NDA Date

NDA Assay Number

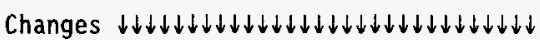

-NDA_PKG_ID

*NDA- DT

VARCHAR2(14) $R$

*NDA-ASSAY NUM

DATE

NUMBER

$\uparrow \uparrow \uparrow \uparrow \uparrow \uparrow \uparrow \uparrow \uparrow \uparrow \uparrow \uparrow \uparrow \uparrow \uparrow \uparrow \uparrow \uparrow \uparrow \uparrow \uparrow \uparrow \uparrow \uparrow \uparrow \uparrow \uparrow \uparrow \uparrow \uparrow \uparrow$ Phase 2 Changes $\uparrow \uparrow \uparrow \uparrow \uparrow \uparrow \uparrow \uparrow \uparrow \uparrow \uparrow \uparrow \uparrow \uparrow \uparrow \uparrow \uparrow \uparrow \uparrow \uparrow \uparrow \uparrow \uparrow \uparrow \uparrow \uparrow \uparrow \uparrow \uparrow \uparrow \uparrow \uparrow \uparrow$

NDA Future Evaluation Reqd

NDA FUT EVAL REQD VARCHAR2(1)

NDA Number of ISO Records

NDA Profile ID

NDA Ratio (PU239/PU240)

NDA ISO TOT

NUMBER(3)

-NDA-PROF ID

NDA RATIŌ

VARCHAR2 (6)

NDA Revisit Flag

NDA Secondary Waste Type Group

NDA Decay Heat

NDA-RVST FLAG

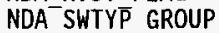

NDA- THERMĀL POWER

FLOAT

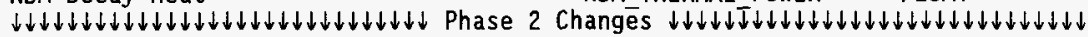

NDA Total Alpha $C i$ TMU

NDA TOT ALPHA CI TMU FLOAT

NDA Total PE Ci TMU

NDA TotaT PU FGE TMU

NDA Thermal Power TMU

NDA ${ }^{-} \mathrm{TOT}^{-} \mathrm{PE} \mathrm{CI}^{-} \mathrm{TMU}^{-}$FLOAT

NDA TOT PU FGE TMU FLOAT

NDA- THERMAL POWER TMU FLOAT

$\uparrow \uparrow \uparrow \uparrow \uparrow \uparrow \uparrow \uparrow \uparrow \uparrow \uparrow \uparrow \uparrow \uparrow \uparrow \uparrow \uparrow \uparrow \uparrow \uparrow \uparrow \uparrow \uparrow \uparrow \uparrow \uparrow \uparrow \uparrow \uparrow \uparrow \uparrow \uparrow$ Phase 2 Changes $\uparrow \uparrow \uparrow \uparrow \uparrow \uparrow \uparrow \uparrow \uparrow \uparrow \uparrow \uparrow \uparrow \uparrow \uparrow \uparrow \uparrow \uparrow \uparrow \uparrow \uparrow \uparrow \uparrow \uparrow \uparrow \uparrow \uparrow \uparrow \uparrow \uparrow \uparrow \uparrow \uparrow \uparrow$

NDA Total Alpha Ci

NDA Total PE C $j$

NDA Total PU FGE

NDA Waste Category

NDA TOT ALPHA CI FLOAT

NDA ${ }^{-} T^{-}$PE $\mathrm{CI}^{-}$FLOAT

NDA-TOT PU-FGE $\quad$ FLOAT

NDA_WASTE_CAT

VARCHAR2 (5)

NDA Assay Isotopic Records (NDAIS0)

The radioactive isotopes present in a container are identified through

this table which contains WRAP generated isotopic results. For each

isotope present, one occurrence of this entity will exist.

NDA Isotopic Package ID -NDAISO PKG ID VARCHAR2(14) $R$

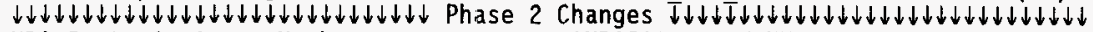

NDA Isotopic Assay Number

- NDAISO ASSAY NUM NUM

$\uparrow \uparrow \uparrow \uparrow \uparrow \uparrow \uparrow \uparrow \uparrow \uparrow \uparrow \uparrow \uparrow \uparrow \uparrow \uparrow \uparrow \uparrow \uparrow \uparrow \uparrow \uparrow \uparrow \uparrow \uparrow \uparrow \uparrow \uparrow \uparrow \uparrow \uparrow \uparrow$ Phase 2 Changes $\bar{\uparrow} \uparrow \uparrow \uparrow \uparrow \uparrow \uparrow \uparrow \uparrow \uparrow \uparrow \uparrow \uparrow \uparrow \uparrow \uparrow \uparrow \uparrow \uparrow \uparrow \uparrow \uparrow \uparrow \uparrow \uparrow \uparrow \uparrow \uparrow \uparrow \uparrow \uparrow \uparrow$

NDA I sotopic Name

-*NDAISO NAME

NDAISO-CONFIDENCE_CK VARCHAR2(2)

NDA Isotopic Measurement Confidence Check

NDA Isotopic GEA Data Used

NDA Isotopic Quantity

NDA Isotopic Quantity TMU

NDA Isotopic Measurement Status

NDAISO GEA

NDAISO QTY

NDAISO QTY TMU FLOAT

VARCHAR2 (32)

NDA Isotopic PAN Active Data Used

NDAISO MEA $\bar{S}$ STATUS

VARCHAR2 (3)

NDAISO-PAN ACTIVE

VARCHAR2 (2)

NDA Isotopic PAN Passive Data Used

NDAISO_PAN_PASSIVE

VARCHAR2 (2)

NDE Results (NDE)

This table contains all data generated as a result of a completed NDE examination.

NDE Results Package ID

NDE Results Date

NDE Comments

NDE Operator ID

NDE Container Video Disk File

NDE Container Video Disk Number

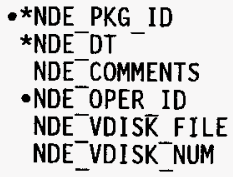

VARCHAR2 (14)

DATE

VARCHAR2 (255)

VARCHAR2 (7)

VARCHAR2 (5)

VARCHAR2 (5)

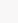
$R$ 
WHC-SD-W026-SDD-001, Rev. 2

NDE Container Video Tape Number

NDE VTAPE NUM

NDE Container Video Tape Start

NDE_VTAPE_START

VARCHAR2 (5)

NUMBER(5)

Not Process List (NOTPROCLIST)

This table is used to control the DMSS0902 screen.

Not Process List Package ID •*NOTPROC_PKG_ID

VARCHAR2 (14) $R$

Not Ship Pick List (NOTSHIPPICK)

This table is used to control the DMSS0904 screen.

Not Ship Pick List Package ID •*NOTSHIP PKG ID

VARCHAR2(14) R

Isotopic Distribution (PAM)

This data record provides those data elements required to support the operation of the Packet Assay Monitor (PAM).

PAM Package ID number

- *PAM PKG ID

PAM_PU FGE

VARCHAR2 (14) $R$

PAM Plutonium 239 Fissile Gram

Equivalent

PAM Gram Quantity

PAM QTY

FLOAT

PAM Uncertainty

PAM UNCERTAINTY FLOAT

Payload Container Certification Record (PAYLOAD)

(Journal)

This data table provides data required to support the shipment of a specific waste container to WIPP.

Payload Package ID Number

Payload Package Assembly ID

Payload Certification Date

Payload Certification Official

Payload Container Type

Payload Decay Heat

Payload Filter Model

Payload Filter Installed

Payload Fissile Mass Error (2X)

Payload Gas Generation Rate

Payload Container Decay Heat Error

Payload Decay Heat Limit

Payload Hydrogen Generation Rate

Payload Liner Punctured/Fittered

Payload Record Type

Payload Sequence Number

Payload Approved To Ship

Payload Shipping Category

Payload TRUCON Code

Payload Flammable VOC Concentration

Payload WAC Exception

Payload Container Weight Error

\begin{tabular}{|c|c|}
\hline 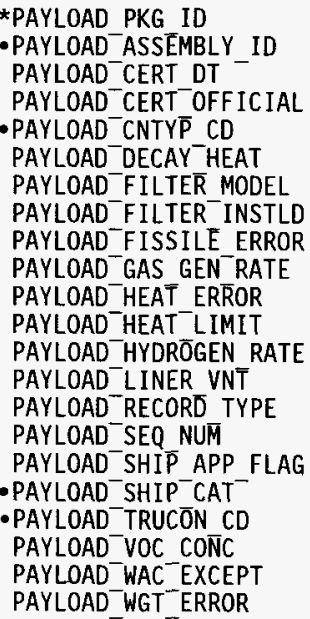 & $\begin{array}{l}\text { VARCHAR2 (14) } \\
\text { VARCHAR2 (8) } \\
\text { DATE } \\
\text { VARCHAR2 (25) } \\
\text { VARCHAR2 (3) } \\
\text { FLOAT } \\
\text { VARCHAR2 (10) } \\
\text { VARCHAR2 (3) } \\
\text { FLOAT } \\
\text { NUMBER (3) } \\
\text { FLOAT } \\
\text { FLOAT } \\
\text { VARCHAR2 (1) } \\
\text { VARCHAR2 (8) } \\
\text { VARCHAR2 (1) } \\
\text { NUMBER }(2) \\
\text { VARCHAR2 (1) } \\
\text { VARCHAR2 (10) } \\
\text { VARCHAR2 (6) } \\
\text { NUMBER (3) } \\
\text { CHAR) } 7) \\
\text { NUMBER }(10,2)\end{array}$ \\
\hline
\end{tabular}

Payload Assembly Certification Record (PAYLOADASBLY) (Journal)

This data table provides specific information required to support the loading and shipment of a TRUPACT waste container.

Assembly Number

Assembly Shipment Number

Assembly Approved For Shipment Flag

*ASBLY NUM VARCHAR2 (8) R

-*ASBLY SHIPMENT NUM VARCHAR2 (8) R ASBLY ${ }^{-}$APPROVED SHIP FLAGVARCHAR2 (1) 
WHC-SD-W026-SDD-001, Rev. 2

Assembly Cert Date

Assembly Cert Official

Assembly Payload Configuration

Assembly Dose Rate - Pkg

Assembly Dose Rate at $2 \mathrm{~m}$

Assembly Date of ICV Closure

Assembly TRUPACT OCA Body Number

Assembly TRUPACT OCA Lid Number

Assembly Position

Assembly Payload Shipping Category

Assembly Decay Heat Limit - Ship Cat

Assembly Weight of TRUPACT

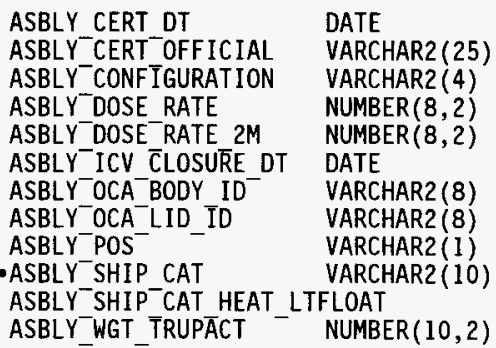

(Journal)

Physical Component Record (PHYSCOMP) - SWITS Data Record

This entity identifies those physical components present within a container. One occurrence of the entity will exist for each different physical component present.

Physical Component Package ID

Physical Component Description

Physical Component Volume Percent

Physical Component Weight

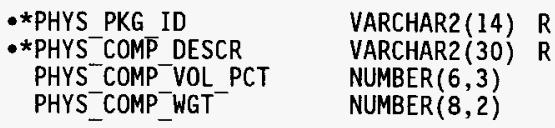

Package Dangerous Waste Numbers Record (PKGDW) - SWITS Data Record (Journal) The Dangerous Waste Numbers associated with a package of hazardous or mixed waste.

Dangerous Waste Package ID

Dangerous Waste Number

Dangerous Waste Land Banned

Dangerous Waste Sort Order

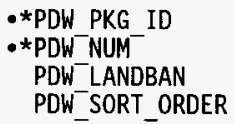

VARCHAR2 (14) $\mathrm{R}$ VARCHAR2 (4) $R$ VARCHAR2 (1) NUMBER(3)

\section{Process Pick List (PROCLIST)}

This table is used to generate a pick list of waste containers to be removed from the AS/RS for processing in WRAP.
Process List Package ID
Process List Compliant Flag
Process List PCS Flag
Process List Profile ID
Process List Route Code
Process List Sample Flag
Process List Sequence Number
$\star$ PROC PKG ID
PROC ${ }^{-}$PCS FLAG
- PROC ${ }^{-}$PROF ID
- PROC ROUTE CD
PROC ${ }^{-}$SAMPLE FLAG
PROC SEQ NUM

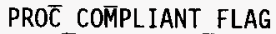
VARCHAR2 (14) R
VARCHAR2 (1)
VARCHAR2 (1)
VARCHAR2 (6)
VARCHAR2 (4)
VARCHAR2 (1)
NUMBER(4)

Processing Add List (PROCADD)

This table is used to generate a listing of waste containers to be

processed in WRAP. It also designates the route and sampling and processing requirements. This list is added to PROCLIST.

Processing Add List Package ID

Processing Add List Compliant Flag

Processing Add List Profile ID

Processing Add List Route Code

Processing Add List Sample Flag

Processing Add List Sequence Number

$\begin{array}{ll}\text { ^PROCADD_PKG_ID } & \text { VARCHAR2 (14) R } \\ \text { PROCADD_COMPLIANT_FLAGVARCHAR2 (1) } \\ \text {-PROCADD_PROF_ID } & \text { VARCHAR2 (6) } \\ \text {-PROCADD_ROUTE CD } & \text { VARCHAR2 (4) } \\ \text { PROCADD_SAMPLE FLAG } & \text { VARCHAR2 (1) } \\ \text { PROCADD_SEQ_NUM } & \text { NUMBER(4) }\end{array}$


WHC-SD-W026-SDD-001, Rev. 2

Radioactive Waste Container Detail Record (RADDETAIL) - SWITS Data Reçdodrnal) This is a one-to-one entity, a single occurrence being present for those containers that hold radioactive or mixed waste. The entity is not required for containers holding only hazardous waste.

Radioactive Detail Package Id

Radioactive Detail Assay Date

Radioactive Detail Assay Number

Radioactive Detail Beta/Gamma Dose Rate

Radioactive Detail Certification Date

Radioactive Detail Dose Equivalence Curie Flag

Radioactive Detail Handling

Radioactive Detail Neutron Dose Rate

Radioactive Detail Organic Volume Percent

Radioactive Detail Organic Weight

Radioactive Detail Property Disposal Request Number

Radioactive Detail RSWIMS Count

Radioactive Detail SDAR Approval No.

Radioactive Detail Seal Number

Radioactive Detail Solid Waste

Information Management System Code

Radioactive Detail Secondary Waste Type Code

Radioactive Detail Secondary Waste Type Group

Radioactive Detail Thermal Power

Radioactive Detail Thermal Power TMU

Radioactive Detail Total Alpha Ci

Radioactive Detail Total Alpha Ci TMU

Radioactive Detail Total Beta/Gamma C $i$

•*RDET PKG ID

RDET $^{-}$ASSĀY DT

RDET $^{-}$ASSAY NUM $^{-}$

RDET_BG_DOS̄E_RATE

RDET CERT DT

RDET_DE_CI_FLAG

RDET HANDLING

RDET $^{-}$NEUT DOSE RATE

RDET_ORGAN̄IC_VD̄L_PCT

RDET_ORGANIC WGT

RDET $^{-}$PDR NUM

RDET RSWIMS COUNT

RDET ${ }^{-}$SDAR AP PRV NUM

RDET SEAL NUM

RDET_SWIMS_CD

-RDET SWTYP CD

RDET_SWTYP_GROUP

RDET THERMAL POWER

RDET THERMAL-POWER TMU FLAT

RDET $^{-}$TOT ALPHA CI

RDET $^{-}$TOT $^{-}$ALPHA ${ }^{-}$CI TMU

RDET $^{-}$TOT $^{-} \mathrm{BG}$ CI

RDET_TOT_DE_CI

RDET TOT PE CI

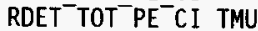

RDET $^{-}$TOT $^{-} \mathrm{PU}^{-} \mathrm{FGE}$

RDET $^{-}$TOT $^{-} \mathrm{PU}^{-}$FGE TMU

RDET ${ }^{-}$OID C $\bar{D}$

RDET WASTE CAT

RDET WASTE $^{-}$MAKEUP

RDET_WRAP CAT
VARCHAR2 (14) R

DATE

VARCHAR2 (14)

FLOAT

DATE

VARCHAR2 (1)

VARCHAR2 (1)

$\operatorname{NUMBER}(8,2)$

NUMBER (3)

$\operatorname{NUMBER}(8,2)$

VARCHAR2 (9)

NUMBER (4)

VARCHAR2 (14)

VARCHAR2 (14)

VARCHAR2 (2)

VARCHAR2 (2)

VARCHAR2 (3)

FLOAT

FLOAT

FLOAT

FLOAT

FLOAT

FLOAT

FLOAT

FLOAT

FLOAT

VARCHAR2 (6)

VARCHAR2 (5)

VARCHAR2 (1)

VARCHAR2 (2)

Radiologic Material Inventory (RADMAT) This table defines data elements required to track radiological levels
within WRAP.

Area ID

Area Alarm Flag

Area Description

Date \& Time of calculation

Glovebox Package ID

Area Limit

*RADMAT_ID
RADMAT-ALARM
RADMAT-DESCR
RADMAT-DT
-RADMAT_GB PKG_ID
RADMAT_LIMIT

VARCHAR2 (1) R

$\operatorname{VARCHAR} 2(1)$

VARCHAR2 (50)

DATE

VARCHAR2 (14)

FLOAT 
Receiving Display Record (RECDISP)

Table to record incoming PCS message of received container package IDs. This table is an internal temporary data store used during the Receiving process.

Receiving Display Block Number

Receiving Display Inner Package ID

Receiving Display Package ID

\begin{tabular}{|c|c|}
\hline $\begin{array}{l}\text { RECDISP BLK NUM } \\
\text { RECDISP-INNER PKG ID } \\
\text { RECDISP-PKG ID } \\
\text { RECDISP-ERROR STATUS }\end{array}$ & $\begin{array}{l}\text { NUM } \\
\text { VARCHAR2 }(14) \\
\text { VARCHAR2 (14) } \\
\text { VARCHAR2 (50) }\end{array}$ \\
\hline
\end{tabular}

Receiving Display Error Status Message

Sample Bottle Location (SAMLOC)

This table is used to record the current location of specific sample

(Journa1) bottles within WRAP.

Sample Location Bottle ID

Sample Location Date

Sample Location Location ID

$\begin{array}{ll}\text {-*SAMLOC_BOTTLE_ID } & \text { VARCHAR2 (12) R } \\ \text { SAMLOC_DT } & \text { DATE } \\ \text {-SAMLOC_LOCN_ID } & \text { VARCHAR2 (10) }\end{array}$

Sample Data Record (SAMPLE) - SWITS Data Record (Data Elements Added) (Journal)

Status data used to track samples through laboratory testing sites.

Sample ID

Sample COC Form ID

Sample Package ID

Sample Closed Flag

Sample Comments

Sample Sampling Location

Sample Matrix Code

Sample Report Date

Sample To Be Returned

Sample Sampling Method Code

Sample Taken By

Sample Taken Date

Sample Temperature

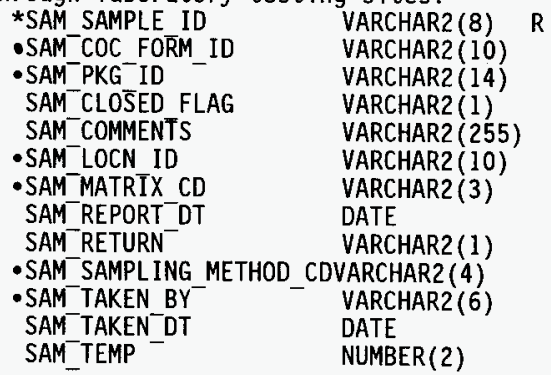

* SAM SAMPLE ID

- SAM ${ }^{-}$COC FORM ID

- SAM PKG ${ }^{-}$ID

SAM CLOS̄ED FLAG

SAM COMMENTS

- SAM-LOCN ID

- SAM MATRIX CD

SAM REPORT DT

SAM RETURN

SAM RETURN $\quad$ VARCHAR2(1)

- SAM- TAKEN BY-

SAM-TAKEN - DT

SAM TEMP

VARCHAR2 (8) $R$

VARCHAR2 (10)

VARCHAR2 (14)

VARCHAR2 (1)

VARCHAR2 (255)

VARCHAR2 (10)

VARCHAR2 (3)

DATE

Sample Data Relationship Record (SAMREL) - SWITS Data Record

The table linking containers to packages. Can be a many-to-many

relationship.

Sample Relationship Bottle ID

Sample Relationship Package ID

Sample Relationship Date

Sample Relationship Use Code

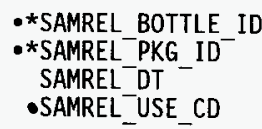

Sample Analysis Request (SAR)

The table linking sample IDs to specific sample analyses.

Sample Analysis Request Sample ID * SAR SAMPLE ID

Sample Analysis Request Analysis Code
VARCHAR2 (12) R VARCHAR2 (14) $R$ DATE VARCHAR2 (2)

\section{(Journa1)}

$\operatorname{VARCHAR2}(8) \quad R$ VARCHAR2 (8) $R$ 
Shipment History Record (SHIPHIST) - SWITS Data Record

This entity records all shipments of a container. Combined with the

FACILITY HISTORY and CONTAINER RELATIONSHIP entities, a complete history of all activity for a container is maintained.

Shipment History Manifest Number

Shipment History Item Number

Shipment History Package ID

Shipment History Nuclear Material

Item Transfer Number

Shipment History Return

Shipment History Radioactive Shipment

Record Number

Shipment History 741 Number
• SHPHST MFST_NUM
*SHPHSTIITEM NUM
•SHPHST_PKG ID
SHPHST_NMIT_NUM

SHPHST RETURN

SHPHST $^{-}$RSR NUM

SHPHST_741 NUM
$\operatorname{VARCHAR2}(10) \mathrm{R}$

VARCHAR2 (4) $R$

VARCHAR2(14) $R$

VARCHAR2 (10)

VARCHAR2 (1)

VARCHAR2 (10)

VARCHAR2 (11)

\section{Shipment Item Record (SHIPITEM) - SWITS Data Record}

This entity identifies a specific line item within a waste shipment. One or more containers may be associated with the shipment through the SHIPMENT HISTORY entity.

Shipment Item Manifest Number

Shipment Item Number

Shipment Item Container Count

Shipment Item DOT Hazardous Class

Shipment Item DOT ID Number

Shipment Item DOT Name

Shipment Item Not Otherwise Specified Description

Shipment Item Profile Number

Shipment Item Quantity Unit

Shipment Item Reportable Quantity Flag

Shipment Item Total Quantity

Shipment Item TSD Process

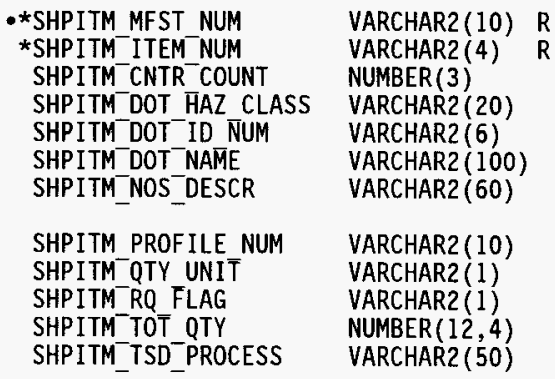

Shipment Record (SHIPMENT) - SWITS Data Record

This entity identifies a specific line item within a waste shipment. One or more containers may be associated with the shipment through the SHIPMENT HISTORY entity.

Shipment Manifest Number

Shipment Certification Date

Shipment Group ID

Shipment Manifest Return Date

Shipment Manifest Type Code

Shipment offsite Company ID

Shipment offsite Company Type

Shipment Receiving Facility ID

Shipment Radioactive Shipment Record Type

Shipment Scheduled Date

Shipment Ship Date

Shipment Transportation Company ID

Shipment Transportation Company Type

Shipment TSD Accept Date

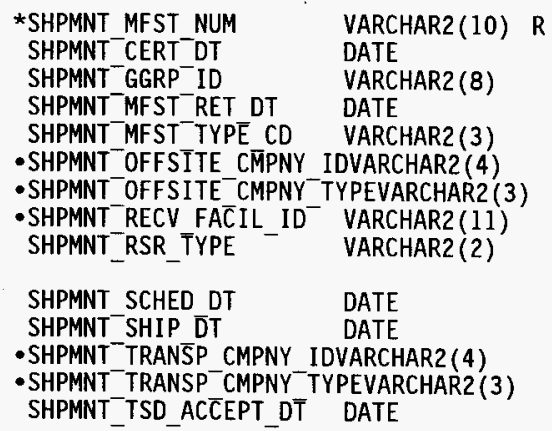


Shipping Pick List (SHIPPICK)

Table to identify and group containers for retrieval from the AS/RS for shipment. This table provides a unique WRAP shipment number to relate other data in the DMS.

Shipping Pick List WRAP Number *SHIPPICK WRAP NUM

$\operatorname{VARCHAR2}(8) \quad R$ Shipping Pick List Package ID •*SHIPPICK_PKG_ID VARCHAR2(14) $R$

WRAP Shipment (SHIPWRAP)

This table provides all the data associated with the shipment of waste

(excluding TRUPACT shipments) from the WRAP facility.
WRAP Shipment Number
WRAP Shipment Absorbent Flag
WRAP Shipment Alpha Contamination
WRAP Shipment Beta/Gamma Contamination
WRAP Shipment Cab Dose
WRAP Shipment Carrier Person
WRAP Shipment Carrier Vehicle ID
WRAP Shipment Chemical Form
WRAP Shipment Container reusable Flag
WRAP Shipment Description
WRAP Shipment Ship from Facility
WRAP Shipment Ship from Name
WRAP Shipment Max Package Dose
at Contact
WRAP Shipment Max Package Dose at IM
WRAP Shipment Max Vehicle Dose at Sides
WRAP Shipment Max Vehicle Dose at 2M
WRAP Shipment Manifest Complete Flag
WRAP Shipment Manifest Number
WRAP Shipment Radionuclide List
WRAP Shipment 0ther Pertinent Info
WRAP Shipment Quantity Category
WRAP Shipment RM Escort Flag
WRAP Shipment RM Supervisor
Review Flag
WRAP Shipment RSR Complete Flag
WRAP Shipment RSR Number
WRAP Shipment Secondary Hazards
WRAP Shipment SNM Flag
WRAP Shipment Ship to Facility
*SHIPWRAP NUM
SHIPWRAP' ABSORB FLAG
VARCHAR2 (8) R
SHIPWRAP ALPHA CONTAM
SHIPWRAP ${ }^{-} B G$ CONTAM
VARCHAR2 (1)
SHIPWRAP ${ }^{-}$CA $\bar{B}$ DOSE
VARCHAR2 (8)
VARCHAR2 (8)
- SHIPWRAP ${ }^{-}$CARRIER PERS
VARCHAR2 $(8)$
SHIPURAP-CARRIER- ${ }^{-}$- IDH VARCHAR2 (6)
SHIPWRAP-CHEM_FORM - VARCHAR2 (12)
SHIPWRAP ${ }^{-}$CNTR $^{-}$REUSE FLAG VARCHAR2 (1)
SHIPWRAP DESCR
VARCHAR2 (255)
- SHIPWRAP ${ }^{-}$FROM FACIL ID VARCHAR2 (11)
-SHIPWRAP_FROM_PERS_ID VARCHAR2 (6)
SHIPWRAP MAX PKG DOSE CT VARCHAR2 (8)
SHIPWRAP_MAX_PKG_DOSE_IM VARCHAR2 (8)
SHIPWRAP MAX VEH DOSE SD VARCHAR2 (8)
SHIPWRAP ${ }^{-}$MAX ${ }^{-}$VEH $^{-}$DOSE $^{-}$2M VARCHAR2 (8)
SHIPWRAP MFST_COMP_FLĀG VARCHAR2 (1)
-SHIPWRAP ${ }^{-}$MFST $^{-}$NUM - VARCHAR2 (10)
SHIPWRAP ${ }^{-}$NUCLIDE LIST VARCHAR2 (255)
SHIPWRAP ${ }^{-}$OTHR PERT_DATA VARCHAR2 (255)
SHIPWRAP ${ }^{-}$QTY $\bar{C}$ CAT - VARCHAR2 (35)
SHIPWRAP_RM_ESCRT_FLAG VARCHAR2 (1)
SHIPWRAP RM SUPR REV FLAG VARCHAR2 (1)
SHIPWRAP ${ }^{-}$RSE $\bar{R}$ COMP FLA $\bar{P}$ VARCHAR2 (1)
SHIPWRAP_RSR_NUM - VARCHAR2 (10)
SHIPWRAP ${ }^{-}$SEC $^{-}$HAZ
VARCHAR2 $(10)$
VARCHAR2 $(255)$
SHIPWRAP ${ }^{-}$SNM $^{-}$FLAG
VARCHAR2 (1)
- SHIPWRAP'TO FACIL ID
VARCHAR2 (11)
WRAP Shipment Ship to Name
-SHIPWRAP_TO_PERS_ID
VARCHAR2 (6)

\section{TRUPACT Shipping Record (TRUSHIP)}

This table provide information associated with a specific TRUPACT shipment

which may contain up to three TRUPACT II shipping casks.

TRUPACT Shipment Number

Actual Ship Date

-TRUSHIP SHIP NUM

TRUSHIP-DT

VARCHAR2 (8) R

DATE 
Contajner and Content Record (WASTE) - SWITS Data Record

This table is used for all global container information. Data elements are updated as waste containers are processed through the facility. This table is downloaded from SWITS.

Container Package ID

Container Accumulation Date

Container Chemical Nature Code

Container Volume

Container Type Code

Container DOT Specification

Container Generator Comment

Container Generator Waste Description

Container Gross Weight

Container Item Number

Container Labpack Flag

Container Liner Thick

Container Liner Type

Container Location Facility Area

Container Location Facility ID

Container Manifest Number

Container Physical State Code

Container Package Date

Container Package Status

Container Primary Waste Type Code

Container Routine

Container Sample Flag

Container Storage Category Code

Container Secondary Package ID

Container Ship Date

Container Size Description

Container Source Charge Code

Container Source Company Id

Container Source Company Type

Container Source Facility ID

Container Source Organization

Container Tare Weight

Container Treatment Date

Container TSD Accept Date

Container Waste Weight

\begin{tabular}{|c|c|}
\hline 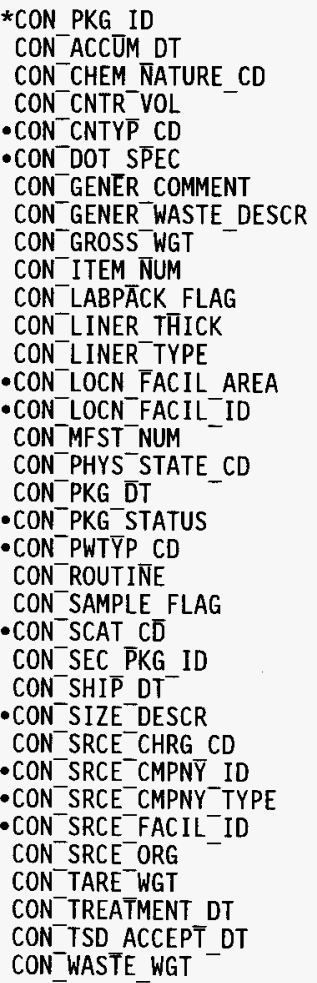 & 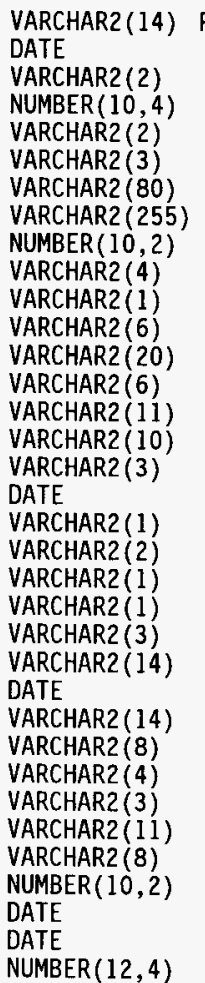 \\
\hline
\end{tabular}

Container \& Content Extension Record (WASTEXT)

This table is used for all WRAP-specific container information. Data elements are updated as waste containers are processed through the facility.

Container Extension Package ID

Container Assay Verification Date

Container Assay Verification Flag

Container Status

Container Compliant Flag

Container Contamination Flag

Container Filler Weight

Container Haz Materials Verified Flag

Container Height

Container Material Group Code

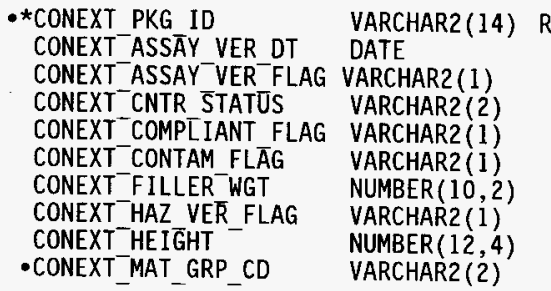

C-17 
WHC-SD-W026-SDD-001, Rev. 2

Container NDE Verified $\mathrm{Flag}$

Container Non-Listed Long-Lived

Detected Date

Container Profile Flag

Container Profile ID

Container RADMAT ID

Container Route Code

Container Revisit Flag

Container Screening Verification $\mathrm{Flag}$

Container Shipment Pick Llist Code

Container Treatment Flag

Container Use Code

Container Verification Gross Weight

Container Verification Gross

Weight Flag

Container WRAP Sample Flag

Container WRAP Status Code

\begin{tabular}{|c|c|}
\hline CONEXT_NDE_VER_FLAG & VARCHAR2 (1) \\
\hline $\begin{array}{l}\text { CONEXT NLLL_DET DT } \\
\text { CONEXT-PROF-FLAG } \\
\text {-CONEXT-PROF ID } \\
\text { CONEXT_RADMAT ID } \\
\text { CONEXT-ROUTE CD } \\
\text { CONEXT-RVST_FLAG } \\
\text { CONEXT_SCRN VER_FLAG } \\
\text { CONEXT-SHIPFICK_CD } \\
\text { CONEXT-TREATMENT_FLAG } \\
\text { CONEXT-USE CD - } \\
\text { CONEXT-VER_GROSS WGT }\end{array}$ & $\begin{array}{l}\text { DATE } \\
\text { VARCHAR2 }(1) \\
\text { VARCHAR2 (6) } \\
\text { VARCHAR2 (1) } \\
\text { VARCHAR2 (4) } \\
\text { VARCHAR2 (1) } \\
\text { VARCHAR2 (1) } \\
\text { VARCHAR2 (4) } \\
\text { VARCHAR2 (1) } \\
\text { VARCHAR2 (2) } \\
\text { NUMBER }(10,2)\end{array}$ \\
\hline $\begin{array}{l}\text { CONEXT VER GROSS WGT } \\
\text { CONEXT_WRAP SAM FLAG } \\
\text { CONEXT_WRAP_STAT_CD }\end{array}$ & $\begin{array}{l}\text { LAG VARCHAR2 (1) } \\
\text { VARCHAR2 (1) } \\
\text { VARCHAR2 (2) }\end{array}$ \\
\hline
\end{tabular}

Treatment Worksheet (WORKSHEET)

This data record is used to summarize the waste containers (not drums)

that are to be treated using a common treatment procedure. Containers to

be treated at the same time.

Treatment Worksheet ID

Treatment File Pointer

Treatment Worksheet Name

Treatment Procedure Number

Treatment Procedure Revision Number

$\begin{array}{ll}\text { *WORKSHEET_ID } & \text { VARCHAR2 (8) } \\ \text { WORKSHEET_FILE_POINT } & \text { VARCHAR2 (14) } \\ \text { WORKSHEET_NAME- } & \text { VARCHAR2(12) } \\ \text {-WORKSHEET_PROC_NUM } & \text { VARCHAR2 (14) } \\ \text { WORKSHEET_PROC_REV_NUMVARCHAR2(4) }\end{array}$

Verification (VERIFICATION) - New SWITS Data Record

This data record documents (Journal) of newly-generated waste evaluated at WRAP.

Verification Package ID

Verification Method

Verification Date

Verification Pass/Fail

Verification Failure Reason

**VER PKG ID

*VER METHOD

*VER-DT

VER PASS

VER_FAIL_REASON

(Journal)

VARCHAR2 (14)

VARCHAR2 (4)

DATE

VARCHAR2 (1)

VARCHAR2 (255)

Worksheet Item (WORKITEM)

(Journa1)

This data record contains the list of transfer drum/purge port PINs and packet/sample PINs to be treated on a worksheet.

Worksheet Item ID

Worksheet Item Package ID

-*WORKITEM ID

-*WORKITEM_PKG_ID

$\operatorname{VARCHAR2}(8) \quad \mathrm{R}$

VARCHAR2 (14) $R$ 


\section{C.1.2 Data Look-Up Tabies}

Miscellaneous Code Table (CODECHECK) - SWITS Lookup Table Occurrences of this entity contain the name of a data element and a specific valid value that may be stored in the data element of the same name in the functional database. A data element with 1-9 valid values will have a corresponding number of occurrences within this table to provide database maintenance software with a reference of those valid values. Data elements with greater than nine valid values may have a separate validation table where desirable.

Code Field Name

Code Value

Code Description

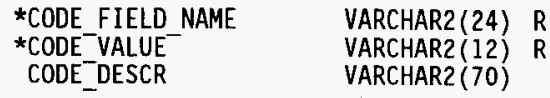

Company Table (COMPANY) - SWITS Lookup Table

The table identifies a11 companies involved with the generation,

transportation, or disposition of waste tracked by the SWITS system.

Company ID

Company Type

Company city

Company Environmental Protection Agency (EPA) ID

Company Location

Company Phone

Company State Code

Company Street

Company Title

Company Zip Code
*CMPNY ID

*CMPNY TYPE

CMPNY' CITY

CMPNY_EPA_ID

CMPNY LOCATION

CMPNY-PHONE

- CMPNY STATE CD

CMPNY' STREET

CMPNY TITLE

CMPNYZZIP_CD
VARCHAR2 (4) R

VARCHAR2 (3) R

VARCHAR2 (15)

VARCHAR2 (12)

VARCHAR2 (3)

VARCHAR2 (12)

VARCHAR2 (2)

VARCHAR2 (36)

VARCHAR2 (60)

VARCHAR2 (10)

Container Size Table (CONSIZE) - SWITS Lookup Table

This table holds all the valid size descriptions for the various container types, such as ' 55 Gallon' for drums.

Container Size Container Type Code

Container Size Description

Container Size Volume

${ }^{*}$ CSZ_CNTYP CD
${ }^{*}$ CSZ_DESCR $^{-}$
CSZ_VOL

VARCHAR2 (2) $\mathrm{R}$

VARCHAR2 (14) $R$

$\operatorname{NUMBER}(10,4)$

Container Type Table (CONTYPE) - SWITS Lookup Table

All containers fall into one of several specific types. This entity identifies all valid container types.

Container Type Code

Container Type Description

*CNTYP CD

CNTYP DESCR

VARCHAR2 (2) $R$ VARCHAR2 (42)

\section{Field Help Table (DATADICT)}

This table contains help information which provides help messages at the
field level.

Data Dictionary Table Name

Data Dictionary Field Name

Data Dictionary Help Text

Data Dictionary Type
*DD TABLE NAME
*DD-FIELD ${ }^{-}$NAME
DD HELP TEXT
DD_DATA-TYPE

VARCHAR2 (20) $R$

VARCHAR2 (36) $R$

LONG

VARCHAR2 (15) 
DOT Container Specification Table (DOTSPEC) - SWITS Lookup Table This table holds Department of Transportation specifications for container types, such as $17 \mathrm{C}$.

DOT Specification

DOT Specification Description

*DOT SPEC

DOT_DESCR
$\operatorname{VARCHAR2}(3) \quad \mathrm{R}$

VARCHAR2 (60)

Dangerous Waste Number Table (DWNUM) - SWITS Lookup Table

The table of Dangerous Waste Numbers which are codes used to classify the

type of hazards in a container of hazardous or mixed waste.

Dangerous Waste Number

Dangerous Waste Description

Dangerous Waste Landban

Dangerous Waste Sort Hazardous

Dangerous Waste Sort Mixed

*DW NUM

DW'DESCR

DW'LANDBAN

DW' SORT HAZ

DW_SORT_MIXED
VARCHAR2 (4) $R$

VARCHAR2 (20)

VARCHAR2 (1)

NUMBER (3)

NUMBER (3)

Error Message Table (ERRMESSAGE)

This entity maintains a list of all error messages that may be displayed by the DMS system. A narrative is provided to guide the recipient of the message in the proper actions to correct the error.

Error Message Number

Error Message Description

*ERR NUM

ERR DESCR

VARCHAR2 (4) $R$

Error Message Text

ERR TEXT

VARCHAR2 (255)

VARCHAR2 (72)

Facility Table (FACILITY) - SWITS Lookup Table

Each facility on the Hanford site is identified by this entity.

Facility ID

Facility Area

Facility Bar Code ID

Facility Name

*FACIL ID

FACIL AREA

VARCHAR2 (11) $R$

FACIL-BAR ID

VARCHAR2 (6)

FACIL NAME

VARCHAR2 (5)

VARCHAR2 (55)

Field Analysis Type Table (FLDANALTYP)

This table will be used to define the various field screening analyses

which may be performed in WRAP ( $\mathrm{pH}$, temperature, organic vapor, HAZCAT)

Field Analysis Type Code

Field Analysis Type Description

Field Analysis Type Units

*FAT CD

FAT DESCR

FAT UNITS
VARCHAR2 (4) R

VARCHAR2 (70)

VARCHAR2 (6)

Form Help Table (FORMHELP)

This table contains help information which provides help messages at the

form level.

Form Help Name

Form Help Text

*FH FORM NAME

FH_HELP_TEXT
VARCHAR2 (8) $R$

LONG 
Hazardous Chemical Component Table (HAZCOMP) - SWITS Lookup Table Each hazardous chemical that is present in a container package is identified by an occurrence of this entity. If a container contains four different hazardous chemicals, four occurrences of this entity will be present.

$\begin{array}{lll}\text { Hazardous Chemical Component ID } & \text { *HCC_ID } & \text { VARCHAR2(12) } R \\ \text { Hazardous Chemical Component Chemical } & \text { HCC_CAS } & \text { VARCHAR2(12) }\end{array}$ Abstract Number

Hazardous Chemical Component Description HCC DESCR VARCHAR2(70)

Hazardous Chemical Component New ID HCC NEWID

VARCHAR2 (12)

Isotope Table (ISOTOPE) - SWITS Lookup Table

Each isotope that can be present in a waste container is represented by an occurrence of this entity.

I sotope Number

Isotope Class A Limits

Isotope Class B Limits

Isotope Class C Limits

Isotope Class 1 Limits

Isotope Class 3 Limits

Isotope Concentration Limits

Isotope Conversion Factor

Isotope Dose Equivalence Curie Factor

Isotope Daughter Products Isotope No.

Isotope Daughter Products Factor

Isotope Enrichment

Isotope Half Life

Isotope Mixed Activation Prod. Factor

Isotope Mixed Activation Products Name

Isotope Mixed Fission Products Factor

Isotope Name

Isotope Unit

Phase 3 Data Elements:

Isotope Fissile Gram Equivalent Factor Isotope Plutonium Equivalent $\mathrm{Ci}$ Factor Isotope Alpha Curie Factor
* ISO NUM

ISO-CLASS A LIM

ISO- CLASS $^{-}$B $^{-}$LIM

ISO- CLASS $^{-} C^{-}$LIM

ISO $^{-}$CLASS $^{-} 1^{-}$LIM

ISO- CLASS $^{-}{ }^{-}$LIM

ISO- CONSTR LIM

ISO- CONV FĀCTR

ISO ${ }^{-}$DE C I FACTR

ISO-DTR ISOO

ISO DTRPRD FACTR

ISO ${ }^{-}$ENRICH $^{-}$

ISO- HALFLIFE

ISO ${ }^{-}$MAP FACTR

ISO MAP NAME

ISO MFP ${ }^{-}$FACTR

ISO ${ }^{-}$NAME

ISO UNIT

$\operatorname{NUMBER}(3) \quad R$

FLOAT

FLOAT

FLOAT

FLOAT

FLOAT

FLOAT

FLOAT

FLOAT

NUMBER (3)

FLOAT

VARCHAR2 (1)

FLOAT

FLOAT

VARCHAR2 (5)

FLOAT

VARCHAR2 (20)

VARCHAR2 (2)

ISO FGE FACTR

FLOAT

ISO-PE $\bar{C}$ I FACTR

FLOAT

ISO_ALPHA_CI_FACTR FLOAT

Laboratory Table (LAB) - SWITS Lookup Table

This entity identifies all the laboratories available to test waste samples.

Laboratory ID

Laboratory Name

$\begin{array}{ll}* \text { LAB ID } & \text { VARCHAR2 }(6) \quad R \\ \text { LAB_NAME } & \text { VARCHAR2 }(30)\end{array}$

Laboratory Analysis Table (LABANAL)

The table defines the specifics associated with an analysis.

Laboratory Analysis Code

* LABANAL CD

Laboratory Analys is Container Count

LABANAL CNTR COUNT

VARCHAR2 (8) $R$

Laboratory Analysis Container Type Code - LABANAL ${ }^{-}$CNTY $\bar{P}$ CD

Laboratory Analysis Description

Laboratory Analysis Preservative

LABANAL DESCR

NUMBER (1)

VARCHAR2 (3)

Laboratory Analysis Required Volume

LABANAL PRESERV

LABANAL REQD VOL

VARCHAR2 $(20)$

VARCHAR2 (12)

NUMBER(4) 
Location Table (LOCN)

This table is used to validate WRAP facility locations.

Location ID

Location Description

*LOCN ID

LOCN_DESCR

VARCHAR2 (10) $R$

VARCHAR2 $(60)$

Material Table (MATL)

This table is used to validate detailed descriptions for waste packet group codes.

Material Group Code

Material Group Description

$\begin{array}{ll}* \text { MATL_GRP_CD } & \text { VARCHAR2 (2) } \quad R \\ \text { MATL_GRP_DESCR } & \text { VARCHAR2 (30) }\end{array}$

Material Safety Data Sheets (MSDS) - SWITS Data Table

The reference number and description of Material Safety Data Sheets.

Material Safety Data Sheet ID *MSDS ID $\quad$ VARCHAR2 (6) R

Materia1 Safety Date Sheet Description MSDS_DESCR VARCHAR2(40)

Person Table (PERSON)

This entity keeps track of all the persons associated with SWITS, whether they are users or not.

Person ID

Person City

Person Company ID

Person Company Type

Person MSIN

Person Name

Person Phone Number

Person State Code

Person Street

Person Zip Code

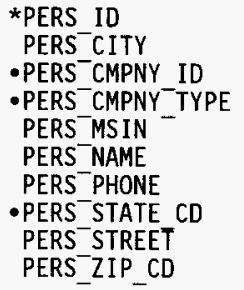

VARCHAR2 (6) $R$

VARCHAR2 (15)

VARCHAR2 (4)

VARCHAR2 (3)

VARCHAR2 (5)

VARCHAR2 (20)

VARCHAR2 (12)

VARCHAR2 (2)

VARCHAR2 (36)

VARCHAR2 (10)

Physical Component Description Table (PHYSDESC) - SWITS Data Table

A list of all physical components that may be present in a waste container is maintained by this entity.

Physical Description

*PDESC_DESCR VARCHAR2 $(30) \mathrm{R}$

Package Status Table (PKGSTAT)

A table defining the various status codes which may be associated with a package during its existence, the edits which must be passed for other data about the package, and who owns the data.

Package Status

Package Status Description

Package Status Edit

Package Owner

$\begin{array}{ll}\text { *PKS STATUS } & \text { VARCHAR2 }(1) \quad \mathrm{R} \\ \text { PKS_DESCR } & \text { VARCHAR2 (60) } \\ \text { PKS_EDIT } & \text { VARCHAR2 (1) } \\ \text { PKS_OWNER } & \text { VARCHAR2 (3) }\end{array}$

Primary Waste Type Code Table (PRIWASTYPE) - SWITS Data Table The entity identifies a particular grouping of waste types that are considered as primary to a particular container which includes radioactive waste.

Primary Waste Type Code

Primary Waste Type Description

$\begin{array}{ll}\text { *PWTYP_CD } & \text { VARCHAR2 (2) } R \\ \text { PWTYP_DESCR } & \text { VARCHAR2 }(20)\end{array}$


WHC-SD-W026-SDD-001, Rev. 2

Primary Waste Type Hazardous

PWTYP HAZ

PWTYP' RAD

Primary Waste Type Radioactive

PWTYP_SHIP_TIME

VARCHAR2 (1)

VARCHAR2 (1)

Primary Waste Type Ship Time

Generator Assay Profile Table (PROFILE)

This table provides a definition of the source of an isotopic profile for a specific waste stream.

Profile ID

Profile Description

Profile Date

VARCHAR2 (6) $R$

VARCHAR2 (50)

DATE

\section{Profile Isotopic Table (PROFILEISO)}

This table provides the specific isotopic profile data required to support calculations of isotopic quantities during NDA operations.

Profile Isotopic Profile ID

Profile Isotopic Name

Profile Relative Abundance

Profile Relative Abundance TMU

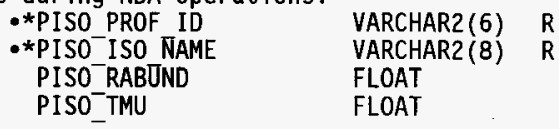

Report Table (REPORTABLE)

This entity supports the report preparation activity.

Report Table Name

Report Table Generator Specific

Report Table Select

Report Table Timing

Report Table Title
*RPT NAME
RPT GENSPEC
RPT ${ }^{-}$SELECT
RPT $^{-}$TIMING
RPT $^{-}$TITLE

Role Table (ROLE)

The list of roles to which users may be assigned, such as Generator.

Role Code

Role Description

$$
\begin{aligned}
& \text { *ROLE_CD } \\
& \text { ROLE_DESCR }
\end{aligned}
$$

\author{
VARCHAR2 (8) $\mathrm{R}$ \\ VARCHAR2 (1) \\ VARCHAR2 (8) \\ VARCHAR2 (1) \\ $\operatorname{VARCHAR2}(40)$
}

\section{Role Screen Relationship Table (ROLESCREEN)}

The entity relates the screen and its access to a particular role.

Role Screen Role Code

Role Screen Screen Name

Role Screen Screen Access for Role
-*RSCRN ROLE CD

•*RSCRN ${ }^{-}$SCRN $^{-}$NAME

RSCRN_ACCESSS
VARCHAR2 (6) R

VARCHAR2 $(60)$

Route Description Table (ROUTE)

This table defines the WRAP Process routes used to transfer waste

containers from various waste streams through the facility.

Route Code

Route Description

*ROUTE CD

ROUTE DESCR

VARCHAR2 (4) $\mathrm{R}$

VARCHAR2 (25)

Sample Container Type (SAMPCONTYP)

The table defines the containers to be used during sample collection.

Sample Container Type Code

Sample Container Description

* SAMP CNTYP CD

SAMP_CNTR_DESCR

VARCHAR2 (3) R

VARCHAR2 (30) 
Sample Matrix Table (SAMPMATX)

The table defines the physical matrices for a given sample ID

Sample Matrix Code

Sample Matrix Description

* SAMPMATX CD

SAMPMATX_DESCR

$\operatorname{VARCHAR2~(3)~} R$

VARCHAR2(12)

Sampling Method (SAMPMETH)

This table shall be used to define the methods used to obtain samples in WRAP.

Sampling Method Code

Sampling Method Description

*SAMPLING_METHODCD VARCHAR2 (4) $R$

SAMPLING_METHOD_DESCR VARCHAR2(30)

Screen Table (SCREEN)

The list of screens which are within the DMS system.

Screen Name

Screen Title

*SCRN NAME

SCRN_TITLE

VARCHAR2 (8) $R$

VARCHAR2 (40)

Secondary Waste Type Code Table (SECWASTYPE) - SWITS Data Table

The occurrences of this entity define the particular kind of waste in a container.

Secondary Waste Type Code

Secondary Waste Type Group

Secondary Waste Type Description

*SWTYP CD

SWTYP ${ }^{-}$GROUP

SWTYP'DESCR
VARCHAR2 (2) $R$

VARCHAR2 ( 3 )

VARCHAR2 (50)

Shipping Pick List Type (SHIPPICKTYP)

Table to identify and group containers, based on waste type, for retrieval from the AS/RS for shipment.

Shipping Pick List Type Code *SHIPPICKTYP CD VARCHAR2 (4) $R$

Shipping Pick List Type Description

SHIPPICKTYP-DESCR

VARCHAR2 (24)

SIE I sotopic Name Table (SIEISO)

This table provides a reference to the isotope descriptions and isotopic numbers used in WRAP 1 assays.

SIE Isotopic Name

SIE Isotopic Number

* SIE ISO NAME

$\operatorname{VARCHAR2}(8) \quad R$

-SIE_ISO_NUM

$\operatorname{NUMBER}(3)$

State Table (STATE) - SWITS Data Table

This table identifies all states involved with the generation,

transportation, or disposition of waste tracked by the SWITS system.

State Code

State Name

* STATE CD

STATE-NAME

VARCHAR2 (2) $R$

VARCHAR2 (15)

Storage Category Table (STORAGECAT) - SWITS Data Table

Each waste container is assigned a specific storage category that groups

the types of waste stored within the container. This entity identifies each possible category.

Storage Category Code

Storage Category

$$
\begin{aligned}
& \text { ^SCAT_CD } \\
& \text { SCAT_CATEGORY }
\end{aligned}
$$

VARCHAR2 (3) $R$

VARCHAR2 (20) 
Treatment Procedure (TREATPROC)

(Journal)

This record provides a description of the WRAP I treatment procedure for waste in the RWM gloveboxes.

Treatment Procedure Number

Treatment Procedure Revision Number

Treatment Procedure Author

Treatment Procedure Description

Treatment Procedure Expiration Date

$\begin{array}{ll}\text { *TREAT_PROC_NUM } & \text { VARCHAR2 (14) } \\ \text { *TREAT_PROC-REV_NUM } & \text { VARCHAR2 (4) } \\ \text { *TREAT-PROC-AUTHOR } & \text { VARCHAR2 (30) } \\ \text { TREAT_PROC-AUTOR } & \text { VARCHAR2 (30) } \\ \text { TREAT_PROC-DESCR } & \text { DARE } \\ \text { TREAT_PROC_EXP_DT } & \text { DATE }\end{array}$

TRUCON Code Table (TRUCON)

This table lists the WIPP TRUCON codes used to describe the source and type of waste to be shipped to WIPP.

TRUCON Code

TRUCON Description

*TRUCON CD
TRUCON_DESCR
$\operatorname{VARCHAR2}(6) \mathrm{R}$ $\operatorname{VARCHAR2}(90)$

IRU Shipping Category Table (TRUSHIPCAT)

This table defines the TRUPACT II shipping categories and their applicable decay heat limits for waste shipped to the WIPP facility. The shipping categories define the waste type, packaging configuration, and decay heat limits for the waste streams.

TRU Shipping Category Code

TRU Shipping Category Description RUPACT Container Limit

TRUPACT Cask Limit

$\begin{array}{ll}\text { *TRUSHIPCAT_CD } & \text { VARCHAR2 }(7) \\ \text { TRUSHIPCAT-DESCR } & \mathrm{R} \\ \text { TRUSHIPCAT_CON LIM } & \text { NARCHAR2 (90) } \\ \text { TRUSHIPCAT_CASK_LIM } & \text { NUMBER }(5,4) \\ \text { TRUS }(5,4)\end{array}$

TSD Facility Table (TSDFACIL) - SWITS Data Table

This table identifies the treatment, storage, and disposal facilities

involved with storage and disposition of waste tracked by SWITS.

TSD Facility ID

TSD Manifest Address

TSD Scheduler

TSD Supervisor
-*TFAC FACIL ID

TFAC MFST ĀDDR

- TFAC SCHEDULER

-TFAC ${ }^{-}$SUPERVISOR
VARCHAR2 (11) $R$

$\operatorname{VARCHAR2}(40)$

VARCHAR2 (6)

VARCHAR2 (6)

User Role Relationship Table (USERROLE)

The entity relates the screen and its access to a particular role.

User Role User Id

User Role Role Code

**URL USERID

•*URL ROLE CD

$\operatorname{VARCHAR2}(7) \quad R$

User Table (USERS)

Each functional, system manager, and developer user of DMS is mainournal)

by occurrences of this entity.

User ID

User Account

User Bulletin Date

User Logon Date

User Name

User Organization

User Person ID

User Print Deliver To

User Printed Where

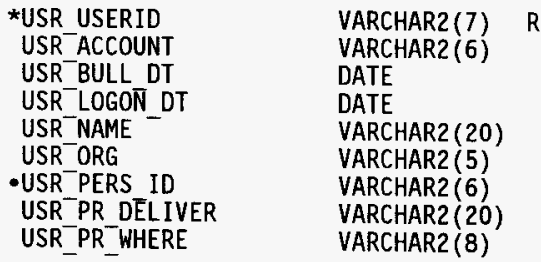


WHC-SD-W026-SDD-001, Rev. 2

User Term Type

USR TERM TYPE

User Train Date

USR TRAIN DT

VARCHAR2 (6)

DATE

User Signature Password (USERSIGNPASS)

The entity is used to store the signature password for a User Id in a secured area.

User Signature Password User ID

-*UP USERID

$\operatorname{VARCHAR2}(7) \quad \mathrm{R}$

User Signature Password

$U U^{-} S P$

VARCHAR2 (10)

WRAP Miscellaneous Table (WRAPMISC)

This table will contain miscellaneous values to be used during setup or processing of the WRAP 1 DMS. The data fields may be used to store constants for use in the DMS programming or selected data ranges. WRAP Field Name

WRAP Value

WRAP Description

*WRAP FIELD NAME

*WRAP CODE VALUE

WRAP_CODE_DESCR
VARCHAR2 (24) $R$

VARCHAR2 (12) $R$

VARCHAR2 (70) 


\section{2 DMS DATA ELEMENT DESCRIPTIONS}

Section C.2 provides descriptions for each of the data elements in the DMS database. This section follows the same alphabetical data record organization and sequence as Section C.l.

\section{C.2.1 Data Record Tables Element Descriptions}

Activity Comment Record (ACTCOM) -*ACT PKG ID

*ACT DT

$\stackrel{?}{\underline{1}}$
VARCHAR2(14) Activity Comment Required

Package ID

$\begin{array}{ll}\text { DATE } & \text { Activity Date } \\ \text { Required } & \\ \text { VARCHAR2(10) } & \begin{array}{l}\text { Activity Comment } \\ \text { Activity Code }\end{array}\end{array}$

Associates the activity comments with a particular PIN. Domain:

Alphanumeric. Must match a package ID in the Container and Content Record (CON_PKG_ID).

Date of activity comment. Domain: Oracle format date.

Type of activity that comments were made against which includes receipt inspection, assay, examination, treatment, or repackaging. Domain: Alphanumeric; WRAP Miscellaneous Table (WRAPMISC) WRAP FIELD NAME = ACT CD.

'RECEIVING'

'STORAGE

'AGV'

'NDE'

'PAN'

'GEA'

'BWAS'

'LLW GB'

'LLWRWM GB'

'TRU GB'

'TRURWM GB'

'SHIPPING' 
ACT_COMMENTS

VARCHAR2 (255)

-ACT_OP_ID

\section{Applicable MSDS \\ -*APP_PKG_ID}

$\stackrel{\substack{i \\ \infty}}{\sim}$

•*APP_MSDS

Bin List (BIN)

*BIN_NUM

U**BIN_PKG_ID
$\operatorname{VARCHAR2}(7)$
VARCHAR2 (3) Bin Number

Required

VARCHAR2 (14) Bin Package ID
Activity Comment

Operator ID

Appl icable Package

ID Number

Applicable MSDS

VARCHAR2 $(6)$
Required

Required
Comments generated by an operator during receipt inspection, assay, examination, treatment, or repackaging waste (multiple occurrences). Domain: Alphanumeric.

Identifier of person performing a specific activity in WRAP Module 1 such as NDE, NDA, packaging the waste, sampling, or treating.

Domain: Alphanumeric. Must match a user ID in the User table (USR USERID).

Package ID associated to an Material Safety Data Sheet (MSDS), Domain: Alphanumeric. Must match a package ID in the Container and Content Record (CON PKG ID).

The identifier of the applicable MSDS as described in the Material Safety Data Sheets table (MSDS). Domain: Material Safety Data Sheet Table (MSDS) MSDS_ID.

The bin location returned from the AS/RS when a pallet is put into storage. Domain: Alphanumeric.

The package ID of a the drums on the pallet. Domain: Alphanumeric. Must match a package ID in the Container and Content Record (CON PKG ID). 
$\frac{\text { Bottle Data Record }}{\text { *BOT BOTTLE_ID }}$ (BOTTLE)

-BOT SAMPLE ID

กิ
VARCHAR2(12) Bottle ID

Required

VARCHAR2(8) Bottle Sample ID

VARCHAR2(255) Bottle Comments

VARCHAR2(15) Bottle Disposed By

DATE

VARCHAR2 (25) Bottle Disposal Method

BOT_OK_AT_LAB
VARCHAR2 (1)

\section{Bottle OK at} Laboratory
The unique identification number assigned to the individual sample bottle. Domain: Alphanumeric. Format shall be $Y Y$-NNNNN-BBL where

$$
Y Y=\text { year }
$$

$N N N N N=$ sequential sample number $B B=$ bottle number

' $L$ ' = 1aboratory sample.

The unique identification of the sample itself. Domain:

Alphanumeric. Format shall be $Y Y-N N N N N$ where

$$
\text { YY }
$$$$
=\text { year }
$$

NNNNN = sequential sample number . Must be in SAM_SAMPLE_ID.

Comments by the user about the sample bottle. Domain: Alphanumeric.

Identifies the person responsible for the final disposal of the sample bottle. Domain: Alphanumeric.

The date that the sample bottle was disposed. Domain: Oracle format date.

The method used for final disposal of the bottle. Domain: Alphanumeric.

Yes/No code to indicate whether a bottle arrived at the laboratory intact. Domain: ' $Y$ ' or ' $N$ '. 
BOT_RETURN_TO_PKG

BOT_RETURN_DT

Bottle Analysis Record (BOTANAL) - *BOTANAL BOTTLE ID

$\stackrel{T}{\omega}$

\section{VARCHAR2(12) Bottle Analysis Required}

BOTANAL_REQUEST_FLAG

BOTANAL_PERFORM_FLAG
Bottle Returned To Package

Bottle Return Date

\section{VARCHAR2 (8)} Required

VARCHAR2 (1)

Bottle Analysis Analys is Code

Bottle Analysis Requested Flag

VARCHAR2 (1)
Bottle Analysis Performed Flag
Yes/no code indicating whether the bottle of sample has been returned or not. Domain: ' $Y$ ' or ' $N$ '.

The date the bottle of sample is returned. Domain: Oracle format date.

The unique identification number assigned to the individual sample bottle. Domain: Alphanumeric. Format shall be $Y Y-N N N N N-B B L$ where $Y Y$ = year

NNNNN = sequential sample number

$B B=$ bottle number

' $L$ ' = laboratory sample. Must be in BOT BOTTLE_ID.

Code relating a specific analysis to a sample bottle. Domain:

Alphanumeric. Lookup to Laboratory Analysis table (LABANAL) LABANAL_CD.

Flag indicating that an analysis is requested for the sample bottle.

Flag indicating that an analysis was actually performed on the sample bottle. 
Hazardous Chemical Component Record (CHEMCOMP) - SWITS Data Record -*HAZ_PKG ID VARCHAR2(14) Hazardous Package Required ID

-*HAZ_COMP_ID

$\stackrel{?}{\omega}$

HAZ_COMP_PPM

HAZ_COMP_TEXT

HAZ_COMP_WGT

HAZ COMP WGT PCT
$\operatorname{VARCHAR2}(70)$

Hazardous Chemical Component Text

$\operatorname{VARCHAR2}(7)$

VARCHAR2(12) Hazardous Chemical Required

Component ID

Hazardous Chemical Component Parts Per Million

NUMBER $(12,4) \quad$ Hazardous Chemical Component Weight

Hazardous Chemical Component Weight Percent
The unique package identification number that is assigned to the outer waste package. The number is assigned by the waste generator and is used for tracking all waste. Domain: Alphanumeric. Must match a package ID in the Container and Content Record (CON PKG ID).

Unique identification of a hazardous chemical component. The hazardous chemical ID must be in the HAZCOMP table. Domain: Hazardous Chemical Component Table (HAZCOMP) HCC ID.

The portion of the waste in a container of a chemical component such as heavy metal, polychlorinated bipheny1. Domain: Alphanumeric. Units are parts per million (ppm).

The name of the hazardous chemical component. Domain: Derived from Hazardous Chemical Component Table (HAZCOMP) HCC_DESCR (not maintained).

The weight of a hazardous chemical component found in a specific waste container. Domain: Numeric. Must be $>0$. Units are kilograms.

The percent by weight of a component. Relates to container Waste Weight (CON WASTE WGT). Domain: Alphānumerīc. 


\author{
$H A Z$ EPCRA_FLAG \\ $\frac{\text { Chain of Custody }}{{ }^{*} \text { COC FORM ID }}(\mathrm{COC})$ \\ COC_BILL_LADING \\ $\underset{\sim}{\omega} \quad$ COC_CHEST_ID \\ COC_HAZ_REMARKS \\ -COC_LAB_ID
}

COC_LOG_ID

COC_METH_SHIPMENT
$\operatorname{VARCHAR2}(1)$

Hazardous Chemical Component Emergency Planning and Community Right-toknow Act (EPCRA) Flag

\section{VARCHAR2 (10) Chain of Custody Required Form ID}

NUMBER(25)

Chain of Custody Bill of Lading/Air Bi11 Number

VARCHAR2 (11) Chain of Custody Ice Chest ID Number

VARCHAR2 (255) Chain of Custody Possible Sample Hazard/Remarks

VARCHAR2(6) Chain of Custody Laboratory ID

VARCHAR2(20) Chain of Custody $\log$ ID

$\operatorname{VARCHAR2}(20)$
Chain of Custody Method of Shipment
Flag indicating that this waste is reportable according to EPCRA, al so known as Title III of the Superfund Amendments Reauthorization Act

(SARA). Domain: ' $Y$ ', ' $N$ ', or nul1.

This unique identifier is used to track the samples to the COC form. Domain: Alphanumeric.

The bill of 1 ading number for the samples shipped to the laboratory. Domain: Numeric.

Identification number of the ice chest used to ship samples to the laboratory. Domain: Alphanumeric.

Remarks or comments describing any hazardous conditions pertaining to the samples. Domain: Alphanumeric.

The identifier for the laboratory to which the sample is sent. Domain: Alphanumeric (Lookup to Laboratory table (LAB) LAB_ID.

Identifies the log book in which the COC entries exist. Domain:

Alphanumeric.

Method used to ship the samples to the laboratory. Domain: Alphanumeric. 
- COC_PERS_ID

COC_PROJ_DESIG

COC_PROPERTY NUM

COC SAF NUM

COC_SHIP_DT

COC_SPEC_HANDLING

COC_SPEC_INSTRUCTION

COC_TURN_AROUND
VARCHAR2 (6) Chain of Custody

Company Contact

VARCHAR2 (25) Chain of Custody Project Designation

NUMBER(14)

Chain of Custody Offsite Property Number

NUMBER(10) Chain of Custody SAF Number

DATE

VARCHAR2 (255) Chain of Custody Special Handling or Storage

VARCHAR2(255) Chain of Custody Special

Instructions

VARCHAR2(1) Chain of Custody Data Turnaround
ID of the person who is the facility point of contact pertaining to the samples. Domain: Alphanumeric. Lookup to PERSON PERS ID.

Project designation for the sampling activities. Domain: Alphanumeric.

Any other property numbers that need to be tracked along with the sample numbers. Domain: Numeric.

Unique number provided by HSAM to track samples. Domain: Numeric.

Date of shiopment of the sample to the laboratory. Domain: Oracle format date.

Special handling instructions for the samples. Domain: Alphanumeric.

Special instructions pertaining to the sample. Domain: Alphanumeric.

Turn-around time that a laboratory is expected to return the analys is results on samples. Domain: Alpha $' P^{\prime}=$ Priority

' $N$ ' = Norma1. 


\begin{tabular}{|c|c|c|}
\hline $\begin{array}{l}\text { Chain of CUSLOay iranste } \\
\text { **COCXFR_PKG_ID }\end{array}$ & $\begin{array}{l}\text { VARCHAR2 (14) } \\
\text { Required }\end{array}$ & $\begin{array}{l}\text { Chain of Custody } \\
\text { Transfer Pkg ID }\end{array}$ \\
\hline${ }^{*}$ COCXFR_DT & $\begin{array}{l}\text { DATE } \\
\text { Required }\end{array}$ & $\begin{array}{l}\text { Chain of Custody } \\
\text { Transfer Date }\end{array}$ \\
\hline -COCXFR_RECVD_BY_OP_ID & $\operatorname{VARCHAR2}(6)$ & $\begin{array}{l}\text { Chain of Custody } \\
\text { Transfer Received } \\
\text { By Operator }\end{array}$ \\
\hline -COCXFR_RELIN_BY_OP_ID & $\operatorname{VARCHAR2}(6)$ & $\begin{array}{l}\text { Chain of Custody } \\
\text { Transfer } \\
\text { Relinquished By } \\
\text { Operator }\end{array}$ \\
\hline \multicolumn{3}{|c|}{$\frac{\text { Communication Table (COMMUNICATION TABLE) }}{\text { COMM FROM }}$} \\
\hline COMM_TO & VARCHAR2 (8) & Communication To \\
\hline COMM_MSG_ID & $\operatorname{VARCHAR2}(20)$ & $\begin{array}{l}\text { Communication } \\
\text { Message ID }\end{array}$ \\
\hline COMM_MSG_TEXT & $\operatorname{VARCHAR2}(80)$ & $\begin{array}{l}\text { Communication } \\
\text { Message Text }\end{array}$ \\
\hline
\end{tabular}

ID of the exterior package used to transport one or more samples.

Domain: Alphanumeric. Must match a package ID in the Container and Content Record (CON_PKG_ID).

Date that a transfer of custody occurs. Domain: Oracle format date.

ID of the operator who receives custody of samples Domain:

Alphanumeric. Lookup to Person table PERS_ID.

ID of the operator who relinquishes custody of samples. Domain:

Alphanumeric. Lookup to Person table PERS ID.

Identifies where the message was initiated from (i.e., DMSCOM, SQL*FORMS program, etc). Domain: Alphanumeric.

Identifies where the message is being sent (i.e., DMSCOM, SQL*FORMS program, etc). Domain: Alphanumeric.

Identifier for message. Domain: Alphanumeric.

Additional text for message. Domain: Alphanumeric. 
COMM PRIORITY

COMN DT

Container Location (CONLOC)

- ${ }^{*}$ ONLOC_PKG_ID

$\stackrel{?}{w}$
DATE

VARCHAR2 (10)
Communication

Priority

Communication Date

$\begin{array}{ll}\text { VARCHAR2(14) } & \text { Container Package } \\ \text { Required } & \text { ID }\end{array}$

Container Location

Date

Container Location ID
Priority for message. Lower the number, higher the priority. Domain: Numeric.

Date/Timestamp of message. Domain: Oracle format date.

The unique package identification number that is assigned to the outer waste package. The number is assigned by the waste generator and is used for tracking all waste.

Domain: Alphanumeric. Must match a package ID in the Container and Content Record (CON_PKG_ID).

Date and time that the waste container was moved to the current location. Domain: Oracle format date.

Name of a location within WRAP Module 1 where waste item or empty drum is stored or processed. Domain: Alphanumeric. Lookup to LOCATION Table LOCN_ID.

The package ID from which the contents were moved. Domain: Alphanumeric. Must match a package ID in the Container and Content Record (CON PKG ID).
Container Relationship Record (CONREL) - SWITS Data Record -*CONR_FROM_PKG_ID
VARCHAR2 (14)

Required
Container Relationship From Package ID 
-*CONR_TO_PKG_ID

*CONR DT

CONR REL CD

$\stackrel{?}{\omega}$

Container Treatment (CONTREAT)

-*CONTREAT_PKG_ID

*CONTREAT DT

\section{VARCHAR2 (14) \\ Required \\ Container \\ Relationship To \\ Package ID}

DATE

Required

$\operatorname{VARCHAR2}$ (1)

Container

Relationship Date

Container

Relationship Code

VARCHAR2 (14) Container Treatment Required Package ID

DATE

Required

Container Treatment Date
The package ID to which the contents were moved. Domain: Alphanumeric. Must match a package ID in the Container and Content Record (CON_PKG_ID).

The date the repackaging took place. Domain: Oracle format date.

The relationship between the two containers. Domain:

${ }^{\prime} \mathrm{C}$ ' = Combine (the contents of several containers being placed into one)

${ }^{\prime} O^{\prime}$ = 0verpack (a container and its contents being placed in another container)

${ }^{\prime} S^{\prime}=$ Split (the contents of one container being distributed to several others)

' $W$ ' = WRAP-generated container relationship; may be many to many.

The package ID of a container to be treated with the following treatment worksheet. Domain: Alphanumeric. Must match a package ID in the Container and Content Record (CON_PKG_ID).

Date that the treatment is performed on the container. Domain: Oracle format date. 


\section{CONTREAT_COMMENT}

- CONTREAT USER ID

CONTREAT WS ID

VARCHAR2 (8)

Container Treatment

$\begin{array}{ll}\text { NUMBER(12) } & \text { Discharge Conveyor } \\ \text { Required } & \text { Sequence Number }\end{array}$

Discharqe Conveyor List (OISCHARGE)

$\stackrel{?}{\omega}$ Worksheet ID

Container Treatment Comments

Container Treatment User ID

Discharge Conveyor Package ID
VARCHAR2 (14)
Comments by the user about the treatment process. Domain:

Alphanumeric.

User ID of the person performing the treatment process. Domain:

Alphanumeric. Lookup to USERS USR USERID.

The worksheet ID that describes the treatment process to be performed. Domain: Alphanumeric.

Record sequence number assigned by Oracle. Domain: Numeric; whole number $\leq 5$.

Package ID of a container on the discharge conveyor. Used to display the waste characteristics of the container to the user at the discharge conveyor to plan the makeup of the pallets to go into the AS/RS. Domain: Alphanumeric. Must match a package ID in the Container and Content Record (CON_PKG_ID). 
Field Screening Record (FIELDSCRN)

* SCRN_PKG_ID

VARCHAR2 (14)

Required

Field Screening

Package ID

*SCRN_ID

$\stackrel{i}{\omega}$

SCRN_COMMENTS

SCRN DT

- SCRN LOCN ID

-SCRN_PERS_ID
VARCHAR2(12) Field Screening ID

VARCHAR2 (255) Field Screening

Comments

DATE

Field Screening

Date

VARCHAR2(10) Field screening location

VARCHAR2 (6) Field Screening Person
Required
The unique package identification number that is assigned to any waste packet which undergoes field

screening. Domain: Alphanumeric. Must match a package ID in the Container and Content Record (CON_PKG_ID).

The unique identification number for samples taken during field screening operations. Domain: Alphanumeric. Format shall be $Y Y-N N N N N-B B F$ where $Y Y=$ year

NNNNN = sequential sample number $B B={ }^{\prime} 01^{\prime}$ for field screening sample

${ }^{\prime} F^{\prime}=$ field screening sample

Operator comments about the field screening. Domain: Alphanumeric.

Date that the field screening took place. Domain: Oracle format date.

Location where the field screening activity takes place (Process Area gloveboxes) Domain: Alphanumeric. Must be in Location table (LOCN) LOCN ID.

ID of person who takes the field screening sample Domain: Alphanumeric. Lookup to PERSON PERS ID. 


\author{
SCRN_SAMPLE_VOL \\ -SCRN SAMPLING_METHOD_CD \\ SCRN_VER_PASS_FLAG
}

$\underset{\stackrel{\omega}{\omega}}{\text { Field Analysis (FIELDANAL) }}$

$\bullet * F I E L D \_F A T \_C D$
NUMBER(4) Field Screening

Sample Volume

VARCHAR2 (4) Field Screening

Sampling Method

Code

VARCHAR2 (1)

Field Screening Verification Pass Flag

$\begin{array}{ll}\text { VARCHAR2(12) } & \text { Field Analysis } \\ \text { Required } & \text { Field Screening ID }\end{array}$

VARCHAR2 (4) Required

Field Analysis Code
Volume of the field screening sample. Domain: Numeric, units are in milliliters.

Defines the method used to obtain the field screening sample. Domain: Alphanumeric. Lookup to Sampling Method table (SAMPMETH) SAMPLING_METHOD CD.

Designates that the field screening resuits confirmed the data provided by the generator. Domain: Alpha ( $Y$ or $\mathrm{N}$ ).

This unique identifier relates the required analysis to the field sample that is taken. Domain:

Alphanumeric. Format shall be $Y Y$ NNNNN-01F where

$$
\begin{aligned}
Y Y & =\text { year } \\
N N N N N & =\text { sequential sample number } \\
{ }^{\prime} O 1 F^{\prime} & =\text { field screening sample. }
\end{aligned}
$$

Must match screening ID in Field Screening Table (SCRN ID).

This code is used to uniquely identify the screening analysis to be performed in WRAP. Domain:

Alphanumeric. Must be in Field Analys is Type table (FLDANALTYP) FAT CD. 


\section{FIELD RES}

VARCHAR2 (30)

Field Analysis Results
This data element is used to record the field analysis results obtained during field screening operations. Domain: Alphanumeric.

Hazardous Waste Container Detail Record (HAZDETAIL) - SWITS Data Record

\section{**HDET_PKG_ID \\ VARCHAR2 (14) \\ Hazardous Detail}

Required

Package ID

HDET_CNTR_STATUS

$\stackrel{?}{1}$

\section{VARCHAR2(2) Hazardolis Detāil}

Container Status

VARCHAR2 (3)
Hazardous Detail Designation Code
The unique package identification number assigned to a hazardous waste container package. Domain:

Alphanumeric. Must match a package ID in the Container and Content Record (CON_PKG_ID).

Status codes of an hazardous waste container. Domain: (CODECHECK)

$$
\begin{aligned}
& ' M T '=\text { empty } \\
& ' T R^{\prime}=\text { triple rinsed } \\
& { }^{\prime} F^{\prime}=\text { ful1 } \\
& ' P F^{\prime}=\text { part full. }
\end{aligned}
$$

The designation type applied to hazardous, mixed-radioactive and PCB waste in this waste package.

Washington Administrative Code (WAC) 173-303 provides the criteria for these solid waste types. Domain: (CODECHECK)

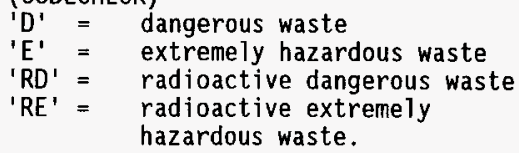


HDET DW NUM

HDET FLASHPOINT

$\stackrel{?}{!}$
VARCHAR2(85) Hazardous Detail Dangerous Waste

Numbers

VARCHAR2 (6)

VARCHAR2 (6)
HDET_HAZPROP_CD
Hazarouous Detāi Flashpoint

Hazardous Detail Hazardous Property Codes
Provides a list of all the dangerous waste numbers applying to the waste in this package. This list contains 1 to 14 four-character dangerous waste numbers. Each set is separated by a single blank. Each set is validated to the dangerous waste numbers in the DWNUM table. These sets are automatically sorted into the proper order using the sort information in the DWNUM table. Domain: Dangerous Waste Numbers Table (DWNUM) DW NUM.

Description of flashpoint of the contents, necessary only for a flammable material. Domain:

Alphanumeric.

' $F^{\prime}$ = Fahrenheit

$$
\text { ' } \mathrm{C} \text { ' = Celsius. }
$$

Identifies the Hazardous property categories applicable to the waste in this container. Domain: (CODECHECK)

$$
\begin{aligned}
& { }^{\prime} C^{\prime}=\text { corrosive } \\
& ' E '=\text { explosive } \\
& I^{\prime}=\text { ignitable } \\
& { }^{\prime} P^{\prime}=\text { persistent } \\
& T^{\prime}=\text { toxic } \\
& X^{\prime}=\text { carcinogenic. }
\end{aligned}
$$


HDET_IND_DOT_ID_NUM

$\stackrel{\tilde{L}}{\stackrel{1}{N}}$
VARCHAR2 (5)

Hazardous Detail Individual DOT ID Number

$\operatorname{VARCHAR2}(60)$
Hazardous Detail Individual Not Otherwise Specified Description
This field is used when a container has the option of being shipped separately. "Standard" shipping information for groups of containers is stored in the shipping records.

DOT identification number for waste in this individual container. The DOT identification number assigned to hazardous materials is given in the 49 CFR table 172.101. The numbers prefixed with 'UN' are appropriate for both international and domestic shipments. Those preceded by 'NA' are not recognized for international shipments except to and from Canada. Domain: Alphanumeric.

This field is used when a container has the option of being shipped separately. "Standard" shipping information for groups of containers is stored in the shipping records.

Text description of the two main hazardous components in the waste in this container. When waste is listed as Not Otherwise Specified (NOS), the two main hazardous components must be listed on the manifest. This field will be null if the shipping name HDET DOT ID NUM doesn't indicate NOS. Domaīn: -Alphanumeric. 
-

:utemog 'pautueq puel sam!̨amos ade qe47 sa7sem a47 dof $N, 10$

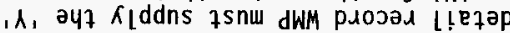

s!̣7 UI pauueq puel saw!łaulos

כue 7ey7 safsem lof L Lnu e pue pauueq puel ale qeyt sazsem dof $\lambda_{1}$

e sutequos N甘gONG7 MO suaqunu azseM snodə6uep to fas чวea dot paubisse әq 7snw, $N$, do , $N_{1} \forall$ WNN MO $130 \mathrm{H}$ u! suәqunu ә7sem snova6uep to słas ayf of dịsuoţe

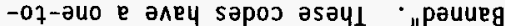

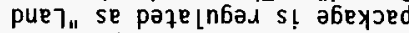

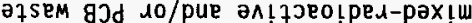

'snopuezey s!47 47!m paze!cosse

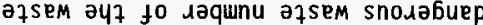
әч7 1әч7әчм 6u!feว!pu! sәроว

- oțəunueud Iy

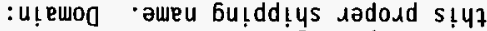
of paqe las axe ol á6exaed ayz pue ' laqel lo0 "Aaqunu uo!feo!f!quap! 100

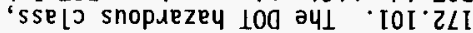
y」J $6 t$ ut punot $s !$ ameu $s ! 4 !$-2ueu

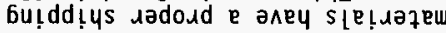
snopuezey 100 LL u! ә7sem lof aueu butdd!̣s ladold

- spuojal buṭdțys ayz u! parozs s! suaulequos to sdnoub lof uolfeuto ful butdd!ys "puepuezs ${ }_{\mathrm{H}} \cdot \kappa$ lazejedas paddius butaq to uolfdo ayf sey uәu!̣equoj e uәчM pasn s! pla!t s!4! pauueg pue?

L!eqәO snopuezeH ( LI)ZУ甘HכУ

NVgONG $7^{-} 1 \exists \mathrm{OH}$

$\stackrel{m}{\mathfrak{j}}$ 6utddius Ienplatpu

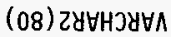

JWWN' ${ }^{-} I_{H S}^{-}{ }^{-}{ }^{-} I^{-} 130 H$ 

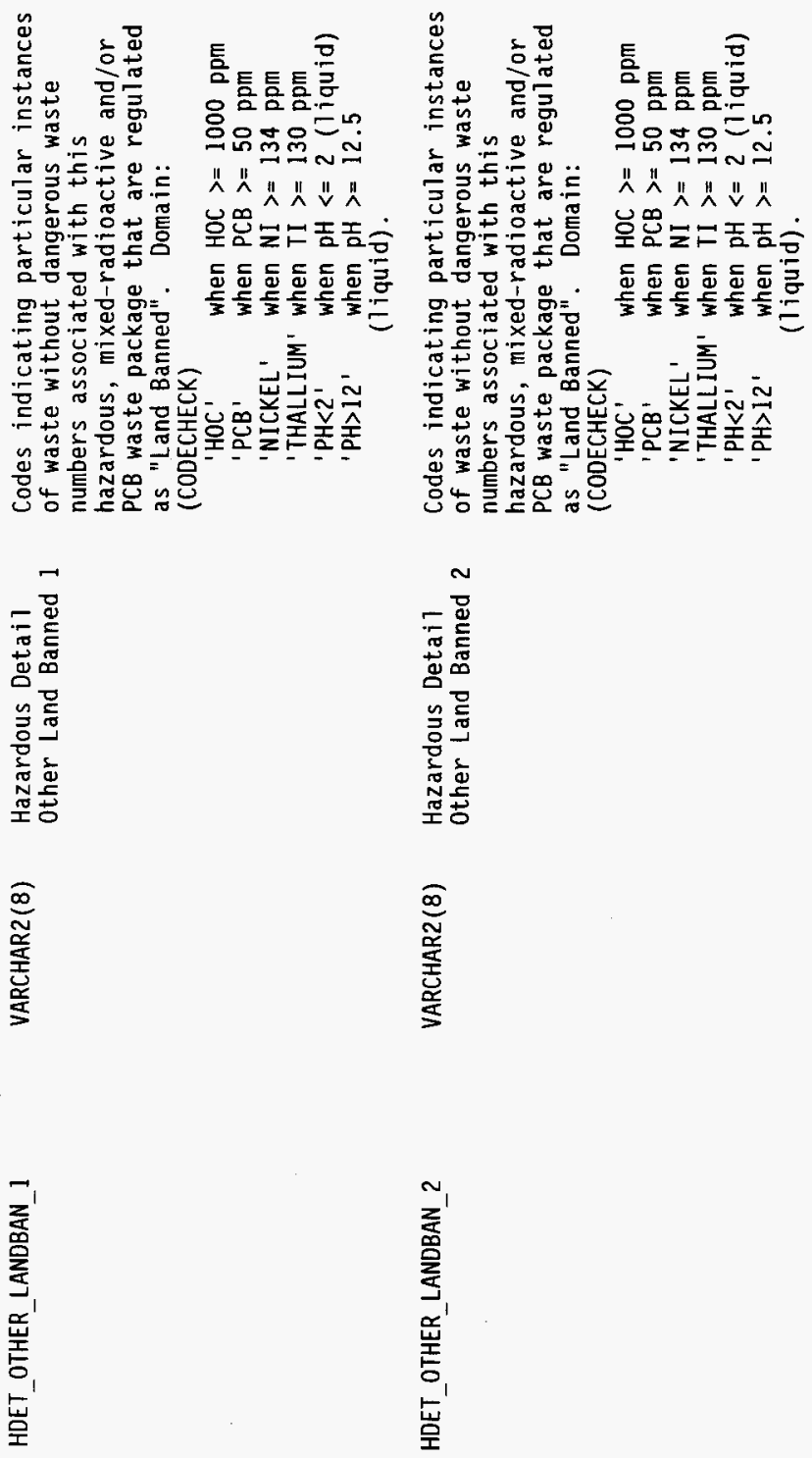
HDET_OTHER_LANDBAN_3

HDET_PCB_DESCR

I

\section{VARCHAR2 (8)}

Hazardous Detail other Land Banned 3

VARCHAR2 (40) Hazardous Detail PCB Description

VARCHAR2 (6)

Hazardous Detail PCB Parts Per Million

DATE

Hazardous Detail PCB Removed Date
Codes indicating particular instances of waste without dangerous waste numbers associated with this hazardous, mixed-radioactive and/or PCB waste package that are regulated as "Land Banned". Domain:

(CODECHECK)

' $\mathrm{HOC}$ '

'PCB'

when $\mathrm{HOC}>=1000 \mathrm{ppm}$

'NICKEL'

when $\mathrm{PCB}>=50 \mathrm{ppm}$

'THALLIUM'

' $\mathrm{PH}<2$ '

when $\mathrm{NI}>=134 \mathrm{ppm}$

' $\mathrm{PH}>12$ '

when $T I\rangle=130 \mathrm{ppm}$

when $\mathrm{pH}<=2$ (liquid)

when $\mathrm{pH}>=12.5$

( 1 iquid).

Standard description of PCB contents valid for PCB wastes only. Validated against the miscellaneous codes table. Domain: Miscellaneous Code Table (CODECHECK) CODE_FIELO NAME = PCB_DESCR

Concentration of PCB material. Domain: (CODECHECK)

'<2', '2-49', '50-499', '>499'.

Date $\mathrm{PCB}$ item was removed from service and became PCB waste. Domain: Oracle format date or null. 
DET_PCB_SUBTYPE

VARCHAR2 (1)

ardous Detail PCB Sub-Type

HDET_PCB TYPE

P
a

HDET_PCB_WGT
HDET_PH
HDET_WASTE_STATUS

\section{VARCHAR2(1) Hazardous Detai1 PCB Type}
NUMBER $(12,4)$ Hazardous Detai1 PCB Weight

\section{VARCHAR2 (5)}

VARCHAR2 (2)
Hazardous Detail pH

Hazardous Detail Waste Status
Storage category code for hazardous, mixed-radioactive and/or PCB solid waste. One-character code defining the PCB according to sub-type.

Doma in: (CODECHECK)

' $C$ ' = Container

' $\mathrm{E}$ ' = Contaminated Electrical Equipment (50-499 ppm)

' $P$ ' = Capacitor

$'{ }^{\prime}{ }^{\prime}=$ Contaminated Electrical Equipment ( $\geq 500 \mathrm{ppm}$ )

' $R$ ' = Article Container

' $S$ ' = Submarine Reactor Compartment

$\leq T !$ = Trāns former .

One-character code defining the type of PCB item. Domain: (CODECHECK)

$$
\begin{aligned}
& { }^{\prime} A{ }^{\prime}=\text { Article } \\
& { }^{\prime} C \text { ' }=\text { Container } \\
& { }^{\prime} R \text { ' }{ }^{\prime} \text { Article container. }
\end{aligned}
$$

The weight of PCBs in the waste package. Domain: Numeric. Units are kilograms.

The $\mathrm{pH}$ of waste package content. Domain: Alphanumeric.

Status code identifying waste origin. Doma in:

$$
\begin{aligned}
& ' S^{\prime}=\text { spilled } \\
& U^{\prime}=\text { used } \\
& { }^{\prime} O^{\prime}=\text { old but not used }
\end{aligned}
$$$$
\text { ' } R \text { ' = reacted. }
$$

Combinations: 'SU', 'SO', 'SR', 'RU', 'RO'. 
$\begin{array}{ll}\text { HDET_WASTE_VOL NUMBER }(10,4) & \begin{array}{l}\text { Hazardous Detail } \\ \text { Waste Volume }\end{array}\end{array}$

Radioactive Isotope Quantity Record (ISOQTY) - SWITS Data Record -*RAD_PKG_ID VARCHAR2(14) Radioactive Package Required ID

\section{$\stackrel{?}{!} \quad *$ RAD_ISO_NUM}

RAD ALPHA CI

FLOAT

Radioactive Alpha CI

Radioactive Isotope

NUMBER ( 3

Required Number

RAD_PE_CI

FLOAT
The actual volume of the hazardous waste as opposed to the container volume. This value is less than or equal to the container volume.

Domain: Numeric. Units are liters.

The unique package identification number that is assigned to the outer waste package. The number is assigned by the waste generator and is used for tracking all waste. Domain: Alphanumeric. Must match a package ID in the Container and Content Record (CON_PKG_ID).

Code arbitrarily assigned for solid waste to identify a specific isotope or entity reported as an isotope, such as mixed fission products, Co-60 and Sr-90. Domain: Isotope Table (ISOTOPE) ISO NUM.

Alpha emission of listed transuranic elements (isotopes) identified in the isotope table as being measured in grams. Domain: Numeric. Must be $\geq 0$. Units are alpha curies.

Plutonium equivalent curies of 1isted transuranic elements (isotopes) identified in the isotope table as being measured in grams. Domain: Numeric. Must be $\geq 0$. Units are plutonium equivalent curies. 
RAD_PU_FGE

RAD_QTY

RAD QTTY TMI

$\stackrel{\infty}{0}$

RAD_UNKNOWN
FLOAT

FLOAT

FIOAT

Radioactive PU FGE

Radioactive

Quantity

Radioactive Qty

Total Measurement

Uncertainty

FLOAT
Plutonium 239 fissile gram equivalent of listed transuranic elements

(isotopes) identified in the isotope table as being measured in grams.

Domain: Numeric. Must be $\geq 0$.

Units are Plutonium 239 fissile gram equivalents.

The quantity of a radioactive isotope in the container. Domain: Numeric.

Must be $\geq 0$. Units are grams or curies as defined in the Isotope Table for that isotope (ISO_UNIT).

This value represents the Total Measurement Uncertainty associated with the isotopic quantities recorded in the record Domain: Numeric.

Radioactive Unknown
The curie amount of unknown

constituents in the package. This is calculated only for Isotope 19, Mixed Fission/Activation Products. The individual isotopes RAD QTY with an ISO UNIT of ' $\mathrm{CI}$ ' is summed, then subtracted from the RAD QTY of RAD_ISO NUM 19. The remainder is RAD UNKNNOWN. Domain: Numeric. Must be $\Sigma 0$. Units are curies. 
Metrics Record (METRICS) - MET PKG ID

*MET DT

MET_ASSAY_VER_FLAG

$\stackrel{?}{1}$

MET_COMPLIANT_FLAG

MET HAZ VER FLAG

MET LOCN ID

MET_NDE_VER_FLAG

MET_SWTYP_GROUP
VARCHAR2(14) Metric Package ID Required

DATE

Required

Metric Date

VARCHAR2(1) Metric Assay

Verified Flag

VARCHAR2(1) Metric Compliant Flag

VARCHAR2(1) Metric Hazardous

Materials Verified

Flag

VARCHAR2(10) Metric Location

VARCHAR2(1) Metric NDE Verified Flag

VARCHAR2 (2)
Metric Secondary Waste Group
Defines the waste package with which the metrics table entry is associated. Domain: Alphanumeric. Must match a package ID in the Container and Content Record (CON_PKG ID).

Date that the facility metrics record was generated Domain: Oracle format date.

Records the current value of CONEXT ASSAY VER FLAG. Domain: Alphanumeric-

Records the current value of CONEXT COMPLIANT FLAG. Domain: Alphanūmeric.

Records the current value of CONEXT_HAZ VER FLAG.

Data element records the current value of CONLOC LOCN ID. Domain: Alphanumeric. Must be in Location table (LOCN) LOCN ID.

Data element records the current value of CONEXT NDE VER FLAG.

Domain: Alphanumeric.

Data element records the current value of RDET SWTYP GROUP. Domain: Alphanumeric. 


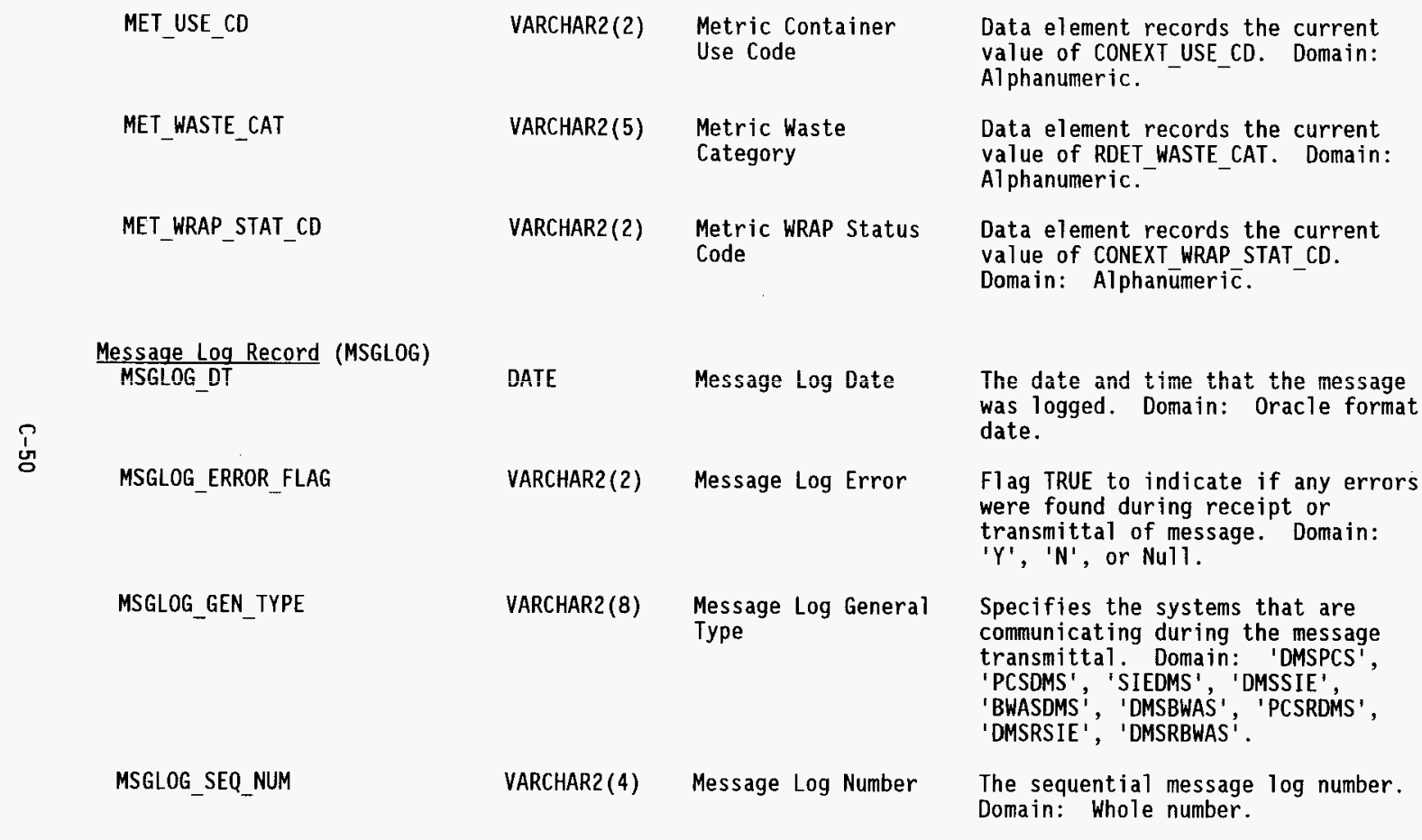


MSGLOG_SPEC_TYPE

MSGLOG STRING1

$\stackrel{\mathfrak{s}}{\mathfrak{s}}$
NDA Assay Results (NDA) -NDA_PKG_ID

*NDA_DT

*NDA_ASSAY_NUM
VARCHAR2 (4)

VARCHAR2

(2000)

LONG RAW

Message Log String - HEX

VARCHAR2 (14) NDA Package ID
Required

Message Log

Specific Type

Message Log String - ASCII

DATE

Required

NUMBER

Required
NDA Date

NDA Assay Number
Specifies the type of message that is being transmitted. Domain: ' $A C C^{\prime}$, 'ADDT', 'BAA', 'BAC', 'BAS', 'CDBI', 'CL', 'CLW', 'CRIT', 'DCS', 'DD', 'FCL', 'FML', 'LSPL', 'NCIP', 'NCIT', 'NLLL', 'OCW', 'OWEL', 'PAMR',

'POPD', 'PPL', 'PPLI', 'PPTP', 'WA', 'RCDB', 'RDMS', 'REMT', 'RESS',

'RID', 'RPCS', 'RSIE', 'RWPP',

'RWPT', 'SBWA', 'SDG', 'SDMS', 'SDP',

'SPCS', 'SPDP', 'SPP', 'SSIE',

'TAPL', 'TCIC', 'TCLD', 'TCPL',

'TRSP', 'TSPL'.

The contents of the message received from the PCS, SIE, or BWAS.

Converted to ASCII character format. The fields delimited by the tilde ( ${ }^{\prime}$ ) character. Domain: Not Applicable.

The contents of the message received from the PCS, SIE, or BWAS in HEX format. Domain: Not Applicable.

Package ID associated with the NDA results in the message from the SIE. Domain: Alphanumeric. Must match a package ID in the Container and Content Record (CON PKG ID).

Date of assay in the message from the SIE. Domain: Oracle format date.

Unique number to identify a specific drum assay. Domain: Numeric. 


$$
\text { NDA_FUT_EVAL_REQD }
$$

NDA_ISO_TOT

-NDA_PROF_ID

I

NDA_RATI0

NDA_RVST_FLAG

NDA_SWTYP_GROUP

NDA_THERMAL_POWER
VARCHAR2 (1)

NDA Future

Evaluation Required

NUMBER(3)

VARCHAR2 (6)

NDA Profile ID

FLOAT

NDA Ratio

(PU239/PU240)

VARCHAR2(1) NDA Revisit Flag

VARCHAR2(3) NDA Secondary Waste Type Group

NDA Therma] Power

FLOAT
The confidence flag is true (Y) if the checks indicate discrepancies between declared and measured ratios and is false (N) if no discrepancy is identified. Domain: Alpha (' $Y$ ' or 'N').

The number of Isotopic records to follow in this message from the SIE. Domain: Numeric $(<100)$.

The profile ID sent to the SIE for this assay. Domain: Alphanumeric; lookup to Generator Assay Profile Tatole (PROFILE) PROF_IO.

The Pu239/Pu240 ratio returned in the SIE message. Domain: Numeric.

The revisit flag will be used by the DMS to denote whether a revisit of the drum assay is required. Domain: Alpha ('Y' or ' $N$ ').

The secondary waste type group code, LLW or TRU, returned in the SIE message. Domain: Alphanumeric (Lookup to SECWASTYPE Table SWTYP GROUP).

Thermal Power in watts/cu.ft. The value reported from the SIE will be in WATTs which will be converted to W/cu.ft prior to storing in the DMS. Domain: Numeric. 


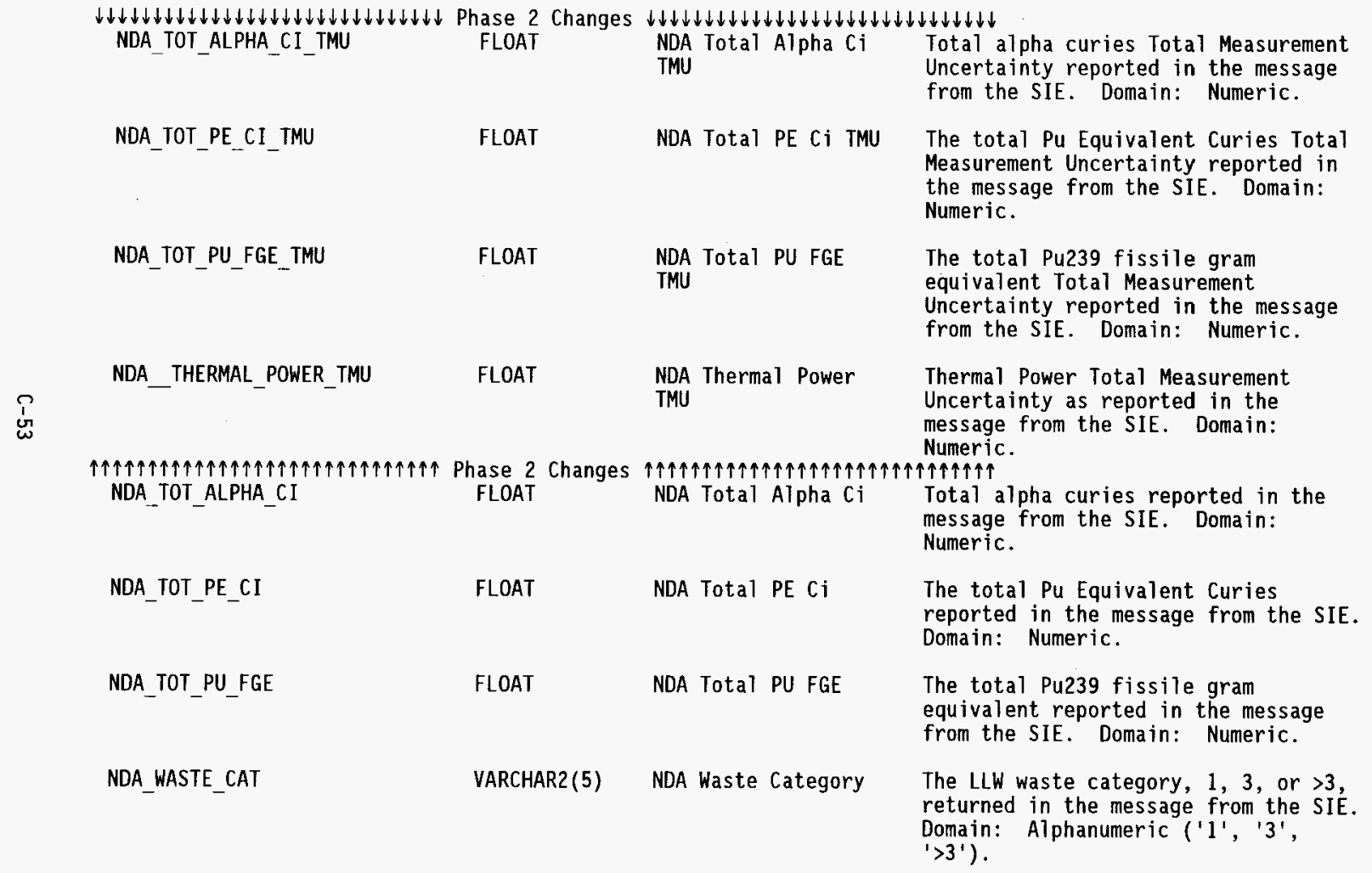




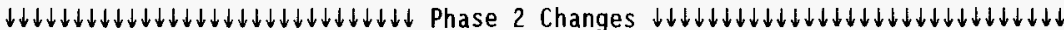
NDA Assay Isotopic Records (NDAISO) -NDAISO PKG ID

*NDAISO_ASSAY_NUM NUMBER Required

$\uparrow \uparrow \uparrow \uparrow \uparrow \uparrow \uparrow \uparrow \uparrow \uparrow \uparrow \uparrow \uparrow \uparrow \uparrow \uparrow \uparrow \uparrow \uparrow \uparrow \uparrow \uparrow \uparrow \uparrow \uparrow \uparrow \uparrow \uparrow \uparrow \uparrow \uparrow$ Phase 2 Change -*NDAISO NAME

$\underset{1}{\mathfrak{1}}$

\section{NDAISO CONFIDENCE CK}

NDAAISO GEA

NDAISO MEAS_STATUS
VARCHAR2 (2)

VARCHAR2 (32)

VARCHAR2 (3)
NDA Isotopic Package ID
NDA I sotopic Measurement Confidence Check

NDA Isotopic GEA Data Used

NDA Isotopic Measurement Status
Package ID associated with the NDA results in the message from the SIE. Domain: Alphanumeric. Must match a package ID in the NDA Assay Results Table (NDA PKG_ID).

NDA Isotopic Assay Number

Unique number to identify a specific drum assay. Domain: Numeric.

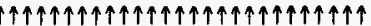

The radionuclide name as reported in the message from the SIE. This name should match a name in the SIEISO table. Domaiñ: Alphanumeric. Must be in SIE Isotopic Name table (SIEISO) SIE_ISO_NAME.

The radionuclide quantity confidence check, T, F or NA, as reported in the message from the SIE. Domain:

Alphanumeric. ' $T$ ', ' $F$ ', or ' $N A$ '.

The source of the GEA data as reported in the message from the SIE. Domain: Alphanumeric.

The isotopic measurement status, as reported in the message from the SIE. Domain: Alphanumeric.

' $A C T$ ' = actual

' $\angle O D '$ = limit of detection

'NP' = not present. 
NDAISO_PAN_ACTIVE

NDAISO_PAN_PASSIVE

NDAISO_QTY

I

NDE Results (NDE)

*NDE PKG ID

*NDE_DT

NDE_COMMENTS
VARCHAR2 (2)

NDA Isotopic PAN Active Data Used

VARCHAR2 (2)

NDA Isotopic PAN Passive Data Used

NDA Isotopic Quantity

NDA Isotopic Quantity TMU

VARCHAR2 (14) Required

NDE Results Package ID

DATE

Required

NDE Results Date

VARCHAR2 (255) NDE Comments
The PAN active detector chain used or not, A, B, or N0, as reported in the message from the SIE. Domain:

Alphanumeric. ' $A$ ', 'B', or ' $N O$ '.

The PAN passive detector chain used or not, A, B, or NO, as reported in the message from the SIE. Domain: Alphanumeric. ' $A$ ', ' $B$ ', or ' $\mathrm{NO}$ '.

The radionuclide quantity detected in Curies for fission and active products and grams for actinides as reported in the message from the SIE. Domàìn: Numèíc.

The radionuclide quantity Total Measurement Uncertainty as reported in the message from the SIE. Domain: Numeric.

The package ID of the container being reviewed in the NDE vault. Domain: Alphanumeric. Must match a package ID in the Container and Content Record (CON_PKG_ID).

The date the results were obtained from the NDE vault. Domain: Oracle format date.

User comments about the container and its contents. Domain: Alphanumeric. 
-NDE_OPER_ID

NDE_VDISK_FILE

NDE_VDISK_NUM

NDE_VTAPE_NUM

İ
VARCHAR2 (7)

VARCHAR2 (5)

VARCHAR2 (5)

VARCHAR2 (5)

NUMBER (5)
NDE Operator ID

NDE Container Video Disk File

NDE Container Video Disk Number

NDE Contáiner Videó Tape Number

NDE Container Video Tape Start
VARCHAR2 (14) Not Process List Required
Not Process List (NOTPROCLIST) **NOTPROC_PKG_ID
The operator ID of the user gathering the NDE results. Domain:

Alphanumeric (lookup from USERS table USR USERID).

The name of the file on the optical disk where a specific image of a waste container is recorded. Domain: Alphanumeric.

The number of the optical disc that is used to record container images. Domain: Alphanumeric.

The number identifying the Vis tape that is used to record a container image. Domain: Alphanumeric.

The footage location on the VHS tape were a specific image of a waste container is recorded. Domain: Numeric.

ID of a package not on a process list. Domain: Alphanumeric. Must match a package ID in the Container and Content Record (CON_PKG_ID).

ID of a packages not on a shipping pick 1ist. Domain: Alphanumeric. Must match a package ID in the Container and Content Record (CON_PKG_ID).
Not Ship Pick List (NOTSHIPPICK) -*NOTSHIP_PKG_ID
VARCHAR2 (14) Required
Not Ship Pick List Package ID 
Isotopic Distribution (PAM)

- PAM_PKG_ID

PAM PU FGE

FLOAT

PAN_QTY

FLOAT

FLOAT

PAM UNCERTAINTY
VARCHAR2 (14)

Required

PAM Package ID

Number

PAM Plutonium 239

Fissile Gram

Equivalent

PAM Gram Quãantity

PAM Uncertainty

Payload Container Certification Record (PAYLOAD) - *PAYLOAD_PKG_ID VARCHAR2 (14)

Required

Payload Package ID Number
Unique package identification number assigned to a packet removed from a waste package and which requires further tracking. Doma in:

Alphanumeric. Must match a package ID in the Container and Content Record (CON PKG ID).

Plutonium 239 fissile gram equivalent calculated using the quantity of Pu240 identified for a given packet. Domain: Numeric.

The amount of the $\mathrm{Pu}-2 \mathbf{4 0}$ in the waste package. Domain: Numeric. Units are grams.

The uncertainty value associated with the packet assay. Domain: Numeric.

The unique package identification number that is assigned to the outer waste package. Domain:

Alphanumeric. Must match a package ID in the Container and Content Record (CON PKG ID). 
-PAYLOAD_ASSEMBLY_ID

PAYLOAD CERT DT

PAYLOAD_CERT OFFICIAL

点
VARCHAR2 (8)

Payload Package

Assembly ID

Payload

Certification Date

VARCHAR2(25) Payload

Certification Official

\section{VARCHAR2 (3) Payload Container Type}

Payload Container Decay Heat

\section{VARCHAR2(10) Payload Filter} Mode1

VARCHAR2 (3)

\section{Payload Filter} Installation
The identification number for the package assembly that will be placed into a TRUPACT II cask. The numbering sequence order is the 2letter site ID code, last 2 digits of the year, and 4-digit package assembly number. Domain: Alphanumeric.

Date that a payload has been certified for shipment to WIPP. Domain: Oracle format date.

The name of the site transportation certification official assuring that the contents meet the requirements for shipment in a TRUPACT II cask and the payload is qualified for transport. Domain: Alphanumeric.

The code for the various containers approved for shipment to WIPP.

Domain: Alphanumeric. Must be in Container Type table (CONTYPE) CNTYP CD.

The decay heat value for a specific container. Domain: Numeric.

The model number of the filter used on the payload container. Domain: Alphanumeric.

Answered yes or no as to whether or not a filter is installed. Domain: Alpha (' $Y$ ' or ' $N$ '). 


\begin{tabular}{|c|c|c|}
\hline PAYLOAD_FISSILE_ERROR & FLOAT & $\begin{array}{l}\text { Payload Fissile } \\
\text { Mass Error }(2 X)\end{array}$ \\
\hline PAYLOAD_GAS_GEN_RATE & NUMBER(3) & $\begin{array}{l}\text { Payload Gas } \\
\text { Generation Rate }\end{array}$ \\
\hline PAYLOAD_HEAT_ERROR & FLOAT & $\begin{array}{l}\text { Payload Container } \\
\text { Decay Heat Error }\end{array}$ \\
\hline PAYLOAD_HEAT_LIMIT & FLOAT & $\begin{array}{l}\text { Payload Decay Heat } \\
\text { Limit }\end{array}$ \\
\hline PAYLOAD_HYDROGEN_RATE & NUMBER(1) & $\begin{array}{l}\text { Payload Hydrogen } \\
\text { Generation Rate }\end{array}$ \\
\hline PAYLOAD_LINER_VNT & VARCHAR2 (8) & $\begin{array}{l}\text { Payload Liner } \\
\text { Punctured/Filtered }\end{array}$ \\
\hline PAYLOAD_RECORD_TYPE & $\operatorname{VARCHAR2}(1)$ & Record Type \\
\hline PAYLOAD_SEQ_NUM & NUMBER(2) & $\begin{array}{l}\text { Payload Sequence } \\
\text { Number }\end{array}$ \\
\hline
\end{tabular}

The assigned error value for the fissile mass of a payload container. Domain: Numeric.

Total gas generation rate for a specific container. Domain: Numeric. Units are psig.

The error value assigned for decay heat by shipping category. Domain: Numeric.

The allowable decay heat for a specific shipping category. Domain: Numeric.

Hydrogen gas generation rate measured in a percentage of payload and the package. Domain: Numeric.

Identifies if the liner has been punctured or has a filter is in place in the liner. Domain: Alphanumeric. 'filter' or 'puncture'.

The code that identifies the type of record for a specifi data package. Domain: Alphanumeric.

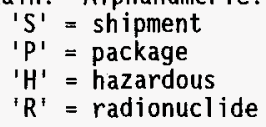

Defines the position of the waste container in the 14-drum/2-SWB payload. Domain: Numeric (1-14). 


$$
\text { PAYLOAD_SHIP_APP_FLAG }
$$

PAYLOAD_SHIP_CAT

- PAYLOAD_TRUCON_CD

g
$\operatorname{VARCHAR2}(1)$

VARCHAR2(10) Payload Shipping

$\operatorname{VARCHAR2}(6)$

NUMBER(3)

$\operatorname{VARCHAR2~(7)~}$ Category

Payload Approval to Ship Container TRUCON
Code

Payload Flammable VOC Concentration

WAC Exception Number
Flag that identifies if a payload container has been approved for shipment. Domain: Alpha (' $Y$ ' or 'N').

The shipping category for a particular container content. Shipping categories are defined in the TRUCON document (Example

III.1.A.4). Domain: Alphanumeric. Lookup to TRU Shipping Category table (TRUSHIPCAT) TRUSHIPCAT_CD.

The TRUPACT II code or designation for a particular waste streami.

Domain: TRU Container Code Table (TRUCON) TRUCON_CD.

Flammable volatile organic compound concentration measured in $\mathrm{ppm}$ for a specific container. Domain:

Numeric.

The WIPP Waste Acceptance Criteria exception tracking number. Domain: Alphanumeric. 
PAYLOAD WGT ERROR

$\operatorname{NUMBER}(10,2)$

Payload Container Weight Error
Payload Assembly Certification Record (PAYLOADASBLY)

VARCHAR2(8) Assembly Number
Required

=ASBLY SHIPMENT NUM

VARCHAR2(8)

Assembly Shipment Number

$\stackrel{?}{\mathfrak{g}}$
VARCHAR2(1)

DATE

ASBLY_CERT_DT

ASBLY_CERT_OFFICIAL
VARCHAR2 (25)
Assembly Approved for Shipment Flag

Assembly Shipment Certification Date

Assembly Certification official
The weight error value calculated for a specific payload container. Domain: Numeric.

The number for the TRUPACT II assembly. This numbering sequence is the 2-letter site code, last 2 digits of the year, and 4-digit assembly number. (Three assemblies to a typical shipment) Domain:

Alphanumeric.

The shipment number for waste going to WIPP. This numbering sequence is the 2-letter site code, last 2 digits of the year, and 4-digit shipment number. Domain: Alphanumeric.

Identifies that the TRUPACT II shipping container is ready to be shipped. Domain: Alpha (' $y$ ' or 'N').

Date that the TRUPACT II shipping container is certified to be shipped. Domain: Oracle format date.

Name of the officer assuring that the transportation requirements of the TRUPACT II safety analysis report are being meet. Domain: Alphanumeric. 


\section{ASBLY CONFIGURATION}

ASBLY_DOSE RATE

ASBLY_DOSE_RATE_2M

ASBLY_ICV_CLOSURE_DT

$\stackrel{?}{\text { I }} \quad$ ASBLY_OCA_BODY_ID

ASBLY_OCA_LID_ID
VARCHAR2 (4)

Payload

Configuration

NUMBER $(8,2) \quad \begin{aligned} & \text { Assembly Dose Rate } \\ & - \text { Pkg }\end{aligned}$

$\operatorname{NUMBER}(8,2)$

Assembly Dose Rate at 2 Meters

DATE

VARCHAR2 (8)

Assentoly Date of ICV Closure

Assembly TRUPACT OCA Body Number

VARCHAR2 (8)
Assembly TRUPACT OCA Lid Number
Payload container configuration.

Domain: Alphanumeric.

'drum ${ }^{*}=$ drum

'SWB' = Standard Waste Box

'ovpk' = overpack.

Neutron dose rate of the shipping container measured at the surface. Domain: Numeric.

Neutron dose rate of the shipping container measured at 2 meters. Domain: Numeric.

The date the ICV is closed. Domain: Oracle format date.

The identification number on the TRUPACT II OCA body. Domain:

Alphanumeric.

The identification number on the TRUPACT II OCA 1id. Domain:

Alphanumeric. 
ASBLY_POS

ASBLY_SHIP_CAT

?

ASBLY_SHIP_CAT_HEAT_LT

FLOAT

ASBLY_WGT_TRUPACT

VARCHAR2

$(10,2)$
As sembly Position

Assembly Payload Shipping Category

Assembly Decay Heat Limit - Shipping Category

Assembly Weight of TRUPACT
Position on the TRUPACT trailer for the cask assembly. Domain: Numeric (1-3);

$'{ }^{\prime}{ }^{\prime}=$ TRUPACT closest to $\mathrm{cab}$

' 2 ' = TRUPACT in middle of the trailer

$' 3^{\prime}=$ TRUPACT at back end of trailer

The shipping category for a

particular container content.

Shipping categories are defined in the TRUCON document. Domain:

Alphanumeric. Lookup to TRU Shipping Category táte (TRUSHIPCAT) TRUSHIPCAT CD.

The allowable decay heat for a specific shipping category. Domain: Numeric.

Tota] weight of the TRUPACT II shipping container. Domain:

Numeric. Must be $>0$.

The unique package identification number that is assigned to the outer waste package. The number is assigned by the waste generator and is used for tracking all waste. Domain: Alphanumeric. Must match a package ID in the Container and content Record (CON PKG ID). 


$$
\text { •*PHYS_COMP_DESCR }
$$

PHYS_COMP_VOL_PCT

PHYS_COMP_WGT

@
$\operatorname{NUMBER}(6,3)$

VARCHAR2 (30) Physical Component

Required

Description

Physical Component Volume Percent

$\operatorname{NUMBER}(8,2)$
Physical Component Weight $\begin{array}{lll}\text { Package Dangerous Waste Numbers } & \text { Record (PKGDW) } & \text { SWITS Data Record } \\ \text { *PDW_PKG_ID } & \text { VARCHAR2(14) } & \begin{array}{l}\text { Dangerous Waste } \\ \text { Required }\end{array} \\ \text { Package ID }\end{array}$

$\bullet * P D W$ NUM
VARCHAR2 (4)

Required
Dangerous Waste Number
The description of a physical component in radioactive or mixed waste. Descriptions include paper, plastic, rags, concrete. Domain: Physical Component Description Table (PHYSDESC) PDESC_DESCR.

Percent by volume of a physical (not hazardous) component found in a specific waste container of radioactive or mixed waste. Domain: Numeric. Must be between 0 and 100 .

Weight of a physical (not hazardous) component found in a specific waste container of radioactive or mixed waste. Domain: Numeric. Units are kilograms.

Unique package identification number assigned to the outer waste package. Domain: Alphanumeric. Must match a package ID in the Container and Content Record (CON_PKG_ID).

Unique dangerous waste number identification. Domain:

Alphanumeric. Must be in Dangerous Waste Number table (DWNUM), DW NUM. 
PDW_LANDBAN

PDW_SORT_ORDER

$\begin{array}{ll}\text { I Process List } \\ \text { of } & \text { (PROCLIST) }\end{array}$

PROC_COMPLIANT_FLAG

PROC_PCS_FLAG

-PROC_PROF_ID
$\operatorname{VARCHAR2}(1)$

Dangerous Waste

Land Banned

NUMBER(3) Dangerous Waste Sort Order

VARCHAR2 (14) Required

Process List Package ID

VARCHAR2 (1)

Process List Compliant Flag

VARCHAR2 (1)

Process List PCS Flag

VARCHAR2 (6)
Process List Profile ID
Code indicating whether the waste associated with the dangerous waste number is regulated as "Land Banned". Yes - defined as always land banned. No - defined as never land banned. Nul1 - may be land banned on a case by case basis. Domain: ' $Y$ ', ' $N$ ', or null.

The Annual Dangerous Waste Report and LLW IDB Report has a unique reporting order. The value in this field will determine the sort order for the waste. Domain: whole number $>0$.

The package ID to be retrieved from the AS/RS to be processed in 1ist sequence. Domain: Alphanumeric. Must match a package ID in the Container and Content Record (CON_PKG_ID).

Identifies the container as being compliant. Domain: ' $Y$ ', ' $N$ ', or nu11.

Flag to designate containers to send to the PCS. Domain: ' $Y$ ', ' $N$ ', or null.

Defines which profile is to be used by the NDA equipment. Domain: Profile Table (PROFILE) PROF_ID. 


\section{CHANGES TO DMS AND SWITS REQUIRED TO IMPLENENT DMS/SWITS INTERFACE}

\section{Changes Affecting Both SWITS and DMS}

1. ADD new conatainer status code CON PKG STATUS = ' $M$ ' for mobile shipping overpack containers. The mobile shipping overpack containers will not have any detail records. The detail records will be maintained with the waste records for the inner (overpacked) drum and the CON PKG STATUS for the inner drum will not have a container status of ' $R$ ' (rēpackaged).

2. Add new container relationship code CONR_REL_CD = ' $M$ ' for waste containers in mobile shipping overpackes:

\section{DMS Driven SWITS Changes}

1. Add new container relationship code CONR REL CD = ' $W$ ' to allow for manyto-many relationships. The only container rēlationships uploaded to SWITS from WRAP will be ' $W$ ' relationships for repackaged waste and processed waste placed in product drums.

2. Add following data elements to the RADDETAIL table (SWITS SCR \#786) RDET TOT PE CI TMU RDET ${ }^{-}$TOT $^{-}$PU FGE-TMU RDET $^{-}$TOT $^{-}$ALPHA CI TMU RDET_THERMAL_POWER_THU

3. Add data element RAD_QTY_TMU to the ISOQTY table (SHITS SCR \#786) SWITS Driven DMS Changes

1. Add designation of waste stream codes (CON_WASTE_STREAM) for product drums. 
WHC-SD-W026-SDD-001, Rev. 2

This page intentionally left blank. 


\begin{tabular}{|c|c|c|c|c|c|}
\hline \multicolumn{6}{|c|}{ DISTRIBUTION SHEET } \\
\hline & \multirow{2}{*}{\multicolumn{3}{|c|}{$\begin{array}{l}\text { From } \\
\text { JR Weidert/87810/T4-02/ } \\
376-8132\end{array}$}} & \multicolumn{2}{|l|}{ Page 1 of 1} \\
\hline Distribution & & & & \multicolumn{2}{|l|}{ Date $4 / 9 / 96$} \\
\hline \multirow{2}{*}{$\begin{array}{l}\text { Project Title/Work Order } \\
\text { WRAP } 1 \text { - W026 }\end{array}$} & & & & EDT No. $\quad N / A$ & \\
\hline & & & & ECN No. 193 & 79 \\
\hline Name & MSIN & $\begin{array}{l}\text { Text } \\
\text { With All } \\
\text { Attach. }\end{array}$ & Text Only & $\begin{array}{c}\text { Attach./ } \\
\text { Appendix } \\
\text { Only }\end{array}$ & $\begin{array}{c}\text { EDT/ECN } \\
\text { Only }\end{array}$ \\
\hline $\begin{array}{l}\text { R. J. Bottenus } \\
\text { D. E. Caldwell } \\
\text { R. W. Carey } \\
\text { D. L. Chien } \\
\text { T. A. Gates, Jr } \\
\text { E. E. Hawker } \\
\text { D. R. LuCas } \\
\text { D. C. McCann } \\
\text { J. R. MCGee } \\
\text { M. E. Palmer } \\
\text { W. A. Robertson } \\
\text { C. K. Rosnick } \\
\text { J. S. Trent } \\
\text { J. R. Weidert } \\
\text { WRAP } 1 \text { DMC } \\
\text { Station } 34 \\
\text { OSTI }\end{array}$ & $\begin{array}{l}\text { T4-02 } \\
\text { H8-44 } \\
\text { H8-44 } \\
\text { H8-44 } \\
\text { H8-44 } \\
\text { H8-44 } \\
\text { T4-02 } \\
\text { H8-44 } \\
\text { T4-50 } \\
\text { T4-02 } \\
\text { T4-02 } \\
\text { T4-03 } \\
\text { H7-32 } \\
\text { T4-02 } \\
\text { T4-02 } \\
G 3-11 \\
\text { L8-07 }\end{array}$ & $\begin{array}{l}X \\
x \\
X \\
x \\
X \\
X \\
x \\
x \\
X(5) \\
x \\
X \\
X(2) \\
X \\
X(2)\end{array}$ & & & $\begin{array}{l}x \\
x\end{array}$ \\
\hline
\end{tabular}




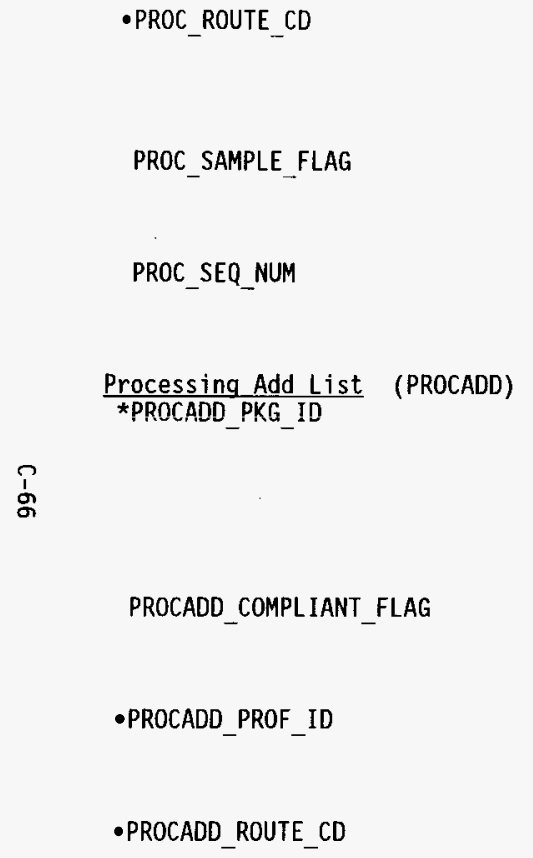

PROCADD_SAMPLE_FLAG
VARCHAR2 (4) Process List Route

VARCHAR2(1) Process List Sample Flag

NUMBER(4) Process List

Sequence Number

VARCHAR2(14) Processing Add List Required

Package ID

VARCHAR2 (1)

VARCHAR2 (6)

VARCHAR2 (4)

Processing Add List Compliant Flag

Processing Add List Profile ID

Processing Add List Route Code

VARCHAR2 (1)
The route this container is to take through the areas of the facility. Domain: Route Table (ROUTE) ROUTE_CD.

Designates that a sample needs to be taken from this container. Domain: ' $Y$ ', ' $N$ ', or null.

Sequence number for sequencing the process list. Domain: Numeric.

The package ID to be retrieved from the AS/RS to be processed in list sequence. Domain: Alphanumeric. Must match a package ID in the Container and Content Record (CON_PKG_ID).

Identifies the container as being compliant. Domain: ' $Y$ ', ' $N$ ', or null.

Defines which profile is to be used by the NDA equipment. Domain: Profile Table (PROFILE) PROF ID.

The route this container is to take through the areas of the facility. Domain: Route Table (ROUTE) ROUTE CD.

Designates that a sample needs to be taken from this container. Domain: ' $Y$ ', ' $N$ ', or null. 

PROCADO_SEQ_NUM
NUMBER(4)
Processing Add List
Sequence number for sequencing Sequence Number
Domain: Numeric.

Radioactive Waste Container Detail Record (RADDETAIL) - SWITS Data Record

\begin{tabular}{|c|c|c|}
\hline •*RDET_PKG_ID & $\begin{array}{l}\text { VARCHAR2 (14) } \\
\text { Required }\end{array}$ & $\begin{array}{l}\text { Radioactive Detail } \\
\text { Package ID }\end{array}$ \\
\hline RDET_ASSAY_DT & DATE & $\begin{array}{l}\text { Radioactive Detail } \\
\text { Assay Date }\end{array}$ \\
\hline
\end{tabular}

Î

\author{
RDET_ASSAY_NUM \\ RDET_BG_DOSE_RATE
}

RDET_CERT_DT
FLOAT

DATE Assay Date $\begin{array}{ll}\text { VARCHAR2(14) } & \begin{array}{l}\text { Radioactive Detail } \\ \text { Assay Number }\end{array}\end{array}$

Radioactive Detail Beta/Gamma Dose Rate

Radioactive Detail Certification Date
The unique package identification number that is assigned to the outer waste package. The number is assigned by the waste generator and is used for tracking a 11 waste. Domain: Alphanumeric.

This date is the date that the assay abundance data was obtained for a giveñ assáy Domain: Oracie format date.

The number that identifies the results of an assay done on the package. Domain: Alphanumeric.

Dose rate of a container. The dose rate is measured at $1 \mathrm{~cm}$ for contact handled waste and 1 meter for remote handled waste. Domain: Numeric. Must be $\geq 0$. Units are mrem/hr.

Date that a waste container of transuranic waste was certified. The certification of each container's assay results is completed by the generator. Domain: 0racle format date. 
RDET_DE_CI_FLAG

RDET_HANDLING

RDET_NEUT DOSE_RATE

$\stackrel{?}{\mathfrak{s}}$

RDET_ORGANIC_VOL_PCT
VARCHAR2 (1)

VARCHAR2 (1)

Radioactive Detail Handling

$\operatorname{NUMBER}(8,2)$

Radioactive Detail Dose Equivalence Curie Flag

Radioactive Detail Neutron Dose Rate

NUMBER(3)
Used by SWE to identify specially packaged waste container(s) excluded from the $D E-C i$ sum for a facility. Domain: ' $Y$ ', ' $N$ ', or null.

Identifies whether a container is considered contact handled or remote handled. RDET HANDLING will be set whenever RDET $\bar{B} G$ DOSE RATE (Cntr Dose Rate) is changed. RDET HANDLING will be set to $R$ if a dose ráte over 200 is entered, will be set to $C$ if a dose rate of 200 or less is entered, and will be ignored if a null dose rate is entered. Domain:

Alphanumberic.

$$
\begin{aligned}
& C^{\prime}=\text { Contact hand } 1 \text { ing } \\
& R^{\prime}=\text { Remote hand } 1 \text { ing. }
\end{aligned}
$$

Neutron dose rate contributions for transuranic waste with greater than $20 \mathrm{mrem} / \mathrm{hr}$ shall be reported separately on the SWSDR. The dose rate is measured at $1 \mathrm{~cm}$ for contact handled waste and $1 \mathrm{~m}$ for remote handled waste. Domain: Numeric. Must be $\geq 0$. Units are $\mathrm{mrem} / \mathrm{hr}$.

The percentage by volume of organic material that is in the waste container. Organic material includes plastic, paper, cloth, wood, solvents, oils, and hydrocarbon diluents used in solvent extraction (e.g., hexone and normal paraffin hydrocarbon). Domain: Numeric. Must be between 0 and 100 .
Rioactive Detail Organic Volume Percent 
RDET ORGANIC WGT

$\operatorname{NUMBER}(8,2)$

Radioactive Detail Organic Weight

RDET_PDR_NUM

RDET RSWIMS COUNT

ำ

RDET_SDAR_APPRV_NUM

RDET_SEAL_NUM
VARCHAR2(9) Radioactive Detail

Property Disposal

Request Number

NUMBER(4)

Radioactive Detail RSWIMS Count

VARCHAR2 (14)

Radioactive Detail SDAR Approval Number

VARCHAR2 (14)
Radioactive Detail
The total weight of the organic material in a waste container. Organic material includes plastic, paper, cloth, wood, solvents, oils, and hydrocarbon diluents used in solvent extraction (e.G., Hexone and normal paraffin hydrocarbon).

Domain: Numeric. Units are kilograms.

Identification number from the Property Disposal Request used to remove equipment from the property accounting system. Domain:

Alphanumeric.

The count of containers described by the current container record. Not available for data entry. The source is old RSWIMS data from the time when multiple containers could be defined in one record. Domain: Whole number $>0$.

Identifies a number given to a specific Storage/Disposal Approval Record (SDAR). The number is used to track approval for the storage or disposal of radioactive waste. Domain: Alphanumeric.

The number assigned to the outer waste container seal. Domain: Alphanumeric. 


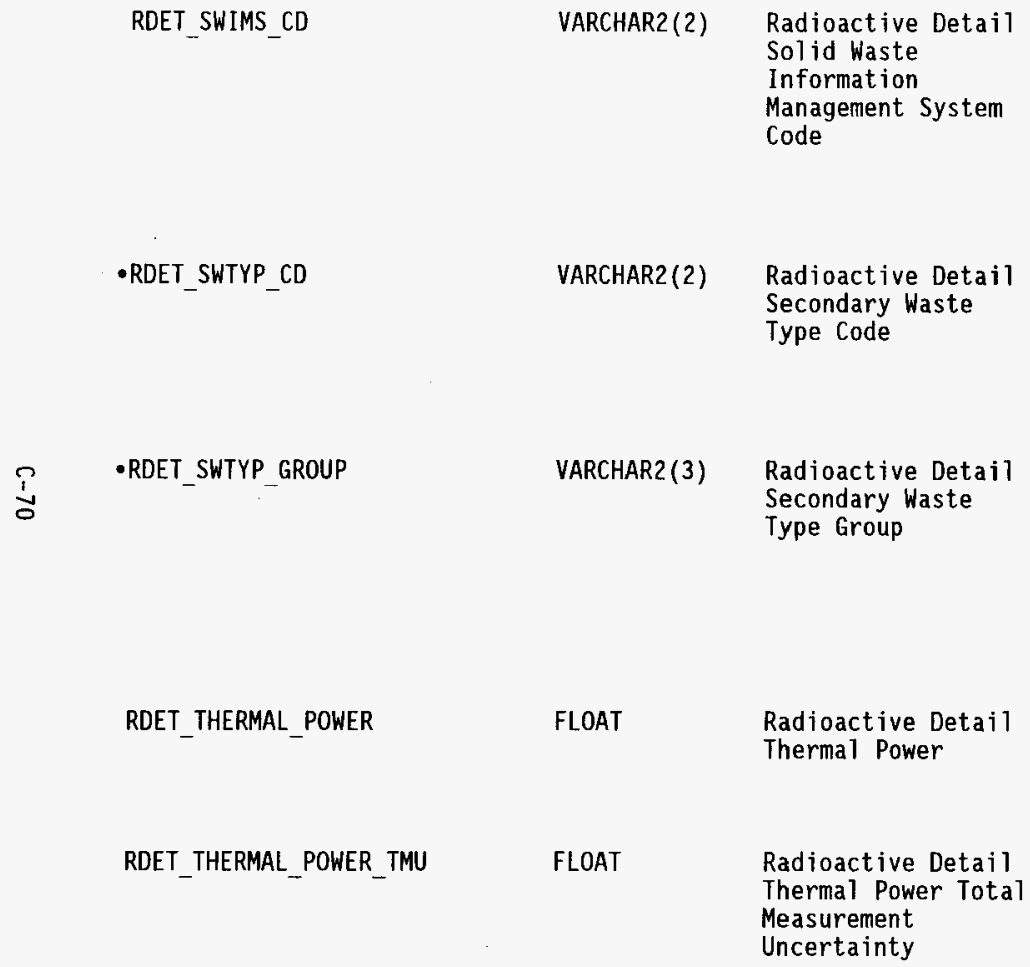

These codes identify waste

descriptions that are defined by the "Solid Waste Information Management System - SWIMS Users Manual," EG\&G Idaho, Idaho National Engineering Laboratory (INEL). Domain:

Miscellaneous Code Table (CODECHECK) CODE_FIELD_NAME $=$ SWIMS_CD.

Identifies the type of waste in a particular container or waste stream; used for radioactive or mixed waste on $7 y$. Domain: Alphanumeric; lookup to Secondary Waste Type Code Type (SECWASTYPE) SHTYP CD.

This code identifies the waste group in a particular container or waste stream. This is used for radioactive or mixed waste only. Groups are LowLeve1, Transuranic, Unsegregated, and High Leve1. Domain: Secondary Waste Type code Table (SECWASTYPE) SWTYP_GROUP.

The thermal power generation of a specific radioactive waste package. Domain: Numeric. Must be $\geq 0$. Units are watts per cubic foot.

Tota1 Measurement Uncertainty associated with the thermal power generation of a specific radioactive waste package. Domain: Numeric. 
RDET_TOT_ALPHA_CI_TMU

FLOAT

RDET_TOT_BG_CI

FLOAT

$\stackrel{?}{1}$
RDET TOT ALPHA CI
FLOAT

FLOAT
Radioactive Detail

Total Alpha Ci

Radioactive Detail Total Alpha Ci

Total Measurement Uncertainty

Radioactive Detail Total Beta/Gamma Ci

Radioactive Detail Total Dose

Equivalence Curies

RDET_TOT_PE_CI
Radioactive Detail Tota 1 Plutonium Equivalent Curies
Total alpha emission (in curies) of listed transuranic elements

(isotopes) identified in the isotope table. Domain: Numeric. Must be $\geq 0$. Units are curies.

Total Measurement Uncertainty associated with the total alpha emission (in curies) of listed transuranic elements (isotopes) identified in the isotope table. Domain: Numeric.

Total beta/gamma curies for the contents of a container. Differs from RDET BG DOSE RATE in that the dose is réduced by the shielding properties of the container. Domain: Numeric. Must be $\geq 0$. Units are beta/gamma curies.

Contains the sum total dose equivalence for a given package. Domain: Numeric. Must be $\geq 0$. Units are dose equivalent curies.

Total plutonium equivalent curies of listed transuranic elements

(isotopes) identified in the isotope table as being measured in grams.

Domain: Numeric. Must be $\geq 0$. Units are plutonium equivalent curies. 


$$
\text { RDET_TOT_PE_CI_TMU }
$$

FLOAT

RDET TOT PU FGE

FLOAT

RDET TOT PU FGE TMU

FIOAT

$\frac{T}{N}$
VARCHAR2 (6)

VARCHAR2 (5)
Radioactive Detail Total Plutonium

Equivalent Curies Total Measurement

Uncertainty

Radioactive Detail Total Plutonium

Fissile Gram

Equivalent

Radioactive Detail Total Plutonium Fissile Gram Equivalent Total Measurement Uncertainty

RDET VOID CD

RDET_WASTE_CAT
Radioactive Detail Void Code

Radioactive Detail Waste Category
Total Measurement Uncertainty associated with the total plutonium equivalent curies of listed transuranic elements (isotopes) identified in the isotope table as being measured in grams. Domain: Numeric.

Total plutonium 239 fissile gram equivalent of listed transuranic elements (isotopes). Domain: Numeric. Must be $\geq 0$. Units are fissile gram equivalents.

Total Measurement Uncertainty associated with the total plutonium 239 fissile gram equivalent of 1 isted transuranic elements (isotopes). Domain: Numeric.

Code for approved void space filler material for radioactive waste container. By regulation there must be no free space in radioactive waste containers. Domain: Miscellaneous Code Table (CODECHECK) CODE FIELD NAME = VOID.

Waste Category of radioactive and mixed waste. Domain:

$$
\begin{aligned}
& \text { 'WC1' }=\text { LLW Category } 1 \\
& { }^{\prime} W C 3^{\prime}=\text { LLW Category } 3 \\
& { }^{\prime} \text { GTWC3' }=\text { LLW Category }>3 .
\end{aligned}
$$


RDET_WASTE_MAKEUP

RDET_WRAP_CAT

VARCHAR2 (2)

Radioactive Detail WRAP Category

Radioactive Detail Waste Makeup

के

$\frac{\text { Radiologic Inventory (RADMAT) }}{\text { tRADMAT }}$ *RADMAT_ID

VARCHAR2 (1)

Required

VARCHAR2 (1)

RADMAT_DESCR

VARCHAR2 (50)

RADMAT_DT

DATE

Radiologic

Inventory Area ID

Radiologic Inventory Area Alarm Flag

Radiologic Inventory Area

Description

Radiologic Inventory Date \& Time of calculation
A code indicating whether unknown radioactive components should be considered MAP or MFP. Domain:

$$
\begin{aligned}
& A^{\prime}=\text { MAP } \\
& F^{\prime}=\text { MFP. }
\end{aligned}
$$

Description codes that define the waste that will be processed in the WRAP plant. When processing takes place, the predominant category will help determine the type of processing. One code is assigned per container. Domain: Miscellaneous Code Table (CODECHECK) CODE_FICLD_NAME = WRAP_CAT.

Identifies which area of the facility the Rad Total is being calculated for. Domain: $' F^{\prime}=$ Facility

' $T$ ' = TRU Process Glovebox

' $R$ ' = TRU RWM Glovebox.

Set to yes ( $Y$ ) if the Rad calculations for a given area exceeds the area limit. Domain: ' $Y$ ' or ' $N$ '.

Description of the area of the facility the Rad Total is being calculated for. Domain:

Alphanumeric.

The date and time the current Rad total was calculated. Domain: Oracle format date. 


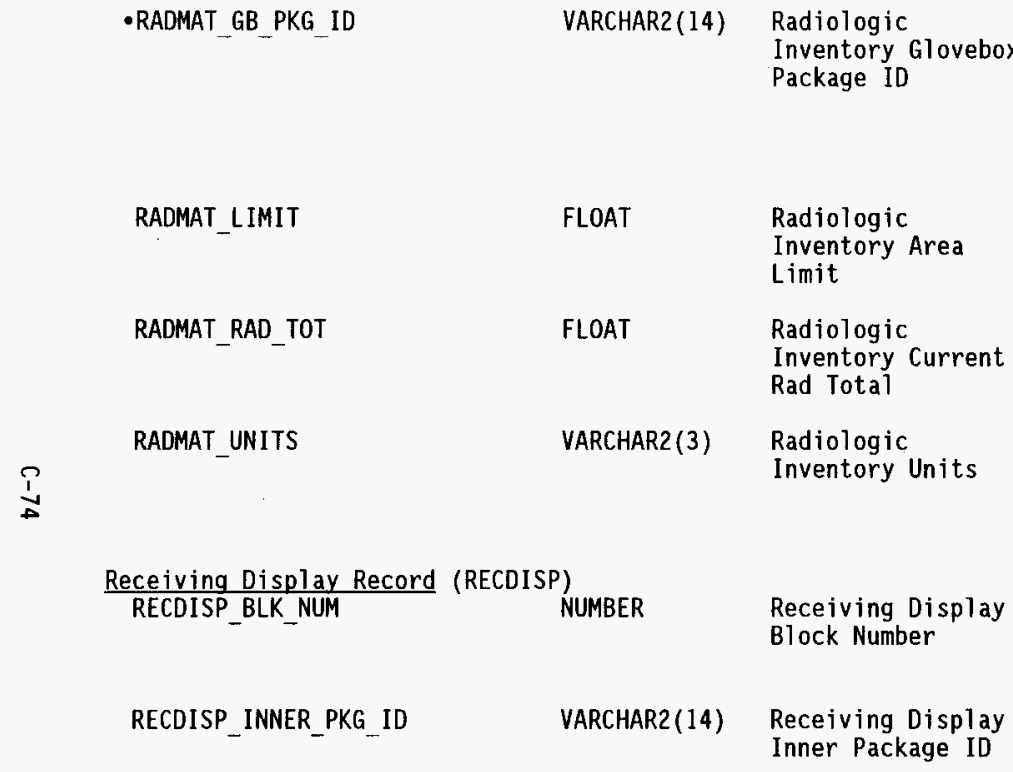

The Package ID of the drum 1ast added to or removed from the identified glovebox inventory. Domain:

Alphanumeric. Must match a package ID in the Container and Content Record (CON_PKG_ID).

Fissile Inventory Limit for the area referenced by this record. Domain: Numeric.

The current Rad total calculated for this area. Domain: Numeric.

Identifies which units are used for this area's calculations. Domain: 'FGE' or 'CI'.

Unique internal sequence number to record the shipment. Domain: Whole number.

PIN of a drum contained in an overpack drum. Domain: Alphanumeric. 
RECDISP PKG ID

RECDISP_ERROR_STATUS

Sample Bottle Location (SAMLOC) - New Data Record
VARCHAR2(50) Receiving Display

Error Status

VARCHAR2(14) Receiving Display Package ID

VARCHAR2 (12)

Required Location Bottle ID
Sample Bottle
SAMLOC_DT
DATE
Sample Bottle Location Date
The list of package IDs on the receiving dock received from the PCS. This list will be used to resolve any differences between the DMS and

SWITS. When the list is correct and the data downloaded from SWITS, this list will be sent to the PCS as the set of containers received. Domain: Alphanumeric.

Message area for informative messages to be displayed on the DMSSO101

screen. Domain: Alphanumeric.

The unique sample bottle number.

Domain: Alphanumeric. Format shall be $Y Y-N N N N N-B B L$ where

$$
Y Y=\text { year }
$$

NNNNN = sequential sample number

$B B=$ bottle number for laboratory sample

' $L$ ' = laboratory sample.

Must be in BOTTLE Table BOTTLE_ID.

Date and time that the sample bottle was moved to the current location. Domain: Oracle format date. 
-SAMLOC_LOCN_ID

VARCHAR2 (10)

Sample Bottle

Location Location ID

Sample Data Record (SAMPLE) - SWITS Data Record *SAM_SAMPLE_ID VARCHAR2 (8)

Required

Sample ID

-SAM COC FORM ID

VARCHAR2(10)

Sample COC Form ID

$\frac{?}{1}$

-SAM PKG ID

VARCHAR2 (14)

Sample Package ID

SAM CLOSED FLAG

VARCHAR2(1) Sample Closed Flag

SAM_COMMENTS

VARCHAR2 (255) Sample Comments
Identifier of a location within WRAP Module 1 where the sample bottle is stored or processed. Domain: Alphanumeric (lookup to LOCATION Table LOCN ID).

Unique identification number of the sample itself. Domain:

Alphanumeric. Format shall be $Y Y$ NNNNN where

YY $=$ year

NNNNN = sequential sample number.

The chain of custody form number used to ship this sample to another laboratory. Domain: Alphanumeric.

Unique identification number of the waste container from which the sample is taken. Domain: Alphanumeric. Must match a package ID in the Container and Content Record (CON PKG ID).

Yes/No flag indicating whether or not a sample is closed. $' y '=$ closed, meaning no more information is expected to be input. Domain: ' $Y$ ' or ' $N$ '.

General comments pertaining to a sample. Domain: Alphanumeric. 


$\begin{array}{lll}\text { •SAM_LOCN_ID } & \text { VARCHAR2(10) } & \begin{array}{l}\text { Sample Sampling } \\ \text { Location }\end{array} \\ \text { •SAM_MATRIX_CD } & \text { VARCHAR2(3) } & \text { Sample Matrix Code } \\ \text { SAM_REPORT_DT } & \text { DATE } & \text { Sample Report Date } \\ \text { SAM_RETURN } & \text { VARCHAR2(1) } & \begin{array}{l}\text { Sample To Be } \\ \text { Returned }\end{array} \\ \text { •SAM_SAMPLING_METHOD_CD } & \text { VARCHAR2(4) } & \begin{array}{l}\text { Sample Sampling } \\ \text { Method Code }\end{array} \\ & & \\ \text { •SAM_TAKEN_BY } & \text { VARCHAR2(6) } & \text { Sample Taken By } \\ & & \\ \text { SAM_TAKEN_DT } & \text { DATE } & \text { Sample Taken Date } \\ \text { SAM_TEMP } & \text { NUMBER(2) } & \text { Sample Temperature }\end{array}$

Location where the sample was taken.

Domain: Alphanumeric. Lookup to Location Table (LOCN) LOCN_ID.

Code defining the physical matrix of the sample. Domain: Alphanumeric.

Lookup to Sample Matrix table (SAMPMATX) SAMP_MATR_CD.

The date the analysis report is returned. Domain: Oracle format date.

Yes/No code to indicate whether a sample should be returned or not. Domain: ' $Y$ ' or ' $N$ '.

Used to identify the sampling method to be employed in the sampling process. Doma in: Alphanumeric. Lookup to Sampling Method table (SAMPMETH) SAMPLING METHOD CD.

Identification of the person who took the sample. Domain: Alphanumeric. Lookup to Person table (PERS) PERS ID.

Date the sample was taken. Domain: Oracle format date.

Temperature of the sample at the time it was taken. Domain: Numeric (units are $\operatorname{deg} C$ ). 
Sample Data Relationship Record (SAMREL) - SWITS Data Record

* SAMREL BOTTLE ID

VARCHAR2 (12) Sample Relationship

Required

•*SAMREL_PKG_ID

SAMREL DT

- SAMREL uSE CD
VARCHAR2(14) Sample Relationship

Required

Package ID

DATE

Sample Relationship Date

VARCHAR2 (2)

Sample Relationship Bottle ID

Sample identification code. Domain: Alphanumeric. Must match a bottle ID in the BOTTLE table (BOT BOTTLE ID).

Format shall be $Y Y-N N N N N-B B L$ whère $Y Y=$ year

NNNNN = sequential sample number $B B=$ bottle number for laboratory sample or ' 01 ' for field screening sample

' $L^{\prime}$ = 1 aboratory sample.

Package identification for the associated waste container; may be the original waste packet, treatment container, or the purge port

container. Domain: Alphanumeric. Must match a package ID in the Container and Content Record (CON PKG ID).

Date that the sample relationship was established. Domain: Oracle format date. Use Code

This field will be used to identify whether the sample relationship is to a waste packet or a purge port container Domain: CODECHECK table, USE CD (see CONEXT USE CD domain). 
Sample Analysis Request (SAR)

-*SAR_SAMPLE_ID

$\operatorname{VARCHAR2}(8)$

Required

Sample Analysis

Request Sample ID

* SAR_ANAL_CD

VARCHAR2 (8)

Required

Sample Analys is Request Analysis
Code

Record

Shipment History Record (SHIPHIST) - SWITS Data VARCHAR2 (10)

Required

Shipment History

Manifest Number

\footnotetext{
•*SHPHST ITEM NUM
}

VARCHAR2 (4)

Required
Shipment History

Item Number
Unique identifier relating the sample to the specific laboratory analys is requested. Domain: Alphanumeric. Must match a sample ID in the SAMPLE table (SAM SAMPLE ID). Format shall be $Y Y-N N N N \bar{N}$ where

$r Y$ $=$ year

$N N N N=$ sequential sample number.

Code used to relate the sample to a specific analysis type and its

associated parameters. Domain: Alphanumeric. Lookup to Laboratory Analysis table (LABANAL) LABANAL CD.

A unique identifier for a uniform hazardous waste manifest form consisting of 5-digit number. The manifest is used for hazardous waste, radioactive mixed waste, and $\mathrm{PCB}$ contaminated waste. Domain:

Alphanumeric. Must be in Shipment Record table (SHIPMENT)

SHPMNT MFST NUM.

Identifies the page number and letter for a specific line on a uniform hazardous waste manifest (e.g., ' $1 A$ ', '1B'). Domain: Alphanumeric. Must be in Shipment Item Record table (SHIPITEM) SHPITM ITEM NUM. 
•*SHPHST PKG ID

SHPHST_NMIT_NUM

$\stackrel{?}{1}$
VARCHAR2 (14) Shipment History Required Package ID

VARCHAR2(10) Shipment History Nuclear Material Item Transfer Number

\section{VARCHAR2 (1) Shipment History}

The unique package identification number that is assigned to the outer waste package. The number is assigned by the waste generator and is used for tracking all waste.

Domain: Alphanumeric. Must match a package ID in the Container and Content Record (CON_PKG_ID).

The number assigned to the Nuclear Material Item Transfer (NMIT) form or the Shipping Receiving Report (SRR). These forms are submitted to WHC Safeguards and Security division to provide information to complete the DOE/NRC 741 form which is used to document a 71 transactions and adjustments that affect the materials balance, material usage, and the preparation of inventory reports. Domain: Alphanumeric.

Flag showing that a package was returned to the generator and is no longer associated with the manifest. Domain: ' $Y$ ' or ' $N$ '. 


\begin{tabular}{|c|c|c|}
\hline SHPHST_RSR_NUM & $\operatorname{VARCHAR2}(10)$ & $\begin{array}{l}\text { Shipment History } \\
\text { Radioact ive } \\
\text { Shipment Record } \\
\text { Number }\end{array}$ \\
\hline
\end{tabular}

SHPHST_741 NUM

卢
VARCHAR2(11) Shipment History 741 Number
This references the form number identified on the Radioactive Shipment Record (RSR). An RSR is required for all shipments of radioactive material, including radioactive waste on the hanford site. Although this form is not required by solid waste management, its number is tracked for information only. Domain: Alphanumeric. See SHIPWRAP RSR NUM.

The number assigned on a DOE/NRC 741 form, Nuclear Material Transaction report. This form is generated to document all transactions and adjustments that affect the materials balance, materials usage and preparation of inventory lists for a11 accountable nuclear material. The DOE/NRC 741 form is the official record for nuclear material accountability. Domain: Alphanumeric.

A unique identifier for a uniform hazardous waste manifest form consisting of 5-digit number. The manifest is used for hazardous waste, radioactive mixed waste, and PCB contaminated waste. Domain:

Alphanumeric. Must be in Shipment Record table (SHIPMENT)

SHPMNT MFST NUM.

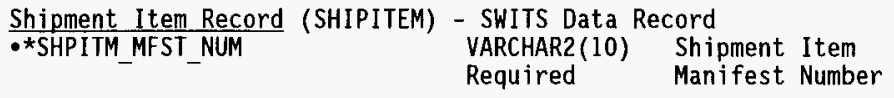




\section{*SHPITM_ITEM_NUM}

SHPITM_CNTR_COUNT

SHPITM DOT HAZ CLASS

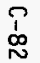

VARCHAR2 (4)

Required

NUMBER(3)

VARCHAR2 (20)

Shipment Item DOT Hazardous CTass

$\operatorname{VARCHAR2}(6)$

Shipment Item DOT ID Number

VARCHAR2(100) Shipment Item DOT
This identifies the page number and letter for a specific line on a uniform hazardous waste manifest (e.g., '1A', '1B'). Domain:

Alphanumeric.

Identifies the total number of individual containers in a particular line item on a uniform hazardous waste manifest. Domain: Numeric. Whole number $>0$.

Hazard Class as defined in 49 CFR, Hazardous Material Table; DOT hazard class tied to elements: shipment item dot number \& name. Classes include flammable liquid, corrosive material, ORME. Domain:

Alphanumeric.

Identifies the proper DOT identification number for each waste. This ID is prefixed by either 'UN' or 'NA'. Tied to proper shipping name. Domain: Alphanumeric.

The proper DOT shipping name assigned to a specific waste stream as identified in the code of federal regulations. Domain: Alphanumeric. 
SHPITM_NOS_DESCR

SHPITM_PROFILE_NUM

$\underset{1}{\mathfrak{c}}$ $\begin{array}{ll}\text { VARCHAR2(60) } & \text { Shipment Item Not } \\ \text { 0therwise Specified }\end{array}$ Description

VARCHAR2 (10)

Shipment Item Profile Number

\author{
SHPITM QTY UNIT
}

\section{VARCHAR2(1) Shipment Item Quantity Unit}

Text description of the two main hazardous components in the waste associated with this item. This waste can be in multiple containers. When waste is listed as Not Otherwise Specified (NOS), the two main hazardous components must be listed on the manifest. This field will be null if the shipping name

SHPITM DOT NAME doesn't indicate NOS. See HDET INDD NOS DESCR. Domain:

Alphanumēric.

"Waste Product Questionnaire" (WPQ). A reference number for a waste stream profile as required by the off-site disposal contractor. The WPQ is the contractor's form, and subject to change depending on contract

assignment. Domain: Alphanumeric.

This code identifies the appropriate unit of measure for waste on a specific line on the uniform hazardous waste manifest. The codes include ' $G$ ' for gallon, ' $P$ ' for pounds, ' $T$ ' for tons, ' $L$ ' for liter, ' $K$ ' for kilogram, ' $M$ ' for metric ton, and ' $N$ ' for cubic meter. These codes are defined in 49 CFR. Domain: Alphanumeric. 
SHPITM RQ FLAG

$\operatorname{VARCHAR2(1)}$

Reportable Quant

Flag

SHPITM TOT QTY

$\underset{\substack{1 \\ \infty}}{\infty}$
$\operatorname{NUMBER}(12,4)$

$$
\text { Quantity }
$$

VARCHAR2 (50) Shipment Item TSD
Process
Shipment Record (SHIPMENT) - SWITS Data Record *SHPMNT_MFST_NUM
VARCHAR2 (10)

Required
Shipment Manifest Number
Yes/No flag indicating whether or not a reportable quantity exists. The details are contained in SHPITM DOT NAME, but this flag is used in mañifest creation to add ' $R Q$ ' in a box before the proper shipping name. Yes - reportable quantity exists. No - quantity is not reportable. Domain: ' $Y$ ' or ' $N$ '.

The total quantity of waste described on each line of the uniform hazardous waste manifest. Containers and inner liners are not considered part of the waste when measuring or calculating the quantity of dangerous waste. Domain: Numeric. Must be $>0$.

Handling codes and treatment method EPA code IDs, containment vessel and treatment. Codes may include: SolC, S02T, T31T, D810. Domain:

Alphanumeric.

A unique identifier for a uniform hazardous waste manifest form consisting of 5-digit number. The manifest is used for hazardous waste, radioactive mixed waste, and PCB contaminated waste. For the purpose of recording movement of radioactive waste, where no manifest is used, the RSR number will be used instead. Domain: Alphanumeric. 
SHPMNT CERT DT

DATE

Shipment

Certification Date

$?$
$\mathfrak{m}$
$\mathfrak{m}$
SHPMNT_GGRP_ID

SHPMNT MFST RET DT

VARCHAR2 (8)

DATE

VARCHAR2 (3)

SHPMNT MFST TYPE CD

-SHPMNT OFFSITE CMPNY ID
VARCHAR2 (4)
Shipment Group ID

Shipment Manifest Return Date

Shipment Manifest Type Code

Shipment offsite Company ID
The date that a qualified generator certifies that the contents of the waste shipment are fully and accurately described, packaged, marked, labeled, and are in all respects in proper condition for transport by highway according to all applicable regulations. Domain: oracle format date.

Identification of the generator group responsible for this shipment. Doma in: Alphanumeric.

The date the original manifest is returned to the Generator. Domain: Oracle format date.

The code which identifies whether or not a uniform hazardous waste manifest has been generated for onsite or offsite shipping of hazardous, mixed, or PCB waste. Domain: ' 0 ' for Onsite or ' $F$ ' for offsite.

Identifies the offsite company which disposes of the waste. For offsite manifests only. Domain:

Alphanumeric. Lookup to Company table (COMPANY) CMPNY ID. 


\begin{tabular}{|c|c|c|}
\hline -SHPMNT_OFFSITE_CMPNY_TYPE & VARCHAR2 (3) & $\begin{array}{l}\text { Shipment offsite } \\
\text { Company Type }\end{array}$ \\
\hline -SHPMNT_RECV_FACIL_ID & VARCHAR2 $(11)$ & $\begin{array}{l}\text { Shipment Receiving } \\
\text { Facility ID }\end{array}$ \\
\hline SHPMNT_RSR_TYPE & VARCHAR2 (2) & $\begin{array}{l}\text { Shipment } \\
\text { Radioactive } \\
\text { Shipment Record } \\
\text { Type }\end{array}$ \\
\hline SHPMNT_SCHED_DT & DATE & $\begin{array}{l}\text { Shipment Scheduled } \\
\text { Date }\end{array}$ \\
\hline SHPMNT_SHIP_DT & DATE & Shipment Ship Date \\
\hline -SHPMNT_TRANSP_CMPNY_ID & VARCHAR2 (4) & $\begin{array}{l}\text { Shipment } \\
\text { Transportation } \\
\text { Company ID }\end{array}$ \\
\hline -SHPMNT_TRANSP_CMPNY_TYPE & VARCHAR2(3) & $\begin{array}{l}\text { Shipment } \\
\text { Transportation } \\
\text { Company Type }\end{array}$ \\
\hline
\end{tabular}

Additional identifier of off-site company responsible for the storage/disposal of the waste in this shipment. Domain: Alphanumeric. Lookup to Company table (COMPANY) CMPNY TYPE.

Specific facility to which waste is shipped. For onsite manifests only. Domain: Alphanumeric. Lookup to Facility table (FACILITY) FACIL_ID.

Identifies the source and destination of waste being shipped on an RSR. Doma in: Alphanumeric.

'GT' = generator to TSD

' $T G '$ ' = TSD to generator

' $T T^{\prime}$ ' = TSD to TSD.

Shipping date scheduled for the shipment. Domain: Oracle format date.

The date the shipment starts moving. Domain: Oracle format date.

Identifies the company which transports the waste. Typical codes are 'WHC', 'KEH', 'PNL'. Domain: Alphanumeric. Lookup to Company table (COMPANY) CMPNY ID.

Additional identifier of the company that transports the waste shipment. Domain: Alphanumeric. Lookup to Company table (COMPANY) CMPNY_TYPE. 
SHPMNT TSD ACCEPT DT

Shipping Pick List (SHIPPICK)

**SHIPPICK_PKG_ID

SHIPWRAP_ABSORB_FLAG

SHIPWRAP_ALPHA_CONTAM

SHIPWRAP BG CONTAM
VARCHAR2 (8)

Required

VARCHAR2 (14)

Required

VARCHAR2 (8)

Required

VARCHAR2 (1)

Shipment TSD Accept Date

Shipping Pick List Shipment Number

Shipping Pick List Package ID

WRAP Shipment

Number

WRAP Shipment

Absorbent Flag

VARCHAR2 (8)

WRAP Shipment Alpha Contamination

VARCHAR2 (8)
WRAP Shipment Beta/Gamma

Contamination
The date the shipment is accepted at a TSD facility. Domain: Oracle format date.

The WRAP specific shipment number assigned to this shipment pick list. Domain: Alphanumeric.

The package ID assigned to this shipment number. Domain:

Alphanumeric. Must match a package ID in the Container and Content Record (CON PKG_ID).

Unique WRAP number to identify a specific shipment leaving the WRAP facility. Domain: Alphanumeric.

Designates whether or not absorbents are required for the shipment, external to the waste containers. Domain: Alphanumeric (' $y$ ' or Null).

Value for the measured removable Alpha contamination. Domain:

Alphanumeric (units $=\mathrm{dpm} / \mathrm{sq} . \mathrm{cm}$ ).

Value for the measured removable Beta/Gamma contamination. Domain: Alphanumeric (units are dpm/sq. cm). 
SHIPWRAP_CAB_DOSE

-SHIPWRAP_CARRIER_PERS_ID

SHIPWRAP_CARRIER_VEH_ID

SHIPWRAP_CHEM_FORM

$?$
1
$\infty$
$\infty$
VARCHAR2 (6) WRAP Shipment

Carrier Person

VARCHAR2 (8)

WRAP Shipment Cab Dose Rate

$\begin{array}{ll}\text { VARCHAR2(14) } & \begin{array}{l}\text { WRAP Shipment } \\ \text { Carrier Vehicle ID }\end{array} \\ \text { VARCHAR2(12) } & \begin{array}{l}\text { WRAP Shipment } \\ \text { Chemical Form }\end{array}\end{array}$

VARCHAR2 (1) WRAP Shipment Container Reusable Flag

$\begin{array}{ll}\text { VARCHAR2 (255) } & \begin{array}{l}\text { WRAP Shipment } \\ \text { Description }\end{array} \\ \text { VARCHAR2(11) } & \begin{array}{l}\text { WRAP Shipment Ship } \\ \text { from Facility }\end{array}\end{array}$

VARCHAR2 (6) from Facility

WRAP Shipment Ship from Name

\author{
SHIPWRAP_DESCR \\ -SHIPWRAP_FROM_FACIL_ID \\ -SHIPWRAP_FROM_PERS_ID
}

Dose rate measured within the cab of the transport vehicle. Domain:

Alphanumeric (mrem/hr).

Unique identification number of the person who is transporting the waste. Domain: Alphanumeric. Lookup to PERSON table PERS_ID.

ID number of the vehicle transporting the waste. Domain: Alphanumeric.

Defines the chemical form for the RSR document. Domain: Alphanumeric ('Oxide', 'Nitrate', 'Elemental', 'Mixture', 'Organic', Other [user entry]).

Determines whether or not the waste container is a single trip or reusable container. If ' $\gamma$ ', container is reusable. Domain: ' $\gamma$ ' or ' $N$ '.

Shipper's description of the waste shipment. Domain: Alphanumeric.

ID for the facility that is shipping the waste. Domain: Alphanumeric (Lookup to FACILITY).

ID of the responsible person that is shipping the waste. Domain: Alphanumeric (Lookup to PERSON). 


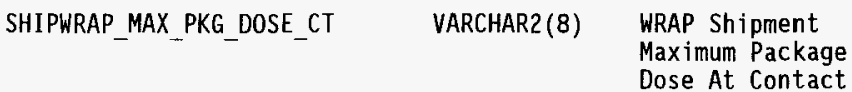

SHIPWRAP_MAX PKG_DOSE_1M

VARCHAR2 (8)

WRAP Shipment

Maximum Package

Dose At IM

?ִ
SHIPWRAP_MAX_VEH_DOSE_SD

SHIPWRAP MAX VEH DOSE 2M

VARCHAR2 (8)

VARCHAR2(8)

VARCHAR2 (1)

SHIPWRAP_MFST_COMP_FLAG

-SHIPWRAP_MFST_NUM

SHIPWRAP NUCLIDE_LIST

SHIPWRAP OTHR_PERT DATA
VARCHAR2(255) WRAP Shipment Radionuclide List

VARCHAR2(255) WRAP Shipment other Pertinent Info
Dose rate of the package with the highest measured dose rate at contact. Domain: Alphanumeric (mrem/hr).

Dose rate of the package with the highest measured does rate at

1 meter. Domain: Alphanumeric (mrem/hr).

Highest dose rate measured at the sides of the vehicle. Domain: Alphanumeric (mrem/hr).

Maximum dose rate measured for the vehicle at a distance of 2 meters. Domain: Alphanumeric (mrem/hr).

Flag to indicate when the manifest has been completed for a specific shipment. Domain: ' $Y$ ' or ' $N$ '.

Manifest number if the waste contains hazardous constituents. Domain: Alphanumeric. Must be in Shipment Record table (SHIPMENT) SHPMNT_MFST_NUM.

List of the significant radionuclides contained in the waste shipment as defined by EP-0063 guidelines. Domain: Alphanumeric.

User entry of data applicable to the waste shipment. Domain: Alphanumeric. 


\begin{tabular}{|c|c|c|}
\hline SHIPWRAP QTY_CAT & VARCHAR2 (35) & $\begin{array}{l}\text { WRAP Shipment } \\
\text { Quantity Category }\end{array}$ \\
\hline SHIPWRAP_RM_ESCRT_FLAG & VARCHAR2 (1) & $\begin{array}{l}\text { WRAP Shipment RM } \\
\text { ESCORT FLAG }\end{array}$ \\
\hline SHIPWRAP_RM_SUPR_REV_FLAG & VARCHAR2 (1) & $\begin{array}{l}\text { WRAP Shipment RM } \\
\text { Supervisor Review } \\
\text { Flag }\end{array}$ \\
\hline SHIPWRAP_RSR_COMP_FLAG & VARCHAR2 (1) & $\begin{array}{l}\text { WRAP Shipment RSR } \\
\text { Complete Flag }\end{array}$ \\
\hline SHIPWRAP_RSR_NUM & VARCHAR2 $(10)$ & $\begin{array}{l}\text { WRAP Shipment RSR } \\
\text { Number }\end{array}$ \\
\hline SHIPWRAP_SEC_HAZ & VARCHAR2 (255) & $\begin{array}{l}\text { WRAP Shipment } \\
\text { Secondary Hazards }\end{array}$ \\
\hline SHIPWRAP_SNM_FLAG & $\operatorname{VARCHAR2}(1)$ & $\begin{array}{l}\text { WRAP Shipment SNM } \\
\text { Flag }\end{array}$ \\
\hline -SHIPWRAP_T0_FACIL_ID & VARCHAR2 (11) & $\begin{array}{l}\text { WRAP Shipment Ship } \\
\text { to Facility }\end{array}$ \\
\hline -SHIPWRAP_TO_PERS_ID & $\operatorname{VARCHAR2}(6)$ & $\begin{array}{l}\text { WRAP Shipment Ship } \\
\text { to Name }\end{array}$ \\
\hline
\end{tabular}

Defines the shipping quantity category for the RSR form. Domain: Alphanumeric.

Flag noting whether or not an HPT escort is required. Domain: ' $Y$ ' or ' $N$ '.

Flag noting whether or not an HPT supervisor review of the RSR data is required. Domain: ' $Y$ ' or ' $N$ '.

Flag to indicate when the RSR has been completed for a specific shipment. Domain: ' $Y$ ' or ' $N$ '.

RSR number associated with a specific WRAP shipment. Domain:

Alphanumeric.

Shipper's description of hazards associated with the waste shipment. Domain: Alphanumeric.

Flag to indicate when a shipment container Special Nuclear Materials. Domain: ' $Y$ ' or ' $N$ '.

ID of the facility that a shipment is going to. Domain: Alphanumeric. Lookup to FACILITY FACIL_ID.

ID of responsible person that a shipment is going to. Domain: Alphanumeric. Lookup to PERSON PERS_ID. 
TRUPACT Shipping Record (TRUSHIP)

-TRUSHIP SHIP NUM

VARCHAR2 $(8)$

TRUSHIP DT

DATE

Container/Content Record *CON_PKG_ID

$\stackrel{?}{1}$
DATE VARCHAR2 (14) Required

VARCHAR2 (2)
Actual Ship Date

cord

Container Package ID

Container Accumulation Date

Shipment Number

Container Chemical Nature Code
The shipment number for waste going to WIPP. This numbering sequence is the 2-1etter site code, last 2 digits of the year, and 4-digit shipment number. Domain: Alphanumeric.

The actual ship date for a TRUPACT II cask. Domain: Oracle format date.

The unique package identification number that is assigned to the outer waste package. The number is assigned by the waste generator and is used for tracking all waste. Domain: Alphanumeric.

Accumulation date, the date the waste was accumulated. This date is the beginning of the storage time limit identified in the Primary Waste Type table. This field is also used as the general date of waste generation for all waste types. Domain: Oracle format date.

A code required on the annua dangerous waste report. Domain: The code is either ' 0 ' for organic or ' I' for inorganic. In some cases it may be both. 


$$
\text { CON_CNTR_VOL }
$$

-CON_CNTYP_CD

-CON_DOT_SPEC

?

CON_GENER_COMMENT

CON_GENER_WASTE_DESCR

CON_GROSS_WGT

CON_ITEM_NUM
NUMBER $(10,4) \quad$ Container Volume

VARCHAR2(2) Container Type Code

$\operatorname{VARCHAR2}(3)$

Container DOT Specification VARCHAR2 (80) Container Generator
Comment

VARCHAR2(255) Container Generator Waste Description

NUMBER(10,2) Container Gross Weight

VARCHAR2 (4)

Container Item Number
Total volume for a specific container. Domain: Container Size Table (CONSIZE) CSZ VOL. Default units are cubic meters.

Codes which identify the type of container per Department of

Transportation and other requirements. Domain: Container Type Table (CONTYPE) CNTYP_CD.

The Department of Transportation Specification for the outer waste container. Domain: DOT specification Táte (DOTSPEC) DOT_SPEC.

Generator comment related to this package. Domain: Alphanumeric.

Generator prepared waste content description. Domain: Alphanumeric.

Gross weight of a waste container. It includes the weight of the waste, of the container and of any shielding. Gross weight cannot exceed waste description weight plus container weight plus hazardous component weight. Domain: Number. Units are kilograms.

Line item number for the manifest on which the package is shipped from the generator. Domain: Whole number. 


$\begin{array}{lll}\text { CON_LABPACK_FLAG } & \text { VARCHAR2(1) } & \begin{array}{l}\text { Container Labpack } \\ \text { Flag }\end{array} \\ \text { CON_LINER_THICK } & \text { VARCHAR2(6) } & \begin{array}{l}\text { Container Liner } \\ \text { Thickness }\end{array} \\ \text { CON_LINER_TYPE } & \text { VARCHAR2(20) } & \begin{array}{l}\text { Container Liner } \\ \text { Type }\end{array} \\ \text { CON_LOCN_FACIL_AREA } & \text { VARCHAR2(6) } & \begin{array}{l}\text { Container Location } \\ \text { Facility Area }\end{array}\end{array}$

i⿱ $)$. CON LOCN_FACIL_ID

-CON_MFST_NUM

CON_PHYS_STATE_CD $\begin{array}{ll}\text { VARCHAR2(11) } & \begin{array}{l}\text { Container Location } \\ \text { Facility ID }\end{array}\end{array}$

VARCHAR2 (10) Container Manifest Number

VARCHAR2(3) Container Physical
Flags whether or not a container is a lab pack. Domain: ' $Y$ ' or ' $N$ '.

Designates the thickness of a waste container 1 iner. Domain:

Alphanumeric.

Specifies the type of waste container liner used. Domain: Alphanumeric.

The approved name of the areas identified on the Hanford site used for the storage or disposal of waste; area names include 200E, 200W.

Domain: Alphanumeric; populated from Facility Table (FACILITY) FACIL AREA.

The specific facility where waste is generated, received, or stored on the Hanford site. Domain: Facility Table (FACILITY) FACIL_ID.

Manifest number on which the package is being shipped from the generator. Domain: Alphanumeric. Must be in Shipment Record table (SHIPMENT) SHPMNT MFST NUM.

Code that describes the actual physical state of the waste. Domain: Alphanumeric;

$$
\begin{aligned}
' S '=\text { solid } \\
' L '=\text { liquid } \\
' G '=\text { sludge } \\
' M '=\text { compressed gas. }
\end{aligned}
$$


CON_PKG_DT

-CON_PKG_STATUS

$\stackrel{?}{8}$

- CON PWTYP CD

CON ROUTINE

CON_SAMPLE_FLAG
DATE

Container Package

Date

VARCHAR2 (1)

Container Package Status

VARCHAR2 (2)

Container Primary Waste Type Code

VARCHAR2 (1)

Container Routine

VARCHAR2 (1)
This is the date that a container was closed and physically sealed. For radioactive waste, it applies mainly to WIPP certified transuranic waste but may apply to LLW in the future. For hazardous and mixed waste, it is used as the accumulation date. This applies to the package closure mechanism and not to an official seal such as a numbered tag. Domain: oracle format date.

Package status code indicating status of waste package, required edit

leve1, and data ownership. Domain: Package Status Table (PKGSTAT) PKS_STATUS.

Primary waste type code identifying the type of waste in a particular container or waste stream. Domain: Primary Waste Type Code Table (PRIWASTYPE) PWTYP_CD.

Indicates whether waste is routine or other. Domain: Alphanumeric.

$' R^{\prime}$ = Routine

$' P^{\prime}=$ PCB

$' E^{\prime}=$ Environmental Restoration

$' D$ ' $=D \& D$.

Identifies wastes that must be sampled prior to shipment offsite. The sampling is required for acceptance of the waste at the offsite TSD. Domain: ' $Y$ ', ' $N$ ', or null.
Container Sample Flag 
$\cdot C O N \_S C A T \_C D$
$U$ CON_SEC_PKG_ID

CON_SHIP_DT

-CON_SIZE_DESCR

$?$
1
0
VARCHAR2 (8) Container Source Charge Code

VARCHAR2 (4) Container Source Company ID

-CON_SRCE_CMPNY_TYPE

VARCHAR2 (3)
VARCHAR2 (3)

VARCHAR2 (14)

DATE

VARCHAR2 (14) Container Size Description

-CON_SRCE_CMPNY_ID

Category Code Package ID
Container Storage

Container Secondary

Container Ship Date

\section{The date on which the package was shipped from the generator. Domain:} that generates the waste. Domain:
Container Source Company Type Oracle format date.

The dimensions of the container. Length $x$ width $x$ height or diameter $x$ length for cylindrical waste packages, which could include containers such as 55 gallon, 30 gallon, 12-B. Domain: Container Size Table (CONSIZE) CSZ_DESCR.

A charge code to be used in billing for this package. Domain: Alphanumeric.

Identifies the company who generates the waste. Typical codes are WHC, KEH, PNL. Domain: Alphanumeric. Company Table (COMPANY) CMPNY ID.

Additional identifier of the company Alphanumeric. Company table

(COMPANY) CMPNY_TYPE.

Code indicating the container storage category. Domain: Storage Category

A secondary package ID that the identify the inner container of an overpack. Domain: Alphanumeric. 
-CON_SRCE_FACIL_ID

CON_SRCE_ORG

CON_TARE_WGT

I̊

CON_TREATMENT_DT

CON_TSD_ACCEPT_DT

CON_WASTE_WGT
VARCHAR2 (11)

Source Facility ID $\begin{array}{ll}\text { VARCHAR2 (8) } & \begin{array}{l}\text { Container Source } \\ \text { Organization }\end{array}\end{array}$

NUMBER(10,2) Container Tare Weight

DATE

DATE

$\operatorname{NUMBER}(12,4)$
Container Treatment Date

Container TSD Accept Date

Container Waste Weight
Identifies the facility where waste is generated. The facility is identified by number and is the official WHC building number. Domain: Alphanumeric. Facility Table (FACILITY) FACIL_ID.

Source of the waste. Used for identification in generator reports. Domain: Alphanumeric.

The weight of an empty waste container. This tare weight may include any shielding material required. Domaiñ: Number. Uñits are kilograms.

The date the waste is actually treated, such as incinerated.

Domain: Oracle format date.

Identifies the date that the waste was accepted for treatment, storage, or disposal at an EPA approved TSD facility. Domain: Oracle format date.

Total weight of the contents found in a specific waste container. Domain: Number. Units are kilograms. 
Container \& Content Extension Record (WASTEXT)

**CONEXT PKG ID VARCHAR2 (14)

Container Extension

$\stackrel{1}{1}$
CONEXT ASSAY VER DT

CONEXT_ASSAY VER FLAG

DATE

VARCHAR2 (1)

VARCHAR2 (2)

CONEXT_CNTR_STATUS

CONEXT_COMPLIANT_FLAG

VARCHAR2 (1)
Required

\section{Package ID}

Container Assay

Verification Date

Container Assay

Verification Flag

WRAP RWM Container Status
The unique package identification number that is assigned to the outer waste package. The number is assigned by the waste generator and is used for tracking all waste. Domain: Alphanumeric. Must match a package ID in the Container and Content Record (CON_PKG_ID).

The date of the assay that is chosen as the WRAP verification assay Domain: Oracle format date.

The flag denotes whether the NDA results obtained in WRAP 1 are consistent with the generator supplied NDA results for drums which are not processed in WRAP 1 . Domain: ' $Y$ ', ' $N$ ', or Null.

Status codes of an RWM transfer drum. Domain: Alphanumeric.

$$
\begin{aligned}
& ' E^{\prime}=\text { empty } \\
& F^{\prime}=\text { full } \\
& P^{\prime}=\text { part full. }
\end{aligned}
$$

Flags a container to identify if it Container Compliant Flag is compliant or non-compliant based on the assay, examination, or visual inspection. This flag will be used to re-route a newly generated noncompliant waste drum to the processing area or route it within the glovebox where it witl be opened. Domain: ' $C$ ' or null. 


$\begin{array}{lll}\text { CONEXT_CONTAM_FLAG } & \text { VARCHAR2(1) } & \begin{array}{l}\text { Container } \\ \text { Contamination Flag }\end{array} \\ \text { CONEXT_FILLER_WGT } & \operatorname{NUMBER}(10,2) & \begin{array}{l}\text { Container Filler } \\ \text { Weight }\end{array}\end{array}$

CONEXT HAZ VER FLAG

VARCHAR2 (1) Container Haz Materials Verified Flag

1
1
$\infty$

\author{
CONEXT_HEIGHT \\ -CONEXT_MAT_GRP_CD
}

CONEXT_NDE_VER_FLAG

CONEXT_NLLL_DET_DT
VARCHAR2 (1)

Container NDE Verified Flag

NUMBER $(12,4)$ Container Height

VARCHAR2(2) Container Material Group Code

Container NonListed Long-Lived Detected Date
Flags whether or not an overpack drum is contaminated. Domain: ' $Y$ ', ' $N$ ', or null.

This data element records the weight of the filler material added to a drum during processing in WRAP 1 .

Filler weight to be subtracted prior to NDA calculations. Domain:

Numeric (units in $\mathrm{kg}$.)

This data element will be used to document the verification of the hazardous constituents in a waste drum. Domain: Alphanumeric (' $Y$ ' for verified, ' $N$ ' for not verified, ' $R$ ' for additional evaluation required, 'Null' for not applicable).

Height of a puck loaded out of the glovebox after processing. Domain: Numeric $\geq 0.12$, units in meters.

This unique code is used to identify the WRAP 1 specific waste components for packets. Domain: Material Table (MATL) MATL_GRP_CD.

Flags a container to identify if it is verified or not verified based on non-destructive examination. Domain: ' $V$ ' or null.

Date the NDA results identified Nonlisted, long-lived nuclides Domain: date or null. 


\begin{tabular}{|c|c|c|}
\hline CONEXT_PROF_FLAG & VARCHAR2 (1) & $\begin{array}{l}\text { Container Profile } \\
\text { Flag }\end{array}$ \\
\hline -CONEXT_PROF_ID & $\operatorname{VARCHAR2}(6)$ & $\begin{array}{l}\text { Container Assay } \\
\text { Profile ID }\end{array}$ \\
\hline CONEXT_RADMAT_ID & $\operatorname{VARCHAR2}(1)$ & $\begin{array}{l}\text { Container Fissile } \\
\text { Material ID }\end{array}$ \\
\hline -CONEXT_ROUTE_CD & VARCHAR2 (4) & $\begin{array}{l}\text { Container Route } \\
\text { Code }\end{array}$ \\
\hline CONEXT_RVST_FLAG & VARCHAR2 (1) & $\begin{array}{l}\text { Container Revisit } \\
\text { Flag }\end{array}$ \\
\hline CONEXT_SCRN_VER_FLAG & VARCHAR2 (1) & $\begin{array}{l}\text { Container Screening } \\
\text { Verification Flag }\end{array}$ \\
\hline
\end{tabular}

Flag indicates whether default profile data is used. Domain: ' $Y$ ', ${ }^{\prime} \mathrm{N}$ ', or null.

The generator assay profile ID associated with this container. Domain: Profile Table (PROFILE) PROF ID.

The fissile material ID that describes the area that the container fissile material has been added to. Domain:

' $F$ ' = Facility

$' T '=$ TRU Giovebox

'R' = TRU RWM Glovebox.

Container Route Code used to identify the various container routings within WRAP Module 1 . The routing codes will be used by the PCS to identify the routings.

Code that identifies the processing route assigned to the container. Domain: Route Table (ROUTE)

ROUTE CD.

Flag used to determine if the NDA results need to be revisited. Domain: ' $Y$ ', ' $N$ ', or null.

This flag designates whether or not the sampling performed is to verify generator data Domain: ' $Y$ ' or ' $N$ '. 
-CONEXT_SHIPPICK_CD

VARCHAR2 (4)

Container Shipment

Pick List Code

CONEXT_TREATMENT_FLAG

$\operatorname{VARCHAR2}(1)$

Container Treatment

Flag
Shipment code assigned to the container following processing, used to assign the container to the appropriate shipping pick list. Domain: Shipment Pick List

Description Table (SHIPPICKTYP) SHIPPICK_CD.

The treatment $f 1$ ag that indicates

that the container has been treated. Domain: ' $Y$ ', ' $N$ ', or null. 
CONEXT_USE_CD

$\stackrel{1}{5}$
VARCHAR2(2) Container Use Code

$\operatorname{NUMBER}(10,2)$

Container

Verification Gross Weight
Code assigned to identify what a container is or is used for, i.e., transfer drum, calibration drum,

purge port, PIG, packet, inner waste item, collection or treatment

container. Domain: CODECHECK table, USE CD

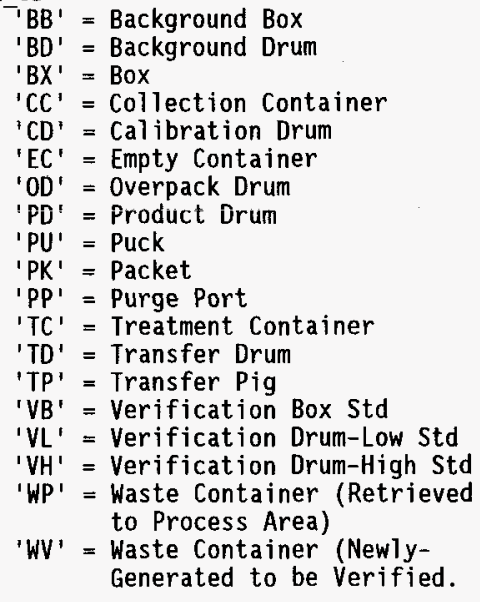

Container weight obtained within the WRAP facility. Domain: Numeric (units in kgs). 


$\begin{array}{ll}\text { CONEXT_VER_GROSS_WGT_FLAG VARCHAR2(1) } & \begin{array}{l}\text { Container } \\ \text { Verification Gross } \\ \text { Weight Flag }\end{array}\end{array}$

CONEXT WRAP SAM FLAG

CONEXT_WRAP_STAT_CD

若

\section{VARCHAR2(1) Container WRAP \\ Sample Flag}

VARCHAR2 (2) Container WRAP Status Code
This flag will be set $=$ ' $Y$ ' if the original container weight is verified or will be set to ' $N$ ' if the original weight deviates from the WRAP 1 weight by a predetermined amount. Domain: ' $Y$ ', ' $N$ ' or $\mathrm{Nu} 11$.

Indicates that this container has been sampled $(Y)$ or not $(N)$. Domain: ' $Y$ ', ' $N$ ', or null.

Code that identifies current status of the package at WRAP. Domain: Alphanumeric.

$$
\begin{aligned}
& \text { ' } W \text { " = Waiting for processing } \\
& \text { ' } I \text { ' = In-process } \\
& ' C^{\prime}=\text { Processing complete, }
\end{aligned}
$$

The unique package identificaiton assigned to the package to which the verification applies. Domain:

Alphanumeric. Must match a package ID in the Container and Content Record (CON PKG ID). 


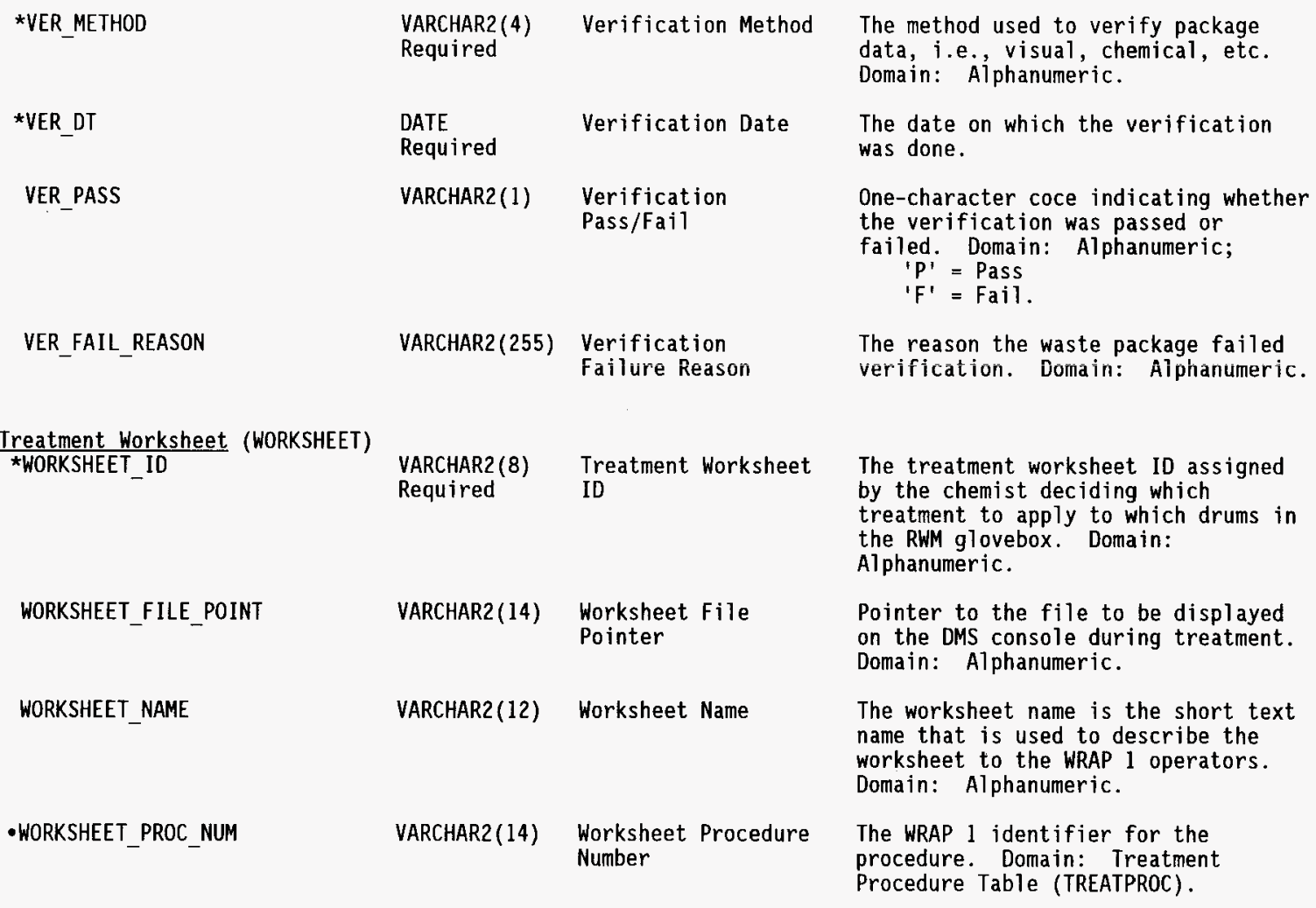




\section{WORKSHEET_PROC_REV_NUM}

Worksheet Item (WORKITEM)

-*WORKITEM_ID

•*WORKITEM_PKG_ID
$\operatorname{VARCHAR2}(4)$

Worksheet Procedure Revision Number

VARCHAR2 (8) Worksheet Item ID Required

VARCHAR2 (14) Worksheet Item Required
Revision number of the procedure worksheet. Domain: Alphanumeric.

The treatment worksheet ID assigned by the chemist deciding which

treatment to apply to which drums in the RWM glovebox. Domain:

Alphanumeric. Must be in Treatment Worksheet table (WORKSHEET) WORKSHEET_ID.

PIN from the packet of waste or sample removed from the transfer drum or purge port for treatment in the RWM glovebox. Domain: Alphanumeric. Must match a package ID in the Container and Content Record (CON PKG ID). 


\section{C.2.2 Data Look-Up Tables Element Descriptions}

$\begin{array}{ll}\frac{\text { Miscellaneous Code Table }}{\star \text { CODE_FIELD_NAME }} & \begin{array}{l}\text { (CODECHECK) - SWITS Lookup Table } \\ \text { VARCHAR2 (24) } \\ \text { Required } \\ \text { Code Field Name }\end{array} \\ \star \text { CODE_VALUE } & \begin{array}{l}\text { VARCHAR2 (12) Code Value } \\ \text { Required }\end{array} \\ \text { CODE DESCR } & \text { VARCHAR2(70) Code Description }\end{array}$

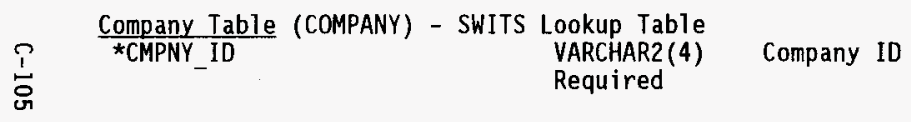

*CMPNY_TYPE

CMPNY CITY

CMPNY_EPA_ID
VARCHAR2(15) Company City

VARCHAR2(3) Company Type
Required

VARCHAR2 (12)
The name of a data field as specified in the data dictionary for which a code validation edit is required. Domain: Alphanumeric.

A valid value for the data field being tested. Domain: Alphanumeric.

A description of the code and its purpose. Domain: Alphanumeric.

Identifies the company which generates, transports, treats, stores, or disposes of the waste. Typical codes are WHC, KEH, PNL. Domain: Alphanumeric.

Additional identifier for the company performing solid waste activities. Domain: Alphanumeric. Company Types include:

' TRA $^{\mp}=$ Transportation Company

'GEN' = Generator

'TSD' = TSD.

City in which the company resides. Domain: Alphanumeric.

Unique identification number assigned by the EPA to a company. Domain: Alphanumeric.
Environmental

Protection Agency (EPA) ID 
CMPNY_LOCATION

CMPNY_PHONE

-CMPNY_STATE_CD

CMPNY STREET

옹

CMPNY_TITLE

CMPNY_ZIP_CD
VARCHAR2 (10)

Company Location

VARCHAR2 (12) Company Phone

VARCHAR2 (2) Company State Code

VARCHAR2(36) Company Street

VARCHAR2(60) Company Title

Company Zip Code

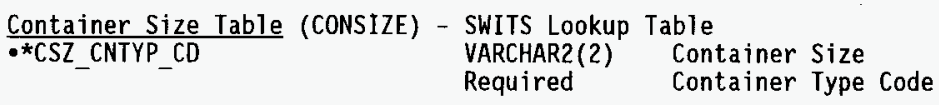

*CSZ_DESCR

CSZ_VOL
VARCHAR2(14) Container Size Required Description

NUMBER $(10,4) \quad$ Container Size Volume
A code to describe the company as onsite (ON) or off-site (OFF). Domain: Alphanumeric. 'ON' or 'OFF'.

Phone number for the official point of contact for the organization specified by the company ID and company type code. Domain:

Alphanumeric.

Standard state abbreviation code. Domain: Alphanumeric. Lookup to State table STATE CD.

Street address for the company. Domain: Alphanumeric.

The name of a company. Domain: Alphanumeric.

The zip code for the area in which the company resides. Domain: Alphanumeric.

The code which refers to the type of container. Domain: Alphanumeric. Lookup to Container Type table (CONTYPE) CNTYP_CD.

Describes the size of the container. Domain: Alphanumeric.

Provides the volume of a certain container type. Domain: Number. 

Container Type Table (CONTYPE) - SWITS Lookup Table *CNTYP CD VARCHAR2 (2) Required
Container Type Code

CNTYP_DESCR

VARCHAR2 (42)

Container Type Description

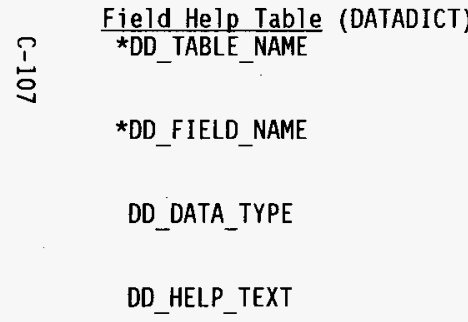

DOT Container Specification Table *DOT SPEC
Code which identifies the type of container per Department of Transportation (DOT) and other requirements. Codes include DM for metal drums, barrels. Domain: Alphanumeric.

The DOT or other specifications describing a waste container. Specification includes $17 \mathrm{c}, 17 \mathrm{~h}$, self contained, plywood box, metal box. Domain: Alphanumeric.

The table name for each data element. Domain: Alphanumeric.

The data element name. Domain: Alphanumeric.

The data element type and size. Domain: Alphanumeric.

The data element description. Domain: Alphanumeric.

The unique identification of a DOT specification entered by WMP when a DOT specification becomes associated with SWITS. Domain: Alphanumeric. 
DOT_DESCR

VARCHAR2 (60)

DOT Specification

Description

$\stackrel{1}{\frac{1}{8}}$

$\begin{array}{lll}\text { Dangerous Waste Number Table } & \begin{array}{c}\text { (DWNUM) - SWITS } \\ \text { VARCHAR2 (4) } \\ \text { Required } \\ \text { VARCHUM }\end{array} & \begin{array}{l}\text { Lookup Table } \\ \text { Dangerous Waste } \\ \text { Number }\end{array} \\ \text { DW_DESCR } & \text { VARCHAR2(1) } & \begin{array}{l}\text { Dangerous Waste } \\ \text { Description }\end{array} \\ \text { DW_LANDBAN } & \begin{array}{l}\text { Dangerous Waste } \\ \text { Landban }\end{array}\end{array}$

DW_SORT_HAZ

$\operatorname{NUMBER}(3)$

Dangerous Waste Sort Hazardous

DW_SORT_MIXED
NUMBER(3)
Text description of a DOT specification entered by WMP when a DOT specification becomes associated with SWITS. Domain: Alphanumeric.

Unique identifier for a Dangerous Waste Number. Domain: Alphanumeric.

Text description for a Dangerous Waste Number. Domain: Alphanumeric.

Code indicating whether the waste associated with the dangerous waste number is regulated as "Land Banned." Yes - defined as always land banned. No - defined as never land banned. Null - not defined. The user must determine for each package. Domain: ' $Y$ ', ' $N$ ' or Null.

Reports generated using dangerous waste numbers have a unique reporting order. The value in this field will determine the sort order for hazardous waste. Domain: Number.

Reports generated using dangerous waste numbers have a unique reporting order. The value in this field will determine the sort order for mixed waste. Domain: Number.

\section{Dangerous Waste} Sort Mixed 


$\begin{array}{lll}\text { Error Message Table (ERRMESSAGE) } & \begin{array}{l}\text { vaRCHAR2 (4) } \\ \text { Required }\end{array} & \begin{array}{l}\text { Error Message } \\ \text { Number }\end{array}\end{array}$

ERR_DESCR

ERR_TEXT

$\stackrel{1}{1}$
FACIL_AREA

FACIL_BAR_ID

FACIL_NAME

\section{VARCHAR2(255) Error Message} Description

VARCHAR2 (72) Error Message Text

Lookup Table

VARCHAR2 (11)

Required

VARCHAR2(6) Facility Area

VARCHAR2(5) Facility Bar Code ID

VARCHAR2(55) Facility Name
The code which identifies an error message. Consists of an alpha, E for error or I for information, followed by 3 numerics $(X N N N)$. Domain: Alphanumeric.

A more complete description of the error. Domain: Alphanumeric.

A one-1ine error message. Domain: Alphanumeric.

The specific facility where waste is generated, received, or stored on the Hanford site. Domain: Alphanumeric.

The approved name of the areas identified on the Hanford site used for the storage or disposal of waste; area names include 200E, $200 \mathrm{~W}$. Domain: Alphanumeric.

The approved machine readable code (MRC) assigned by the MRC Council to identify location within bar code labels. Domain: Character.

The proper name given to a facility which generates or receives waste for treatment, storage, or disposal. Domain: Alphanumeric. 
Field Analysis Type (FLDANALTYP) *FAT CD

VARCHAR2 (4) Required

Field Analysis Type Code

FAT DESCR

$\stackrel{?}{1}$
$\operatorname{VARCHAR2}(70)$

Field Analys is Type Description

Field Analysis Type Units

VARCHAR2 (8)

Required

LONG

VARCHAR2 (6)
Form Help Name

Form Help Text

Unique identifier for each WRAP screening analysis Domain:

Alphanumeric.

$$
\begin{aligned}
& \text { 'COLR' = Color } \\
& \text { 'TEXT' = Texture } \\
& \text { 'VISC' = Viscosity } \\
& \text { 'PHPR' = pH using paper } \\
& \text { 'PHMT' = pH using meter } \\
& \text { 'TEMP' = Temperature } \\
& \text { 'ORGV' = Organic Vapor. }
\end{aligned}
$$

Text description of the fourcharacter analysis code Domain: Alphanumeric.

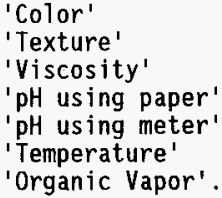

Applicable units for the field screening analysis that is performed. Domain: Alphanumeric.

$' \operatorname{deg} C$

'centip' = centipoise.

\section{Form Help Table (FORMHELP) *FH FORM NAME}

FH HELP TEXT
WRAP 1 DMS menu or screen name.

Domain: Alphanumeric.

Help description for the WRAP 1 DMS screen. Domain: Alphanumeric. 


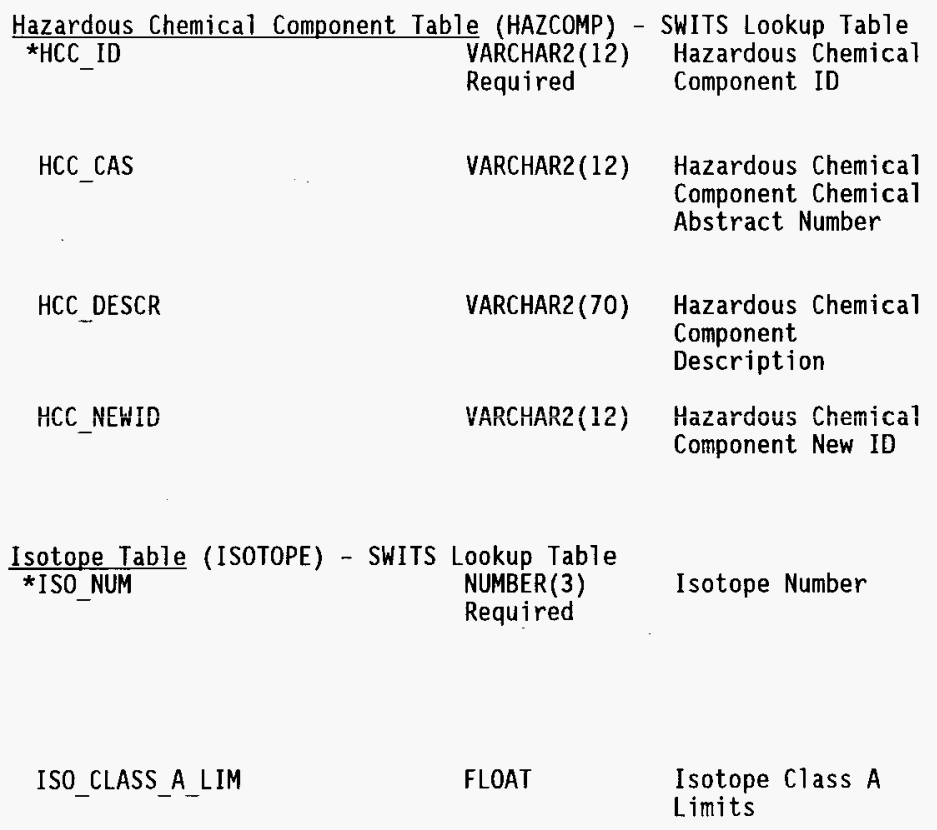

Unique identification of a hazardous chemical component. Domain:

Alphanumeric.

Chemical abstract number of a hazardous chemical component. This is needed for EPCRA-313 reportable chemicals. Domain: Alphanumeric.

Text description of a hazardous chemical component. Domain: Alphanumeric.

Identification used for conversion of temporary IDs to permanent IDs. Domain: Alphanumeric.

Code arbitrarily assigned for solid waste to identify a specific isotope or entity reported as an isotope, such as mixed fission products, $\mathrm{Co}-60, \mathrm{Sr}-90$. Domain: Whole Number $>0$.

Defines the upper limits for determining $C$ lass $A$ radionuclides. Units are curies per cubic meter $\left(\mathrm{ci} / \mathrm{m}^{3}\right)$, or $\mathrm{nci} / \mathrm{g}$ for alpha emitting transuranic radionuclides. Domain: Number. 


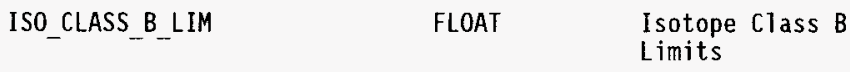

ISO_CLASS_C_LIM

$\stackrel{T}{2}$

ISO_CLASS_1_LIM

ISO_CLASS_3_LIM
FLOAT

FLOAT

FLOAT
Isotope Class $\mathrm{C}$ Limits

Isotope Class 1 Limits

Isotope Class 3 Limits
Defines the upper limits for determining $C$ lass $B$ radionuclides. Units are curies per cubic meter $\left(\mathrm{ci} / \mathrm{m}^{3}\right)$, or $\mathrm{nci} / \mathrm{g}$ for alpha emitting transuranic radionuclides. Limits are defined in 10 CFR 61.55. Domain: Number.

Defines the upper limits for determining Class $C$ radionuclides. Units are curies per cubic meter $\left(\mathrm{ci} / \mathrm{m}^{3}\right)$, or $\mathrm{nci} / \mathrm{g}$ for alpha emitting transuranic radionuclides. Limits are defined in 10 CFR 61.55. Note: not all radionuclides are Class $C$. Domain: Number.

Defines the upper limits for determining Class 1 radionuclides. Units are curies per cubic meter $\left(\mathrm{ci} / \mathrm{m}^{3}\right)$, or $\mathrm{nci} / \mathrm{g}$ for alpha emitting transuranic radionuclides. Domain: Number.

Defines the upper limits for determining Class 3 radionuclides. Units are curies per cubic meter $\left(\mathrm{ci} / \mathrm{m}^{3}\right)$, or $\mathrm{nci} / \mathrm{g}$ for alpha emitting transuranic radionuclides. Domain: Number. 
ISO_CONSTR_LIM

FLOAT

I sotope

Concentration

Limits

\begin{tabular}{lll} 
ISO_CONV_FACTR & FLOAT & $\begin{array}{l}\text { Isotope Conversion } \\
\text { Factor }\end{array}$ \\
& FLOAT & $\begin{array}{l}\text { Isotope Dose } \\
\text { Equivalence Curie }\end{array}$ \\
& Factor \\
\hline ISO_DE_CI_FACTR & &
\end{tabular}

ISO_DE_CI_FACTR

$\stackrel{?}{\text { 草 }}$

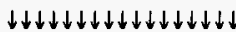
ISO FGE FACTR

\section{Phase 3} FLOAT $\downarrow \downarrow \downarrow \downarrow \downarrow \downarrow \downarrow \downarrow \downarrow \downarrow \downarrow \downarrow \downarrow \downarrow \downarrow$
Isotope Fissile
Gram Equivalent Gram Equi
Concentration limits set for disposal/storage for waste. The values are not static. This field is used to contain values where a one time special report is needed. When the report is done, these values should be deleted making the fields available for other reports. Domain: Number.

Factor for converting grams of the specific isotope to curies. Domain: Number.

Dose Equivalence Factor for the given Isotope. This value is multiplied with the quantity of the isotope to get the dose equivalence sum for an isotope. The sum of all the isotopes in a package is stored in RDET TOT DE CI. Domain: Number.

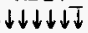

Fissile Gram Equivalent Factor for the given Isotope. This value is multiplied with the quantity of the isotope to get the fissile gram equivalent contribution for an isotope. The sum of all the isotopes in a package is stored in RAD PU FGE. Domain: Number. 
ISO_PE_CI_FACTR

FLOAT

ISO_ALPHA_CI_FACTR

FLOAT

Isotope Alpha Curie Factor
Isotope Plutonium Equivalent $\mathrm{C} i$ Factor

\section{$\uparrow \uparrow \uparrow \uparrow \uparrow \uparrow \uparrow \uparrow \uparrow \uparrow \uparrow \uparrow \uparrow \uparrow \uparrow \uparrow \uparrow \uparrow \uparrow \uparrow \uparrow \uparrow \uparrow \uparrow \uparrow \uparrow \uparrow \uparrow \uparrow \uparrow \uparrow \uparrow$ ISO_DTR_ISO}

ISO_DTRPRD_FACTR

ISO_ENRICH

ISO_HALFLIFE
FLOAT
VARCHAR2(1) Isotope Enrichment

Isotope Half Life
Plutonium Equivalent Curie Factor for the given Isotope. This value is multiplied with the quantity of the isotope to get the PE curie contribution for an isotope. The sum of all the isotopes in a package is stored in RAD PE CI. Domain: Number.

Alpha Curie Factor for the given Isotope. This value is multiplied with the quantity of the isotope to get the alpha curie contribution for an isotope. The sum of all the isotopes in a package is stored in RAD ALPHA_CI. Domain: Number.

\section{Phase $3 \uparrow \uparrow \uparrow \uparrow \uparrow \uparrow \uparrow \uparrow \uparrow \uparrow \uparrow \uparrow \uparrow \uparrow \uparrow \uparrow \uparrow \uparrow \uparrow \uparrow \uparrow \uparrow \uparrow \uparrow \uparrow \uparrow \uparrow \uparrow \uparrow \uparrow \uparrow \uparrow \uparrow \uparrow \uparrow \uparrow \uparrow \uparrow \uparrow \uparrow \uparrow \uparrow \uparrow$}

Isotope Daughter

Products Isotope

The isotope number of any daughter product produced by radioactive decay. Domain: Whole Number $>0$.

Factor for the parent/daughter radionuclide pairs showing the corresponding activity of the daughter product. Domain: Number.

Yes/No flag to indicate the possibility of the isotope occurring in multiple enrichments. Yes enriched isotope may exist. No enriched isotope can not exits. Domain: ' $Y$ ' or ' $N$ '.

Halflife of isotope in days, rate of decay. Domain: Number. 
ISO_MAP_FACTR

FLOAT

\section{ISO MAP NAME}

ISO_MFP_FACTR

FLOAT

点

\section{ISO NAME}

ISO_UNIT
VARCHAR2 (2) Isotope Unit

Laboratory Table *LAB_ID

LAB NAME
VARCHAR2 (5)

VARCHAR2 (20)

Isotope Name

Isotope Mixed

Activation Products

Factor

Isotope Mixed Activation Products Name

Isotope Mixed

Fission Products

Factor

Laboratory ID

VARCHAR2 (6)

Required

VARCHAR2(30) Laboratory Name
The proportion of MAP (Mixed Activation Products, Isotope 19) which is assumed to consist of the specific isotope in question, if and only if, the source of the waste is 100 Area facilities with the exception of $108 \mathrm{~F}$ facility or the waste source is identified in the company table as a generator of MAP instead of MFP. Domain: Number.

Name given to specific isotope to be used if it has a non-zero value for MAP factor. Domain: Alphanumeric.

The proportion of MFP (Mixed Fission Products, Isotope 19) which is assumed to consist of the specific isotope in question. Domain: Number.

Name of a specific isotope. Domain: Alphanumeric.

Units by which amounts of a specific isotope are measured. Normally gm for grams or ci for curies. Domain: Alphanumeric.

A unique identifier for a laboratory approved to perform waste sample analysis. Domain: Alphanumeric.

Name of a laboratory approved to perform waste sample analysis. Domain: Alphanumeric. 


\begin{tabular}{|c|c|c|c|}
\hline *LABANAL_CD & $\begin{array}{l}\text { VARCHAR2 (8) } \\
\text { Required }\end{array}$ & $\begin{array}{l}\text { Laboratory Analysis } \\
\text { Code }\end{array}$ & $\begin{array}{l}\text { Unique code identifying specific } \\
\text { analysis requested Domain: } \\
\text { Alphanumeric. }\end{array}$ \\
\hline LABANAL_CNTR_COUNT & NUMBER(1) & $\begin{array}{l}\text { Laboratory Analysis } \\
\text { Container Count }\end{array}$ & $\begin{array}{l}\text { Defines the number of containers to } \\
\text { be used for a single analysis. } \\
\text { Domain: Number }>0 \text {. }\end{array}$ \\
\hline -LABANAL_CNTYP_CD & VARCHAR2 (3) & $\begin{array}{l}\text { Laboratory Analysis } \\
\text { Container Type Code }\end{array}$ & $\begin{array}{l}\text { This code will be used to define the } \\
\text { type of container to be used to take } \\
\text { the sample. Domain: Alphanumeric. } \\
\text { Lookup to Sample Container Type table } \\
\text { (SAMPCONTYP) SAMPCNTYP_CD. }\end{array}$ \\
\hline LABANAL_DESCR & VARCHAR2 (20) & $\begin{array}{l}\text { Laboratory Analysis } \\
\text { Description }\end{array}$ & $\begin{array}{l}\text { Text description of the analysis } \\
\text { Domain: Alphanumeric. }\end{array}$ \\
\hline LABANAL_PRESERV & VARCHAR2 (12) & $\begin{array}{l}\text { Laboratory Analysis } \\
\text { Preservative }\end{array}$ & $\begin{array}{l}\text { Description of any preservatives } \\
\text { required to be used during } \\
\text { acquisition of the sample. Domain: } \\
\text { Alphanumeric. }\end{array}$ \\
\hline LABANAL_REQD_VOL & NUMBER(4) & $\begin{array}{l}\text { Laboratory Analysis } \\
\text { Required Volume }\end{array}$ & $\begin{array}{l}\text { Volume of the sample to be taken for } \\
\text { analysis Domain: Numeric (units in } \\
\text { m1). }\end{array}$ \\
\hline$\frac{\text { Location Table }}{{ }^{\text {LOCN_ID }} \text { (LOCN) }}$ & $\begin{array}{l}\text { VARCHAR2 }(10) \\
\text { Required }\end{array}$ & WRAP I Location ID & $\begin{array}{l}\text { Identifies a location within WRAP } \\
\text { Module } 1 \text { where waste item or empty } \\
\text { drum is stored or processed. This } \\
\text { includes nondestructive examination } \\
\text { equipment, assay equipment, } \\
\text { gloveboxes, AS/RS, carrousels, } \\
\text { conveyors. Domain: Alphanumeric } \\
\text { (see Appendix E). }\end{array}$ \\
\hline
\end{tabular}


LOCN_DESCR

$\operatorname{VARCHAR2}(60)$

Location

Description

Material Table (MATL)

*MATL GRP CD

MATL_GRP_DESCR

Material Safety Data Sheets (MSDS) - SHITS Lookup Table

$\begin{array}{ll}\text { *MSDS_ID } & \text { VARCHAR2(6) } \\ \text { Required } & \begin{array}{l}\text { Material Safety } \\ \text { Data Sheet ID }\end{array}\end{array}$

$\stackrel{?}{!}$

MSDS_DESCR
$\operatorname{VARCHAR2}(30)$

Material Group

Description

VARCHAR2(2) Material Group Code

Required

Required

Data Sheet ID

VARCHAR2(40) Material Safety

Data Sheet

Description
Description or name of a location within WRAP Module 1. Domain:

Alphanumeric (see Appendix E).

This unique code is used to identify the WRAP 1 specific waste components for packets. Domain: Alphanumeric.

Unique description for material group codes. Domain: Alphanumeric.

Unique identification number for a Material Safety Data Sheet (MSDS). Domain: Alphanumeric.

A description of the waste package on the Material Safety Data Sheet.

Domain: Alphanumeric. 
Person Table (PERSON) - SWITS Lookup Table *PERS_ID VARCHAR2 (6)

Required

Person ID

莒

\section{PERS CITY}

- PERS CMPNY ID

-PERS CMPNY TYPE
VARCHAR2 (15) Person City

VARCHAR2 (4) Person Company ID

VARCHAR2 (3) Person Company Type
This is the primary identifier for any person of interest to SWITS.

This key will be used in other tables which have information for special subsets of individuals in the PERSON table (e.g. the GENERATOR table).

For onsite (Hanford) employees, this is the employee ID. For offsite persons, an ID is created using the CMPNY ID plus a number; where LENGTH (CMPNY ID) $\leq 3$, the PERS ID will be CIDNNN, and where LENGTH(CMPNY ID) $=$ 4, PERS ID will be CIDNN where CID = the CMPNY ID and $N N$ or $N N N=001 / 01$ for the lst entry from that company and then incremented as needed, e.g., the first PERS ID entered for University of Washington (CMPNY ID = UOW) would be UOWOO1. Domain: Alphanumeric.

City part of address. Domain: Alphanumeric.

Code identifying the company the person is associated with. Domain: Alphanumeric. Lookup to Company table CMPNY ID.

Additional identifier of the company with which the person is affiliated. Domain: Alphanumeric. Lookup to Company table CMPNY TYPE. 


$$
\text { PERS_MSIN }
$$

VARCHAR2(5) Person MSIN

PERS_NAME

VARCHAR2(20) Person Name

PERS_PHONE

VARCHAR2(12) Person Phone Number

-PERS_STÁTE_CD

VÁRCHÂR2 (2) Person State Code

$\stackrel{?}{\stackrel{1}{0}}$
VARCHAR2 (36) Person Street

VARCHAR2(10) Person Zip Code

PERS_ZIP_CD

Physical Component Description Table (PHYSDESC) - SWITS Lookup Table *PDESC DESCR VARCHAR2(30) Required Physical Description

VARCHAR2(1) Package Status
Required

MSIN (Mail Stop Identification Number) for onsite employee. NULL for offsite persons. Domain:

Alphanumeric.

Format is 2 initials plus last name. If the person does not have a middle initial, a blank will be used in its place. Domain: Alphanumeric.

Work phone number of person. Format is NNN NNN-NNNN; area code and ful1 prefix are required.

State Code of address. Domain: Alphanumeric. Lookup to State table STATE CD.

Street part of address. Domain: Alphanumeric.

Zip Code part of address. Domain: Alphanumeric.

The description of a physical component in radioactive or mixed waste. Descriptions include paper, plastic, rags, concrete. Domain: Alphanumeric.

Code indicating a package's status. Domain: Alphanumeric.
Package Status Table (PKGSTAT) *PKS STATUS 

PKS_DESCR
VARCHAR2 (60)
Package Status
Description
PKS_EDIT
VARCHAR2 (1)
Package Status Edit

PKS_OWNER

VARCHAR2(3)

Package Owner

$\frac{?}{1}$
PWTYP DESCR

VARCHAR2 (20)

VARCHAR2 (1)

PWTYP HAZ
(PIWASTYPE) - SWITS Lookup Table VARCHAR2 (2) Required Primary Waste Type Code
Text description of a package status. Domain: Alphanumeric.

Edit level associated with a waste package's data when this package status is assigned. Domain: Alphanumeric. Edit levels are:

' 1 ' = Default: Fields defining the container are required.

$' 2 '=$ Contents: Fields defining the waste are required.

${ }^{\prime} 3^{\prime}=$ Shipment: Fields defining the shipment are required.

Package data owner when a waste package is assigned this package status. Domain: Alphanumeric; 'GEN', 'WMP', 'SWO'.

Primary waste type code. This code identifies the type of waste in a particular container or waste stream. Domain: Alphanumeric.

Description of the primary waste type code. Domain: Alphanumeric.

Yes/No flag to indicate if this type of primary waste is hazardous waste. Yes - hazardous, mixed-radioactive, or PCB waste. No - no hazardous components. Domain: ' $Y$ ' or ' $N$ '. 


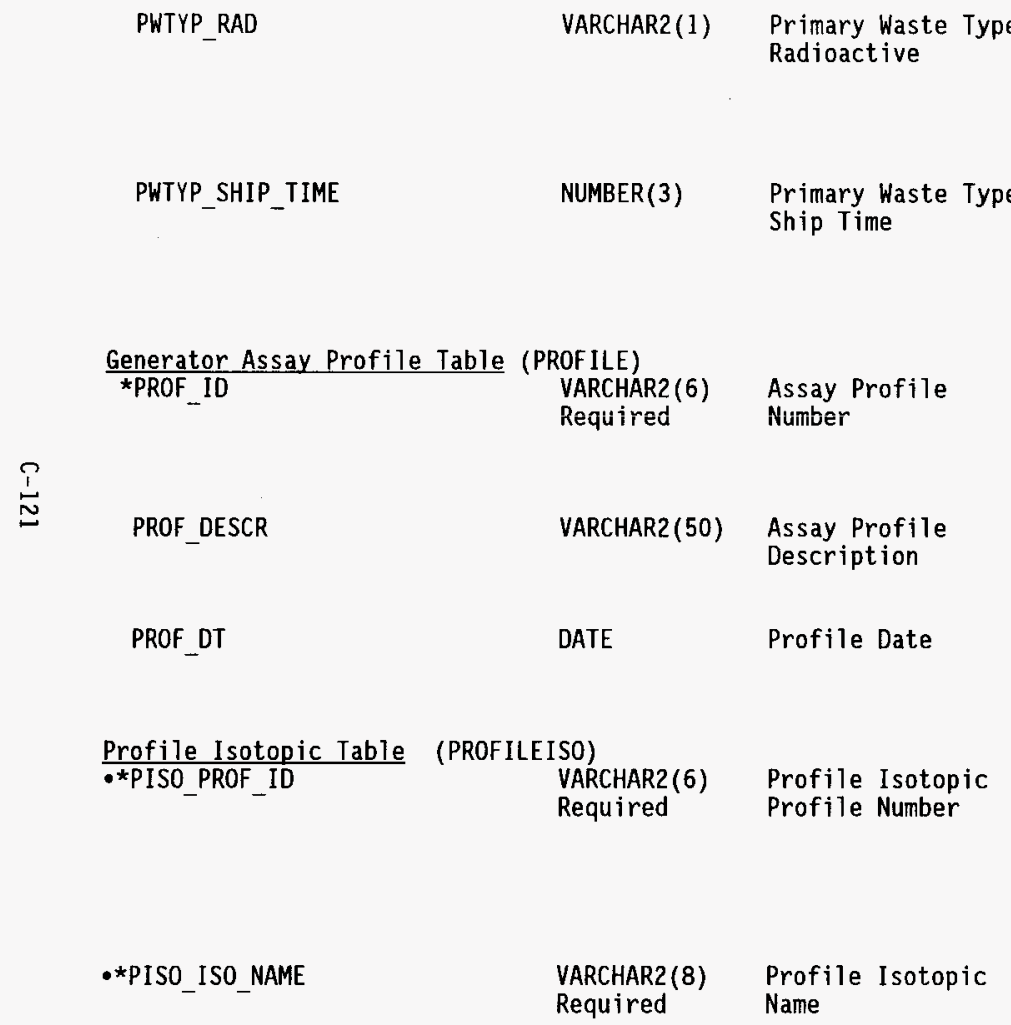

Yes/No flag to indicate if this type of primary waste is radioactive waste. Yes - radioactive. No - no radioactive components. Domain: ' $Y$ ' or ' $N$ '.

Days allowed before generated waste must be shipped. 30 days for PCBs, 90 days for other hazardous or mixed waste. Domain: Number.

Profile number of assay data associated with a generator or multiple generators. Domain: Alphanumeric.

Basic description of the assay profile data such as percentage of Pu. Domain: Alphanumeric.

Assay profile date. Domain: Oracle format date.

Profile number of assay data associated with a generator or multiple generators. Domain: Alphanumeric. Lookup to Generator Assay Profile table (PROFILE) PROF ID.

The isotopic name for this profile. Domain: Alphanumeric (Lookup to SIEISO). 
PISO_RABUND

FLOAT

FLOAT

PISO_TMU

Report Table (REPORTABLE)

*RPT_NAME

RPT_GENSPEC

$\frac{1}{N}$
VARCHAR2 (8) Required

VARCHAR2 (1)

VARCHAR2 (8)

VARCHAR2 (1)

RPT_TIMING

RPT_TITLE
Profile Relative Abundance

Profile Relative Abundance TMU

Report Table Name

Report Table Generator Specific

Report Table Select

Report Table Timing
The relative abundance of this isotope in this profile. Domain: Numeric.

The relative abundance Total Measurement Uncertainty in this profile. Domain: Numeric.

Name of report. Domain:

Alphanumeric.

Yes/No flag used to identify reports specific to the user's generator group. Yes - when the report is specific to data for the user's generator group. No - when the report is not specific to the user's generator group. Domain: ' $Y$ ' or ' $N$ '.

Name of selection criteria forms block. Domain: Alphanumeric.

Parameter restricting how and when a report will run. Domain:

Alphanumeric.

$' I '=$ Immediate

$'{ }^{\prime}{ }^{\prime}$ = Batch only

${ }^{\prime} O^{\prime}$ = Batch overnight (non-prime time).

VARCHAR2(40) Report Table Title
Title or report. Domain: Alphanumeric. 


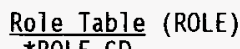

*ROLE CD

ROLE DESCR

Role Screen Relationship Table (ROLESCREEN)

- ${ }_{\text {RSCRN_ROLE_CD VARCHAR2 (6) }}$

* RSCRN_SCRN_NAME

$\stackrel{T}{\stackrel{1}{w}}$

RSCRN ACCESS

Route Description Table (ROUTE) *ROUTE CD
Required

VARCHAR2 (6) Role Code
Required

VARCHAR2(60) Role Description

VARCHAR2 (8)

Required

VARCHAR2 (1)

VARCHAR2 ( 4 Required
Role-Screen

Relationship Role Code

Role-Screen

Relationship Screen

Name

Role-Screen

Relationship Access

Route Code
Unique identification of a role a person can assume in WRAP. Domain: Alphanumeric.

Text description of the role. Domain: Alphanumeric.

Identifying code for the role to be related to a screen. Domain: Role Table (ROLE) ROLE CD.

Name of the screen to which a role is related. Domain: Screen Table (SCREEN) SCRN_NAME.

Type of access allowed to the screen. Domain: Alphanumeric. $'{ }^{\prime}{ }^{\prime}=$ Read Access

$' U^{\prime}=$ Update Access.

Code that identifies the route assigned to a container designating the process routing of that container. Domain: Alphanumeric. '1', '2', '3', '4', '5', '6', '7', '8', '101', '102', and '103'. 
ROUTE DESCR

VARCHAR2(25) Route Description

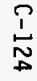

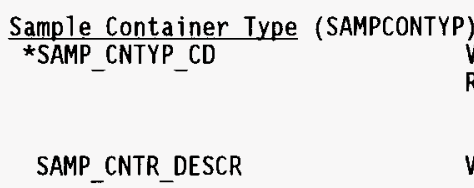

SAMPMATX DESCR

\section{VARCHAR2(3) Sample Container Required \\ VARCHAR2 (30) \\ Type Code \\ Sample Container Description}

VARCHAR2 (3)

Required

VARCHAR2(12)
Sample Matrix Code

Sample Matrix Description
Description of the various processing routes a container may be assigned in WRAP Module 1. Domain:

Alphanumeric.

'VERIFY NG-TRU \& NG-LLW'

'TRU TO PROCESS' (2)

'LLW TO PROCESS' (3)

'55G OT EMPTIES TO PROCESS' (4)

'85G DS EMPTIES TO PROCESS' (5)

'85G EE EMPTIES TO PROCESS' (6)

'BACKGROUND DRUM ASSAYS' (7)

'VERIFICATION DRUM ASSAYS' (8)

'UNCOMPACTED PROCESSED WASTE' (101)

'COMPACTED PROCESSED WASTE' (102)

'EMPTY DRUMS FROM PROCESS' (103):

A code used to identify the type of container to be used during sample acquisition Domain: Alphanumeric.

Text description of sample containers to be used. Domain: Alphanumeric.

A code used to define the physical matrix of the sample Domain: Alphanumeric.

Text description of the sample's matrix. Domain: Alphanumeric. 
Sampling Method (SAMPMETH)

*SAMPLING_METHOD_CD

VARCHAR2 (4)

Required

Sampling Method

Code

SAMPLING_METHOD_DESCR

$\frac{T}{\mathbb{N}}$ $\begin{array}{ll}\text { VARCHAR2(30) } & \begin{array}{l}\text { Sampling Method } \\ \text { Description }\end{array}\end{array}$

\section{VARCHAR2 (8) Screen Name \\ VARCHAR2 (40) Screen Title}

Abbreviated code defining the method to be employed during field sampling operations. Domain: Alphanumeric.

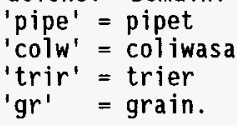

A text description of the sampling method to be utilized. Domain:

Alphanumeric.

'pipet'

'coliwasa'

'trier'

'grain'.

Name of the WRAP 1 DMS screen.

Domain: Alphanumeric.

Title of the WRAP 1 DMS screen.

Domain: Alphanumeric.

Secondary waste type codes are a further breakdown of the SWTYP GROUP. Domain: Alphanumeric.

Used for grouping data on some reports. Groups are Low-Level, Transuranic, Unsegregated, and High Level. Domain: Alphanumeric. 
SWTYP DESCR

VARCHAR2 (50)

Type Description

Shipping Pick List Type (SHIPPICKTYP)

*SHIPPICKTYP_CD

SHIPPICKTYP DESCR

$\stackrel{?}{\stackrel{\Sigma}{\sigma}}$

\section{SIE Isotopic Name Table *SIE_ISO_NAME}

-SIE ISO NUM
VARCHAR2(24)
$\operatorname{VARCHAR2}(4)$

Required
Shipping Pick List Type Code

Shipping Pick List Type Description

VARCHAR2 (8) Required

NUMBER(3)
SIE Isotopic Name

SIE Isotopic Number
The description identifies the type of waste in a particular container or waste stream. The types are lowlevel, transuranic, unsegregated classified, industrial, or special case. Domain: Alphanumeric.

\section{A short code which relates to the} description for the various shipping pick 7 ist types. Domain:

Alphanumeric.

Description of the various shipping categories that will be used during shipping in WRAP 1 . This includes TRU to head gas or storage, TRU to disposal, LLW to disposal, and LLW to storage. Domain: Alphanumeric.

The specific isotopic name that is used by the SIE which it returns in its measurement message to the DMS. Domain: Alphanumeric.

The associated isotopic number used by SWITS to identify isotopes in the ISOTOPE table. Domain:

Alphanumeric. Lookup to ISOTOPE ISO NUM. 


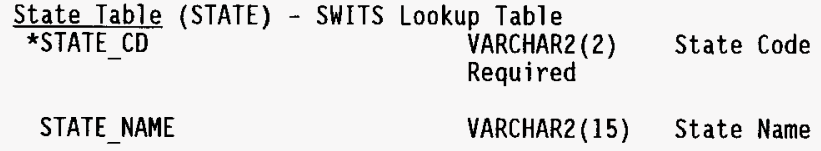

Storage Category Table (STORAGECAT) - SWITS Lookup Table

\begin{tabular}{lll}
\hline *SCAT_CD & $\begin{array}{ll}\text { VARCHAR2 (3) } \\
\text { Required }\end{array}$ & $\begin{array}{l}\text { Storage Category } \\
\text { Code }\end{array}$ \\
SCAT_CATEGORY & VARCHAR2(20) & Storage Category
\end{tabular}

$\stackrel{T}{1}$

\section{VARCHAR2(14) Treatment Procedure Required Number}

VARCHAR2(4) Treatment Procedure Required Revision Number

VARCHAR2(30) Treatment Procedure Author

VARCHAR2 (30) Treatment Procedure
Standard state abbreviation code. Domain: Alphanumeric.

The name of the state. Domain: Alphanumeric.

Arbitrary code assigned by WMP to identify storage categories. Domain: Alphanumeric.

Describes the storage category of the waste container. Each container wil! have only one category assigned.

Categories include acid, caustic, flammable, other mixed waste (OMW), PCBs. Domain: Alphanumeric.

Unique number used to identify the treatment to be used. Domain: Alphanumeric.

Revision for the treatment procedure. Domain: Alphanumeric.

Author of the treatment procedure. Domain: Alphanumeric.

Text description of the treatment procedure. Domain: Alphanumeric. 
TREAT_PROC EXP DT

DATE

VARCHAR2 (6) TRUCON Code

TRUCON Code Table (TRUCON)

*TRUCON_CD

TRUCON_DESCR

VARCHAR2(90)

TRUCON Description

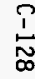

$\frac{\text { TRU Shipping Category Table }}{\text { *TRUSHIPCAT CD }}$

TRUSHIPCAT_DESCR

TRUSHIPCAT_CON_LIM
Treatment Procedure Expiration Date
TRUCON Code as described in the WIPP TRUCON document. This code defines the source and type of waste to be shipped to WIPP. (Example: RH123A) Domain: Alphanumeric.

Description of the waste stream defined by the TRUCON code. Domain: Alphanumeric.

TRU Shipping Category for the waste containers to be loaded into a TRUPACT II container. (Example: IV. 1A2) Domain: Alphanumeric.

TRU Shipping Category Description which defines the category of the waste being shipped, type of waste container, and the number of levels of confinement. (Example: Solid waste shipped in an SWB with two layers of confinement) Domain: Alphanumeric.

This field provides the decay heat limit for the specific waste container identtified by the TRUSHIPCAT CD. Domain: Numeric.
NUMBER(5,4) TRUPACT Container Limit 
TRUSHIPCAT CASK LIM

$\operatorname{NUMBER}(5,4)$

TRUPACT Cask Limit
TSD Facility Table (TSDFACIL) - SWITS Lookup Tabie

**TFAC_FACIL_ID $\begin{aligned} & \text { VARCHAR2(11) TSD Facility ID } \\ & \text { Required }\end{aligned}$

TFAC MFST ADDR

VARCHAR2 (40)

TSD Manifest

Address

$\stackrel{?}{\frac{1}{*}}$

- TFAC SCHEDULER

-TFAC SUPERVISOR

VARCHAR2 (6)

TSD Supervisor

User Role Relationship Table (USERROLE)

$\begin{array}{ll}\text { **URL_USERID } & \begin{array}{l}\text { VARCHAR2 (7) } \\ \text { Required }\end{array} \\ & \text { VARCHAR2(6) } \\ & \text { Required }\end{array}$

User-Role Relationship User ID

User-Role Relationship Role Code
This field provides the decay heat limit for the TRUPACT II cask containing the waste identtified by the TRUSHIPCAT_CD. Domain: Numeric.

Unique identification of a TSD Facility associated with SWITS. Domain: Alphanumeric. Lookup to Facility table FACIL_ID.

TSD facility address used in preparing manifests. Domain: Alphanuinieríc.

Identification of the TSD Facility scheduler. Domain: Alphanumeric. Lookup to Person table PERS ID.

Identification of a TSD Facility supervisor. Domain: Alphanumeric. Lookup to Person table PERS ID.

User ID of the user to which the role is related. Domain: User Table (USERS) USR_USERID.

Code identifying the role related to the user. Domain: Role Table (ROLE) ROLE_CD. 
$\frac{\text { User Table (USERS) }}{\text { *USR_USERIO }}$

USR ACCOUNT

USR_BULL_DT

$\stackrel{?}{\stackrel{\omega}{\omega}}$

USR_LOGON_DT

USR_NAME

USR_ORG

-USR_PERS_ID

USR PR DELIVER

USR PR_WHERE
VARCHAR2 (7) User ID
Required

VARCHAR2 (6) User Account

DATE

User Bulletin Date

DATE

User Logon Date

VARCHAR2(20) User Name

VARCHAR2(5) User Organization

VARCHAR2 (6) User Person ID

VARCHAR2(20) User Print Deliver To

VARCHAR2(8) User Printed Where
User's UserID. A unique identifier for a SWITS user. Generally a person ${ }^{7} s$ payroll number. Domain: Alphanumeric.

Account for computer billing.

Domain: Alphanumeric.

The date a bulletin was published. Provides the user with a way of skipping the system bulletin which appears at logon time once it has been seen. Domain: oracle format date.

The last date on which the user entered the system. Domain:

Alphanumeric.

User's name. Domain: Alphanumeric. User's organization code. Domain: Alphanumeric.

User Person ID number. Domain: Alphanumeric. Lookup to Person table PERS ID.

User's output delivery address.

Domain: Alphanumeric.

Default device for output printed at a central or remote site (not printed through the user's terminal).

Domain: Alphanumeric. 

USR_TERM_TYPE
VARCHAR2 (6)
User Term Type
USR_TRAIN_DT
DATE
User Train Date

User Signature Password (USERSIGNPASS) **UP_USERID

VARCHAR2 (7)

Required

U UP_SP

VARCHAR2 (10)

$\stackrel{T}{\omega}$
WRAP Miscellaneous Table (WRAPMISC) *WRAP_FIELD_NAME
VARCHAR2 (24)

Required
User Signature

Password User ID

User Signature

Password Signature

Password

WRAP Code Field Name
Type of terminal used. Domain: Al phanumeric.

The date the user received SWITS training. Domain: Oracle format date.

User ID. Domain: User Table (USERS) USR USERID.

The signature password. Domain: Alphanumeric.

The data fields may be used to store constants for use in the DMS programming or selected data ranges. Domain: Alphanumeric.

VERL IM WGT

DEFAULT PCK HGHT

DEFAULT PCK MTL HGHT

EMPTY $5 \overline{5}$ OT

EMPTY $55^{-}$EE

EMPTY 85 DS

LLW DEFLT PROF

TRU_DEFLT_PROF. 
*WRAP CODE VALUE

VARCHAR2 (12)

Required
A valid value for the data field

being tested. Domain: Alphanumeric. VERLIM WGT $=$ '. 1 ', unitless

DEFAUL $\overline{\mathrm{T}}$ PCK HGHT $=1.21^{\prime}$, units in meters

DEFAULT PCK MTL HGHT $=' .012 '$, units in meters

EMPTY $550 \mathrm{~T}=$ ' 4 '

EMPTY' $55^{-} \mathrm{EE}={ }^{\prime} 6^{\prime}$

EMPTY ${ }^{-} 85^{-}$DS $='{ }^{\prime}$ '

LLW DEFLT PROF = variable (1 ookup to PROFILE)

TRU LLW DEFLT PROF = variable (Tookup to PROFILE). 
WRAP CODE DESCR

VARCHAR2(70)

AP Code Description
A description of the code and its purpose. Domain: Alphanumeric.

VERLIM WGT - \% deviation waste container certification weight and the weight measured in WRAP 1

DEFAULT PCK HGHT - used as a default height for the LLW pucks

DEFAULT PCK MTL HGHT - used as a default value for the effective height of the metal in a supercompacted puck

EMPTY 55 0T - 55-gallon One Trip drum (used to designate an empty drum with a process route $=4$ )

EHPTY $55 \mathrm{EE}=6-55-\mathrm{g} a \mathrm{l}$ ilon Entry/Exit drum (used to designate an empty drum with a process route $=6$ )

EMPTY 85 DS $=5-85$-ga11on Drath \& Schräder drum (used to designate an empty drum with a process route $=5$ )

LLW DEFLT PROF = variable (value to be revised based on batches of waste processed through the WRAP facility).

TRU DEFLT PROF = variable (value to be revised based on batches of waste processed through the WRAP facility). 


\section{3 MISCELLANEOUS CODE DEFINITIONS}

The Miscellaneous Code (CODECHECK) table values utilized by the DMS are defined in Table $\mathrm{C}-2$. Table $\mathrm{C}-3$ defines the values in the WRAP Miscellaneous Code (WRAPMISC) table.

Table C-2. Miscellaneous Codes.

\begin{tabular}{lll}
\hline Code Name & Data Element & Where Used \\
\hline $\begin{array}{l}\text { Designation Code } \\
\text { Hazardous Property }\end{array}$ & DESIG_CD & HazDetail (HDET) \\
Codes & HAZPROP_CD & HazDetail (HDET) \\
Other Land Banned 1 & OTHER_LANDBAN_1 & HazDetail (HDET) \\
Other Land Banned 2 & OTHER_LANDBAN_2 & HazDetail (HDET) \\
Other Land Banned 3 & OTHER_LANDBAN_3 & HazDetai1 (HDET) \\
PCB Description & PCB_DESCR & HazDetail (HDET) \\
PCB Parts Per Mi11ion & PCB_PPM & HazDetail (HDET) \\
PCB Subtype & PCB_SUBTYPE & HazDetail (HDET) \\
PCB Type & PCB_TYPE & HazDetail (HDET) \\
SWIMS Code & SWIMS_CD & RadDetail (RDET) \\
Void Code & VOID_CD & RadDetail (RDET) \\
WRAP Category & WRAP_CAT & RadDetail (RDET) \\
Use Code & USE_CD & SAMREL; WRAP Container \\
\hline
\end{tabular}

Table C-3. WRAP Miscellaneous Codes.

\begin{tabular}{|c|c|c|}
\hline Code Name & Data Element & Where Used \\
\hline Container Status & CNTR_STATUS & CONEXT_CNTR_STATUS \\
\hline $\begin{array}{l}\text { Weight Verification } \\
\text { Limit }\end{array}$ & VERLIM_WGT & CONEXT_VER_GROSS_WGT \\
\hline LLW Default Profile & LLW_DEFLT_PROF & CONEXT_PROF_ID \\
\hline Default Puck Height DEF & AULT_PUCK_MATL_HEIGHT & CONEXT_HEIGHT \\
\hline $\begin{array}{l}\text { Empty } 55-\text { Gallon Entry/ } \\
\text { Exit Drum Route Code }\end{array}$ & EMPTY_55_EE & CONEXT_ROUTE_CD \\
\hline $\begin{array}{l}\text { Empty } 55-\text { Gallon One } \\
\text { Trip Drum Route Code }\end{array}$ & EMPTY $55 \_0 T$ & CONEXT_ROUTE_CD \\
\hline $\begin{array}{l}\text { Empty D\&S } 85-\text { Gallon } \\
\text { Drum Route Code }\end{array}$ & EMPTY 85_DS & CONEXT_ROUTE_CD \\
\hline
\end{tabular}




\section{4 "ONE-PAgER" DATA ELEMENT LIST}

DMS Data Record Tables Activity Comment Record

ACT DF

ACT COMMENTS

Applicable MSDS (APPMSDS) - SWITS Data

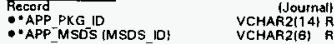

Bin List NUM

Bortle Dato Record (BOTTLE)

- BOT-SAMPLE IO

BOT-DISP BY

BOT-DISP METHOD

BOT OK ST LAB
BOT RETUAN TO PKC

tule Anatysis Rooord IBOTANALI

VCHAR2(12)R

BOTANAL REQUEST FLAG
BOTANAL_PERFORM_FLAG
VCHAR211)

完

Hazardous Chemical Component Record

$\because$ HAZ PKG ID

-HAZ COMPID

HAZ COMP ${ }^{-}$WGT

HAZ-COMP-WGT PC

Chain of Custody (COC)

COC-BILL LADING

COC CHEST ID
COC HAZ REMARK

- COC $\angle A B I D$

COC METH SHIPMENT

COCPERS ID

COC PROJ DESIG

COC-SAF NUM

COC SPEC HANDLING

COC SPEE INSTHUCTION

VCHAR213!

Chain of Custody Transfer (COCXFR)

- CocXfád

- COCXFR-RECVD BY OPID VOPRR VCHAR2(6)

Communication Table (COMMUNICATION TABLE)

COMM TO

COMM-MSG ID

COMM-PRIOAITY

VCHAR2(a)

VCHAR2 201

NUMBER(3)
(ACTCOM)
VCHAR2(14)

VCHAR2(14) R VCHAR21101

(BIN)

[Journal]
VCHAAR2 (121 R
VCHAR2g)

VCHAR2 (8)

VCHAR2 215

VCHAR2125:

VCHAR2 (1)

Container Location (CONLOC)

CONLOCDT -

Container Relationship Record ICONREL

- conR FROM PKG

$\because$ CONATO PKG
- CONR-DT

CONPREL_CD

VCHAR2 $\{14\} R$
VCHAR2 14$\} R$
DATE $R$
VCHAR2 13$]$

Container Treatment iCONTREAT)

CONTREATDDT

CONTREAT'COMMEN
- CONTREAT-USER ID
CONTREAT WS IO

VCHAR2 $\{14\}$ R

VCHAR2 2 255)
VCHAR2 (7)
VCHAA2

Discharge Conveyor Ligt IDISCHARGE

- DISCHARGEPKG_IO NUMERT121

Field Screaning focord (FIELOSCRN)

- SCRN -10

SCRN-COMMENTS

- SCRN LOCN

ScRN'SAMSFie vo

- SCRN' SAMPLING Meth

Field Andygis, (FIELDANAL)

- FiELD-FAT_CD

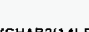

VCHAR2(1)।

VCHAR2 2701
NUMBER $(12,4)$ VCHAAR2 (7)

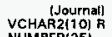

VCMAR2111

VCHAR2 (6)

VCHAR2 2201

NUMAR2 (25)

VATE 21255

(1)

HDET PCB REMOVED DT

\section{Mazardous Waste Contsiner Detail Record}

- HDET PKG ID V (Journal)

HDET-CNTR STATUS

HDET'DW NUM

HDET FLASHPOINT

HDETIND DOT ID NUM

HDET IND SHIP NAME

HDET LANDBAN

HDET-OTHER-LANDBAN -2

HDET-OTHER-LANDBAN-3

HDET $P$ PCB DESCR

HDE ${ }^{-P C E}$ - SUBTYPE

MDETPCB TYPE

HDET WASTE STATU

DEET_WASTE_VOL

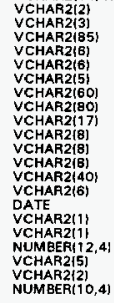

Radigactive Isotope Quantity Record (ISOOTY).

- RAD PKG ID

RAD_ALPHA_CI

RAD PU FGE

RAD OTY

RAD-UNKNOWN

VCHAR2 (14) R

FLOAT

FLOAT
Metrics Record (METRICS)

MET-DT-

METASSAY VER FLAG

MET HAZ VER_FLAG
MET-LOCN IO-

MET-NOE VER FLAG

MET USE CD

MET WRAP STAT CD

Message Log Record [MSGLOG]

MSGLOGERAOR FLAG

MSGLOG-GEN-TYPE

MSGLOG-SPEE TYP

MSGLOG STRING1
MSGLOG STRING2

NDA Assar Results (NDA)

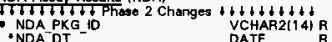

- NDA ASSAY NUM

NDA FUT 1 Phase 2 Change

NDA ISO TOT

- nDa profe in

NDA-RATIO FLAG

NOA SWTYP GROUP

$+1+1+t+t+$ Phäes 2 Changes

NDA TOT PE CI TMO

NDA-TOT PU FGE TMU

NDA THEAMAL POWWER IMU

NDA TOTAPAPHA CI CI TO PE CI

NDA TOTPUFGE

NDA Assay lsotopic Records (NDAISO)

it $+1+1 T+1$ Phease 2 Changes t 4

NDAISO ASSAY NUM NUM

NDAISO NAME 2 Changes

NDAISO-GEA

NDAISO- OTY

NOAISO MEAS STATUS

NDAISO PAN ACTIY

NDAISO-PAN_PASSIVE

NDE Resulte 'NDE

+NDE-DT

- NDE-COMMENT

NDE- VDISR FILE

NDE VDISK NUM

NOE Process Ligt (NOTPROCLIST)

VCHARzIIj

VCHAR2(2)

FLOAT

VCHAR213!

VCHAR2(3)
VCHAR2(2)
VCHAR2(2)

Not Ship Pick List (NOTSHIPPIC

VCHAR2(14) R

DATE 21255

VCHAAR2 255
VCHAR2 271
VCHAA2

VCHAR 2(5)

NUMBER(5)

Not Shig Pick List INOTS

VCHAR2 (14) A
Sotopic Distribution IPAM)

PAM-PU FGE

PAM-QTY

VCHAR2114) R FLOAT
FLOAT

Payload Container Cerrification Record

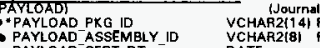

PAYLOAD CERT DT

- PAYLOAD CERT OfFICIal

PAYLOAD DECAY HEAT

PAYLOAD FLTER MODEL

PAYLOAD-GAS GEN RATE

PAYLOAD-HEAT ERREOR

PAYLOAD HEAT HIMIT

PAYLOAD-LINER VNT -

PAYLOAD SHIP APP FLAO

- PAYLOAD SHIP CAT

- PaYload-TRUCON CD

PAYLOAD VOC CONC

VCHAR2 (8)
DATE
VCHAR2(25)

VCHAR2(3)

VCHAR2 (10)

VCHAR2 (3)

NUMBERI3)

FLOAT

VCHAR2!1!

VCHAR2:8

NUMBER $(2)$

VCHAR2IO

NUMBERI3)

aylood Assernbly Certification Record

AASBY NUM
-ASBLY SHIPMENT NUM VCHAR2 (Jim) R
VCHAR2(6)

ASBLYAPPROVED_SHIP,FLAG VCHAR2(1)

$\begin{array}{ll}\text { ASBLY-CERT-DT } & \text { DATE } \\ \text { ASBLY CERT OFFICIAL } & \text { VCHAR2 (25) } \\ \text { ASBLY CONFIGURATION } & \text { VCHAR2 (4) }\end{array}$

ASBLY CONFIGURATION
ASBLY DOSE RATE
NUMBERIQ,

ASBLY DOSE RATE 2M NUMBERIB,

ASBLY OCA BODY IO

ASBLYY POA

ASBLY SHIP CAT MEAT

VCHAR2(日)

VCHAR2(B)

VCHAR2 (10\}

NUMEERI0,21

Physiced Component Record (PHYSCOMP) -

$\because$ PHYS PKG ID

$\because$ PHYS PKG ID

PHYS COMP VOL PCT

(Journal)
VCHAR2(14) $R$

NUMBER(6,3)

Pack age Dangerous Waste Numbers Record

-PDW PKG 10

POW-LANDBAN
POW-SORT ORDER

Process Pick Ligt (PROCLIST)

PROC- COMPLIANT FLAG

- PROC PROF FLAG

- procórouté cD

PROC SAMPLE FLAG
PRoc SEq Nǘm

(Journal!
VCHAR2 14$\}$ R
VCHAR2

VCHARE(1]

VCHAR2114I R

VCHAR211

VCHAR2

VCHAR2t 
WHC-SD-W026-SDD-001, Rev. 2
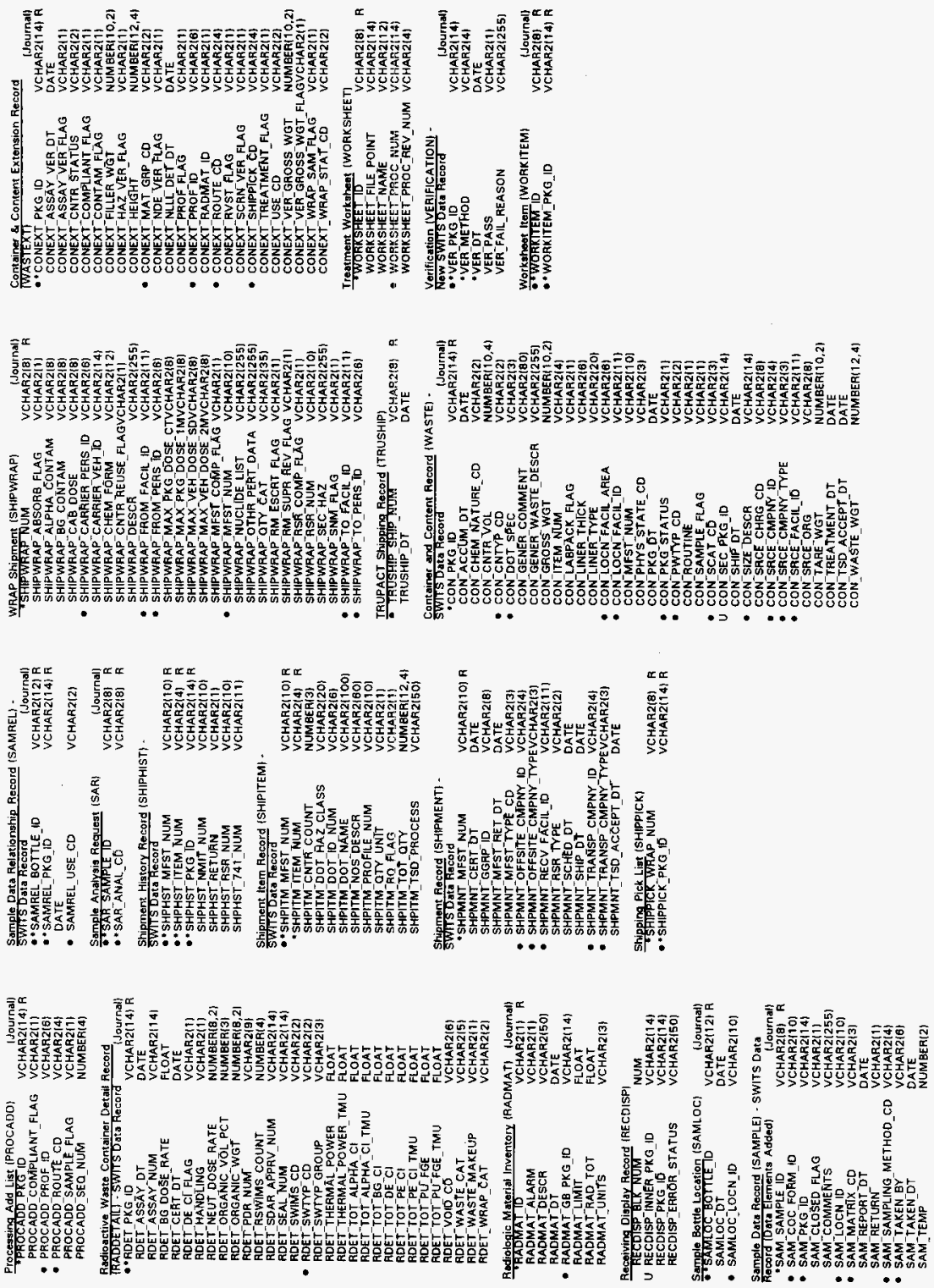


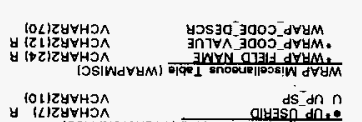

y TOLZZYZHOA

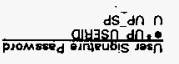

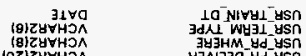

IOZZZZYHOSA

(S)ZZYHTA

$10 z) z \forall 450$
$3 \perp \forall 0$
$3 \perp \forall 0$

19]Zษ४HOA

פดO_- BSก

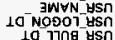

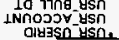

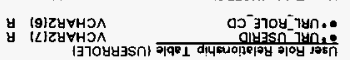

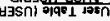

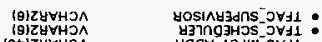

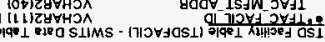

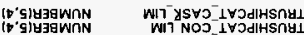

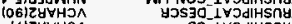

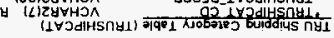

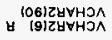

yอS30_Noony1

(NOJกYL)

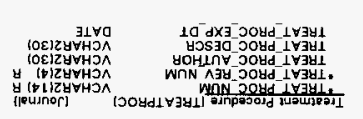

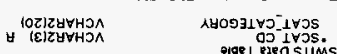

$$
\begin{aligned}
& \text { - (IRD3. }
\end{aligned}
$$

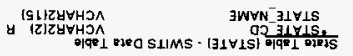

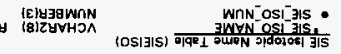

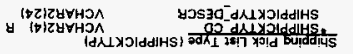

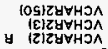

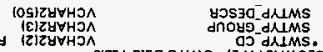

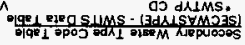

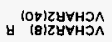

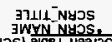

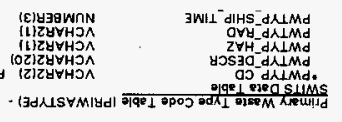

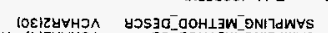

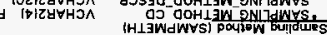

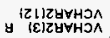

HวS30-XIVWaWrs

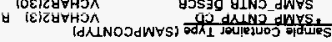

\& I\$ZIZY甘HOA

yวsjo-3inoy

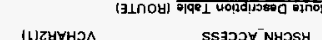

y (8)ZYZHOA

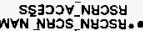

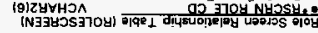

Ч $\begin{gathered}(09) Z \forall \forall H O A \\ (9) Z \forall \forall H J \wedge\end{gathered}$

yวsวa-ตาเท

Іоріzчұнол

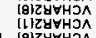

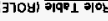

४

$3711-1 d 4$
อNIWIII-1dy

OBdSN39-1dY

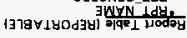

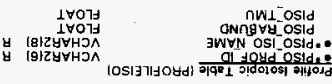

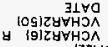

Hos $30-70 \mathrm{OAd}$

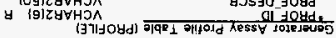

(OE)ZZYHOA
(E)ZUVHOA

IOIIZYYHOA

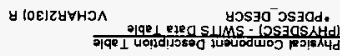

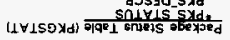

INMO'S

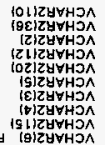

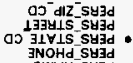
INFN-SYG

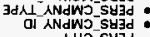

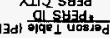

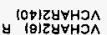

yos $30-$ sosw

(Z)

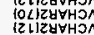

更

al $20 \mathrm{JH}$.

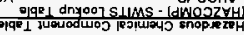

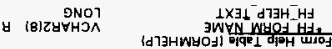

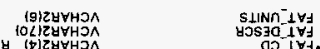

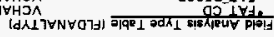

IG IZZYYHOA

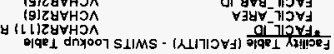

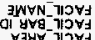

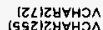

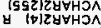

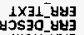

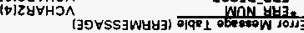

(E)yjgWnN $\quad$ O3XW-1Yos-Mo

(OZZZDYHOA

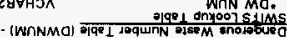

(า) 8 (1)

lOglZYYHOA
YOLIZYYHOA

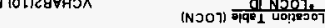

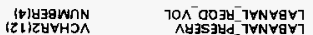

(ZLIZZYHOA

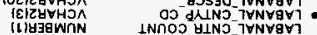

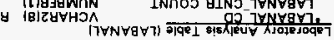

10E|ZYVHJA

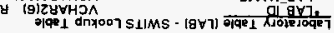

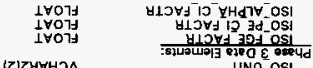

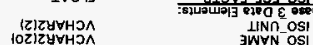

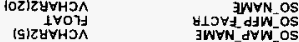

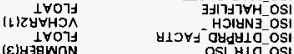

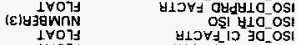

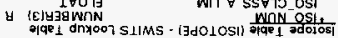

$3 W \forall N^{-}$-

HLOY d

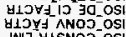

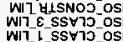

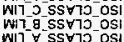

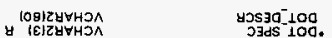

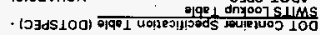

(Gi)ZYYHOA

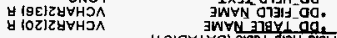

(1ว।

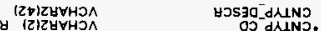

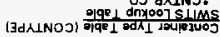

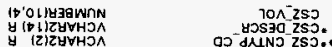

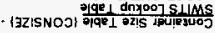

10LIZYZHOA OOA

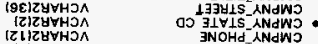

Iซo]

I
I $\forall 079$
I

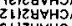

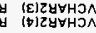

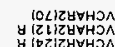

NolitZOOT_ANdW

NID ANaWD

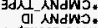

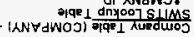

y

IWVN atyly 3000 :

SoL L 
WHC-SD-W026-SDD-001, Rev. 2

This page intentionally left blank. 


\begin{tabular}{|c|c|c|c|c|c|c|}
\hline & $\begin{array}{l}\text { UNIT } \\
\text { PROCESS }\end{array}$ & SCREENS AND REPORIS & TRIGGER & CONDITION/EVENT & DATA STORE & AITRBBUTE \\
\hline 10 & & (DMSS0101 cont.) & & & $\begin{array}{l}\text { CHEMCOMP } \\
(0, m)\end{array}$ & 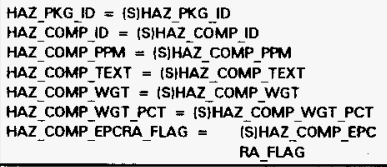 \\
\hline 11 & & & & & ISOQTY $10 . \mathrm{mt}$ & 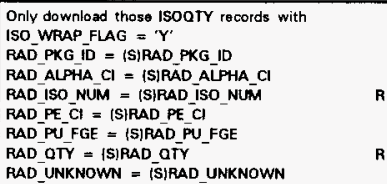 \\
\hline$i \mathbf{z}$ & & & & & \begin{tabular}{|l} 
APPMSDS \\
10,11
\end{tabular} & $\begin{array}{l}\text { APP_PKG ID = (S) } \mid \text { APP PKG ID } \\
\text { APP_MSOS = (S)APP_MSOS }\end{array}$ \\
\hline \multirow[t]{6}{*}{13} & & & & $\begin{array}{l}\text { Store facility inventory variables to RADMAT } \\
\text { Pass parameters to DMSCOM for DMSPCS FCL } \\
\text { message } \\
\text { Field } 1 \text { = 'DMSPCS' } \\
\text { Field } 2=\text { = FCL' } \\
\text { Field } 3 \text { = RADMAT_PAD_TOTAL } \\
\text { Field } 4=\text { RADMAT_ALAFM } \\
\end{array}$ & RADMAT & $\begin{array}{l}\text { RADMAT ID = 'F' } \\
\text { RADMAT_RAD_TOTAL = TOTTEMP } \\
\text { RADMATDT = SYStom date } \\
\text { RADMAT_ALAFM = RADALARM }\end{array}$ \\
\hline & & & & $\begin{array}{l}\text { Pass Parameters to DMSCOM for DMSPCS CL with } \\
\text { all RECDISP_PKG_ID }\end{array}$ & & \\
\hline & & & & $\begin{array}{l}\text { History and Delete RECDISP } \\
\text { DISPAY STATUS "CONIAINERS LOGGED INTO } \\
\text { PCS" }\end{array}$ & RECDISP & Dolete \\
\hline & & & User solisct [Commit] & Commit RECDISP data without selecting [Exit] & & \\
\hline & & & User seltect [Exit] & Allow user to commit RECDISP Data and oxit & & \\
\hline & & END OF MODULE & & & & \\
\hline
\end{tabular}

